\title{
A Cyber-Physical Systems Perspective on Decentralized Energy Management
}
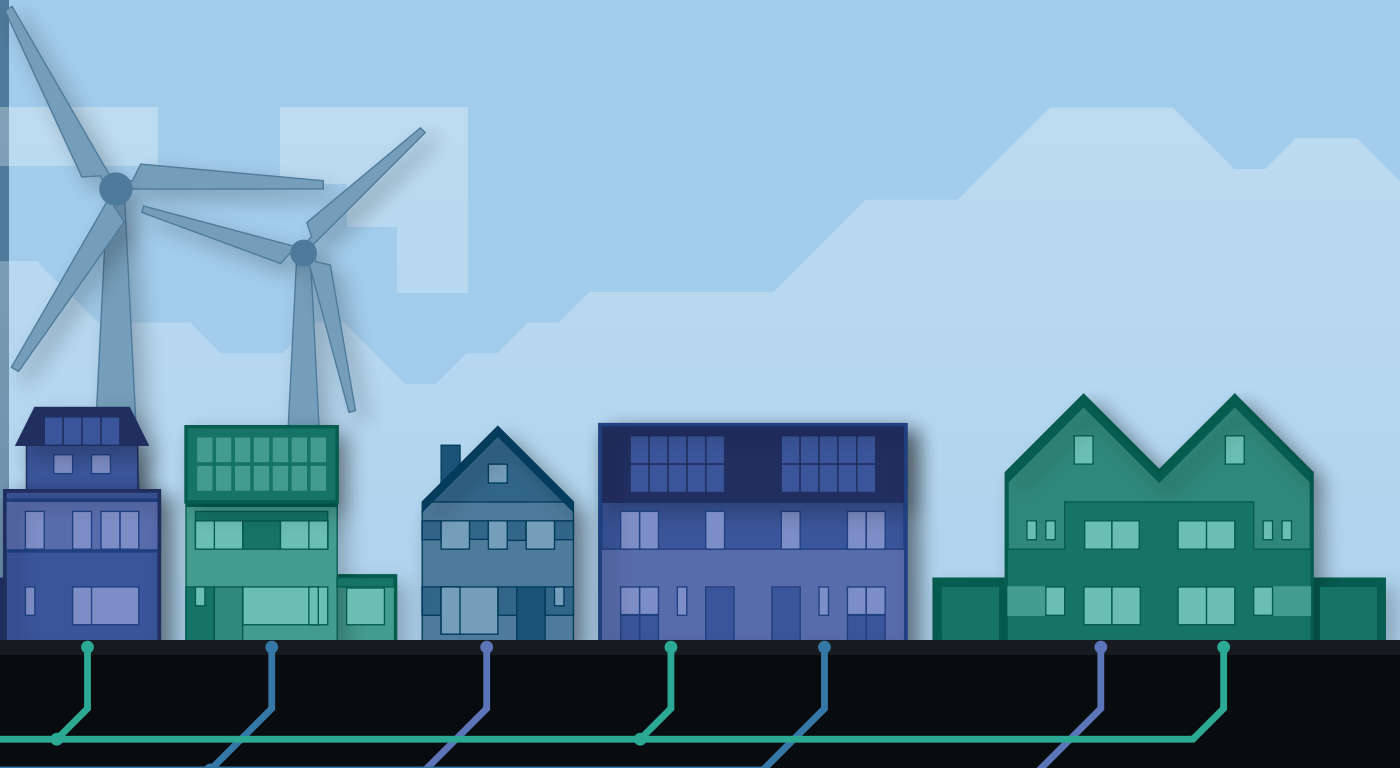

Gerwin Hoggsteen 
Promotiecommissie:

Prof. dr. ir. G. J. M. Smit

Universiteit Twente (promotor)

Prof. dr. J. L. Hurink

Universiteit Twente (promotor)

Prof. dr. ir. B. R. H. M. Haverkort

Universiteit Twente

Prof. dr. A. H. M. E. Reinders

Universiteit Twente

Prof. dr. ir. G. Deconinck

Prof. dr. I. G. Kamphuis

Katholieke Universiteit Leuven

Dr. S. Nykamp

Technische Universiteit Eindhoven

Westnetz GmbH

Prof. dr. P. M. G. Apers

Universiteit Twente (voorzitter en secretaris)

\section{UNIVERSITY OF TWENTE.}

Faculty of Electrical Engineering, Mathematics and Computer Science, Computer Architecture for Embedded Systems (CAES) group and Discrete Mathematics and Mathematical Programming (DMMP) group

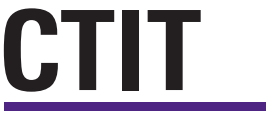

$\widehat{N W O} \mid \begin{aligned} & \text { Applied and } \\ & \text { Engineering Sciences }\end{aligned}$

CTIT Ph.D. thesis Series No. 17-449

Centre for Telematics and Information Technology

PO Box 217, 7500 AE Enschede, The Netherlands

This work is part of the research programme Energy Autonomous Smart Micro-grids (EASI) with project number 12700 which is partly financed by the Netherlands Organisation for Scientific Research (NWO) and partly financed by Alliander.

Copyright (c) 2017 Gerwin Hoogsteen, Enschede, The Netherlands. This work is licensed under the Creative Commons AttributionNonCommercial 4.o International License. To view a copy of this license, visit https://creativecommons.org/licenses/by-nc/ $4.0 \%$.

This thesis was typeset using $\mathrm{HT}_{\mathrm{E}} \mathrm{X}$, TikZ, and Kile. This thesis was printed by Gildeprint Drukkerijen, The Netherlands.

ISBN 978-90-365-4432-0

ISSN 1381-3617; CTIT Ph.D. Thesis Series No. 17-449

DOI $10.3990 / 1.9789036544320$ 


\title{
A Cyber-Physical Systems Perspective on Decentralized Energy Management
}

\section{PROEFSCHRIFT}

\author{
ter verkrijging van \\ de graad van doctor aan de Universiteit Twente, \\ op gezag van de rector magnificus, \\ prof. dr. T. T. M. Palstra, \\ volgens besluit van het College voor Promoties \\ in het openbaar te verdedigen \\ op vrijdag 8 december 2017 om 12.45 uur
}

door

Gerwin Hoogsteen

geboren op 3 mei 1988

te Grootegast 
Dit proefschrift is goedgekeurd door:

Prof. dr. ir. G. J. M. Smit (promotor)

Prof. dr. J. L. Hurink (promotor)

Copyright (C) 2017 Gerwin Hoogsteen

ISBN 978-90-365-4432-O 


\section{Abstract}

Driven by the effects of climate change, our world is in a rapid transition towards a sustainable society powered by renewable energy, such as produced by solar panels and wind turbines. The advanced civilization we live in today depends on a stable and reliable supply of energy. However, renewable energy sources are intermittent and the generated energy may fluctuate heavily throughout the day. Next to this, the number of locally installed renewable microgenerators is rapidly rising. As a result, the supply of energy becomes less controllable, endangering the stability of the electricity system and the reliable supply of energy to consumers.

The adoption of renewable energy results in a shift of the energy generation mix towards electricity. This also implies that the share of electricity consumption increases. Notable is the rising market share of electric vehicles and the adoption of electricity powered space heating and cooling solutions. This shift has significant impact on the existing infrastructure, which in general is not designed to distribute the amount of electricity we face within the energy transition, with the risk of an increased number of supply interruptions. On the other hand, these new developments also provide an opportunity as the distance between consumers and producers reduces due to the decentralization.

To benefit from this opportunity, coordination among a cluster containing a heterogeneous set of producers and consumers, also known as distributed energy resources (DERs), is required. Therefore, the scope of this thesis is to perform decentralized energy management, specifically within residential distribution grids where large scale adoption of DERs is expected. Such a cluster in a particular subgrid, often referred to as a microgrid, may achieve a high degree of energy autarky. A cyber-physical systems approach is taken to study the interaction between control systems, the operation of devices and the effect on the physical grid.

The first contribution is a proactive control methodology for decentralized energy management based on model predictive control. The foundation of this methodology is the profile steering heuristic to decentralize the coordination between all DERs in such a microgrid. This approach uses predictions to estimate the future state and the available flexibility of one or multiple DERs. In an iterative and coordinated manner, each element receives an incentive to schedule its flexibility towards a desired power profile for a number of future time intervals. These predictions and schedules are created locally, e.g. within a household or microgrid. Parallelism can be exploited as only local information is required to create such a schedule, resulting in a decentralized and scalable solution. 
The profile steering algorithm utilizes a hierarchical structure to spread its steering signals. As distribution grids are commonly operated in a tree structure as well, characteristics and power limits of the distribution grid are embedded into the control structure as optimization constraints. Another important aspect to power delivery is the supplied power quality, such as the voltage levels and balance in a three-phase distribution system. Therefore, the profile steering approach is extended with multiple steering signals to perform phase balancing and reactive power control simultaneously. In the realization of the planned profile, prediction errors in both the energy and time domain may arise. As a consequence, plannings may become infeasible. However, a complete replanning of a cluster of DERs is often too computationally intensive. Therefore, an event-based variant of profile steering is presented to perform partial replanning. The model predictive nature of this approach, resolves prediction errors in both the time and energy domain.

A second contribution is a control methodology based on double-sided auctions, for real-time balancing in microgrid islanding situations. In such situations, DERs can assist conventional backup solutions in supplying and balancing the microgrid. Within this process, the reaction time of DERs is included to avoid overreaction and unstable behaviour. This method can be combined with the profile steering approach to benefit from predictive control. Secondly, since communication is expected to play a crucial role to maintain reliability in future grids, precautions need to be taken for emergency situations when communication networks fail. Locally available measurement data, such as the voltage or frequency, are used as an alternative communication channel to infer the microgrid state. Subsequently, this information is used to perform a local market clearing to balance a microgrid.

The third contribution is the developed simulation and demonstration framework to test these control methodologies in a cyber-physical systems context. Next to this framework, an artificial load profile generator is developed to generate futuristic use-cases with the explicit modelling of available flexibility. The combination of these two tools is used to evaluate the performance of the presented control methodologies in various use-cases.

The accuracy of individual models is validated using measurements and field tests conducted in a smart grid test site in the Dutch town of Lochem. Based on the models of the grid and baseline power consumption, futuristic scenarios are created to evaluate the impact of electrification in this town. Simulation results indicate that without control power quality issues and grid overloading occurs in such a scenario. If control is applied, the current grid is capable of delivering reliable electricity as the aforementioned opportunity of coordination between local production and consumption translates into reduced utilisation of the distribution network.

A real-life stress-test, in which a 2025 scenario was created, resulted in a supply interruption due to grid overloading. The lack of controllability was a major cause for this, illustrating the importance of control in future distribution grids. The presented decentralized energy management approach is therefore a valuable tool to unlock flexibility of DERs and provide means for a smooth energy transition. 


\section{SAMENVATTING}

De wereld bevindt zich, gedreven door de effecten van klimaatverandering, in een transitie richting een duurzame maatschappij die draait op hernieuwbare energie afkomstig van, onder andere, zonnepanelen en windturbines. Onze beschaving is afhankelijk van een stabiel en betrouwbaar energiesysteem. De energietransitie vormt daarbij een grote uitdaging voor de stabiele aanvoer van energie, doordat de productie van hernieuwbare energie stevig kan fluctueren. Hierbij spelen deze uitdagingen niet alleen op grote schaal, maar door de introductie van kleine opwekkingseenheden, zoals zonnepanelen op daken van huizen, ook op lokale schaal. Deze trends resulteren in een alsmaar moeilijker aan te sturen energiesysteem, wat de stabiliteit van dit systeem en de betrouwbare aanvoer van energie in gevaar kan brengen.

De integratie van hernieuwbare energie leidt daarnaast ook tot een toename van elektriciteitsconsumptie in de energiemix. Sprekende voorbeelden zijn het groeiend aantal elektrisch aangedreven voertuigen en de installatie van warmtepompen. Door deze elektrificatie moet een toenemend aandeel van de energiebehoefte worden aangeleverd door het elektriciteitsnet, welke doorgaans niet is ontworpen om de verwachte hoeveelheden energie te kunnen transporteren. Dit kan in de toekomst leiden tot overbelasting, netcongestie en storingen. De energietransitie biedt echter ook mogelijkheden om het net te ontlasten, doordat de afstand tussen opwekking en verbruik van elektriciteit afneemt door decentralisatie.

Coördinatie van een heterogene groep kleine generatoren en lasten, ook bekend als gedistribueerde energie-eenheden, is vereist om voordelen van de energietransitie te kunnen benutten. Dit proefschrift richt zich dan ook op het toepassen van gedecentraliseerde energiesturing, met de focus op residentiële elektriciteitsnetten. Een cluster van gedistribueerde energie-eenheden in een subnet, ook wel een microgrid genoemd, kan met intelligente aansturing grotendeels energieonafhankelijk worden. Een cyber-physical systems-aanpak is gekozen om de interactie tussen het ontwikkelde aanstuursysteem, de werking van apparatuur en het effect op het energienet te kunnen analyseren.

De eerste contributie van dit proefschrift is een proactieve aanstuurmethodologie voor gedecentraliseerde energiesturing op basis van een voorspellend model. De basis voor deze methode is profielsturing, welke de coördinatie tussen energieeenheden decentraliseert. Profielsturing maakt gebruik van voorspellingen over de toekomstige toestand en beschikbare flexibiliteit van deze energie-eenheden. Vervolgens wordt een doelprofiel naar elke eenheid gestuurd, welke daarop zijn 
eigen flexibiliteit optimaliseert richting dit doelprofiel. Op deze manier wordt een aantal profielen aangeboden, waarvan de beste wordt gekozen. Middels een iteratief proces beweegt het totale elektriciteitsverbruik van het cluster zich richting het gezamenlijke doelprofiel. Aangezien voorspellingen en planningen lokaal worden gemaakt, zoals op apparaat- of huisniveau, kan in dit proces gebruik maken van parallellisme om het systeem schaalbaar te houden.

Bij profielsturing wordt gebruik gemaakt van een hiërarchische boomstructuur om de stuursignalen te verspreiden. Deze structuur past op natuurlijke wijze bij de opbouw van distributienetwerken, welke doorgaans radiaal worden bedreven. Daarmee kunnen op elk niveau karakteristieken en limitaties van het distributienet worden meegenomen in het aanstuursysteem. Naast het respecteren van fysieke limitaties, moet de energielevering ook voldoen aan de normen voor de spanningskwaliteit. Daarom is profielsturing uitgebreid met ondersteuning voor meerdere simultane stuursignalen, zodat ook op blindvermogen en fasebalans kan worden gestuurd. Het resultaat van de sturing is een op voorspellingen gebaseerde planning, die uiteindelijk uitgevoerd moet worden. Tijdens deze uitvoering kunnen zich voorspellingsfouten voordoen in zowel het tijds- als energiedomein, welke ervoor zorgen dat de planning niet meer volledig uitgevoerd kan worden. Aangezien het maken van zo'n planning veel rekenkracht vereist, presenteren wij een op observaties gebaseerde asynchrone variant van profielsturing, welke partiële planningen maakt op cruciale momenten om voorspellingsfouten op te lossen in zowel het tijds- als energiedomein.

De tweede contributie is een op dubbelzijdige veilingen gebaseerde aanstuurmethode voor tijdkritische balancering van microgrids in eilandbedrijf. De lokaal aanwezige energie-eenheden kunnen bij eilandbedrijf conventionele generatoren, welke essentieel zijn voor de energiebalans in een microgrid, ontlasten door middel van gecoördineerde vraag- en aanbodsturing. Hierin is de reactietijd van apparatuur meegenomen om te zorgen voor een correcte reactie op basis van observaties, zodat overreactie en instabiliteit worden voorkomen. Voorspellend gedrag kan worden toegevoegd door deze op veilingen gebaseerde aanstuurmethode te combineren met profielsturing. Daarnaast kan deze aanstuurmethode ook worden ingezet op momenten dat kritische communicatie infrastructuur faalt. Lokaal beschikbare informatie, verkregen uit metingen van de spanning en/of netfrequentie, kunnen worden gebruikt als alternatief voor het communicatiekanaal. Op basis van deze lokale informatie kan de toestand van het net worden afgeleid, om zo regelacties uit te voeren die overbelasting of spanningsproblemen in microgrids voorkomen.

De derde contributie is een simulatie en demonstratieplatform waarmee de aanstuursystemen kunnen worden getest in een cyber-physical systems model. Naast dit platform is ook een generator voor artificiële belastingprofielen ontwikkeld. Hierin is de aangeboden flexibiliteit door apparatuur expliciet aangegeven. Met deze twee programma's kan de effectiviteit van de ontwikkelde aanstuurmechanismen in diverse situaties worden getoetst. 
De nauwkeurigheid van de netwerkmodellen is gevalideerd met behulp van meetdata afkomstig van veldtesten in de proeftuin voor intelligente netten in Lochem. Deze modellen en meetdata zijn gebruikt als basis, waaraan futuristische scenario's zijn toegevoegd om de impact van verdere elektrificatie op het net in dit gebied in kaart te brengen. De resultaten van deze simulaties laten zien dat er zonder intelligente sturing overbelasting en spanningsproblemen optreden in futuristische scenario's. Deze problemen kunnen worden voorkomen indien de gepresenteerde aanstuurmechanismen worden ingezet. Daarbij is de capaciteit van het huidige netwerk toereikend en is het zelfs mogelijk om de piekbelasting te verlagen.

Ervaringen van een echte stress-test, waarin een scenario zoals zich dat kan voordoen in 2025 werd nagebootst, wijzen uit dat voldoende flexibiliteit en aanstuurbaarheid essentieel zijn. Het gebrek hieraan resulteerde in overbelasting met als gevolg een kortstondige stroomstoring. De methodes voor gedecentraliseerde energiesturing zijn daarom belangrijk om de flexibiliteit van energie-eenheden te kunnen benutten en daarmee de energietransitie mogelijk te maken. 


\section{TANKWURD, DANKWOORD \& ACKNOWLEDgEMENT}

$\mathrm{Na}$ iets meer dan vier jaar zit ik met een goed gevoel achter mijn computer dit dankwoord te tikken. Op dit moment kijk je naar een van de resultaten die vier jaar onderzoek naar smart grids en integratie van duurzame energie in ons net heeft opgeleverd. De behaalde resultaten zijn iets waar ik grutsk op ben. Ik ben echter niet de enige die hier trots op mag zijn, tijdens mijn promotieonderzoek heb ik talloze mensen mogen ontmoeten die mijn onderzoek verrijkt hebben met kennis, goede verhalen, interesse en ondersteuning. Iedereen die zo zijn steentje heeft bijgedragen aan dit onderzoek wil ik dan ook graag bedanken in dit dankwoord.

Allereerst wil ik beginnen met mijn promotoren Gerard en Johann. Gerard, jij weet als geen ander hoe belangrijk sfeer en kruisbestuiving binnen een vakgroep is voor de academische prestaties. Koffiepauzes, een dagelijke middagwandeling en uiteraard de VriMiBo, waarbij Gerard vrijdags om stipt 5 uur het kantoor binnen kwam om ons van het werk te houden. Ik voelde me dan ook al snel thuis en ik was nog maar amper begonnen aan mijn afstuderen toen ik maar eens moest nadenken of ik wilde promoveren. Eigenlijk hoefde ik niet lang na te denken om mijn passie voor domotica, smart grids en duurzame energie na te kunnen jagen. Gerard, bedankt voor alle discussies, proefballonetjes, brainstormsessies, je eindeloze interesse in het onderzoek en de gezellige tijd die ik heb mogen meemaken in je vakgroep. Daarnaast moet ik Johann bedanken, als promotor vanuit de DMMP vakgroep. Je achtergrond in de wiskunde, heeft heel veel bijgedragen aan mijn kennis en daarmee ook onderzoeksresultaten. Meermaals heeft dit verschil in achtergrond er ook toe geleid dat er complete delen van papers moesten worden herzien om het ook voor mensen van buiten de elektrotechniek begrijpbaar te houden. Dat kostte vaak veel tijd om alle hurogliefen te ontcijferen, maar kwam de leesbaarheid voor een breder publiek ten goede. Ondanks de wiskundige achtergrond ben je tevens ook een echte vernufteling. Bedankt voor alle constructieve discussies en oplossingen voor de problemen waar ik tijdens het onderzoek tegenaan liep.

Albert, mei dy kaam ik yn oanrekking doe't Jan Oene en ik foar it fak EEES oan de slach gongen. Doe kaam ik d'r achter dat ek op de UT ûndersyk dien waard nei yntelligente oanstjoering fan apparatuer, om sa de enerzjytransysje mooglik te meitsjen. Ik wie drekst om en kaam werom as studintassistint en ôfstudearder, mei dy as myn begelieder. Dank datsto altyd tiid frij meitsje woest om my te helpe by myn eigen ûndersyk. Ik ha in soad hân oan alle diskusjes, brainstormsesjes en dyn krityske blik, wat my skerp hâlden hat. Wat dat betreft wiesto de perfekte 
sparringspartner foar myn ûndersyk en hasto seker bydroegen oan it resultaat dat no foar dy leit. Dêrnjonken bin ik dy ek tankber dat ik by dy in plak hie om alles kwyt te kinnen doe't ik d'r hielendal trochhinne siet. Mar boppenal, dyn entûsjasme foar it ûndersyk, datsto fan herte mei eltsenien dielst, hat foar my echt in ûnmisbere enerzjyboarne west!

Uiteraard kan ik ook alle andere energiekelingen niet weglaten uit dit dankwoord. Ik heb het Energiehok met plezier gedeeld met een arsenaal aan informatica vakidioten Hermen, Jirka, Jonathan en James, wiskundige tovenaars Thijs, Martijn en Victor, uiteraard ook Richard en Gijs, alle studenten, and visiting researcher Krystian. Na verloop van tijd was dit energiehok te klein voor onze groep en openden we diverse dependances, bezet door Bart, Diego, Marco en Maryam. De gezamenlijke kennis uit alle hoeken van de wetenschap en de goede samenwerking daartussen, is van onschatbare waarde voor onderzoek naar smart grids en integratie van duurzame energie. Ik heb genoten van al onze discussies, volgeschreven whiteboards en gezonde dosis (gortdroge)kantoorhumor.

Van deze energiekelingen wil ik een aantal in het bijzonder bedanken. Als eerste Thijs, mijn projectgenoot, jouw kennis van optimalisatiealgorithmes en de wil om deze ook praktisch toepasbaar te houden, is zeer belangrijk geweest voor de simuleerbaarheid van complete straten tot op apparaatniveau. Maar ook voor al onze tripjes, met als absoluut hoogtepunt de drie maanden in Texas. Marco, ook jij verdient extra aandacht voor de uitstekende samenwerking naar een beter stuurmechanisme, waarin je feilloos de belangrijke eigenschappen van het elektriciteitsnet wist te vertalen in algorithmes. Vincent, als één van de energiegroep godfathers (samen met Albert en Maurice), bedankt voor alle kennis die je wilde delen voor zowel het onderzoek als de discussies over het automatiseren vna onze huizen. Lastly, Stefan, thank you for our discussions concerning the practical challenges and implementations of the energiewende in Germany.

Door de jaren heen heb ik ook het voorrecht gehad om een horde aan studenten te mogen begeleiden binnen de energiegroep. Jan Oene, Jorrit, Marius, Robbert, Qiang, Dirk-Jan, Robin, Gerbrand en Jeroen, bedankt voor al jullie inzet om het onderzoek stapje voor stapje verder te helpen. Niet alleen heb ik kennis op jullie kunnen overdragen, maar jullie werk heeft ook mijn eigen kennis verrijkt, wat bijgedragen heeft aan mijn onderzoek en dit proefschrift.

Jan Oene wol ik dêrby yn it bysûnder betankje. Tegearre ha we in soad útdagingen oppakt oan de Hanzehogeschool yn Grins en hir yn Twinte oan 'e universiteit. Fan omgrieme mei elektryske scooters tot it ûndersykjen wat foar apparatuer wy kinne ydentifisearre mei enerzjymeters. Troch dat lêste mochten wy in paper yn Berlyn presintearje, wat my in moaie kâns joech om yn de wûndere wrâld fan 'e wittenskip te sjen. It wie dan suver nuver om op de eftergrûn belutsen te wêzen as begelieder by dyn ôfstudearren op de UT. De goeie gesprekken, mei bjusterbaarlik lekker spesjaalbier, moatte we mar wer flot oppakke, want de lêste tiid hie ik it wat te drok mei dit ûndersyk. 
De CAES vakgroep bestaat echter uit meer dan alleen die energiegroep. Allereerst moet ik Marlous, Nicole en Thelma bedanken voor het regelen en afhandelen van onder andere de vele "snoepreisjes", die daardoor vlekkeloos liepen. Guus, waar zouden we zijn zonder onze kluisbeheerder. Jochem en Robert, bedankt voor het template en hulp zodat ik dit prachtige boekje heb kunnen fabriceren. Bert, bedankt voor het onderhouden van de databases en code repositories. En zo kan ik nog wel even doorgaan. Helaas heb ik niet genoeg ruimte om iedereen persoonlijk te kunnen bedanken in dit dankwoord. Daarom, bedankt CAES voor alle humor en discussies in de circa 2300 koffiepauzes, 1100 lunchwandelingen, 200 inspirerende presentaties, 250 borrels, filmpjes, BBQ's, enz. Dankzij jullie is een promotie veel meer dan alleen maar in je kantoortje naar het einde van je boekje ploeteren!

I am also thankful for everybody who made it possible for Dr. Claw (Thijs) and me to spend three months of research at the other UT, the University of Texas at Austin. More specifically, research on microgrids at the Center for Electromechanics (CEM). Bob, thanks for your warm welcome and openness towards new control concepts for the grids of the twenty-first century. In these three months I learned the significance of adaptive and resilient control mechanisms. Liz, thanks for arranging all non technical matters and driving us around Austin. Thanks CEM for all discussions and boardgames. Paul, and all others behind the scenes in the Netherlands, thanks for arranging this fruitful collaboration with Austin.

Maar het belangrijkste onderzoek en grootste inzichten doe je doorgaans op buiten je kantoor, vakgroep, en de campus. Buiten Enschede, in het pitoreske Lochem, mocht ik meehelpen in een smart grid proeftuin. LochemEnergie, en Tonnie in het bijzonder, bedankt voor jullie actieve houding binnen deze proeftuin, de leerzame presentaties en een schat aan meetdata. Het meest heb ik nog geleerd van jullie wensen, als toekomstige eindgebruikers, om tot een transparant stuursysteem te komen. Verder denk ik nooit weer een feest te zullen meemaken bij een stroomstoring! Suzanne, jou wil ik bedanken voor een kijkje in de wereld van psychologie. De human touch binnen een smart grid is minstens zo belangrijk als feilloos werkende techniek. Ben, Ben en Friso, bedankt voor jullie input en assistentie bij de onvergetelijke experiemnten in Lochem.

As lêste wol ik hjir graach de wichtigste minsken betankje dy my troch de stúdzje en it ûndersykstrajekt lutsen hawwe. Heit en mem, dankewol foar alle belangstelling, mar ek foar de steun doe't ik d'r hielendal klear mei wie. It is altyd noflik thúskomme yn Drachten, sadat ik mysels wer oplade kin. Arjen, Nynke en Martijn wol ik dêr ek foar betankje. Ik ha in soad enerzjy krigen út alle buordspultsjes, potsjes Wolfenstein, films, plaatsjes sjitte yn 'e natuer, it knutseljen oan apparatuer en fansels it jierlikse wintersportaventoer. Ek wol ik pake Melle, beppe Hillie, beppe Jeltje en de rest van de famylje betankje foar alle ynteresse yn it wurk dat ik de ôfrûne jieren dien ha.

Gerwin

Enschede, oktober 2017 


\section{Contents}

1 INTRODUCTION 1

1.1 Energy Transition ... . . . . . . . . . . . . . . . . . . 3

1.1.1 Smart Grids . . . . . . . . . . . . . . . . . 4

$1.1 .2 \quad$ Microgrids ....................... 5

1.1.3 Decentralized Energy Management . . . . . . . . . 6

1.1.4 Cyber-Physical Systems Context . . . . . . . . . . . 6

1.2 Problem Statement . . . . . . . . . . . . . . . . . . . . . . . 8

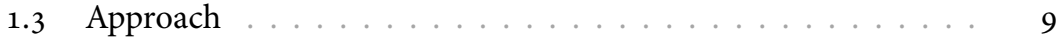

1.4 Outline of this Thesis . . . . . . . . . . . . . 11

2 BACKGROUND 13

2.1 Energy Infrastructure . . . . . . . . . . . . . . 15

$2.1 .1 \quad$ Electricity System . . . . . . . . . . . . . . 15

2.1.2 Energy Markets . . . . . . . . . . . . . . . . 18

$2.1 .3 \quad$ Low Voltage Grids . . . . . . . . . . . . . . 20

2.1.4 Other Energy Carriers . . . . . . . . . . . . . 21

2.2 Changes in Distribution Systems . . . . . . . . . . . . . 23

2.2.1 Flexibility Markets................. . . . 24

2.2.2 Smart Grids and Homes . . . . . . . . . . . 25

2.3 Energy Management . . . . . . . . . . . . . . . . . 28

$2.3 .1 \quad$ Incentives . . . . . . . . . . . . . . . . . 29

$2.3 .2 \quad$ Control Systems . . . . . . . . . . . . . . . 32

$2.3 .3 \quad$ Test Sites . . . . . . . . . . . . . . . . . . . . 38

2.4 Conclusion . . . . . . . . . . . . . . . . . . . . 40

3 Models 43

3.1 Device Components ... . . . . . . . . . . . . 45

3.1.1 Basic Device Component . . . . . . . . . . . 46

3.1.2 Uncontrollable Device . . . . . . . . . . . . . . 51

3.1.3 Curtailable Device . . . . . . . . . . . . . . . 51

$3.1 .4 \quad$ Buffer Device . . . . . . . . . . . . . 52 
$3.1 .5 \quad$ Converter Device .................. 52

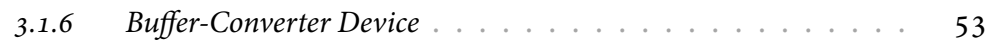

3.1.7 Timeshiftable Device . . . . . . . . . . . . . . . 54

xvi

$3.1 .8 \quad$ Buffer-Timeshiftable Device . . . . . . . . . 55

3.1.9 Other Energy Systems . . . . . . . . . . . . . 56

3.2 Network Components . . . . . . . . . . . . . 56

3.2.1 Topology . . . . . . . . . . . . . . . . . . 58

$3.2 .2 \quad$ Nodes . . . . . . . . . . . . . . . . . . . 59

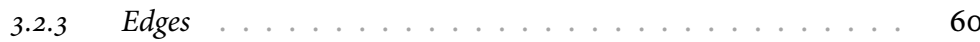

3.3 Load-Flow Analysis . . . . . . . . . . . . . . . 62

$3.3 .1 \quad$ Algorithms ......................... 62

3.3.2 Forward-Backward Sweep Algorithm . . . . . . . . 62

3.3 .3 Convergence Criteria . . . . . . . . . . . . . 66

3.3 .4 Other Energy Systems . . . . . . . . . . . . . . 66

3.4 Control Infrastructure . . . . . . . . . . . . . . . . . 66

$3.4 .1 \quad$ Nodes: Controllers . . . . . . . . . . . . . . 67

3.4.2 Edges: Communication Links . . . . . . . . . . . . 68

3.5 Interaction Between Components . . . . . . . . . . . 68

3.5.1 Controllers and Devices . . . . . . . . . . . . . . 69

3.5.2 Devices and Network ... . . . . . . . . . . . 71

3.5.3 Network and Controllers................ 71

3.6 Conclusion ........................... 72

4 Proactive Control Methodology 75

4.1 Requirements ..................... 76

4.1.1 Related Work . . . . . . . . . . . . . 78

$4.1 .2 \quad$ Approach ........................ 79

4.2 Synchronous Scheduling . . . . . . . . . . . . . 81

4.2.1 Profile Steering Heuristic . . . . . . . . . . . . 82

$4.2 .2 \quad$ Hierarchy . . . . . . . . . . . . . . . . 85

4.2.3 Profile Bookkeeping . . . . . . . . . . . . . . . 86

4.2.4 Local Power Limits . . . . . . . . . . . . . . . . . . 88

4.2.5 Multi-Commodity ................ 90

4.2.6 Device Level Scheduling . . . . . . . . . . . . . . . 93

4.3 Asynchronous Realization ... . . . . . . . . . 95

$4.3 .1 \quad$ Events . . . . . . . . . . . . . . . . . 96

4.3.2 Event-Based Device Scheduling . . . . . . . . . . . 98

$4.3 .3 \quad$ Profile Updates . . . . . . . . . . . . . . . . 101

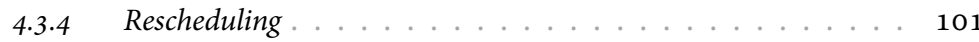

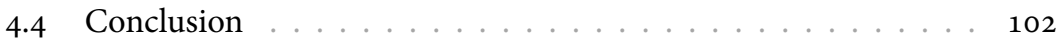


5.1 Requirements ... . . . . . . . . . . . . . . 108

5.1.1 Related Work . . . . . . . . . . . . 109

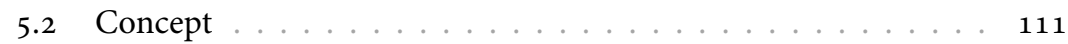

5.2.1 Demand Functions . . . . . . . . . . . . 112

5.2.2 Hierarchical Control Structure . . . . . . . . . . 115

5.3 Online Control . . . . . . . . . . . . . . . . . . . . 119

$5.3 .1 \quad$ Global Market Clearing . . . . . . . . . . 120

$5.3 .2 \quad$ Islanded Grid Control . . . . . . . . . . . . 121

5.4 Communication-Free Control ... . . . . . . . . . 124

$5.4 .1 \quad$ Local Clearing Price . . . . . . . . . . . . . 125

$5.4 .2 \quad$ Voltage Based Control . . . . . . . . . . . . . 128

$5.4 .3 \quad$ Frequency Based Control ................ 128

5.5 Conclusion ... . . . . . . . . . . . . . . . . . 129

6 Simulation AND DEMONSTRATION PLATFORM 131

6.1 Artificial Load Profile Generator . . . . . . . . . . . . . . 133

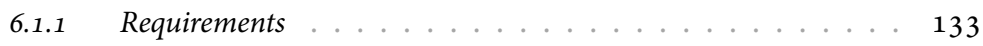

$6.1 .2 \quad$ Related Work . . . . . . . . . . . . . . 134

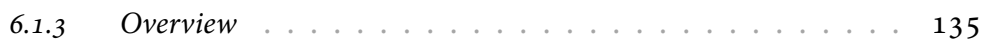

$6.1 .4 \quad$ Input Data . . . . . . . . . . . . . . . . . . 137

6.1 .5 Simulation and Generation . . . . . . . . . . . 138

6.1.6 Output Data . . . . . . . . . . . . . . . 140

6.2 DEMKit . . . . . . . . . . . . . . . . . . 142

6.2 .1 Requirements .................... 142

$6.2 .2 \quad$ Related Work . . . . . . . . . . . . . . 143

$6.2 .3 \quad$ Structure. . . . . . . . . . . . . . . . 145

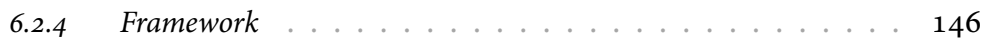

$6.2 .5 \quad$ Components Library . . . . . . . . . . . . . . . . . 149

$6.2 .6 \quad$ Execution . . . . . . . . . . . . . . . . 151

$6.2 .7 \quad$ Simulation . . . . . . . . . . . . . . . 151

6.2 .8 Co-Simulation . . . . . . . . . . . . . . 152

$6.2 .9 \quad$ Validation . . . . . . . . . . . . . . . . 153

6.3 Conclusion ... . . . . . . . . . . . . . . . . 154

7 EXPERIMENTS AND RESUlts $\quad 157$

7.1 Smart Grid Lochem . . . . . . . . . . . . . . . . . 158

7.1.1 Stress Test . . . . . . . . . . . . . . . . . 159

7.1.2 Network Model Validation. . . . . . . . . . . . 160

$7.1 .3 \quad$ Artificial Load Profiles . . . . . . . . . . . . 161 
7.2 Control System Simulations . . . . . . . . . . . . 163

7.2.1 Control Approaches Evaluation . . . . . . . . . . 163

7.2.2 User Accepted Scenario . . . . . . . . . . . . . . 173

xviii

$7.2 .3 \quad$ Islanding Simulations . . . . . . . . . . . . 180

7.2.4 Communication-Free Control . . . . . . . . 182

7.3 Conclusion .......................... 187

8 Conclusions $\quad 191$

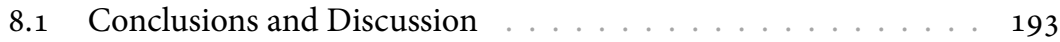

8.2 Contributions . . . . . . . . . . . . . . . . . 196

8.3 Future Work . . . . . . . . . . . . . . . . . . 197

$\begin{array}{lll}\text { A Models and Equipment } & 201\end{array}$

A.1 Device Data and Models . . . . . . . . . . . . . . . 201

A.2 Measurement Data and Equipment in Lochem . . . . . . . 202

$\begin{array}{ll}\text { ACRONYMS } & \mathbf{2 0 5}\end{array}$

$\begin{array}{ll}\text { BibLIOGRAPHY } & 207\end{array}$

$\begin{array}{ll}\text { List Of Publications } & 223\end{array}$ 


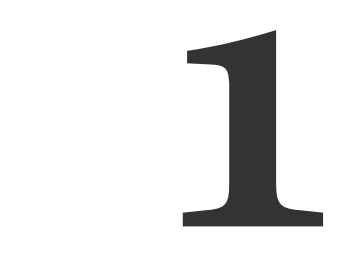

\section{INTRODUCTION}

Energy fulfils an important role within our daily lives. Our advanced and globalized civilization is fuelled by and depends on a stable supply of affordable energy ever since the start of the industrial revolution in the 18th century. Nearly everything we do and come across in our lives depends in some way on the availability of energy. Be it for its operation, transport or manufacturing. Without a reliable supply chain of energy, it would be impossible to transport all goods over large distances, operate water and sewage pumps, cool food in refrigerators, provide access to the internet, etc. An interruption of the stable energy supply would result in a cascading effect, potentially bringing our whole civilization to a standstill.

The dominant energy source during the industrial revolution was coal. By burning coal, steam was produced, which subsequently was used to provide power to machinery. Later on, the principle of the steam engine was used to produce electricity by using steam turbines to drive electricity generators. Over time, other fossil energy sources also entered the stage, such as natural gas and oil. To benefit from the economy of scale, large centralized power plants arose to deliver electricity to customers connected to a larger electricity grid. Next to electricity generation, fossil fuels are also used for space heating through boilers or to power transportation vehicles using internal combustion engines.

However, the use of fossil fuels does result in the emission of carbon-dioxide $\left(\mathrm{CO}_{2}\right)$ and other greenhouse gases, which results in global warming and climate change. The recent observed global warming is caused by us humans according to a $90 \%$ to $100 \%$ consensus of climate scientists [27]. Furthermore, fossil fuels are to a large extent won in political unstable regions, are finite, and become increasingly difficult to obtain as the energy returned on energy invested is declining [63]. In 2014, the total electricity production was 23.8 PWh, of which the lion's share was produced using fossil fuels (66.7\%) [77]. The share of electricity originating from renewable sources was $11.1 \%$ in the Netherlands and $28.8 \%$ for the European Union (EU) in the year 2015 [50] (see Figure 1.1). 


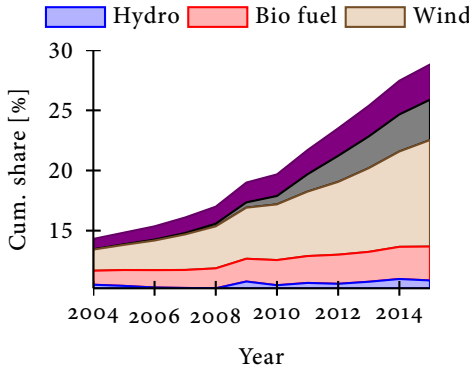

(a) European Union

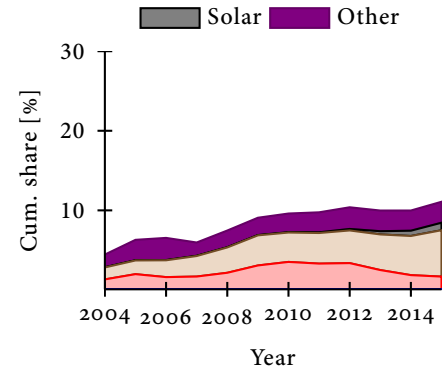

(b) the Netherlands

Figure 1.1: Cumulative share of RES in the electricity production in the European Union and the Netherlands for various technologies. Data taken from [50].

The energy transition towards a civilization powered by alternative and clean renewable energy sources (RES) is initiated by the desire to avert catastrophic effects of climate change and maintain a reliable energy supply chain. As the climate change is a global issue, actions have to be taken by all countries. Therefore, global conventions are held and treaties are signed to stop climate change, such as Kyoto 1997 [145] and Paris 2015 [146]. The goal of the Paris treaty is to limit global warming to well below two degrees Celsius compared to pre-industrialisation levels. Also the European Union has set specific targets for 2020 and 2030 regarding energy and climate $[44,46]$. These goals can be translated in a reduction of greenhouse gas emissions by reducing the energy consumption and increasing the share of clean RES.

To reach these goals, energy consumption reduction is enforced through legislation that limits the power consumption of consumer devices, and by norms to build better insulated buildings. Furthermore, the share of electricity generation by RES is increasing to meet the aforementioned targets of limiting greenhouse gas emissions. The International Energy Agency (IEA) expects $60 \%$ of the global electricity to be produced by RES in 2040, of which half from photovoltaic $(P V)$ and wind energy [79]. For this, the aforementioned devices that consume fossil fuels are replaced by alternatives powered by electricity, referred to as the electrification. Examples are the usage of heat pumps for space heating and the adoption of battery electric vehicles $(B E V s)$ for mobility. As a result, the share of electricity consumption of the total energy consumption is expected to rise to $40 \%$ by 2040 , compared to the steady share of $25 \%$ seen over the last 25 years [79]. These measures help to reduce the emission of $\mathrm{CO}_{2}$, but on the other hand introduce new challenges, such as increased electricity loads and variability of electricity generation.

The remainder of this chapter is organized as follows: Section 1.1 discusses the effects and challenges of this energy transition on our energy supply chain. Additionally, proposed solutions and research directions within this field are introduced. Section 
1.2 introduces the problem statement, research questions and research focus of this thesis. Next, the research approach and contributions of this work are introduced in Section 1.3. This chapter concludes with an outline of the remainder of this thesis in Section 1.4.

\subsection{ENERgy Transition}

The desire to significantly reduce the emission of greenhouse gasses changes our view on electricity usage and generation. Large fossil fuel based power plants are replaced by, e.g. wind turbines, and PV panels. These clean new electricity generators use renewable (non-depletable) energy sources, such as wind and sunlight. As a consequence, a large fraction of RES depends on the weather. A wind turbine will only produce energy when the wind speed is not too low, nor too high. The electricity production from solar panels depends on the cloudiness and inclination angle of the sun. Another trend is the adoption of decentralized electricity generation using micro-generators, instead of large centralized power plants. Most notable is the installation of roof-top solar PV on houses, offices and industrial buildings.

The mentioned changes result in an intermittent generation of electricity, which is less flexible as the generation of electricity cannot be increased on demand. This in contrast to the fossil fuel based power plants, which can increase or decrease the supply of fuel to influence the electricity generation. Another important fact is that production and consumption of electricity must be in balance at all times as the electricity grid has virtually no inherent storage. Therefore, the production of power plants follows the demand. The speed with which these generators can increase and decrease their production does depend on the used technology. This is generally not a problem as the load is usually quite well predictable [8o]. However, with the increasing share of RES, the flexibility on the production side decreases, resulting in an increasing challenge to balance the electricity grid. Additionally, the power plants now also need to react to fast fluctuations of RES production. One peculiar example is the solar eclipse in Germany in March 2015, which resulted in a solar power production ramp rate which was more than 2.1 times as steep as observed otherwise [87]. On the other hand, the predictability of such an event made it possible to take precautions to avert grid instability.

On the demand side, the energy transition also leads to a drastic change. As most RES generate electricity, the desire to shift away from fossil fuels usage results in an increase of the electricity demand. For example, natural gas powered boilers are replaced by heat pumps to provide space heating and in the mobility sector vehicles powered by internal combustion engines, which run on petrol or diesel, are replaced by vehicles driven by electric motors. Examples are the cars with a battery, such as BEVs and plug-in hybrid electric vehicles (PHEVs), or hydrogen fuelled cars. However, on the positive side, battery storage systems are used to balance the grid. All these new devices, with some inherent flexibility, are commonly referred to as distributed energy resources (DERs). 
Summarizing, the electrification implies that more electricity needs to be generated and distributed by the electricity grid. However, most grids have not been designed to facilitate the accelerated electrification that we face with the energy transition. In fact, a real-world electrified stress test resulted in a short supply interruption due to sustained grid overloading, which we discuss in Chapter 7. As a consequence, the main challenges of the energy transition are the variability of electricity production, increased peak loads due to the electrification, and the vast mounts of distributed RES and DER that need to be controlled.

\subsubsection{SMART GRIDS}

One (traditional) solution to the aforementioned transmission and distribution capacity issues is grid reinforcement. However, this is a very expensive solution, and does not solve the balancing problem. As an alternative, the smart grid paradigm is introduced, which adds a communication layer to the old, existing, grid infrastructure. This communication network can be used to collect measurement information, e.g. from smart meters, and to control grid assets. Through active grid monitoring, potential grid operation problems can be detected in time and may be avoided with automated control of the smart grid. Many definitions of the term smart grid can be found in literature. However, in this research we stick to the definition as given by the IEA in [78]:

Definition 1.1. A smart grid is an electricity network system that uses digital technology to monitor and manage the transport of electricity from all generation sources to meet the varying electricity demands of end users. Such grids are able to coordinate the needs and capabilities of all generators, grid operators, end users and electricity market stakeholders in such a way that they can optimize asset utilisation and operation and, in the process, minimize both costs and environmental impacts while maintaining system reliability, resilience and stability.

The addition of a communication network has a prominent role in solving the aforementioned challenges introduced by the energy transition. While flexibility on the generation side is decreasing, new flexibility arises on the demand side; thermal mass of buildings may be used as a buffer to perform pre-heating and the charging of a BEV may be postponed if the end-user does not require a full battery as soon as possible. The emergence of devices connected to the internet, such as e.g. smart thermostats, provide means for the smart grid to shift power consumption in time to match the generation. The act of changing the demand profile is often referred to as demand-side management (DSM) or demand response (DR). Hence, a paradigm shift from generation-follows-demand to demand-follows-generation is seen. This way, the balance between demand and supply can also be achieved with increasing penetrations of RES. Furthermore, it can be used to avoid peak power consumption to defer the need for grid reinforcements. 


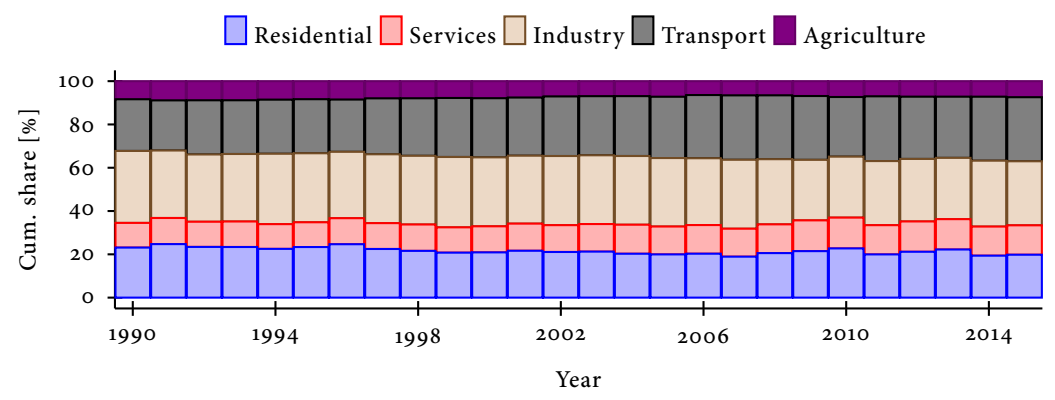

Figure 1.2: Share of the different sectors in the total energy consumption in the Netherlands. Data taken from [50].

\subsubsection{MICROGRIDS}

Decreasing prices for micro-generation units, mostly PV panels and wind turbines, and the desire to be eco-friendly has resulted in a new movement to become (partly) energy independent. Various local communities start green energy initiatives ${ }^{1}$ to accelerate the (local) energy transition. The prominent goal is to increase the share of locally generated energy which also gets consumed locally. This is achieved by, amongst others, sharing knowledge, installing PV panels and batteries, and renting BEVs. This bottom-up movement can have a significant impact on the total energy usage as the residential sector makes up $31.3 \%$ of the global energy consumption [77] and $25.4 \%$ of the EU consumption [50]. In the Netherlands, this number is slightly lower, with an average of $21.6 \%$ over the last 25 years [50] (see Figure 1.2). However, a complete energy independence of a local community only can be achieved when enough generation and storage is available in an area. With enough (battery) storage, supply and demand may be decoupled in time. As a result, the local electricity grid within a community can be supplied with locally generated electricity to become completely independent from the main electricity grid.

A term for such a small electricity grid that could be run independently is called a microgrid. The following definition of a microgrid is given in [135]:

Definition 1.2. Microgrids comprise Low-Voltage (LV) distribution systems with DERs (microturbines, fuel cells, PV, etc.), storage devices (flywheels, batteries) energy storage system and flexible loads. Such systems can be operated in both nonautonomous way (if interconnected to the grid) or in an autonomous way (if disconnected from the main grid). The operation of microsources in the network can provide distinct benefits to the overall system performance, if managed and coordinated efficiently.

\footnotetext{
${ }^{1}$ See www.hieropgewekt.nl for a comprehensive list of Dutch energy communities
} 
An advantage of microgrids is that they can operate independently from the main grid. This so-called islanded operation of a microgrid enhances the reliability and resilience of the energy system. Supply of energy may continue within the microgrid in situations where higher levels of the electricity grid structure malfunction. Examples are blackouts or damaged infrastructure, such as after a hurricane. In gridconnected operation, the microgrid may provide ancillary services to the power system, such as the aforementioned demand and supply matching.

\subsubsection{Decentralized Energy Management}

Control and coordination over RES and DER is crucial in smart grids and microgrids to defer grid investments and perform supply and demand matching. However, the old method of energy management, in which supply follows the demand, is not applicable anymore. The power system now has to deal with millions of generators and devices, spread all over the grid, instead of just a few large central power plants. Furthermore, the control system must deal with a novel and heterogeneous cluster of flexible DERs and RES.

Such a control system must coordinate the energy exchange between various assets according to a predefined goal or set of goals. These goals may include demand and supply matching, peak shaving, maximizing the self-consumption, or maximize profit on energy markets. The underlying control optimization algorithms should result in control actions to achieve the objective of a smart (micro)grid. On the other side, these control actions should not violate end-user comfort and constraints, such as a comfortable indoor temperature. Preferably the control system does so by using a proactive method, such as model predictive control (MPC), to ensure that the objectives are met in both the short and long term.

As the structure of the power grid shifts away from a centralized system in favour of a decentralized system, the control structure should follow the same trend. With the microgrid paradigm, a control system should be able to maintain grid stability in islanded mode, but also fulfil the needs of the main power grid in connected mode. Within this work, we look at decentralized energy management (DEM) strategies for such a control mechanism in residential areas. In contrast to DR and DSM, DEM focusses on both the supply and demand side of the electricity grid by incorporating also loads (e.g. BEVs) micro generators (e.g. PV), buffers (e.g. batteries) and converters (e.g. heat pumps). For such a system, it is important to be flexible in terms of size, structure, and type of controllable assets.

\subsubsection{Cyber-Physical Systems Context}

The addition of control to the smart grid ensures that supply and demand matching can be supported with an increasing share of RES and DER. However, balancing is not the only challenge for electricity grids in the energy transition. The other is the distribution of the energy through the grid. Changes in production and consumption result in different flows of energy within this network. Thus, up to a certain 


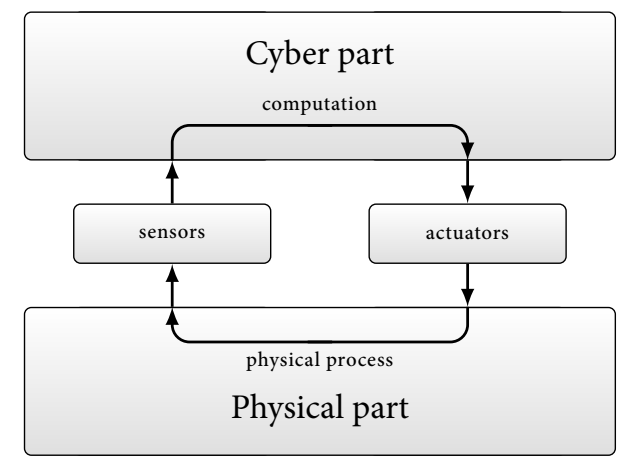

Figure 1.3: Interaction between the cyber part and physical part in a cyber-physical system.

level, energy flows can now be controlled within the smart grid. Furthermore, the grid structure itself may be physically changed through reconfiguration. Different flows also result in different currents, voltage levels and the physical operation of the grid and its assets.

Based on the above, the smart grid is considered to be a cyber-physical system (CPS), as control actions influence the physical state of a system and vice versa (see Figure 1.3). Lee and Seshia [100] define a CPS as follows:

Definition 1.3. A CPS is an integration of computation with physical processes whose behaviour is defined by both cyber and physical parts of the system. Embedded computers and networks monitor and control the physical processes, usually with feedback loops where physical processes affect computations and vice versa. As an intellectual challenge, CPS is about the intersection, not the union, of the physical and the cyber. It is not sufficient to separately understand the physical components and the computational components. We must instead understand their interaction.

Since the electricity grid is not a copperplate with infinite capacity, it is important to consider the results of control actions on this physical infrastructure. In the end, a smart grid must ensure a stable and reliable supply of electricity to consumers. This also includes a supplied voltage and frequency that is conform to local norms and regulations. Furthermore, the resulting load also affects the ageing of grid assets, such as transformers and cables. In the system also feedback loops exist, where the resulting frequency is often fed back in a control system that stabilizes the grid frequency around a nominal frequency. Another example is a feedback loop where the observed voltage is fed back to ensure that the supplied voltage is within limits. For these reasons, it is important to also consider the physical system when designing a smart grid control system. 


\subsection{Problem Statement}

The goal of this research is to investigate the interaction between the control and the physical behaviour in a smart grid. Hereby, we restrict to microgrids in residential settings, which consists of a wide variety of assets, devices and (emerging) technologies. The first key component is the physical electricity grid that enables the exchange of energy between customers in the grid. That brings us to the second involved component, namely the customers who may consume and/or produce the energy that has to be exchanged through the physical grid. The origin of energy consumption and production are the domestically owned assets (devices), of which a subset may be controlled through information communication technology (ICT). Control is the third, and last, critical key component in the smart grid.

The aforementioned definition of a smart grid gives a clear overview of the goals and requirements for such a control system. Crucial is the coordination between all consumers and producers situated within the grid under consideration. In our setting, a residential microgrid, this means that up to hundreds of connected customers may be connected to this microgrid, with each customer owning several devices. This results in possibly thousands of consumer grade assets that can be controlled in a residential microgrid, forming a heterogeneous cluster. With coordination among thousands of devices, a scalable control system is required to influence the behaviour of this heterogeneous cluster of devices. Such a control system can exploit the flexibility offered by this cluster to attain a certain desired, optimized, power profile that minimizes costs, environmental impact or another objective.

Changes in the state of a device may result in a change of power consumption. Therefore, devices that are connected to the electricity distribution grid will also change the state of this distribution grid. For this grid, the overall power profile is not the only thing that matters, a good control methodology should also optimize the operation of the distribution grid itself. Firstly it is important that the physical grid remains in a safe state where no overloading of grid assets, such as cables and transformers, happens to ensure a safe and uninterrupted supply of energy. The supplied power quality of the electric energy must comply with local regulations, e.g. the voltage level must remain within a predefined band. Other objectives of the control system concerning the grid may be the reduction of distribution losses and avoidance of ageing of grid assets.

As argued in the beginning of this introduction, control is necessary, and thus critical, to maintain system wide stability. However, the control system may fail or may become compromised by cyber attacks. Such a scenario puts the reliable supply of electricity, one of the key components of our modern civilization, at risk. Hence, a smart grid control system must be robust and resilient against (long term) failure of the ICT component by implementing proper fall-back plans. Information from the physical grid, e.g. voltage levels, may be the key to both detection of cyber attacks and may assist control when communication fails. 
Next to these technical components within the smart grid, there also exists a human component, namely the prosumers. For the system to be really effective, end-users must observe the added value in participating in a smart grid and trust the system itself. Therefore, it is important that the control system satisfies the constraints that are set by the end-user, e.g. a fully charged BEV before the deadline. Furthermore, a good system should also be transparent in its actions.

The focus of this research is to reach the mentioned objectives and requirements of the smart (micro)grid using control of domestic appliances. The needs of endusers, are not a main focus but are part of the requirements of the control system itself. The common thread throughout this research is the bi-directional interaction between the control system and the physical grid. This results in the following main research question:

How can we effectively exploit the interaction between control systems, devices and physical distribution grids, while respecting physical constraints, in decentralized energy management to reach the objectives of a smart grid?

To tackle this research question, the following sub-questions are formulated:

1. How can models of control systems, devices and the physical grid be integrated in one platform?

2. How can properties and constraints of these device and grid models be integrated in a decentralized energy management system?

3. How can decentralized energy management systems exploit interaction between the physical and cyber parts of smart grids to enhance its robustness?

\subsection{APPROACH}

As a smart grid consists out of multiple crucial sub-systems and technologies that depend on each other (a system of systems), the whole may be greater than the sum of the individual parts. Therefore, to fully benefit from the potential that smart grid technology has to offer, a broad, holistic, perspective is preferred. As a result, we take a CPS approach in which we model the control system, physical devices and the physical distribution grid. Interaction between these three sub-systems can be taken into account with this CPS approach, e.g. the effect of control actions on voltage levels can be studied. The resulting state of the physical grid or devices may then be used as feedback into the control system for next actions. We restrict the model of the physical grid to a discrete time model ${ }^{2}$ as we are interested in the longer term steady state of the grid and not in short term stabilization control, such as frequency control. The latter would require too much computational power to evaluate the performance of smart grid control systems for longer time periods (e.g. weeks up to years).

\footnotetext{
${ }^{2}$ CPS models are not limited to a mix of continuous and discrete systems, purely discrete CPS models can give enough fidelity for the properties of interest as stated by Lee et al. [100]
} 
For the control system two different approaches are developed based on components for the physical subsystem. The first control approach is the profile steering heuristic, which coordinates and optimizes the energy consumption of devices in a microgrid directly to a desired power profile. It does so by employing predictions to perform MPC, to create an optimized power profile for a predefined number of time intervals. This heuristic is specifically designed to minimize currents in the grid which helps to avoid stress on grid assets and power quality issues. Local limitations of the grid can be incorporated using a hierarchical structure that maps directly to the physical infrastructure. An event-based approach is added to the profile steering approach to resolve prediction errors in both the time domain and energy domain. Furthermore, we show that this approach can be extended easily to support multiple commodities.

The second control methodology is based on a double-sided auction. Feedback from the physical system is incorporated in this control approach to enhance the robustness of smart (micro)grids. The first contribution in this context is a method to stabilize islanded microgrids with the addition of time delays of domestic appliances to the physical model. A proportional-integral-derivative controller (PID) is used to avoid instability of the control signals due to these time delays. Another vulnerable component within the smart grid is the need for communication to control assets. To mitigate the negative effects associated to the loss of communication technology, and thus coordinated control, a feedback system based on local measurements is proposed. This method uses the electricity grid itself as a communication channel and determines appropriate control actions based on local information.

A further contribution in this thesis, is the development of a simulation and demonstration platform, named DEMKit. This tool is used to simulate and evaluate the performance of the developed control system of (micro)grids. Critical to the performance of such control methodologies is the amount of flexibility offered by devices and their owners. Therefore, a novel artificial load profile generator (ALPG) that explicitly generates the available flexibility is developed. The output of this tool can be used as input for DEMKit, which contains a library of device and grid components and control implementations. A modular approach is taken to easily integrate more device components and control approaches in the future. The integration of all physical and cyber models within one platform allows for an efficient interaction between the physical and cyber subsystems.

To verify the grid models and the resulting artificial load profiles, measurement data, resulting from a field test in the Dutch town of Lochem, is used. These components form the basis, on which the different control strategies are tested in different scenarios using simulations. In one of these studies, the different variants of profile steering, the double-sided auction, and a combination, are compared to the situation without control. Furthermore, data from a questionnaire in the test site under consideration is used to model a scenario with the flexibility that participants are willing to offer to such a smart grid control system. Finally, the other scenarios are 
used to study the operation of the double-sided auction approach in an islanded grid instead of a connected one. Furthermore, we look at a scenario where the communication network is unavailable.

\subsection{Outhine of this Thesis}

In this chapter we have discussed the energy transition, the resulting challenges and the smart (micro)grid paradigm to deal with these challenges. Based on these challenges, research questions and the approach to create a control system for this smart (micro)grid are introduced. In Chapter 2 we present more background information on the electricity grid, smart grids and proposed solutions and control approaches to the introduced challenges. This information is used in Chapter 3 to derive models for the grid infrastructure and the devices that can offer flexibility to the smart grid. The CPS model is completed with a framework for control systems. The next chapter, Chapter 4, presents a MPC control approach named profile steering, and some extensions. An alternative control methodology, based on double-sided auctions is presented in Chapter 5 . Chapter 6 presents the implementation of these control methods, together with the models presented in Chapter 3 , in a tool chain. This tool chain consists of an artificial load profile generator to derive flexibility information, and a simulation and demonstration platform. These tools are used in Chapter 7 to validate models and evaluate the performance of the presented control methods. Conclusions and recommendations for future work are presented in Chapter 8. 


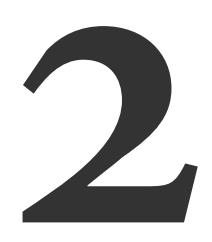

\title{
BACKGROUND
}

\begin{abstract}
This chapter gives some background on the electricity grid as we know it today and the challenges it is facing due to the energy transition. The current centralized power supply chain is the result of past developments and benefits from the economy of scale. However, the system stability becomes stressed with the introduction of micro generation and increased electrification of our energy demand. Overloading and outages may happen more often in the future as the load increases due to the electrification. On the other hand, power quality issues, such as over voltage, may occur as micro generators are installed in the distribution grid. However, the local generation, combined with control through ICT, also provides opportunities to facilitate an efficient energy transition towards a system with more decentralized renewable energy. By shaping the energy profile, grid overloading can be avoided by keeping energy production and consumption as local as possible, thereby avoiding unnecessary transportation of energy. To achieve this, already a broad range of control approaches can be found in literature: from direct load control to distributed control systems, and from reactive to proactive market clearing approaches. These control systems are a key component of the smart grid paradigm. Flexibility frameworks and market models are developed to unlock the full potential of control systems. Validation of these models and control approaches is done in various field tests. Another important aspect is the adoption of such control systems by prosumers as the energy transition and accompanying smart grid technologies changes our view on energy usage.
\end{abstract}

The shift towards renewable energy generation, such as solar energy and wind energy, as sketched in the previous chapter, comes with its own challenges. These renewable energy sources are intermittent and thus do not always provide energy when demanded. This is in contrast to the conventional generation of electricity by fossil fuel powered power plants, which are following the demand. The reason for this is that, at any time, balance between production and consumption of electricity is required as the electricity grid has no notable inherent storage. As a consequence, 
the energy transition requires new means to keep this balance to ensure system stability and reliability. One possible solution is to shape the energy demand, such that the demand follows the generation instead. This solution is commonly referred to as demand-side management (DSM) or demand response (DR) [143].

The energy transition results also in another major shift: decentralization. Instead of central bulk generation of electricity, renewable energy sources (RES) allows for local micro generation, such as e.g. rooftop mounted photovoltaic $(P V)$ panels. The adoption of privately owned small scale energy generators results in a new movement within society. In many places local energy initiatives among neighbours or towns are started to accelerate the adoption of RES and share each other's energy. This local generation reduces the dependence on a centralized energy system. Matching local generation and consumption also reduces the need for large distance distribution of energy across countries.

As RES often generate electricity, we see at the same time an increase of the total electricity demand to become independent from fossil fuels. Mobility and heating are two examples of major domestic energy consumers that were in the past largely based on oil and natural gas based fossil fuels. These consumers are shifting towards electricity powered alternatives, such as replacing gas boilers by electric powered heat pumps for space heating. Electric vehicles see an increasing market share, partly due to financial incentives from governments, but also due to decreasing battery prices [13]. In addition, to increase self-consumption of locally generated energy, the adoption of household batteries is also expected to take-off in the coming years [105]. We refer to all these technologies as distributed energy resources (DERs), since they inherently have some flexibility that can be exploited to shape the demand profile.

The resulting widespread integration of RES and DER makes the control of the energy supply chain increasingly difficult. In the centralized system, only few generators need to be controlled to coordinate the national power production and maintain system balance. With the energy transition, we see a widespread integration of intermittent RES and heterogeneous clusters of DER. To utilize the flexibility on the demand side, millions of DER have to be controlled in a scalable and predictive manner. Furthermore, the interplay between demand, generation and storage is important in the context of the energy transition. To reflect this, we speak of decentralized energy management (DEM) instead of DSM. Since the major challenges of the energy transition lay within the electricity grid, the management of electricity flows is the main focus of this thesis, but where applicable other energy carriers are also considered.

This chapter provides a background on the challenges in the electricity system that lay ahead of us. Section 2.1 sketches a brief history on how we arrived at the current state of the electricity grid. Previous trends, ideas and practices in this field impact the possibilities of this grid to make the energy transition possible. New technologies, such as the smart grid, are introduced in Section 2.2. These technologies promise to assist the old infrastructure in realizing a cost effective 
energy transition. Based upon the smart grid paradigm, novel control mechanisms and technologies have been developed over the last couple of years. These proposed technologies and regulatory frameworks are analysed and surveyed in Section 2.3. This chapter is wrapped up with conclusions in Section 2.4.

\subsection{ENERGy INFRASTRUCTURE}

Ever since the industrial revolution, a stable supply of energy has been important for our civilization. With the invention of electricity, local electricity generators and distribution networks sprout up all across the globe. Eventually, these networks became interconnected to end-up at the centralized energy grid as we know it today. In some developed countries, large portions of this grid exist already longer than their economical lifetime and the energy transition challenges this grid even more as it was never designed to cope with the increase in RES and DER as we anticipate for the coming years. To this end we discuss the history of our energy infrastructure and the challenges that lay ahead to make this electricity grid ready to support the energy transition.

\subsubsection{EleCtricity System}

Initially, power (not necessarily electric power) was generated locally from coal fired steam engines, but in 1882 Thomas Edison started to distribute $110 \mathrm{~V}$ direct current (DC) electrical energy among 59 customers in lower Manhattan. More of these local electricity grids were constructed in the 1880's. The drawback of DC power was that energy could only be distributed locally as the relative low voltage results in high currents and distribution losses over longer distances. Westinghouse Electric started the creation of alternating current $(A C)$ electricity grids in the mid 1880's which were able to increase or decrease the voltage with the use of transformers. The competition between the two systems unchained the "war of currents" [165]. Eventually, the polyphase AC system won this battle as it was able to efficiently transport electricity generated in centralized power plants to consumers over longer distances. Over time, numerous smaller, localized electricity networks were integrated in regional, national and even international electricity networks to benefit from the economy of scale.

The first electricity network in the Netherlands started operation in Kinderdijk in 1886 to service 300 lights and operated also on a DC basis [154]. Since then, the electricity revolution could not be stopped and local electricity grids from municipalities arose in the Netherlands and throughout Europe in the 1900's. In the 1920's, the Netherlands counted approximately 550 AC electricity utilities and started to integrate these networks to share production capacity of generators. The rest of the Netherlands, including rural areas got also connected to the electricity grid by governmental regulation. To facilitate the growth in electricity demand, larger national power lines were constructed, such that all power plants were connected to one national power grid. 
Table 2.1: Total length of the Dutch electricity networks in 2014. Source: [114].

\begin{tabular}{r|ccc}
\hline & $\begin{array}{c}\text { Cables (underground) } \\
{[\mathrm{km}]}\end{array}$ & $\begin{array}{c}\text { Lines (overhead) } \\
{[\mathrm{km}]}\end{array}$ & $\begin{array}{c}\text { Number of } \\
\text { customers }\end{array}$ \\
\hline EHV & 37 & 2,836 & 0 \\
HV & 3,764 & 5,022 & 158 \\
MV & 105,664 & 0 & 32,431 \\
LV & 220,449 & 180 & $8,165,694$ \\
\hline
\end{tabular}

This resulted in the centralized electricity system as we know it today where energy is produced centrally and flows in one direction towards the consumers. This transport of electricity is done through multiple layers of voltage levels to reduce the transport losses. A higher voltage level implies a more efficient transport of electricity due to the reduced current and reduced losses. High voltage levels do come with the downside that they require larger hardware (e.g. transformers) and may therefore not fit in space and safety critical environments, such as city centres. Therefore, the design of a local electricity network is a trade-off between power requirements and distribution length. An often used rough subdivision are the extra high voltage $(E H V)$, high voltage $(H V)$, medium voltage $(M V)$ and low voltage $(L V)$ networks. Herein, the HV grid is primarily used to transport electricity over long distances. To this HV grid centralized power plants are connected, together with few large industrial consumers, such as aluminium smelters. The electrical energy is then stepped down to a lower level using a transformer to service large businesses and local industry connected to the MV network. Small enterprises and residential consumers are connected to the LV network. In addition to the AC power grid, high voltage direct current $(H V D C)$ grids are used for efficient transmission of electricity over longer (international) distances and to connect offshore wind farms. The lengths of the different networks in the Netherlands in either voltage level are given in Table 2.1.

Until the late 1990's, most electricity supply chain companies in European countries were state owned and regulated. The responsible companies had a monopoly to produce, distribute, and deliver and bill energy to customers in a certain area. In the late 1990's, the supply chain was split up in networking companies, and energy producers and/or retailers with legislation passed in the European Union [48] (also known as the unbundling). Since then, customers can freely choose a retailer for the supply of electricity. These retailers generate the demanded electricity using their own power plants or buy the demanded electricity from other generating companies. The result is a competitive market for generation and selling electrical energy to consumers.

Electrical energy is traded through several energy markets that operate on various time scales for planning, day-ahead scheduling and balancing. These markets are further explained in Section 2.1.2. On the other hand, the networking companies 


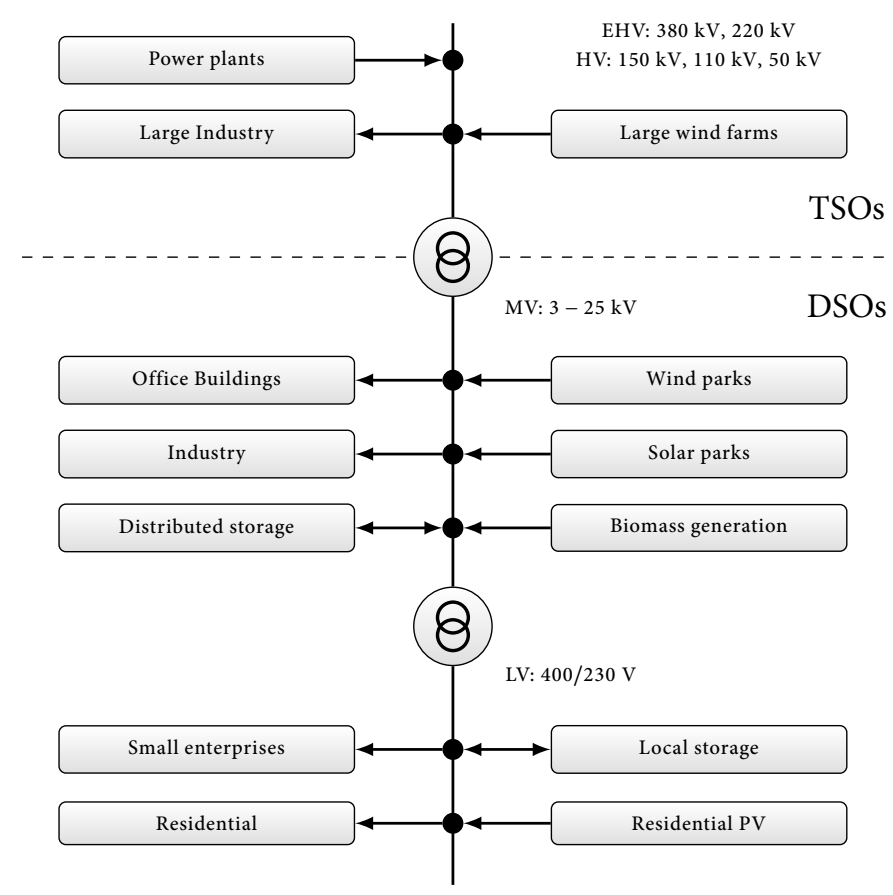

Figure 2.1: A schematic overview of the electricity grid with examples of consumers and producers on each level.

own and maintain the grid assets to facilitate the connection between generation and customer. Asset ownership of the electricity grid results in a natural monopoly and thus these companies are state regulated. These networking companies are roughly split up in transmission system operators (TSOs) responsible for the transmission network (HV and EHV) and distribution service operators (DSOs) who are responsible for the distribution networks (MV and LV). However, there is a grey area where some DSOs are also responsible for (parts of) HV networks.

The voltage levels within the AC networks vary a lot throughout the world. Initially, most local electricity networks were operated on a 220/127 V basis (line-to-line voltage / line-to-neutral voltage) in the Netherlands and the HV transport networks were operated at $50 \mathrm{kV}$ in the western and southern part of the Netherlands whereas the northern part used $60 \mathrm{kV}$, which were later on upgraded to $150 \mathrm{kV}$ and $110 \mathrm{kV}$ respectively. In addition, a $380 \mathrm{kV}$ network was constructed to connect the northern to the western and southern electricity network. In the 1950's the LV network voltage was changed to $380 / 220 \mathrm{~V}$, whereby the mains in old parts of the network could also be supplied with the common $220 \mathrm{~V}$ by using the line-to-line voltage instead of line-to-neutral voltage. The following voltage levels and their respective operators are used within the Netherlands [154] (see Figure 2.1): 
» EHV level: voltages of $380 \mathrm{kV}$ and $220 \mathrm{kV}$ are used for (inter)national transmission. These networks are owned and operated by a TSO.

» HV level: voltages of $150 \mathrm{kV}, 110 \mathrm{kV}$ and $50 \mathrm{kV}$ are used for regional transmission. These networks are usually owned and operated by a TSO.

» MV level: voltages of $3-25 \mathrm{kV}$ are used for local distribution and to service large users. These networks are owned and operated by a DSO.

»LV level: voltage of $400 / 230 \mathrm{~V}$ is used for local distribution to service small enterprises and residential users. These networks are owned and operated by a DSO.

Customer supply voltage levels and power quality regulations nowadays are harmonized within Europe through the implementation of the EN-50160 norm [113]. Furthermore, the electricity grids within continental Europe are interconnected to form the Synchronous Grid of Continental Europe that allows transnational energy trade throughout Europe. Within this area, the (extra) HV levels are largely harmonized between the countries [97]. The European TSOs are represented by the European Network of Transmission System Operators - Electricity (ENTSO-E) organization to support pan-European energy markets. The voltage levels used in the Netherlands are common throughout the rest of continental Europe, where in addition $400 \mathrm{kV}, 330 \mathrm{kV}$ and $132 \mathrm{kV}$ are also used.

Nowadays, we see research advocating for a shift back to localized electricity systems to avoid the grid reinforcements required for the centralized system [67]. Furthermore, local electricity generation, storage and consumption also avoids unnecessary distribution of electricity and accompanying losses. With the invention of power electronics, DC electricity regains interest as well as it cuts out conversion losses on both the production side (e.g. PV generates DC but the inverter converts this to AC) and consumption side (e.g. most consumer electronics convert AC to DC through power electronics) [61]. Only the future will tell if these ideas result in a new "war of currents" and a trend towards more localization to support the energy transition.

\subsubsection{ENERgy Markets}

A crucial aspect in the generation and consumption of electrical energy is the need for balance since there is no (large) inherent energy storage in the grid itself and (large) battery storage systems are still expensive. Today, the demand for electricity is largely uncontrollable in the current state of the grid, which results in the paradigm that the generation of electricity follows the demand. This means that the power plants must be able to respond quickly to changes in the demand to maintain this balance.

There exist different types of power plants, each with their own characteristics regarding start-up times, efficiency, operational costs and power output. The economical most efficient generators are scheduled to follow predictable fluctuations 
of electricity demand. However, even the fastest power plants take minutes to start operation. Therefore spinning reserve generators are standing by to flatten out sudden, fast, fluctuations.

The balance between production and consumption within the power grid is observable through the AC grid frequency, which is synchronized in the whole grid. An increase in demand results in kinetic energy being extracted from the rotor of a generator, causing it to slow down and thereby leading to a decrease of the grid frequency. Through droop curves, power plants can react to this decrease (or increase if the demand drops) by changing their fuel injection and thereby their power production. This keeps the system stable as long as the balance between production and consumption does not change too fast.

Electricity trading markets exist to ensure that electricity production matches the demand in real-time, but also to determine far ahead in time whether new power plants or grid upgrades are required to ensure a reliable supply of electricity in the near future (see Figure 2.2). The structure of these markets is similar across European countries, but local regulations and local situations have resulted in slightly different approaches [130]. Standardization and coupling of these markets is currently ongoing.

\section{Capacity Markets}

The electricity markets can be be split up in two main categories, namely capacity markets and balancing markets (see e.g. [93]). The capacity markets are used to plan the required transmission, distribution and generation capacity based on the predicted electricity demand. Forward (or futures) markets are used to sell future energy production up to several years before the actual delivery. The purpose of these markets is to determine whether new capacity needs to be build, or whether it is economical beneficial to decommission power plants. Closer to the actual delivery of ordered energy are the day-ahead and intraday spot markets. To ensure grid balance, any party with one or more connections to the electricity grid has balance responsibility. Each balancing responsible party $(B R P)$ must therefore balance the demand of its portfolio by sourcing electricity production from the producers. The resulting programs (schedules) must be submitted one day-ahead, before the socalled gate closing, to the TSO. Deviations from the day-ahead programs prognosis, e.g. due to prediction errors in wind or solar energy, can be balanced by buying or selling energy on intraday markets, which operate closer to the time of delivery, but are more expensive. In the Netherlands it is even possible to trade 5 minutes before delivery on the intraday market [42]. In all these markets energy quantities are traded in time blocks, referred to as program time unit (PTU), which often span one hour or fifteen minutes. 


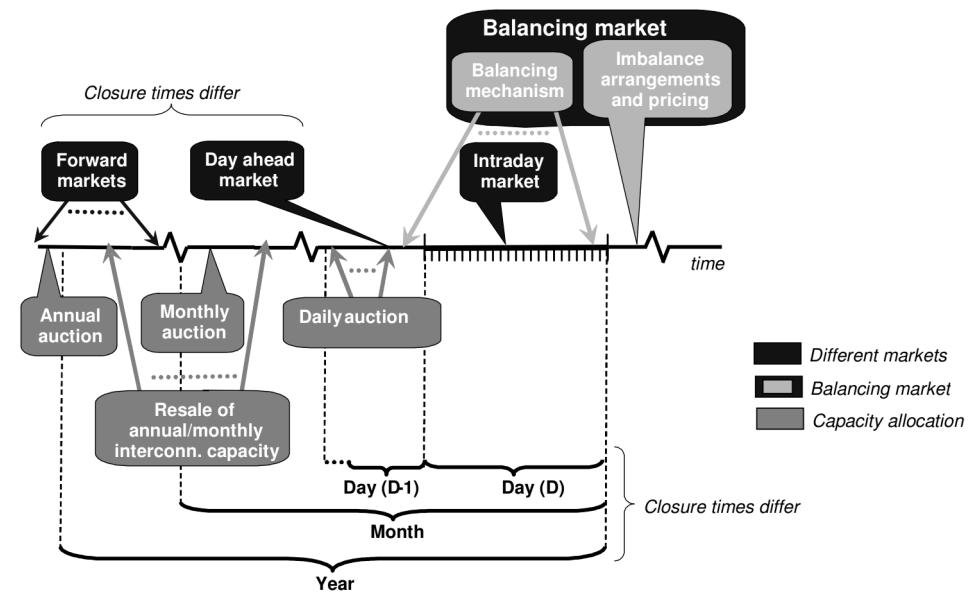

Figure 2.2: Overview of capacity and balancing markets the power grid ([49]).

\section{Balancing Markets}

The balancing markets, organized by the TSO, must ensure real-time balance and stability of the electricity grid and are therefore closest to the actual moment of delivery. At the end of the day, a BRP has to pay a time-dependent penalty to the TSO for the deviations in energy consumption from the previously submitted programs. The ENTSO-E has defined three balancing reserve pools [119]. The frequency containment reserve $(F C R)$ is used to limit grid frequency deviation by automatically activating reserve capacity to balance mismatches between supply and demand and a bit later, the frequency restoration reserve (FRR) kicks in to restore the frequency. Finally, replacement reserve $(R R)$ may be activated by starting stand-by generators if deemed necessary. A BRP can also act on these markets to recuperate some of the costs made by deviating from the program. Note that a minimum power bid is required to act in these balancing market, such as $1 \mathrm{MW}$ for FCR, $4 \mathrm{MW}$ for FRR and $20 \mathrm{MW}$ for RR in the Netherlands [119].

\subsubsection{Low Voltage Grids}

A large part of the energy transition and electrification as sketched in the introduction takes place in the LV network. Together with the rise of prosumers, RES and DER, we take this bottom-up approach and focus on the residential LV grids in this thesis. The introduction of RES introduces local generation in the LV grids and therefore may lead to bi-directional power flows. Already in the LV network, this in contrast to the uni-directional power flows from generators towards the customers, for which the majority of the LV grids were once designed. Furthermore, the electrification results in a rising demand for electrical energy by residential users as they start to use electricity for heating, cooking and transportation. This trend results in 
a shift of the residential energy mix and a natural increased requirement for distribution capacity within the electricity infrastructure [116]. The reverse power flows may occur locally, possibly resulting in local over voltage issues or grid overloading that bypasses protection equipment located at the transformer and households.

Such revolutionary changes were not anticipated a couple of years ago. For a long time, no significant changes in the LV grids have happened, apart from a slow, but steady, rise of electricity demand. Therefore, the current practices on how to design and dimension a new LV grid have been based on the predicted steady growth of uni-directional electricity demand in the LV grid. In the past, the stochastic behaviour of the energy demand of households became quite well predictable with a larger group of residential customers. Peak consumption of large loads, such as washing machines or coffee makers, do often not coincide with those of other households. This results in load diversification, which is used to determine the expected maximum peak load within an LV network based on annual consumption figures. Default load profiles [112], based on Dutch measurement data, are used to dimension the size of transformers and cables. A typical Dutch residential LV grid is designed with a maximum simultaneous power consumption of 1 to $2 \mathrm{~kW}$ per customer [154]. As energy profiles change with the ongoing electrification and the energy transition, more accurate bottom-up load estimations based on user behaviour are being developed to better design new distribution grids [68].

The general structure of a Dutch LV distribution grid starts at the MV/LV transformer that supplies the LV grid. The secondary side of this transformer has a busbar to which multiple cables are connected that run into the streets. We refer to these cables as feeders, since they "feed" the streets with electricity. These cables consist of multiple conductors as the electricity system is a polyphase system, where at least three conductors are used to distribute the voltage of the three phases and a fourth conductor is used as a neutral. Sometimes additional conductors are used in a cable, which are often used to distribute electricity for public lighting. Most Dutch LV grids are operated radially, i.e. there are no loops within the system, such that energy is only fed through one feeder originating from one transformer. The households are connected to this feeder with either a single-phase or a three-phase connection. The network is protected by fuses, where residential users typically have a connection capacity limit of either $40 \mathrm{~A}$ in the single-phase case and $3 \times 25 \mathrm{~A}$ in the three-phase case, see Figure 2.3 for a schematic overview. Most consumer equipment has to be connected to one phase only. We note that the chosen phase for single-phase connections is often random and little to no documentation is available as to what phase a house is connected.

\subsubsection{Other Energy Carriers}

Next to the electricity grid other energy distribution networks also exists, such as the natural gas network and local district heat networks. Heat networks are often used to enhance the overall energy and cost efficiency by heating buildings with waste heat from nearby large industrial factories. Transporting heat, especially 


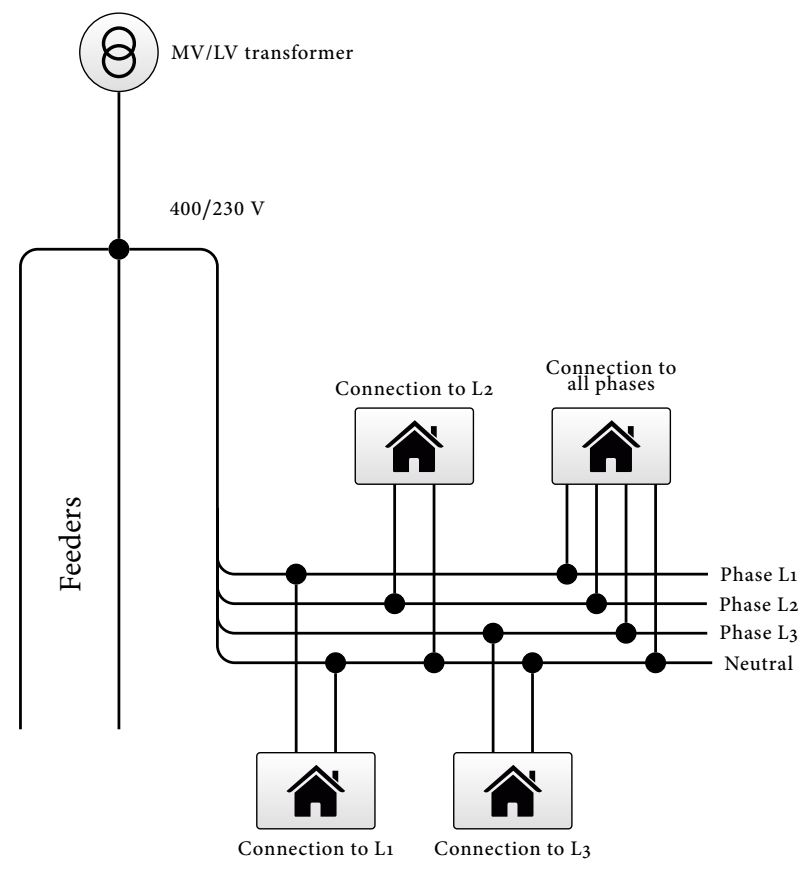

Figure 2.3: A schematic overview of the electricity distribution grid levels with the three-phase four-wire LV grid.

at high temperatures or long distances result in high energy losses, hence these networks can only be applied locally. Research on low temperature heating districts is ongoing to reduce losses in local heat networks.

The natural gas grid in the Netherlands has a similar structure as the electricity network to transport and distribute the natural gas. Analogue to the voltage levels, the gas network is operated on different pressure levels. The Dutch gas distribution networks are often operated by the same local DSO that operates the local electricity distribution grid. These networks have some inherent storage, resulting in a less strict need for constant balance between production and consumption. An advantage of both energy carriers is that mass heat and gas storage is cheaper than electricity storage with current technology, which makes longer term decoupling of consumption from production in these networks economically viable.

Together all the mentioned energy networks, local and national, form the total energy distribution infrastructure. As a result, the energy demand is delivered to customers with the use of different energy carriers, which make up the used energy mix for energy supply. Historically, electricity within the residential sector has supplied energy mainly to lighting, white goods and electronics. Energy for heating and cooking, two notable energy consumers, are in the Netherlands mainly supplied by natural gas from the Dutch province of Groningen since the 1960's, 


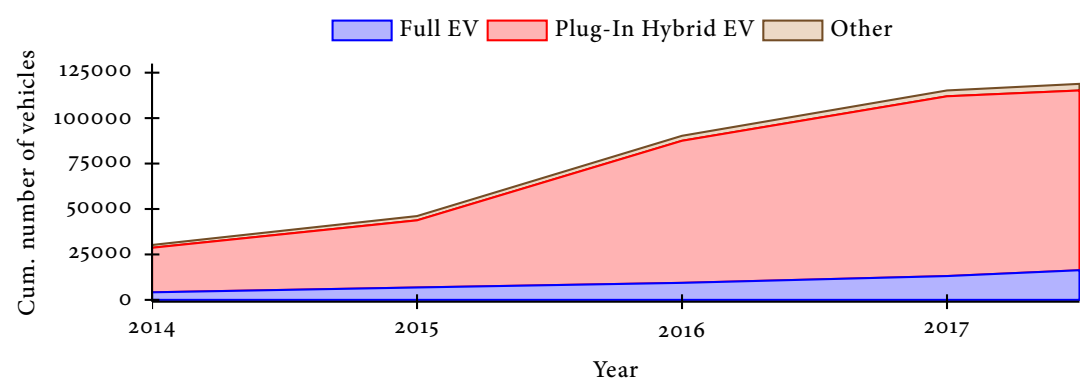

Figure 2.4: Development of the penetration of electric vehicles in the Netherlands. Data taken from [129].

whereas fuel for transportation needs is supplied through a chain of fuelling stations. With the electrification of heating, cooking and transportation the used energy mix for residential areas and small enterprises is about to shift significantly in favour of electricity [79].

\subsection{Changes in Distribution Systems}

The aforementioned trends of increasing amounts of RES and DER, such as battery electric vehicle $(B E V)$ as shown in Figure 2.4, being integrated in distribution grids significantly change the total energy consumption and expected peak load. The chance that multiple large loads consume electricity at the same moment is expressed by the simultaneity factor. In contrast to white goods and kitchen equipment, new consumers such as heat pumps have a high simultaneity factor during cold days in the winter where these devices have to run regularly. The installation of over a hundred heat pumps in an unprepared LV grid has already led to service interruptions in a Dutch neighbourhood [152]. The same holds for electrical vehicles, which consume a considerable amount of electricity to recharge, resulting in long run times and a high simultaneity factor. Within two field tests we showed that simultaneous charging, together with further electrification of heating demand, lead to severe peaks, phase unbalance and even created an outage, of which results are presented in Chapter 7. Not only an increased load is causing stress on the current day distribution structure, also the local production of solar energy is synchronized as all PV setups produce simultaneously. This is nowadays already visible in Germany, where some grids face huge feed-in peaks of electricity from PV setups that are up to a twenty-fold of the electricity demand [118].

The above discussed cases show that the associated risks with the energy transition are grid overloading, under-voltage and over-voltage problems, and phase unbalance, potentially resulting in an increase of service interruptions. One solution to these expected capacity problems is the use of conventional grid reinforcements as thicker cables reduce the voltage drop and larger transformers have more capacity 
to deliver the desired power. However, this solution is very expensive, especially in the Netherlands and other North-West European countries where the LV grid dominantly consists of underground cables [43] (see Table 2.1). According to [45], an investment of up to $€ 2.2$ trillion in the electricity grid is required to facilitate the decarbonization within the European Union (EU). This includes cross border transmission network investments, based on expected electricity flows in a free market. As stated in the introduction of this chapter, DER contain some inherent flexibility, which can be exploited by smart grids to reduce peak load. In Germany, the required grid investments to facilitate the energy transition can be as high as $€_{42.5}$ billion, of which $€ 16.2$ billion is needed in distribution grids within Germany [31]. The study also shows that smart grid technologies can significantly reduce these investments (over 40\%), while market driven control of storage systems will result in significant higher investments to facilitate electricity trade. Until 2050, up to $€ 9.5$ billion can be saved on grid investments in the Netherlands by using smart grid technologies [12]. Note that there is still a large uncertainty on the development of the energy transition and smart grid technology, and therefore also in the required investments and gains. A study by Ecofys [153] finds that annual savings of $€_{20}$ to $€ 120$ per connection can be achieved by smart grids. Subsection 2.2.2 provides more details about these envisioned energy management systems.

\subsubsection{FleXibility Markets}

With the integration of more power generation from volatile RES, the predictability of the plans as submitted on the day-ahead market becomes increasingly uncertain. Therefore, most countries have implemented intraday markets to balance production of RES closer to the moment of actual delivery, such that more accurate predictions can be incorporated [119]. The integration of more RES results in an increased need of flexibility to balance the grid using the power plants. However, with the aforementioned new DER technologies, flexibility can also be offered by residential prosumers' devices by shifting their demand. If such flexibility can be controlled, the fluctuations from RES production may be damped with fluctuating demand, resulting in a more stable and predictable profile. Such predictable and stable profiles help to optimize the usage of power plants economically. However, two problems arise in this context. Firstly, a sufficient amount of flexible power is required to act on these markets, which cannot be offered by a single prosumer. And secondly, current pricing schemes do not encourage load shifting as most customers are billed with a fixed price per kilowatt-hour, or only day-night price differentiation. However, with the distribution of smart meters, differentiated pricing becomes an option [47]. Recently, Easy Energy started to deliver electricity in the Netherlands at day-ahead market prices directly to the customers by announcing the prices for the next day around noon [36]. These prices encourage people to manually shift their energy usage away from intervals with high prices. 
To unlock automated flexibility at prosumers, new market framework extensions are currently proposed. The Universal Smart Energy Framework (USEF) [147] is proposed to integrate flexible energy services into the existing electricity markets in order to unlock flexibility that prosumers can offer. A key role in this framework is the role of a new market party, namely the aggregator. An aggregator procures flexibility from multiple prosumers into one portfolio. A BRP or DSO can buy flexibility from such an aggregator, which then tries to optimize the portfolio to the desired profile. This flexibility can be purchased for both the day-ahead and intraday market. As discussed in Subsection 2.1.1, capacity limitations in the distribution grid are expected to also play a significant role in the future due to the ongoing electrification. Therefore, the DSO should have means to influence the market when required to avoid local service interruptions. Both USEF and the German Bundesverband der Energie- und Wasserwirtschaft (BDEW) [18] discuss a traffic light concept in which the energy market has free play in the green (safe) regime. However, if congestion (overloading) or power quality issues are expected, the yellow and orange (USEF) or amber (BDEW) regimes may be activated, in which the DSO is allowed to buy flexibility in order to resolve congestion issues. In case the normal market operation is unable to find a solution, the regime is switched to the red phase in which the DSO takes over control and is allowed to perform load shedding or production curtailment to avoid outages.

\subsubsection{SMART GRIDS AND Homes}

The smart grid, for which we gave a definition in the first chapter, is seen as a more economically sensible alternative to the conventional grid reinforcements. However, the term smart grid is used as an umbrella for several technologies and visions, resulting in a broad variety of (partial) solutions to the problems that our grid is facing with the energy transition.

\section{Monitoring}

One key aspect in all smart grid solutions is the need for communication technology to provide feedback to the system operator. Actively monitoring the state of an electricity grid by deploying sensor equipment is the main driver as one can only manage what one can measure. Without feedback systems, it is impossible to identify weak or failing parts within the system and react to resulting issues in time. The 2003 blackout in North-Eastern America was partly caused by the lack of active monitoring, leaving system operators in the dark of what was actually happening. Therefore, phasor measurement units (PMUs) have seen a rapid widespread deployment in the grid to provide active grid monitoring and proper state estimation of the grid to prevent another, similar, blackout in the future [115]. In addition, smart meters and substation metering are being deployed to remotely access measurement data of millions of points in the electricity grid. This measurement data can not only be used to provide feedback to customers, but also to identify theft of electricity [82], and prevent power quality issues and local grid overloading [164]. 


\section{Flexible Grid Assets}

Monitoring by itself does not resolve overloading problems and power quality issues in the electricity system, but can be used to plan conventional reinforcements. However, conventional upgrades to increase the hosting capacity for RES and DER in the distribution grid may not be enough. Adding more cables and bigger transformers is often referred to as the act of "copper plating", which eventually results in a practically infinite capacity to transport electricity. However, this is a costly operation that only solves the problem of distributing electricity, but not the balancing problem [116].

For some of the occurring grid problems technical solutions are already developed, which can handle these problems up to a certain extent. A solution to larger voltage drops and rises due to DER and RES is the use of an on-load tap changer (OLTC) that allows transformers to automatically change the number of used windings to influence the voltage supplied on the secondary side. Further developments are seen in the field of automatic power supply restoration in case of a fault by automated switch gear in the grid. To ensure interoperability between these smart grid components from various vendors, the International Electrotechnical Commission (IEC) 61850 standard for substation automation has been developed. Such switch gear can also be used to reconfigure the grid topology for more efficient distribution or to perform islanding.

\section{Storage}

Next to improved (automated) controllability and monitoring of existing assets, new technologies to cope with the balancing challenges emerge. Storage systems are seen as a key component in the smart grid to resolve both the transport and the balancing problem. Storage systems are able to shift energy production or consumption in time, which allows them to limit peak load in both production and consumption. As a result, energy can be stored locally, preventing excessive transport of electricity and thereby avoiding costs for conventional reinforcements for the required peak load capacity. Simultaneously, they provide the means to balance local demand and supply to solve the balancing problem [96]. Discussions are ongoing on whether or not a DSO may use storage systems as an alternative since this enables the DSO to act on energy markets, which is not allowed since the unbundling. Nykamp shows that a storage asset shared by a DSO and a second party, acting on the energy markets, is economically viable [117]. The integration of a battery is tested in Germany to relieve stress from a rural grid under strict conditions to prevent the DSO from influencing the markets [118].

\section{Microgrids}

To increase reliability and to ensure the supply of power, the concept of microgrids that can operate independently from the main grid is introduced [98]. In gridconnected mode, a microgrid may use its control systems to balance consumption 
and generation locally. The potential degree of energy autarky of microgrids depends on the assets available in such a microgrid. With proper control and stabilization equipment, such a microgrid can be detached from the main grid, which is referred to as islanded operation [6o]. This increases the reliability of the microgrid as this part of the grid can be isolated to prevent further propagation of grid instability problems. In the event of islanding, a microgrid should continue operation independently and should reconnect when the situation is stable (normal) again. In the worst case, a part of the grid can be intentionally disconnected from power supply in order to prevent large, (trans)nation wide, blackouts. In [GH:10] we show that with limited storage, a group of 16 houses is able to be self-sufficient in terms of power consumption for 15 minute averages, referred to as soft-islanded operation. Tuttle et al. [144] show that plug-in hybrid electric vehicles (PHEVs) may substitute a diesel generator as islanding backup solution for a household.

\section{Internet of Things}

Next to the smart grid paradigm, a trend is also visible towards smart homes where devices are connected to each other and to cloud services. A broadly used term for these devices, equipped with internet access, is internet of things (IoT) [2]. Examples are smart thermostats and remotely controllable lighting solutions. Communication is often used to improve the end-user comfort such as automated building heating or turning on lighting when it gets dark. Except for being named an IoT device, most devices have not much in common due to a broad variety of communication technologies (e.g. Wi-Fi, Bluetooth or ZigBee) and proprietary messaging protocols. As a consequence, most IoT devices can only communicate with other devices and services from the same vendor, hindering the interoperability between multiple vendors for one integrated solution [17].

Standardized message protocols emerge (e.g. AllJoyn, Z-Wave, ZigBee Home Automation) to enable the interoperability between device vendors, allowing multiple devices to communicate with each other through a central hub. These hubs often support multiple communication technologies and message protocols and provide additional logic to translate between these protocols to allow control over a wider variety of devices. Examples are Google Home and Homey, which are voice controlled physical hubs that are intended to be placed in the centre of a household. Next to physical solutions, cloud based solutions also emerge, such as IFTTT ${ }^{1}$, which can receive triggers from and send command to internet connected IoT devices.

Community driven open-source software projects emerge as well in the field of home automation, such as Home Assistant [70] and OpenHAB [121]. These projects are not bound to vendor specific views and strict quality checks, often resulting in a wider variety of supported devices, sometimes through reverse engineered communication protocols. The development of OpenHAB has also resulted in the Eclipse SmartHome project [95], which utilizes the fundamentals of the OpenHAB

${ }^{1}$ If this, then that, https://ifttt.com/ 
code-base to deliver a framework for use in (commercial) smart home solutions [37]. Currently, such smart home software platforms are being used in smart grid pilot projects as well, see e.g. [1].

\section{Standardization}

Nowadays, most of these technologies are created to bring comfort and convenience to the end-user rather than management of electricity usage. As a consequence the aforementioned message protocols are usually limited to reading out the state of a device (e.g. a temperature) or to directly control device actuators. However, several local DER assets within the prosumer premises together have the potential to form a virtual battery. Thus, the smart home and smart grid paradigms have to merge to ensure a convenient access to the envisioned electricity markets from a user centric perspective. Open standards are required to ensure the interoperability between devices and the smart grid to alleviate obstacles that may hinder prosumers from participating in future energy markets [101]. However, from an electricity market perspective the effect (e.g. the offered flexibility) of a control action is of more importance than the technical capabilities of a device. Therefore, standards for energy management have been developed independently, such as OpenADR [120], IEEE 2030.5 (also known as ZigBee Smart Energy Profile 2.0) [168] and USEF Device Interface [147]. A higher level abstraction approach is taken with the Energy Flexibility Interface (EFI) [51], which provides four generic flexibility classes as an abstraction layer to decouple low-level device capabilities and energy management applications. This generic interface makes it possible to easily switch from one EFI compliant energy application (e.g. an aggregator service) to another or seamlessly add new EFI compliant devices through device drivers, thereby avoiding a vendor lock-in [143]. An example of such a generic platform that merges smart home and smart grid technology is depicted in Figure 2.5.

\subsection{Energy ManAgement}

The developments presented in the previous sections have given rise to the interest in unlocking flexibility potential of customers by influencing their energy demand to maintain system stability. Changing the power demand profile of customers, often called DSM or DR, is seen as an economical viable option to integrate more volatile RES in the grid. However, since the top-down structure of the grid is changing as consumers become prosumers, we prefer to use the term energy management (EM) instead. This reflects that both supply and demand is considered as potential for management as well as the active role the prosumers may have in a new setting.

The rapid transition towards RES and accompanying challenges for the electricity supply chain has resulted in a tremendous increase in research on EM over the last years. One indicator for this is the number of publications on this matter (see e.g. Figure 2 in [156]), but also the numerous recent survey publications on smart grids (e.g. $[3,10,30,136,156])$. In the remainder of this chapter we sketch and discuss 


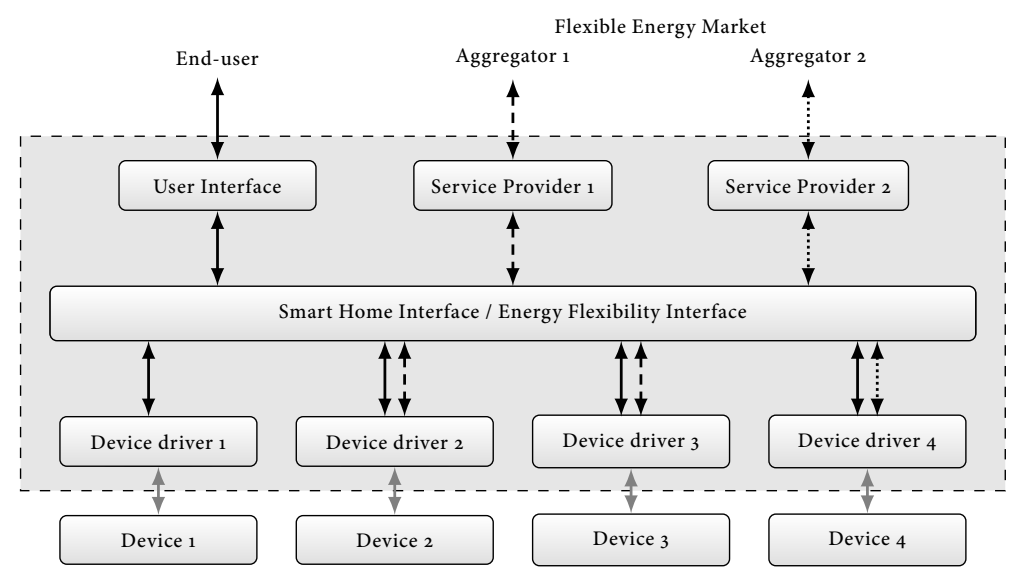

Figure 2.5: Diagram of a smart home software platform where individual devices can be connected to (different) flexibility service providers. Structure based on concepts found in [51] and [121].

the most prominent EM methodologies found in literature as well as pilot projects where new methodologies are tested in practice.

\subsubsection{INCENTIVES}

The commonly used static electricity price or the day and night tariffs per consumed $\mathrm{kWh}$, as used in the Netherlands, do not reflect the state of the electricity grid. Current subsidies and regulations are implemented to encourage the installation of RES and energy savings through better house insulation [151]. One example for supporting RES in the Netherlands is that residential customers receive the same fixed price for each kWh fed back into the grid as they pay for each consumed $\mathrm{kWh}$, as long as the total annual energy consumption remains positive ("salderen" in Dutch). From this point of view, the grid can therefore be considered as large storage device and thus no incentive is given to directly use self generated electricity. Again, these subsidies and regulations are not dependent on the state of the grid.

For some prosumers, being green (sustainable) is the primary motivation, for which the trias energetica paradigm is often followed. This results in, next to reducing overall power consumption, the desire to consume as much own (or locally) produced renewable energy and minimizing the carbon footprint. To motivate other prosumers to consume their own generated PV production directly, one measure would be to lower the feed-in tariff compared to the electricity price. This makes it attractive to directly use the energy, or use a battery to achieve this. External incentives are also required to motivate consumers to follow the fluctuations observed in the power grid. Options to reduce energy costs through price based schemes or incentive based plans as mentioned in [156] are often considered. The distinction 
between these two categories are that price based schemes offer time-varying prices such that prosumers can reduce the electricity costs by consuming more energy in low-tariff periods. In contrast, incentive based schemes offer fixed or time-varying payments for offered flexibility as a rebate. These cost savings can be seen as a compensation to customers for the loss in comfort, e.g. by allowing larger temperature deviations for heating or air conditioning systems.

\section{Time of Use Pricing}

A commonly proposed price based method is to send price based incentives of the day-ahead market directly to the customers, commonly known as time of use (ToU). Within a ToU program, the electricity retailer publishes the electricity prices for different time intervals (often fifteen minute or hourly) on the next day. Customers can schedule their energy usage manually to reduce their electricity bill. This is an easy to implement measure as it does not require intelligent devices, but merely means to inform the customer about the prices. This could be implemented by sending messages, such as an email, or displaying the prices on a wall mounted display in the living room (see e.g. [88]). The installation of smart meters makes it possible to bill customers according to such ToU tariffs [84]. Other programs, such as critical peak pricing $(C P P)$, are also used in pilot projects [156]. This type of control is referred to as passive control by [133].

However, the aforementioned pricing schemes result in an open loop-control system without feedback, such that the exact resulting effect on the power balance of price signals is unknown. Suppliers or future market participants, such as an aggregator, can use historical data to estimate the effect of communicated prices on the power demand through price elasticity models on beforehand [7]. Another drawback with ToU pricing (or other linear pricing programs) is that the prices for the next day are known on beforehand, providing perfect knowledge about the future. Individuals thereby have the incentive to consume as much energy as possible on low tariff time intervals, generally having the risk of peak shifting rather than peak shaving $[10,104]$. In addition, all customers receive the same prices and are thereby encouraged to synchronize their behaviour, potentially resulting in even larger power peaks or ramp rates if the cluster of customer has enough flexibility. Therefore, instead of relieving the stress on grid assets, such pricing schemes can result in more severe grid overloading and power quality issues than without ToU [GH:13]. A proposed alternative is real time pricing (RTP), for which the electricity price for the next time interval is announced shortly before the start of this interval, thereby resolving the issues related to perfect knowledge about future prices. Furthermore, the constant changing prices require substantial effort from customers to change their consumption to profit from such a scheme. As a result, such a scheme is only viable with automated control over domestic assets. 
The aforementioned pricing schemes are mainly driven by the generation costs of electricity, however. Nykamp et al. [117] show that the global energy market prices do not necessarily reflect the state of the local grid. As a result, merely using day-ahead or intraday market prices to manage electricity demand may amplify negative impact on the local grid usage, for example when market electricity prices are low due to global overproduction, but local production by RES is low, resulting in an increased local demand that is not matched with local production. As a result, local grid capacity constraints may be violated and power quality issues may arise. Bach et al. [4] therefore compare three possible capacity market strategies to take the local grid state into account. These three categories are a) a distribution grid capacity market, b) an advance capacity allocation, and c) a dynamic grid tariff. In their evaluation, the distribution grid capacity market is hardest to implement, but yields most benefits and has the lowest risks. Verzeilbergh et al. [159] have evaluated two of these capacity market mechanisms in a simulation study and found that the advance capacity allocation resulted in optimal operation from a grid perspective. The dynamic grid tariff structure shows similar negative synchronization effects as observed with ToU in [104].

\section{Incentive Based Pricing}

The second motivator for adapting energy profiles is an incentive based scheme, for which customers are often rewarded based on the offered flexibility or their response to requests. A commonly used implementation of incentive based DR in the United States (US) is direct load control (DLC). Customers install a switching system between the power supply and their equipment, often a heating, ventilation and air conditioning (HVAC) system, that can be controlled remotely by a utility. In case of a peak load, the utility can switch off the appliance through this switch to perform load shedding, whereas customers receive a compensation for the loss in comfort [160]. These systems typically have feedback systems, allowing for finer control and nearly instantaneous response since user involvement is not required. With the integration of more PV in distribution grids, synchronized feed in can cause over voltage problems or overload the grid. Therefore, similar systems to curtail a part of the PV production are being used as well. Often, the customer is compensated for the loss of generation of electricity. Zhong et al. [167] propose a coupon incentive-based demand response mechanism where customers pay the normal flat rate for electricity, but can voluntarily participate in load reduction in exchange for a compensation. Other incentive based schemes, often only used in industrial settings, are mentioned in [156]. These technologies can be classified as active control (in case of uni-directional communication) or interactive control (with bi-directional communication) as categorized in [133]. 


\subsubsection{Control Systems}

The emergence of IoT give the possibility to remotely control and read out devices, allowing for more automated control systems with the use of communication. To control the operation of a device, some external incentive must be applied to the device. Based on internal logic, the device changes its operation based on one or more of these input incentives, which we refer to as steering signals. Therefore, the steering signals can be seen as stimulus. An often used stimulus are price based incentives. Such an approach, often referred to as 'prices to devices' has the advantage that it is simple and only requires the control system to broadcast a new price to the devices. All devices can change their behaviour based on the received (price) signals and thus the system is device agnostic. Furthermore, all devices (and customers) receive the same price steering signal and hence there is no discrimination. However, the reaction of the devices to a new steering signal is not known. A new steering signal may therefore result in a steep increase or decrease in electricity demand or oscillation in the power profile due to overcompensation. These DLC methods leverage bi-directional communication technologies to shape the demand profile. Typically, such DLC systems use a form of centralized control in which all controllable nodes are directly connected to a master controller which sends control actions in a direct manner. Due to the use of bi-directional communication, the response of devices is known and therefore problems of over steering are avoided.

\section{Model Predictive Control}

The amount of data traffic and computational power to optimize the cluster behaviour is limited with a couple of controllable nodes. However with larger clusters the system requirements may rapidly increase. A comprehensive table with bandwidth and latency requirements for several smart grid technologies can be found in [62]. Communication technologies make it possible to perform more advanced types of control such as model predictive control (MPC) by integrating models and predictions, next to the classical load deferral or load shedding control strategies as commonly seen in the field of EM. As a result, such a system can be used to operate the grid more efficiently, economically or guarantee quality of service to end-users. However, it also requires constant communication about status updates of both the grid and user preferences to change power consumption in accordance, for which the term transactive control [59] is commonly used. In order to control millions of domestic smart devices, a scalable approach to transactive control must be considered.

\section{Decentralized Control}

Following the above reasoning, more recent smart grid optimization algorithms employ a decentralized (or distributed) approach. Decentralized communication structures, and therefore control structures, for energy management can take many forms, such as meshed structures, ring topologies or fully connected peer-to-peer 


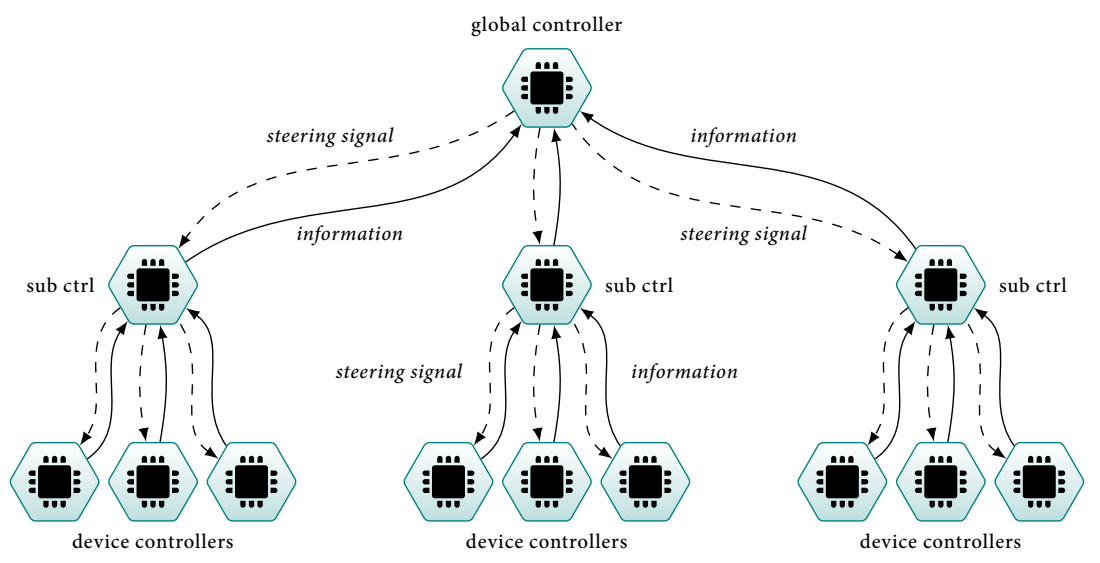

Figure 2.6: A schematic overview of a hierarchical structure of controllers with bi-directional communication.

control. Within DEM the tree (hierarchical) structure is prevalent as it naturally maps to the structure of the grid and/or connected customers [148]. Instead of collecting all information and performing optimization on the central level, a distributed system may perform these tasks via multiple local control nodes, such as at the device itself. From an optimization point of view, several methods exist to decompose the central problem, for which Toersche gives some examples in Chapter 2 of [143]. As a result parts of the optimization process can be executed in parallel on multiple systems with lower computational power and the control system becomes more robust to failure as another controller can take over and control a part of the devices at reduced performance. As a result of the decomposition, an indirect way of control has to be used to coordinate the cluster. These control signals are usually generic, such as price steering signals, and thereby agnostic about the lower level controller as shown in Figure 2.6.

Next to the overall control structure, another classification based on the optimization period considered can be made (e.g. indicated by Molderink et al. in $[109,110]$ ). The distinction is made between systems that optimize energy flows only for the next time interval, i.e the considered time horizon is equal to only one time interval. We refer to this type of control as active control as it continuously changes operation states based on the last observed state of the system. The second type of control takes multiple future time intervals into account to optimize the energy profiles over a longer time span, which we refer to as proactive control. Molderink refers to these two classes as real-time control and planning based control respectively. 


\section{Active Control}

A prevalent coordination approach within DEM is the usage of a double-sided auction. Within such an auction, the controller (auctioneer) asks all devices to construct and communicate a bid function that expresses how much power they are willing to buy/sell for a given price. An auctioneer then selects a market clearing price which clears the market at a given power value. Within power systems, we can use such a mechanism to set a new price steering signal that fulfils the needs of the technical system in terms of balance and ramp rates. Compared to the DLC approach, the usage of device agnostic steering signals makes it possible to conveniently integrate a wide variety of devices into the control system. On the other side, compared to the uni-directional communication of prices, the auction approach allows the system to know the reaction of a group of devices to a new price in advance. The creation of bids also adds the possibility of forceful curtailment and load shedding by enforcing bid options for completely turning off consuming appliances at high prices and curtail production at low prices. The PowerMatcher $[91,92]$ is an example of an DEM approach that uses these double-sided auctions for smart grid control. With the MultiCommodityMatcher $[14,55]$ an extension to the PowerMatcher is proposed to support two commodities to support hybrid energy systems with heat and electricity. The addition of another commodity requires an additional dimension to the bid function, resulting in a (two-dimensional) surface bid. Extensions to the double-sided auctions for communication-free control and time critical islanded microgrids are presented in Chapter 5.

Within active control systems, the actions only rely on the current state of the system or device, which avoids the usage of complex models. However, the drawback is that in its simplest form, such an active control system cannot take the future into account. As a result flexibility may be exhausted before it is actually needed, potentially resulting in larger power spikes or loss of comfort. A different control mechanism, e.g. by using MPC, may prevent exhaustion of flexibility. A planning based proactive system can evaluate the effects of shifting energy consumption or production to the near future with the use of models.

\section{Proactive Control}

Bakker [8], Bosman [15] and Molderink [107] presented a planning based proactive three-step DEM approach called TRIANA. These three steps are prediction, planning and real-time control [108]. Device level predictions are used to identify possible flexibility, which is then used to optimize the power consumption of a cluster. This optimization is done by sending differentiated price incentive vectors (i.e. all devices receive different price vectors) for the upcoming time period to the devices. These devices optimize their local schedules by minimizing the local costs based on these received price vectors. The resulting profile is communicated back, and in an iterative fashion the prices are adjusted to attain a global profile based on the optimization objective. By aggregating this data on several levels in the hierarchy, privacy can be guaranteed as both prediction data and individual 
consumption data can be kept locally. This approach is also designed with multicommodity in mind as it is simple to add more price vectors that represent prices of the different commodities within the system. The devices optimize their schedules according to the applicable commodity price vectors. This optimization process results in schedules for individual devices within households and thereby makes the system robust against loss of communication infrastructure. Locally available historical data may be used during long term service interruption of information communication technology (ICT). However, this approach heavily depends on local predictions. Since predictions are never completely accurate, proactive DEM has to deal with prediction errors. These errors can be both in the energy domain (e.g., underestimates of the energy production by PV) and the time domain (e.g. late arrival of a BEV). Events in real-time therefore may change the constraints that were considered during the planning phase, resulting in invalid device schedules.

As a result, proactive control methodologies are often combined with active control systems to dispatch flexibility in real-time to realize the planning as accurate as possible. Molderink et al. $[109,110]$ have therefore evaluated different real-time control mechanisms to resolve prediction errors and follow the initial plan as good as possible. In their evaluation, the best performing solution is to combine the scheduling approach with a double-sided auction to resolve prediction errors. This auction method considers all available devices to redistribute the planned power value for the current interval. However, this solution only resolves prediction errors in the time domain. Nutma et al. [GH:3] have therefore studied improved bidding strategies that take the local planning errors into account to mitigate prediction errors in both domains. Another, computationally heavy approach is taken by Toersche [143], where simulations are used to predict possible outcomes. These outcomes are used to determine control policies which are used in the bidding process.

Another three step approach is used in the Intelligator [155], in which power and energy constraints by the devices are communicated to a central entity. There, the constraints are aggregated and the flexibility is optimized for future time intervals. Subsequently a double-sided auction similar to the PowerMatcher is used to control the fleet of devices in real-time to follow the devised plan. Hereby, the authors use a priority signal instead of a price signal. A comparison study [23] between the Intelligator and TRIANA finds that both approaches perform quite similar, with a small lead in peak shaving performance for TRIANA. Similar to TRIANA, this method is largely planning oriented and thus requires methods to resolve prediction errors. Ruelens et al. [132] therefore use a stochastic programming approach based on approximate dynamic programming to dispatch resources. To reduce the amount of communication involved with larger clusters, an event-based communication approach is used by De Craemer et al. [28]. Herein, only significant status updates, such as arrival or departure, are communicated without notable loss in overall cluster performance. One concern with the original three step approach is the need to communicate all privacy sensitive information to the central aggregator. Claessens $[24,25]$ lifted this concern by introducing reinforcement learning at the central 
control node to model the expected flexibility available in the cluster. Under strong repetitiveness assumptions this approach gives adequate results. Alternatively, a limited set of virtual tracer devices, which capture the behaviour of a larger cluster of devices, are used to optimize the cluster behaviour of domestic water heaters in [74]. Accurate, non-intrusive, cluster modelling is achieved with a limited set of tracer devices.

The above mentioned approaches combine optimization mechanisms for future time intervals with a lighter weight dispatch mechanism to execute the devised plan. This choice is often justified because of the required balance between energy management in the future and adequate response time to resolve problems at hand. However, in [64] and [157] a different approach is taken by utilizing dual decomposition methods to distribute the optimization workload. In particular the alternating direction method of multipliers [16] is applied, for which adequate solutions can be found in a reasonable number of iterations. Therefore, instead of relying on separate dispatch mechanisms, these methods execute a full (re)planning for each interval while incorporating recent observations. In this work, a proactive control methodology, using incremental updates, is presented in Chapter 4.

\section{Considering Grid Constraints}

So far, most DEM approaches are merely concerned with the overall power consumption. Some approaches, such as the PowerMatcher [91] do introduce capacity constraints on network components to avoid overloading of the grid assets due to control actions. However, a load-flow analysis to evaluated quality of service in terms of power quality as defined in [113] often lacks. In studies with the original TRIANA planning approach we have demonstrated that an overall global flattened profile does not necessarily lead to a better power quality [GH:14] and [GH:13]. Instead, the differentiated price steering signals encourage extreme consumption on household level as devices prefer to consume as much as possible in periods of low prices and try to produce as much in periods with high price. This results in an unbalanced load in space, resulting in local overloading of the grid and violations of the legal norms on power quality. Carefully matching the control structure to the topology of the network shows that these issues can be resolved as power consumption is balanced on a finer, more local, scale.

In [161] it is shown that significant distribution loss reduction and power quality improvement can be achieved by balancing the loads in a three-phase electricity system. In this approach three single-phase inverters for PV and charging stations are connected to a common DC bus, such that the control system can optimize the power drawn or injected on each separate phase. To maintain voltage levels within the legal bounds in an real-time control approach, Weckx et al. [163] have added reactive power control to an intermediate node in an auction approach. This intermediate node optimizes the reactive power for each price point in the bidding function to stay within legal bounds. Based on the market clearing price, this node sends both an active and reactive power setpoint to the connected devices. 


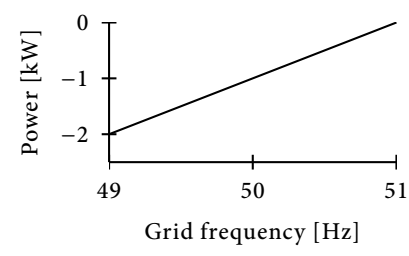

(a) Droop control

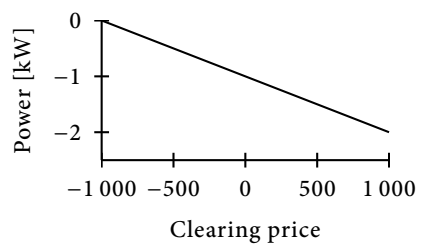

(b) Auction demand function

Figure 2.7: Examples of a droop control function where the power consumption depends on the grid frequency (left) and an auction demand function where the power consumption depends on the market clearing price (right). Note that power generation is negative in this figure.

However, this approach links the reactive power directly to the clearing price used to control the active power, thereby dropping the ability to control the reactive power independently.

\section{Communication Independent Control Systems}

All these mentioned approaches to DEM have one thing in common: they rely on ICT to communicate steering signals in order to influence the demand and supply of devices. However, distribution networks may rely heavily on these DEM methodologies to ensure a safe operation of the distribution grid in the future. Dangerous situations, e.g. a blackout, may be created. Hence, ICT introduces a new vulnerability to the system and an alternative way of control to fall back onto is desired to prevent overloading of the grid, dangerous situations or blackouts [138]. Chromik et al. [22] therefore exploit knowledge of the physical infrastructure in control systems to test whether control commands respect the grid constrains, and whether sensor data is correct. If this is not the case, such as in case of malicious commands, the system blocks these commands and reports warnings.

In contrast, islanded microgrids with micro generators are able to balance grids without external control and ICT communication, by applying droop control [60]. Droop control is used to share supply of electricity among few to hundreds of synchronous generators using a linear relation between output power and target frequency. The target frequency is changed using this relation, resulting in a lower target frequency when the supply is high. With this method, a certain power sharing among generators can be achieved when the droop characteristics are defined properly. This can be seen as a form of distributed control.

However, droop control is not directly applicable to DEM in grid connected microgrids. First of all, the frequency is a global measure and therefore does not reflect the state of the local grid. Secondly, most consumer devices do not offer a continuous range of power options. Iacovella et al. [72, 73] have studied the potential of using droop-control like strategies in residential grids to avoid under- and over 
voltage problems. In their approach, the frequency is replaced by the local voltage, which reflects the local state better. Furthermore, the linear relation is replaced by a discrete point at which a device is forced to switch on or off based on the voltage. This discrete point depends on priorities of the device, which can be user defined. Experimental tests and validations of this system are done by D'hulst et al. [32]. Integration with conventional controllers, such as droop controllers, using a double-sided auction is also possible as the bid functions are similar to droop curves, except for being mirrored as shown in Figure 2.7. This makes it possible to use the system for communication-free control where the market is cleared locally (e.g., on the building level) using local measurements. This allows domestic devices to act as droop controlled loads and generators to assist in finding power balance within the local grid. Weckx et al. [162] show that local data can also be used for inverters to perform local reactive power control in order to improve voltage levels in the grid.

Other systems, such as the internet show similarities with the power grid. Thus solutions might be borrowed from these technologies as suggested by Keshav and Rosenberg [85]. Hartmanns et al. [65, 66] have studied communication network technologies to avoid over-frequency issues resulting from PV in power grids. The production of electricity from PV can be seen as the upload of data in a network. Within communication networks, no collision may occur and hence the channel has to be free before a packet can be send. If the channel is not free, the sender has to wait a random number of time intervals before retrying. The authors show that such an approach also works for PV. Hereby the generation is curtailed when the frequency exceeds $50.2 \mathrm{~Hz}$. In their work only the generation side is considered and not the demand side. Stüdli et al. [140] show that an additive increase, multiplicative decrease $(A I M D)$ (see [166] for more details) control strategy performs well when charging BEVs. However, in their approach, the available capacity on the grid still needs to be communicated to all BEVs and is therefore not a robust solution against loss of communication. We note that this approach merely communicates the power balance, which may be replaced with the microgrid frequency in islanded operation.

\subsubsection{Test Sites}

To maintain stability, reliability of the energy system and make the energy transition possible, aforementioned research has to be brought into practice. The first essential step herein is to test (sub)systems in a small and closed test environment. Therefore smart grid laboratories linked to research institutes arise, such as EnTranCe ${ }^{2}, \mathrm{Na}$ tional Renewable Energy Laboratory ${ }^{3}$ and EnergyVille ${ }^{4}$. A comprehensive overview of all test facilities within the European Union is provided in [6].

\footnotetext{
${ }^{2}$ http://en-tran-ce.org/

${ }^{3} \mathrm{http}: / /$ www.nrel.gov/

${ }^{4}$ http://www.energyville.be/
} 
More mature smart grid technology prototypes are tested in smart grid field test sites, where system size is often increased to test system stability and effectiveness in more realistic situations. The need for smart grid technology as cost-effective alternative to conventional upgrades resulted in increased investments by governments, energy companies and DSOs in pilot projects [52]. Pilot project examples are the Linear project in Belgium [34], PowerMatching City in Hoogkerk, the Netherlands [11] and the Smart Operator project in Germany $[9,56]$. In these projects, the potential of the Intelligator, the PowerMatcher and the TRIANA methodology have been tested respectively by controlling consumer devices. Recently a total of 12 pilot projects (Dutch: "proeftuinen") have finished in the Netherlands [35]. One of those projects, "intelligent net in duurzaam Lochem" (smart grid in sustainable Lochem) [75], takes a central place within this thesis. The goal of the test site is to investigate smart grid technologies and the impact of high penetrations of rooftop $\mathrm{PV}$ and electric mobility usage. Therefore, metering equipment is installed at the substation and in households. Furthermore, three controllable 3-phase AC charging points are installed in the grid. In addition to privately owned BEVs, the local energy corporation LochemEnergie $\mathrm{e}^{5}$ also rents BEVs to participants. This local energy corporation is an initiative of residents in this municipality, resulting in an energetic and involved community willing to help in research experiments.

As smart grid technology does not only consist of a technical challenge, but also a societal one, most of these experiments combined technical testing with behavioural studies such as user acceptance of the systems. The value of DEM technologies lies in the amount of flexibility it receives from end-users and therefore the acceptance of such systems is crucial for its success. According to $[57,158]$ it is therefore crucial to look at the services these systems provide to end-users and their social context (e.g. energy communities). Empirical evidence for this can also be seen in the results of the PowerMatching test site where fully automated systems without any form of feedback and sufficient control hindered participants in achieving their own goals [53]. In another field test [90], users used smart washing machines and dryers together with an energy display showing when energy prices are low. The complexity of the smart white goods resulted in a majority of the users operating their devices manually after consulting the energy display instead of using a smart start function. Paetz et al. [122] held interviews with consumers, whereby a part of the participants were living in a smart home during the research. Their findings are that users are willing to accept smart appliances and control when the system provides cost-saving potential in a transparent manner without loss of comfort. Mert [106] draws similar conclusions after interviews and questionnaires throughout Europe. A reward for each individual smart operation is seen as a good motivator to encourage end-users to consciously provide flexibility and keep users active within a smart grid. Furthermore, RTP is considered as ineffective pricing scheme for smart grids as most users are risk-adverse and the potential cost savings are often too low $[57,106,158]$. Based on pilot project results, Geelen et al. [53] draw recommendations for a more user- and community-centric approach to smart grid

${ }^{5}$ https://www.lochemenergie.net/ 
technology with a transparently acting control system. Other motivators, such as social norms or competition may activate residents to participate in smart energy communities.

\subsection{Conclusion}

In this chapter we sketched how the power grid as we know it today has been evolved over time. The centralized AC power system is the result of technical constraints in the past, such as availability of power transformers, and economy of scale. Furthermore, the available transmission and distribution capacity for electricity is limited since a significant part of the domestic energy consumption is based on other energy carriers, such as natural gas and heat. The energy transition does result in challenges for this energy system. Local micro generation and the electrification result in increased loads, potentially overloading the grid, and more demand fluctuations, which power plants need to follow to balance the electricity grid. Technical advancements, such as the introduction of IoT technology and connected metering equipment, may become key to an economical and affordable energy transition. This addition of metering and control results in what is known as the smart grid.

On the other hand, consumers change from passive electricity users to active prosumers with the adoption of e.g. PV panels. These consumers, assisted by IoT and home automation systems, should actively participate in matching demand and supply locally. Energy market models and frameworks are being developed to enhance the operation of the grid and ensure a reliable supply of energy in the future. Within these models, incentives to perform demand and supply matching are provided to prosumers.

Advanced control and coordination systems emerge to optimize the overall power profile to act on these markets, and avoid overloading and power quality issues. A broad range of control approaches can be found in literature. From DLC to distributed control systems, and from reactive to proactive market clearing price $(M C P)$ approaches. In addition, systems that do not rely on vulnerable communication networks are being developed. The progress in the development of control approaches also leads to real-world tests in various test sites. However, for a large scale adoption of these technologies, it is important to consider the interaction between prosumers and the technical system.

In the next chapter we present key components within smart grids: devices, grid assets and control systems. These components are important to study how various smart grid control mechanisms interact with the physical grid, and vice versa. 


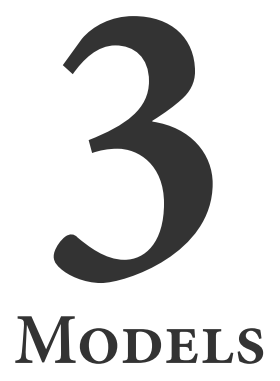

\begin{abstract}
This chapter describes the smart grid model using three separate sub-models: the electricity grid, the devices, and the control infrastructure. These separate building blocks can interact with each other to model the smart grid as a cyber-physical system. The devices form the leaves of the electricity grid and are modelled as sources and sinks to supply power to or demand power from the electricity grid. Therefore, the device components are a behavioural description of the operation of a device. An abstraction approach is taken to create a generic and flexible set of devices to model the power demand and supply. These device components are connected to the physical electricity grid using exchangers. Unbalanced three-phase four-wire components are introduced to evaluate the performance of smart grid control systems within distribution grids. Load-flow algorithms can obtain the total power flow at each node to obtain voltages and currents within the grid. The cyber part consists of an infrastructure of computing units that are coupled to each other, the devices and grid assets using communication links. The goal of the smart grid is to utilize flexibility offered by devices to optimize the operation of the electricity grid. Therefore, the device components describe the flexibility that a certain device can offer to the control system.
\end{abstract}

This chapter describes the model used for simulations and forms the foundation of this research. Models are required to develop control and optimization strategies in two ways. Firstly, models give a description of the physical system that forms the smart grid and therefore specifies operating constraints for the control and optimization strategies. And secondly, the modelling and simulation of a physical grid provides feedback to the control system, on which it can act to keep the smart grid in a safe and stable state.

Parts of this chapter are based on [GH:14]. 


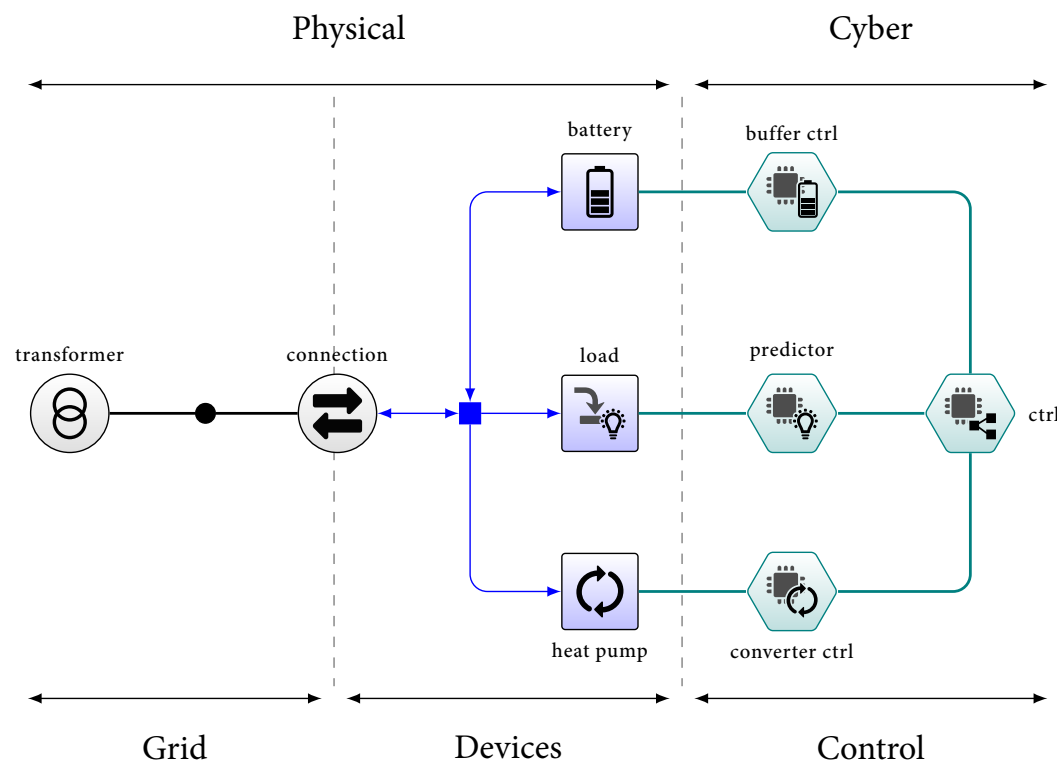

Legend:
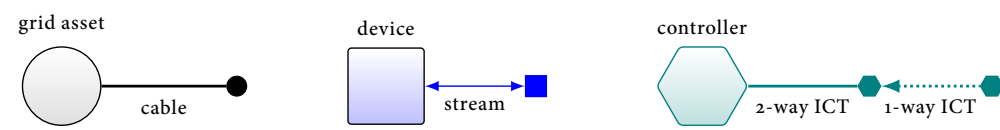

Figure 3.1: An example of a cyber-physical system diagram for smart grids.

The smart grid consists of three main components: devices, grid infrastructure and control systems. Herein, the devices and grid infrastructure form the physical part of this system, whereas the control system forms the cyber part. These devices can be normal household devices, such as a computer, but also emerging technologies such as a battery electric vehicle $(B E V)$ or battery and photovoltaic $(P V)$ panels. Multiple of these devices can be grouped together, such as all devices within a household, and can be connected to the physical grid. This grid consists of conductors that distribute the electric energy and other components such as transformers. A part of these devices can be controlled by a control system. An example is a control system which changes the charging power of a BEV. Therefore, specialized controllers can connect to these devices to alter their operation and subsequently influence the state of the electricity grid. Feedback may also be introduced to the control system, in which measurements from devices, such as the local voltage supply, can be used for new control actions. This system is depicted in Figure 3.1. 
As described in the introduction (Chapter 1) a cyber-physical system (CPS) approach on control in smart grids is taken in this research. To create a complete CPS model, these three classes of components are interconnected, such that properties and information of each of the components can be used and exchanged for interaction in (co-)simulation environments. These include, amongst others, limitations of transport capacity, device operation constraints and controller dependencies. The modularity of this approach also allows to study situations where parts of the model are missing or broken, by disabling parts of one or more sub-models. By doing so, it is possible to study for example the robustness of the control system against failure of communication. Also situations where information is missing, such as the grid topology, can still be studied without a grid model or by using another grid model. Which brings us to another advantage of a modular design: interchangeability. Components in any (part of a) model can be replaced by another component that satisfies some minimum requirements. This allows us to study e.g. the same scenario on different grid topologies or different control systems using the same physical components.

Within this chapter we limit the discussion to models required for smart microgrids, namely radially operated low voltage $(L V)$ grids and flows of electrical energy. Therefore, the components of the discussed devices are also limited to those that have a connection to the electricity grid. However, these components can be extended to include higher level voltage grids (e.g. medium voltage $(M V)$ and high voltage $(H V)$ grids), direct current $(D C)$ grids, other energy carriers (e.g. heat and natural gas) and different devices. As the main interest is in the steady-state of the smart grid, we describe discrete time models in this chapter.

The following sections provide in depth descriptions of the used components in this research in a bottom-up fashion. Firstly we cover the physical part, starting with the devices. Subsequently, detailed descriptions of the grid components and load-flow calculations are presented. From the cyber-part, the general control architecture and the interaction with devices is presented (Chapters 4 and 5 cover more details on the control structure and algorithms). After the presentation of the individual components, Section 3.5 details how these individual components can be integrated into one CPS model.

\subsection{Device Components}

The overall energy profile of a cluster (e.g. a microgrid) is usually of interest within the context of decentralized energy management (DEM) systems. For residential electricity grids, this energy profile is the result of the load and generation of devices owned by the consumers and prosumers connected to the local electricity grid. Therefore, devices are sources and sinks in the power grid. The state of a device determines the amount of electricity it consumes or produces, e.g. a computer only consumes power when it is turned on. If we want to change the overall electricity profile in a smart grid, we must change the state of one or more devices connected 
to this grid. Changing the state of the device is easier said than done, however. The flexibility and controllability differs for each type of device and each device may come with its own application programming interface (API). As a consequence, this results in just as many implementations of device optimization algorithms and control systems as there are devices [143].

However, many devices share basic functionality, flexibility and properties among each other. For example, a smart washing machine, dryer and dishwasher all have a certain power profile when they are active and can defer their starting time. Likewise, batteries and heat buffers can both buffer a certain amount of energy. Using abstraction, most, if not all, behavioural and flexibility descriptions of domestic appliances can be captured using only a few generic classes. Such generic devices classes can be used to model all devices within a building with significantly reduced effort at the cost of some detail. Kok [91] uses such a set of generic device classes to model the consumers and producers within an electricity system to impose realtime control. The foundation of these models is the flexibility that these devices offer for real-time control. In general, the same models are used within the EF-Pi [51] framework to control devices in several field tests using implementations of the PowerMatcher and Triana. Molderink [107] also introduces a set of generic devices to model the complete energy system from a functionality perspective.

This section presents a set of generic, formal, device data models and their behavioural and flexibility descriptions. These models are inspired by the aforementioned models, but differ in the sense that the set of generic device classes is based on both the functionality and flexibility perspective. Furthermore, to impose proactive control, not only the current flexibility is of interest, but also the future flexibility. The purpose of these models is to provide abstract interfaces that cover the most important characteristics of each device class, such that it is technology agnostic. By doing so, the complexity is kept low to make sure that optimization and simulation of a smart grid can be performed in reasonable time. Hereby, the mathematical models and optimization algorithms by Van der Klauw [148] are used. The following subsection addresses the common basis for all device classes, whereas the other subsections present detailed descriptions of device components. Figure 3.2 depicts an inheritance graph of the device components presented in this section.

\subsubsection{Basic Device Component}

The amount of power a device consumes/produces depends on two factors, namely the state of the device and the type of electrical load. For distributed energy management, the device state is of interest, because this is what can be controlled whereas the other factors are static properties of the device and cannot be changed. However, in a cyber-physical environment, these factors cannot be neglected as they may have significant influences on the voltage and power profile. Each device consumes or produces electricity from the power grid and acts as a sink or source to this power grid. Within the scope of this thesis we are not interested in the input or output of other energy carriers by conversion devices, such as heat and gas for 


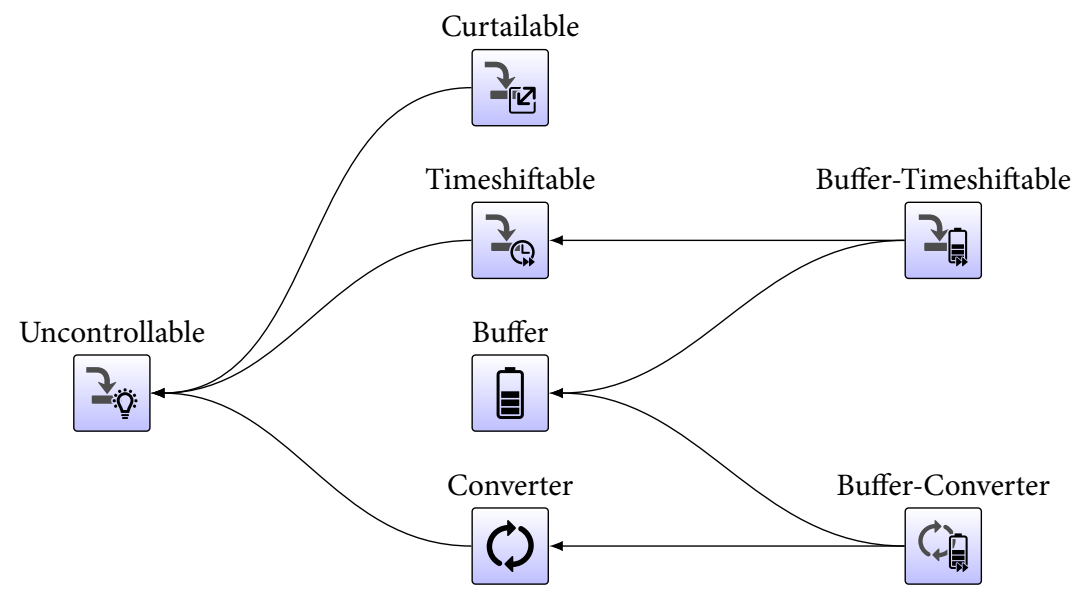

Figure 3.2: Inheritance graph of device components.

a combined heat and power (CHP). Therefore, each device component is only connected to the grid using one stream through which either electricity flows from the grid into the device (i.e. the device consumes electricity) or from the device to the grid (i.e. the device produces electricity). If the device is not consuming or producing any electricity (e.g. it is turned off), then there is no electricity flowing through the stream.

\section{Device States}

The state of a device describes what a device is doing and how much power it consumes or produces in a time interval. Such a state can for instance be a BEV that is charging at a certain power level. An internal device state may for instance be the state of charge $(\mathrm{SoC})$ of a battery pack of this BEV. Let $O_{d}$ be the set of possible states for device $d$. A device state can transition from the current state $o_{d} \in O_{d}$ to a new state $o_{d}^{\prime} \in O_{d}$. Such a state transition (labelled by $\delta_{d}$ ) can occur conditionally or through an (external) event. A BEV changing from the state charging to idle when the SoC of the battery reaches its maximum is a form of a conditional transition. Turning on a computer (i.e. changing the state from off to on) is an event trigger. Within DEM systems, a state transition can be triggered by the control system in addition to transitions triggered by the device itself or those triggered by humans.

Note that the possible state transitions are limited by the current state $o_{d}$, e.g. a fully charged battery (SoC of 100\%) cannot charge and therefore not consume power. The set of possible transitions $\delta_{d}$ is therefore a subset of $O_{d} \times O_{d}$. For this, we denote the set of possible transitions from current state $o_{d}$ to a new state $o_{d}^{\prime}$ as $\Delta_{d}^{o} \in O_{d}$. A valid state transition is described as follows: 


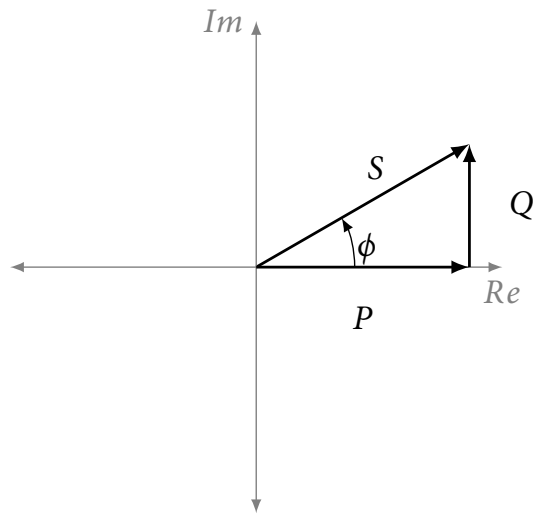

Figure 3.3: Diagram with the apparent power split up in two components.

$$
o_{d} \stackrel{\delta_{d} \in \Delta_{d}^{o}}{\longrightarrow} o_{d}^{\prime}
$$

The set of valid state transitions are also captured within the set of constraints as used for optimization and control actions. The resulting control actions are also tested against the set of possible state transitions.

\section{Load types}

We denote the complex power consumption/production of a device at the current moment in time by a variable $S_{d}$, which depends on the current state of the device. Therefore, the power consumption/production is defined for each state $o_{d} \in O_{d}$, denoted by $S_{d}^{o}$. The convention here is that a positive load indicates consumption of energy, whereas a negative load indicates production of energy. Furthermore, the power consumption is specified at the nominal grid voltage $U_{\text {nom }}$. This is important as we do not know the actual supplied voltage on beforehand, but the actual power consumption depends on the supplied voltage for certain devices.

This complex power can be split up in the real part, which is the active power $P_{d}$ given in watts $(\mathrm{W}$, also $\mathrm{J} / \mathrm{s})$, and the reactive part $Q_{d}$ given in volt-ampère reactive (var), such that $\left|S_{d}\right|=\sqrt{P_{d}^{2}+Q_{d}^{2}}$ (see Figure 3.3). Active power does the real work whereas reactive power merely results in a phase shift between the voltage and current. Hence, reactive power is not really produced or consumed, but conventionally capacitive loads are said to produce reactive power whereas inductors consume reactive power. The apparent power $S_{d}$ is given in volt-ampère (VA). The term power factor $P F$ is used to express the ratio between active and apparent power (i.e. $P F_{d}=P_{d} /\left|S_{d}\right|$ ). Note that the power system has to transport all apparent power, but only the active power is useful. 
Next to the current state, the actual power consumption/production also depends on the supplied (complex) voltage $U_{d}$ to the device and the load type. There exists three load types: constant power $\left(S_{C P, d}\right)$, constant impedance $\left(S_{C I, d}\right)$ and constant current $\left(S_{C C, d}\right)$. Based on its internal components, a load can be modelled as one load type, or as a mix of these three.

Loads with a constant power model consume/produce the same amount of power, regardless of the supplied voltage, such that $S_{C P, d}=S_{d}$. More and more domestic devices act in this way as they are powered by a switched-mode power supply. Examples are computers, television sets and also vacuum cleaners. For devices with a constant impedance model, such as water kettles or irons, the actual power consumption/production depends on the voltage and the impedance $Z_{d}$. The actual power consumption/production has a quadratic dependency with the supplied voltage: $S_{C I, d}=U_{d}^{2} / \overline{Z_{d}}$, where $U_{d}$ is the voltage supplied to the device. With a constant current model, the actual power consumption/production depends on the voltage and this constant current $I_{d}$, such that $S_{C C, d}=U_{d} \overline{I_{d}}$. Constant current models are not often used, as most domestic devices behave as either constant power or constant impedance models.

In order to mix these load types in one single device, a multiplication factor $M_{l, d}$ is introduced for each load type $l=\{C P, C I, C C\}$. This multiplication factor specifies what part of the load $S_{d}$ originates from which load type such that $S_{l, d}=S_{d} \times M_{l, d}$. The sum of all load types of a device makes up the total power consumption and hence we get the following:

$$
S_{d}=M_{C P, d} \times S_{C P, d}+M_{C I, d} \times S_{C I, d}+M_{C C, d} \times S_{C C, d} .
$$

With the focus on steady state discrete time models, the length of an (simulation) interval is often longer than one second. We denote the length of one discrete time period (interval) by $T$ (in seconds), and all power consumption values are given as the average power consumption in such a period.

\section{Streams}

To exchange energy with the power grid, each device is connected to this grid using one or more streams that connect the device to an exchanger. The purpose of this exchanger is to convert the power models used by the devices into a voltage and current as used in the grid models. Let $s r_{(v, d)}$ be a connection between a node in the power grid, denoted by $v$, and device $d$. The power flowing through this stream from the grid to the device is denoted by $S_{(v, d)}$ and from the device to the grid by $S_{(d, v)}\left(S_{(v, d)}=-S_{(d, v)}\right)$. As a device needs to be supplied with the power demand, we have $S_{d}=S_{(v, d)}$. The exchanger ensures that the law of conservation of energy is satisfied by importing an energy deficit from the grid or exporting an energy surplus to the grid. 


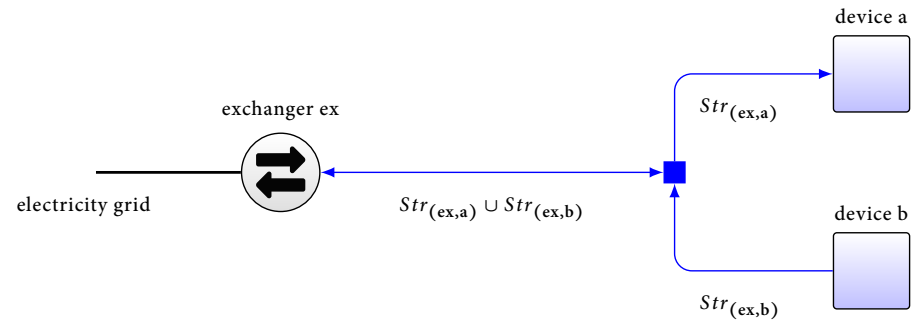

Figure 3.4: Model with an exchanger, two devices and the streams to connect the devices to the exchanger.

Within three-phase electricity grids, devices can connect to more than one phase. In such a case, a set of streams $\operatorname{Str}_{(v, d)}$ between $v$ and $d$ is used. Multiple streams $\operatorname{str}_{(v, d)}^{p} \in \operatorname{Str}_{(v, d)}$ are associated to a device and exchanging node, where $p$ denotes the phase it is connected to. Figure 3.4 shows an example model with two devices (device a and device b) connected to an exchanger (exchanger ex) using streams. The arrows indicate the possible flow directions, which is from $v$ towards $d$ in case $S_{(v, d)} \geq 0$ (consuming device), from $d$ to $v$ if $S_{(d, v)} \geq 0$ (producing device) or both directions otherwise. To ease the notation, the union of multiple sets of streams are combined in the model. Furthermore, let $S t r_{v}$ be the set of streams associated to exchanger $v$, which in the example is $S t r_{\mathrm{ex}}=\left\{\operatorname{Str}_{(\mathrm{ex}, \mathrm{a})}, \operatorname{Str}(\mathrm{ex}, \mathrm{b})\right\}$.

To spread the load over the connected phases, a multiplication factor $M_{(v, d)}^{p}$ is introduced for each stream, which expresses what part of demand $S_{d}$ is supplied by a stream:

$$
S_{(v, d)}^{p}=M_{(v, d)}^{p} \times S_{d}
$$

where $S_{(v, d)}^{p}$ is the amount of power flowing from grid to device. Again, the power demanded by the device must be supplied by the streams, thus the sum of all multipliers associated to a stream must be equal to 1 . These multipliers can be combined with the multipliers introduced for the load types, such that the power consumption for a device on each phase for each load type $l$ can be expressed as:

$$
S_{l,(v, d)}^{p}=M_{l, d} \times M_{(v, d)}^{p} \times S_{d}
$$

In contrary to the cable models used in load-flow calculations, these streams are modelled ideal and loss free. The following subsections elaborate more on the different types of devices, their states and the flexibility they can offer to the system. 


\subsubsection{Uncontrollable Device}

The class of uncontrollable devices Unc is the most basic one. As the name suggests, the operation of this type of device is not influenceable by control systems and is often referred to as static load. Devices such as lighting, computers, stereo sets, induction stoves, are part of this class. These devices operate when the end-user desires them to operate and have no inherent flexibility. The behavioural process of such an uncontrollable device Unc can be modelled as a stochastic process. Another commonly used method is to provide a sequence of consumption values $\widetilde{S_{\text {Unc }}}=$ $\left[\widetilde{S_{\mathrm{Unc}, 1}}, \widehat{S_{\mathrm{Unc}, 2}}, \ldots, \widehat{S_{\mathrm{Unc}, N}}\right]^{T}$ for $N$ upcoming intervals as input. Here, each element represents the average power consumption for a discrete time interval of $T$ seconds (also referred to as the timebase). The power consumption $S_{U n c}$ is then given by $\widetilde{S_{U n c}}$ for each interval. The used symbol for this device is given in Figure 3.5.

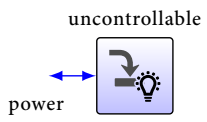

Figure 3.5: Uncontrollable device component icon.

\subsubsection{Curtailable Device}

Curtailable devices Curt inherit from uncontrollable devices and share the same stochastic behaviour, but with the difference that these devices can curtail (lower) their production or perform load shedding (lower the load). Often, producers of renewable energy sources (RES) can curtail their production to prevent local grid overloading (e.g. PV systems that reduce or stop producing in case of over-voltage) or damage to equipment (e.g. wind turbines adjusting their blades to keep the revolutions per minute $(\mathrm{rpm})$ limited). Consuming devices can also shed their loads by forcing them to turn off at the cost of user comfort. The used symbol for this device is given in Figure 3.6.

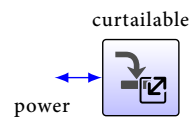

Figure 3.6: Curtailable device component icon.

The amount of consumed power by a curtailable device can be lowered by controlling a multiplier $M_{\text {Curt }}^{\text {CURT }} \in[0,1]$. Let $\overline{S_{\text {Curt }}}$ be the given power demand (negative indicating production) for the curtailable device Curt. The actual consumption is then given by $S_{\text {Curt }}=M_{\text {Curt }}^{\text {CURT }} \times \overline{S_{\text {Curt }}}$. 


\subsubsection{Buffer Device}

A buffer Buf is a device that can temporarily store energy by extracting it from the grid to inject it back on a later moment. Therefore, a buffer can shift energy in time, such that e.g. the (self-)consumption of renewable energy can be increased or peak-shaving is performed to avoid overloading of the grid. For smart microgrids, a battery energy storage system (BESS) is often considered a suitable buffer device, but also flywheels and pumped hydroelectric storage are forms of buffer devices within the power grid. The used symbol for this device is given in Figure 3.7.

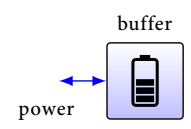

Figure 3.7: Buffer device component icon.

Typically, the power demand $S_{\text {Buf }}$ of a buffer device Buf can be controlled and is constrained by a minimum $\check{S}_{\text {Buf }}$ and a maximum $\hat{S}_{\text {Buf }}$ (i.e. $S_{\text {Buf }} \in\left[\check{S}_{\text {Buf }}, \hat{S}_{\text {Buf }}\right]$ ). The amount of energy that can be stored is constrained by the capacity $C_{\mathrm{Buf}}$ of the buffer in J. At all times, the SoC $E_{\mathrm{Buf}}^{\mathrm{SoC}}$ must be in $\left[0, C_{\mathrm{Buf}}\right]$. Buffers with internal losses can be modelled by adding a variable $P_{\text {Buf }}^{\text {loss }}$ which slowly drains the buffer if $E_{\mathrm{Buf}}^{\mathrm{SoC}}>0$. In discrete models, the next SoC $E_{\mathrm{Buf}}^{\prime} \mathrm{SoC}$ after a time period of $t$ seconds is given by

$$
E_{\mathrm{Buf}}^{\text {SoC }}=E_{\mathrm{Buf}}^{\mathrm{SoC}}+\left(\left(P_{\mathrm{Buf}}-P_{\mathrm{Buf}}^{\text {loss }}\right) \times T\right)
$$

where $P_{\mathrm{Buf}}$ is the real part of $S_{\mathrm{Buf}}$. Note that conversion efficiency is not taken into account in this thesis due to their complexity w.r.t. optimization. Further adoptions of this component are required for non-ideal buffers such as the models presented in [69] and [81]. For feasibility, constraints for $E_{\mathrm{Buf}}^{\mathrm{SoC}}$ must be satisfied too, thus the real power consumption $P_{\text {Buf }}=\left[\check{P}_{\text {Buf }}, \hat{P}_{\text {Buf }}\right]$ is limited:

$$
P_{\text {Buf }} \in\left[\max \left(\check{P}_{\text {Buf }},-E_{\text {Buf }}^{\text {SoC }} \times \frac{1}{T}\right), \min \left(\hat{P}_{\text {Buf }},\left(C_{\text {Buf }}-E_{\text {Buf }}^{\text {SoC }}\right) \times \frac{1}{T}\right)\right] .
$$

\subsubsection{Converter Device}

Converting devices Conv are devices that convert energy from one form to another form. Technically speaking, all devices convert energy, but the discrepancy is that energy converted by converters is used as input for another part of the model. Such devices are e.g. heat pumps that convert electricity into heat or a (micro) CHP that converts natural gas into electricity and heat. The heat may then be consumed by an uncontrollable load that requires its heat demand to be fulfilled. The used symbol for this device is given in Figure 3.8.

These type of devices have in common that there is an energy demand on the secondary side that needs to be fulfilled through energy conversion such as the heat 


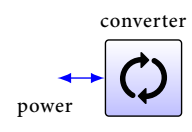

Figure 3.8: Converter device component icon.

demand that needs to be supplied by a heat pump. Therefore the converter device inherits from the uncontrollable device to specify this demand $\widetilde{S_{\text {Conv }}^{\text {demand }}}=\widetilde{S_{\text {Unc }}}$. Often, the conversion of one quantity of input energy does result in a different output quantity of energy (of another type) of which the conversion factor depends on the coefficient of performance $(\mathrm{CoP})$. For example, a heat pump with a CoP of 4 produces 4 quantities of heat for each quantity of electricity consumed. To express this CoP, a (optionally state dependent) multiplier $M_{\mathrm{Conv}}^{\mathrm{CoP}}$ is introduced. The actual power consumption of Conv is then given by $S_{\text {Conv }}=\left(1 / M_{\text {Conv }}^{\text {CoP }}\right) \times \overline{S_{\text {Conv }}^{\text {demand }}}$.

To offer flexibility to the system, converters are usually combined with some form of buffering, which results in the combined Buffer-Converter device component, which is addressed next.

\subsubsection{Buffer-Converter Device}

Converting devices are often coupled to a storage such as a heat pump to a heat store, or a power-to-gas setup to a fuel tank. Even if the storage is not directly visible, it is often inherently available through piping systems or the thermal mass of a building. Just like the buffers, these buffer-converters add flexibility in the sense that demand and production are decoupled in time with the buffer. Therefore, a Buffer-Converter device BufConv is a component that inherits from both Buf and Conv and can be used to model loads connected to the electricity grid that convert this energy into other types of energy, such as heat. The used symbol for this device is given in Figure 3.9.

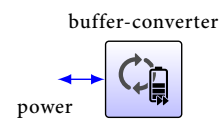

Figure 3.9: Buffer-converter device component icon.

The given demand $\overline{S_{\text {BufConv }}^{\text {demand }}}$ on the output is provided by the buffer and thus does drain the buffer (or fill the buffer in case of negative demand) and includes the internal losses of the buffer component $\left(P_{\mathrm{Buf}}^{\text {loss }}\right)$. Furthermore, this buffer is filled (or drained with negative demand) by the converter. Hence, the next state of the buffer can be obtained using:

$$
E_{\text {BufConv }}^{\text {SoC }}=E_{\text {BufConv }}^{\text {SoC }}+\left(\left(M_{\text {BufConv }}^{\text {CoP }} \times P_{\text {BufConv }}-P_{\text {BufConv }}^{\text {demand }}\right) \times T\right),
$$


where $P_{\text {BufConv }}$ and $P_{\text {BufConv }}^{\text {demand }}$ are the real parts of $S_{\text {BufConv }}$ and $S_{\text {BufConv }}^{\text {demand }}$ respectively. Note that the aforementioned constraints on the SoC of the buffer must be satisfied to meet $S_{\text {BufConv }}^{\text {demand }}$. The valid options for $S_{\text {BufConv }}$ for a given interval must therefore be in the range:

$$
\begin{aligned}
& S_{\text {BufConv }}^{\text {demand }} \in\left[\max \left(\check{P}_{\text {BufConv }},\left(-E_{\text {BufConv }}^{\text {SoC }} \times \frac{1}{T}\right)-P_{\text {BufConv }}^{\text {demand }} \times \frac{1}{M_{\text {BufConv }}^{\text {CoP }}}\right),\right. \\
& \left.\min \left(\hat{P}_{\text {BufConv }},\left(\left(C_{\text {BufConv }}-E_{\text {BufConv }}^{\text {SoC }}\right) \times \frac{1}{T}\right)+P_{\text {BufConv }}^{\text {demand }} \times \frac{1}{M_{\text {BufConv }}^{\text {CoP }}}\right)\right] .
\end{aligned}
$$

\subsubsection{Timeshiftable Device}

Instead of using a buffer, some devices have the ability to directly shift their consumption to another moment in time. Smart white goods, such as washing machines, dryers and dishwashers fall within this class of devices to which we refer as timeshiftable devices Tsh. All these devices have in common that, when they run, they have to execute a consumption profile $\widehat{S_{\mathrm{Tsh}}^{P R O}}=\left[\widehat{S_{\mathrm{Tsh}, 1}^{P R O}}, \ldots, \widehat{S_{\mathrm{Tsh}, N}^{P R O}}\right]^{T}$ of length $N$ intervals. This consumption profile is a discrete profile of which all elements have a fixed time period. The time of which such a device may run is also limited, i.e. the device may not be prepared to run at certain times. The used symbol for this device is given in Figure 3.10.

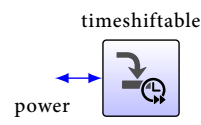

Figure 3.10: Timeshiftable device component icon.

To describe the state of devices a state variable $o_{\text {Tsh }}=\{O F F, A V A I L, 1, \ldots, N, D O N E\}$ is introduced. When the device is running, this variable indicates which element of $\widetilde{S_{\mathrm{Tsh}}^{P R O}}$ is active. Note that $\{O F F, A V A I L, D O N E\}$ are special states of $o_{\mathrm{Tsh}}$, where $O F F$ indicates that the device is turned off, AVAIL indicates that the device is ready, but not yet running and DONE indicates that the device has finished. For all those states $S_{\text {Tsh }}=0$. Additional pre-emption states may be included in $o_{\text {Tsh }}$.

The device does not need to start executing this profile as soon as it becomes available (e.g. when a user turns on the device), but can be deferred. We identify one run of a timeshiftable devices with a job $j$ that becomes available at time $\hat{a}_{\text {Tsh }}^{j}$ and the device must finish the profile on or before a due time $\check{a}_{\text {Tsh }}^{j}\left(\check{a}_{\mathrm{Tsh}}^{j} \geq \hat{a}_{\mathrm{Tsh}}^{j}+N\right)$. To defer the process of the timeshiftable device, the controller must set a start time $a_{\text {Tsh }}^{j}$ for current job $j\left(\hat{a}_{\text {Tsh }}^{j} \leq a_{\text {Tsh }}^{j} \leq \check{a}_{\text {Tsh }}^{j}-N\right)$. The state of the device at time $\tau$ is then given by: 


$$
o_{\text {Tsh }}=\left\{\begin{array}{cl}
O F F & , \text { if } \tau<\hat{a}_{\text {Tsh }}^{j} \wedge \tau>\check{a}_{\text {Tsh }}^{j} \\
A V A L L & , \text { if } \hat{a}_{\text {Tsh }}^{j} \leq \tau<a_{\text {Tsh }}^{j} \\
\frac{\tau-a_{\text {Tsh }}^{j}}{T} & , \text { if } a_{\text {Tsh }}^{j} \leq \tau<\left(\frac{\tau-a_{\text {Tsh }}^{j}}{T}\right) \cdot N \\
D O N E & , \text { if }\left(\frac{\tau-a_{\text {Tsh }}^{j}}{T}\right) \cdot N \leq \tau \leq \check{a}_{\text {Tsh }}^{j} .
\end{array}\right.
$$

Only one job can be active at a time and different jobs may not overlap each other, i.e. $\hat{a}_{\text {Tsh }}^{(j+1)}>\check{a}_{\text {Tsh }}$. Within simulations, a list of jobs is provided for a Tsh by $\hat{A}_{\text {Tsh }}=$ $\left\{\hat{a}_{\text {Tsh }}^{1}, \hat{a}_{\text {Tsh }}^{2}, \ldots, \hat{a}_{\text {Tsh }}^{N}\right\}$ and $\check{A}_{\text {Tsh }}=\left\{\check{a}_{\text {Tsh }}^{1}, \check{a}_{\text {Tsh }}^{2}, \ldots, \check{a}_{\text {Tsh }}^{N}\right\}$

\subsubsection{Buffer-Timeshiftable Device}

Like the timeshifters, there also exist devices with a buffer that have limited availability to offer flexibility, such as a BEV. Therefore, the device component of a device BufTsh inherits from both the buffer and timeshiftable device components. The internal buffer of the buffer-timeshiftable must satisfy the buffer constraints as mentioned before in Subsection 3.1.4. The used symbol for this device is given in Figure 3.11. Furthermore, this type of device uses a similar job system as used with the timeshiftables to indicate when the device is available $\left(o_{\mathrm{BufTsh}}=A V A I L\right)$ or not $\left(o_{\text {BufTsh }}=O F F\right)$ :

$$
o_{\text {BufTsh }}=\left\{\begin{array}{cl}
O F F & , \text { if } \tau<\hat{a}_{\text {BufTsh }}^{j} \vee \tau>\check{a}_{\text {BufTsh }}^{j} \\
A V A I L & , \text { if } \hat{a}_{\text {BufTsh }}^{j} \leq \tau \leq \check{a}_{\text {BufTsh }}^{j} .
\end{array}\right.
$$

Figure 3.11: Buffer-timeshiftable device component icon.

In contrast to the timeshiftable device component, buffer-timeshiftable devices have no specific profile. However, they must satisfy a certain SoC $E_{\mathrm{BufTsh}}^{\mathrm{SoC}}$ at the end of a job $\left(\hat{a}_{\text {BufTsh }}^{j}\right)$. Therefore a target setpoint $\bar{a}_{\text {BufTsh }}^{j}$ is introduced which specifies the SoC that the device must have reached by the end of job $j$. A controller can set the desired power consumption $S_{\text {BufTsh }}$ when the device is available, as long as it satisfies the conditions expressed in Subsection 3.1.4 and meets the target setpoints. The power consumption $S_{\text {BufTsh }}=0$ when $o_{\text {BufTsh }}=O F F$.

Energy can be drained with an arbitrary amount from the buffer when the device is not available prior to the activation of job $j$ specified with $\underline{a}_{\text {BufTsh }}^{j}$. The exact amount by which the buffer is drained is known when the device becomes available again e.g. when a BEV is reconnected to the charging station. Within simulations, a list of SoC setpoints is provided with $\bar{A}_{\mathrm{BufTsh}}=\left\{\bar{a}_{\mathrm{BufTh}}^{1}, \bar{a}_{\mathrm{BufTsh}}^{2}, \ldots, \bar{a}_{\mathrm{BufTsh}}^{N}\right\}$ and $\underline{A}_{\text {BufTsh }}=\left\{\underline{a}_{\text {BufTsh }}^{1}, \underline{a}_{\text {BufTsh }}^{2}, \ldots, \underline{a}_{\text {BufTsh }}^{N}\right\}$. 


\subsubsection{Other Energy Systems}

Similar components as the ones presented above can also be used for energy systems that use another energy carrier, such as heat or natural gas. For these other carriers, a subset of the presented device components is applicable with no to minor changes. For example, a heat system also consists of buffers such as a heat store; converters such as heat pumps or; loads such as radiators and domestic hot tap water. Similarities with natural gas systems exists, such as a storage tank (buffer), microCHPs (converter) and stove (load). The connections of these devices to their respective energy carrier grid are easier than those of the electricity grid since these systems do not have multiple phases. Also other phenomena, such as substitutes for reactive power and the load types are often neglected.

The presented model also has similarities with the stream models presented by Molderink in [107] (Chapter 3). All presented device components can be represented by one or two device components introduced by Molderink. Within this work, we do not require to model pools and exchanging devices as we are not interested in other energy carriers besides alternating current $(A C)$ electricity. The addition of pools with other energy carriers, as presented by Molderink, would allow for advanced hybrid systems modelling. We note that using pools and exchangers as presented by Molderink would lead to a clutter of multiple pools, exchangers and streams to represent the partial loads on each phase and for each electrical load type. The bundling approach of multiple streams and specification of load types form the major difference with the model by Molderink. This change makes it possible to link power flow based device components to physical network models for load-flow analysis using voltages and currents instead.

\subsection{Network Components}

All these devices are connected in some way to the power grid that gives the devices access to an energy distribution system from which they can either extract from or inject energy into. This connection is often provided by domestic outlets, but other devices such as a BEV may be connected using a charging station to charge faster. The focus of this section is on the components that represent this distribution network and its components as well as simulation techniques to derive, amongst others, voltage magnitudes, currents and losses in such a distribution network.

Chapter 2 already gave an overview of the complete hierarchical design of the electricity grid. The electricity network that provides electricity to consumers and prosumers in a microgrid is part of the larger distribution grid. To be more specific, the AC low-voltage LV grid considered in this thesis with a nominal root mean square (RMS) phase voltage $U_{\text {nom }}$ of $230 \mathrm{~V}$ and nominal frequency of $50 \mathrm{~Hz}$ in Europe. These nominal values are only properties of the grids under consideration, other values can be used, such as the $120 \mathrm{~V} 60 \mathrm{~Hz}$ system in the United States. The RMS AC voltage specifies the equivalent DC voltage and unless specified otherwise, all voltages are specified in V RMS. 


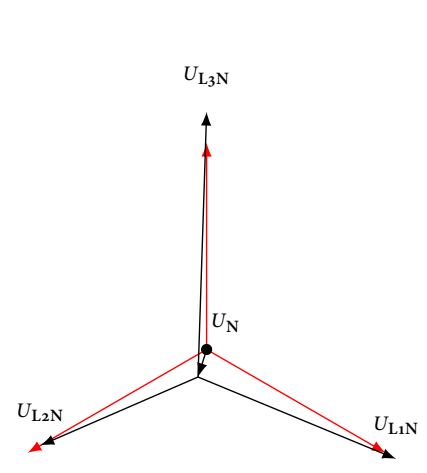

(a) Voltage

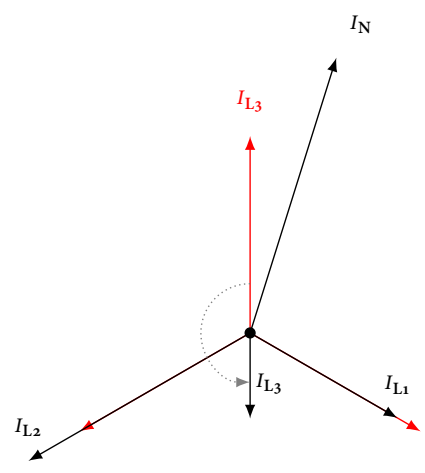

(b) Current

Figure 3.12: Example of a balanced network (red) and an unbalanced network with feed-in with a neutral point shift (black).

Table 3.1: PQ requirements in LV networks as specified in the EN-50160 [113].

\begin{tabular}{r|l}
\hline Aspect & Requirement \\
\hline Voltage & $\begin{array}{l}\bullet U_{\text {nom }}+/-10 \% \text { for } 95 \% \text { of } 10 \text { minute averages during 1 week } \\
-U_{\text {nom }}+10 \% /-15 \% \text { for all 10 minute averages during 1 week }\end{array}$ \\
Asymmetry & $\begin{array}{l}\text { - The inverse component of the voltage }<2 \% \text { of the normal } \\
\text { component for } 95 \% \text { of } 10 \text { minutes measurements during 1 week } \\
\text { - The inverse component of the voltage }<3 \% \text { of the normal } \\
\text { component for all 10 minutes measurements during 1 week }\end{array}$ \\
\hline
\end{tabular}

However, this $230 \mathrm{~V}, 50 \mathrm{~Hz}$ supply is not fixed. Instead, the actual supplied voltage and frequency depend on the power balance and spatial spread in the network at any given moment in time. Balance between the production and consumption of electricity in a grid is crucial for the grid frequency. Too much consumption leads to a reduced frequency, whereas too much generation leads to an increase in frequency. This is a global, synchronized, variable of a grid and is the same at any location. On the other hand, the observed voltage is influenced more by local phenomena as it is the result of voltage drops over cable sections, i.e. an increased local load significantly reduces the local voltage, but not on the other side of the grid and vice versa. Regulations exists, such as the EN-50160 [113] in Europe, that specify what characteristics the supplied electricity must meet to be of sufficient quality. This quality is commonly known as the power quality $(P Q)$.

In this thesis we are interested in the steady state of a microgrid. Therefore we limit our components of the physical grid to those required for steady-state, discrete, 
load-flow analysis. Unbalanced loads in (common) three-phase LV grids require additional attention as they may result in neutral point shifts. These shifts are the result of currents flowing through the neutral conductor of a cable, resulting in an additional voltage drop. As a result, an increased or decreased voltage is supplied, depending on the phase (depicted in Figure 3.12). Hence, unbalanced three-phase AC load-flow analysis are used in this work. Power quality analysis are limited to voltage and asymmetry metrics as specified in Table 3.1.

Next to the previous aspects, also a safe supply of electricity is important for a correct functioning of the smart grid control systems. Therefore, the used components also incorporate thermal limits, e.g the ampacity (ampere capacity) of cables and rated maximum current of fuses. Control algorithms can incorporate this information directly from the components and use them as constraints during the optimization process.

The remainder of this section is structured as follows: First the topology of a distribution grid is discussed, which can be represented by a graph. Subsequently, nodes and edges (cables) for such a grid are discussed.

\subsubsection{Topology}

The part of the distribution grid that is of our interest, namely the microgrid, starts at the MV/LV transformer. On the secondary (LV) side of this transformer, multiple feeders (cables) are connected to the busbar and form the last meters of cable that connect the consumers and prosumers to the larger electricity grid. The total cable length of LV networks in the Netherlands is $223.422 \mathrm{~km}$ ( $66 \%$ of the total electricity network length) [114]. Different distribution grid topologies exists in distribution networks [154]. The first, and most common, is a radial grid structure which is basically a tree or acyclic, and often planar, graph. Dickert et al. [33] describe different structures of radial networks that are commonly found in Western Europe. Another structure is the weakly meshed or ring structure, which is similar to the radial network, but then some of the branches are connected together at the end, forming rings. This increases the reliability of the grid as electricity flows can be re-routed in case a cable section breaks. Weakly meshed grids are usually equipped with normally open points such that they are operated as radial networks. Meshed networks form the last type of networks and consists of a grid structure in which electricity can reach any point in the grid using multiple routes. Meshed grids have the advantage that they provide a more robust $\mathrm{PQ}$ and service to consumers, but costs of security measures are higher. Therefore, most LV networks, and also large portions of the MV grid, are radial by design or operated radially. In the Netherlands, meshed LV networks can be found in old city centres. Some of those networks are being or have been transformed into radial (operated) networks, such as in Amsterdam and Nijmegen [103].

All of these grids can be represented by a (directed) graph $\mathcal{G}=(\mathcal{V}, \mathcal{E})$ with $\mathcal{V}$ being a set of nodes and $\mathcal{E}$ a set of edges. Within this graph, edges represent the cables and nodes represent points of connections. Devices and generators are connected 


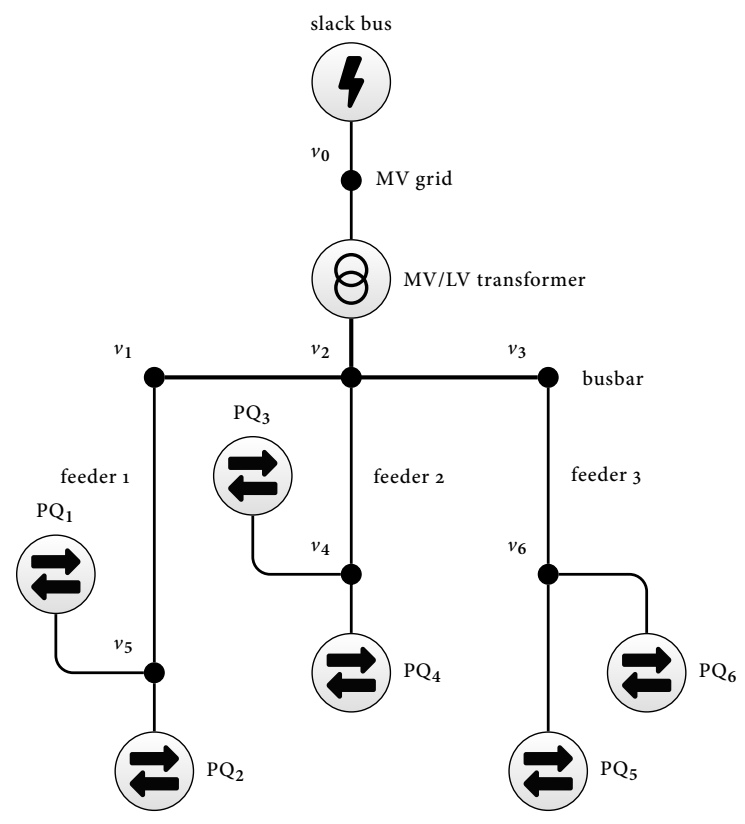

Figure 3.13: Model of a distribution grid with edges and nodes, where one node represents a slack bus (top), another a transformer and multiple nodes represent customers modelled by a $p q$ bus.

to these nodes. Generally speaking, edges perform transformations on the voltage and alter flow of currents between two nodes whereas nodes represent loads and generators connected to the grid. An example of such a network is given in Figure 3.13. The following subsections present the specific grid components that describe the distribution grid.

\subsubsection{NODES}

Within the graph representation of an electricity grid, a node represents a point where flows of current meet and depart again. Within load-flow analysis, these nodes are often referred to as buses. Device as mentioned in 3.1.1 can be connected to these nodes (exchanger), but also other grid assets, such as capacitor banks. All devices and assets that either remove power from the grid or supply power to the grid can be connected to these buses.

Four variables are associated with each node for which the value is either given or has to be found using load-flow analysis. These are the active power $P$, reactive power $Q$, RMS voltage $|U|$ and the phase angle $\delta$. In systems with multiple AC phases, these variables are represented by vectors, specifying the values for each of the phases in the power system. Three generalized model types of buses exist in power flow analysis, namely the load bus, generator bus and slack bus: 
"Load bus $(p q)$ : In contrary to its name, load buses are used for both loads and synchronized generators. This type of bus is also known as $p q b u s$ as the active power $P$ and reactive power $Q$ are specified for this type of bus. Typically, residential loads and RES are modelled using a $p q$ bus.

"Generator bus $(p v)$ : Asynchronous generators are modelled as generator bus, also known as $p v$ bus as the active power $P$ and RMS output voltage $|U|$ are specified. Note that the name $p v$ bus is derived from the given variables and has nothing to do with photovoltaics. This type of bus is not used within the scope of this research as residential RES must be synchronized to the grid voltage and therefore needs to be modelled as $p q$ bus instead.

"Slack bus $(v \delta)$ : Each network model must contain at least one slack bus which sets the reference RMS voltage $|U|$ and phase angle $\delta$ for the grid under consideration. The slack bus supplies a shortage or absorbs an overproduction of apparent power $S$ in the grid, including the distribution losses. Usually, the largest asynchronous generator is designated as slack bus in the model. Within residential microgrids the transformer is often modelled as the slack bus as it exchanges a deficit or surplus with the MV grid.

Only one bus-type $\{p q, p v, v \delta\}$, can be assigned to each node $v$ at a time (denoted by $b u s_{v}$ ), but multiple loads and generators may be lumped into one big load or generator. Within the model, nodes with a specific bus type assigned are represented with a larger circle and icon, whereas normal nodes are represented by black solid dots, as depicted in Figure 3.13. Within distribution grids, all domestic devices can be connected to the network components using the load bus model. To ease the notation, complex numbers are used, where $U$ represents the voltage and $S=(P, Q)$ represents the complex apparent power. Formalized, a node (vertex) $v$ is represented by a tuple:

$$
v=\left(e_{v}, S_{v}, U_{v}, b u s_{v}\right)
$$

with $e_{v}$ being a list of edges connected to node $v$.

\subsubsection{EDGes}

The edges of the graph represent network components that facilitate the exchange of energy between two nodes. More formally, an edge connects the nodes $v_{e}^{\text {from }}$ and $v_{e}^{\text {to }}$, of the graph. Cables are the most common edges, but also other components, e.g. transformers, fall within this category. Dependent on the properties of an edge, transformations on the voltage and currents are applied. In the case of a cable, a voltage drop or rise occurs from one node to the other as result of the current $I$ flowing through a conductor with impedance $Z(\Delta U=I Z)$. Likewise, a transformer transforms the voltage from one level to another (e.g. MV to LV), resulting in different voltage levels at the node connected to the primary side and the node connected to the secondary side of the transformer. Edges may also be added or removed dynamically in the model as they can represent normally open 
points or protection systems such as fuses, protection switches or other circuit breakers. Within the scope of this research, we stick to a model of the LV microgrid in which the transformer is modelled as a slack bus. Hence, the focus is on cables and distribution limitations by fuses and other protective equipment.

Within multi-phase systems, such as the common three phase distribution system, the number of physical links between a pair of nodes is four. Typically, one-line diagrams are used in power engineering where each edge represents multiple wires or conductors. We stick to this representation to ease the notation and represent the impedance $Z$ by a $N \times N$ matrix with the impedance of each conductor on the diagonal. The other elements of this matrix represent the mutual impedance coupling between the conductors or other parts of a cable such as shielding. We take a typical 3-phase 4-wire cable component since such a model adequately represents the cables commonly found in Europe. Three conductors are used to carry the currents of the three phases and the fourth conductor is used as neutral. This results in the following $4 \times 4$ impedance matrix $Z_{e}$ for edge $e$ :

$$
Z=\left[\begin{array}{llll}
Z_{c}^{e} & Z_{a}^{e} & Z_{o}^{e} & Z_{a}^{e} \\
Z_{a}^{e} & Z_{c}^{e} & Z_{a}^{e} & Z_{o}^{e} \\
Z_{o}^{e} & Z_{a}^{e} & Z_{c}^{e} & Z_{a}^{e} \\
Z_{a}^{e} & Z_{o}^{e} & Z_{a}^{e} & Z_{c}^{e}
\end{array}\right]
$$

where $Z_{c}^{e}$ is the impedance of a conductor, $Z_{a}^{e}$ the mutual impedance with the two adjacent conductors and $Z_{o}^{e}$ the mutual impedance to the opposite conductor of edge $e$. Furthermore, all impedances are given in complex numbers where the real part represents the resistance $R$ in $\Omega$ and the imaginary part the reactance $X$ in $\Omega$. These values depend on the used conducting material, conductor thickness, shielding and the length of a cable. Other cable components, such a three-phase three-wire MV cable or a split-phase 3-wire triplex cable can be modelled using a matrix $Z$ of different dimensions.

A boolean $E N A B L E_{e} \in\{0,1\}$ is used to dynamically enable and disable an edge $e$ in the model, therefore edges with $E N A B L E_{e}=0$ are treated as non existent. Normally open points and circuit breakers, such as fuses, can be modelled this way. To incorporate thermal limits in the model, the edge representation is extended with a variable $I_{e}^{\max }$, which specifies the maximum current that is allowed to flow through a conductor. For each edge $e$ the variable $I_{e}$ denotes the complex current flowing through the conductors of edge $e$.

Formally, an edge $e$ can be described using the following tuple:

$$
e=\left(v_{e}^{\text {from }}, v_{e}^{\text {to }}, I_{e}, Z_{e}, E N A B L E_{e}, I_{e}^{\mathrm{max}}\right)
$$




\subsection{LoAd-Flow Analysis}

Load-flow analysis (or computations) are used to determine the steady state of a power grid by computing all flows within a network. The practical purpose of a load-flow analysis is to find the voltages at each node, currents flowing through all edges (cables) and distribution power losses in a network. As such, the results of a load-flow analysis are often used in network planning to verify that a design of a network meets PQ requirements during normal operations, faults and maintenance. Load-flow analysis can also be done in a simulation environment, especially in a CPS setting such that the effect of control actions can be simulated. The following subsections present related work on load-flow algorithms and subsequently the used forward-backward sweep algorithm is presented.

\subsubsection{Algorithms}

Several load-flow calculation algorithms exists and are heavily studied due to the importance in network planning, with a strong focus on transmission grids and MV distribution grids. Commonly known load-flow algorithms are the NewtonRaphson and Fast Decoupled Newton-Raphson methods [169]. These algorithms are widely accepted for use in transmission network calculations with a meshed network structure and a low $R / X$ ratio. However, these algorithms may not converge for radial distribution grids which have a high $R / X$ ratio [86].

Due to the adoption of distributed energy resource (DER) in the LV grid, the interest in load-flow studies on these LV grids is growing. Often, the simple forwardbackward load-flow algorithm is used for these studies, which is based on Kirchhoff's voltage law $(K V L)$ and Kirchhoff's current law $(K C L)$ and in its simplest form is limited to radial networks. Zimmerman [169] has composed a comprehensive overview of variants on this algorithm and the Newton-Raphson load-flow algorithm. Simulation results show that the forward-backward sweep algorithm often requires more iterations to converge. However, due to its simplicity, the algorithms requires the least amount of floating-point operations in practical situations for distribution grids. Furthermore, Zimmerman presents solutions to solve weakly meshed distribution networks with this algorithm as well.

We stick to the forward-backward sweep algorithm as it suits the needs for our analysis in microgrids best. The used models in our work follow those presented in [21], [154], [169] and are adapted to allow unbalanced AC load-flow analysis with neutral point shifts. The graph structure of the network can be conveniently implemented in an object oriented manner, such that an efficient recursive implementation of the forward-backward sweep can be written. Details of this algorithm are given in the next subsections and in Algorithm 1.

\subsubsection{Forward-BackWard Sweep Algorithm}

The forward-backward sweep load-flow algorithm traverses a radial (tree structure) power network using a depth first search. After the initialization phase, the algo- 


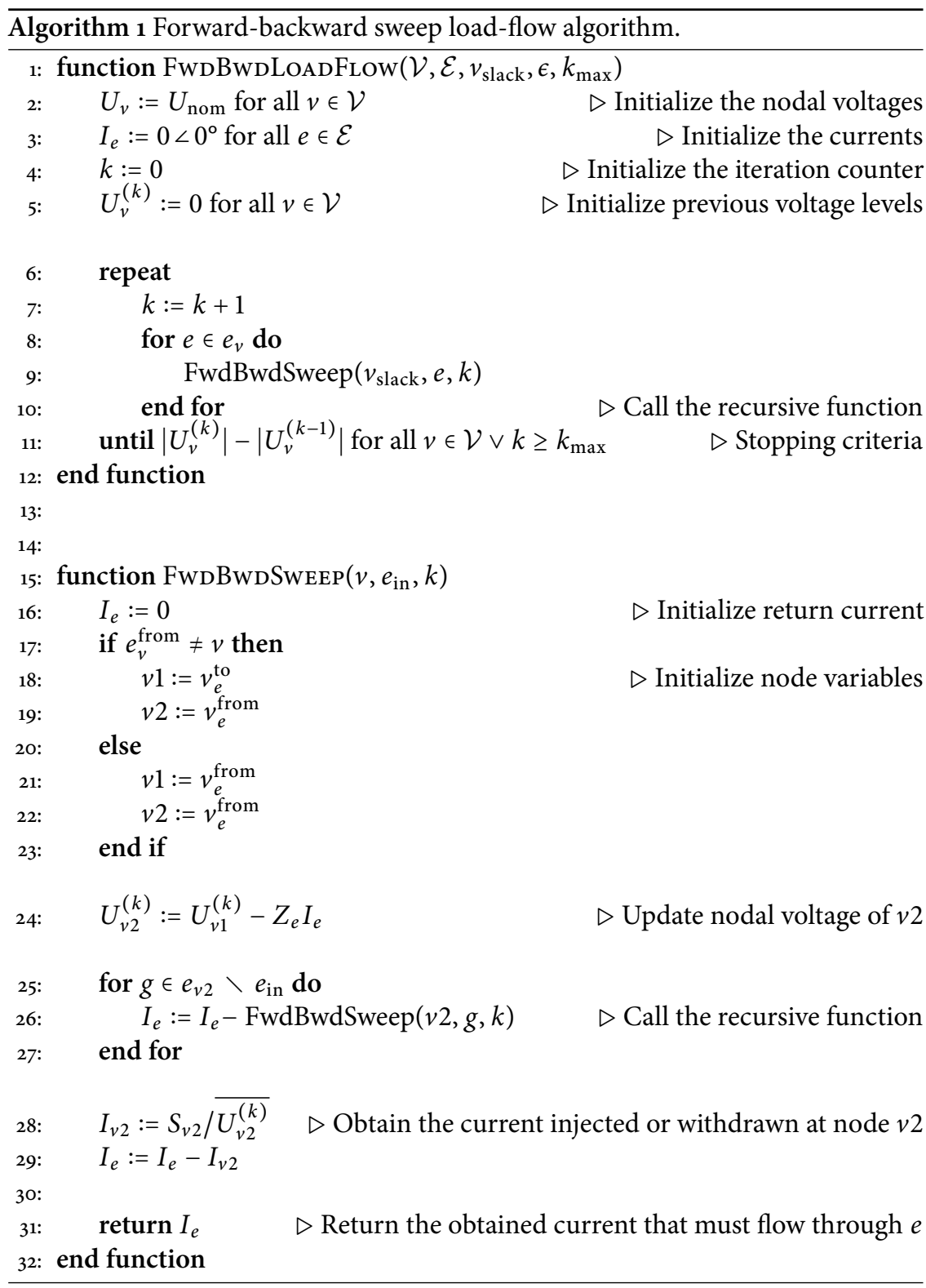


rithm updates the voltages at the nodes using KVL, starting at the slack $(v \delta)$ bus. When the algorithm reaches the end of a branch, it walks in reverse order through the network and updates the currents flowing through the edges using KCL. The iterative process of forward and backward sweeps continues until convergence criteria are met.

\section{Initialization}

During initialization, the voltage at each node has to be initialized. A good candidate for an initial value of the voltage $U_{v}$ at node $v$ is the nominal voltage $U_{\text {nom }}$ of the grid in consideration:

$$
U_{v}=U_{\text {nom }} \text { for all } v \in \mathcal{V}
$$

For a typical European three-phase $\mathrm{LV}$ grid $U_{v}$ represents a vector with 4 elements $\left(U_{v}=\left[U_{v}^{L 1}, U_{v}^{L 2}, U_{v}^{L 3}, U_{v}^{N}\right]^{T}\right)$ of which the first three elements represent the phase voltages and the last element the neutral voltage with respect to ground (0V). For European LV grids, the nominal voltage is $230 \mathrm{~V}$ and the angle between two phases is $120^{\circ}$. Typically, the following initialization is used for LV grids:

$$
U_{v}=U_{\text {nom }}=\left[230 \mathrm{~V} \angle-150^{\circ}, 230 \mathrm{~V} \angle 90^{\circ}, 230 \mathrm{~V} \angle-30^{\circ}, 0 \mathrm{~V} \angle 0^{\circ}\right] \text { for all } v \in \mathcal{V}
$$

Since the consumed and produced powers are unknown at this stage, the currents in all edges $e \in \mathcal{E}$ are initialized at $0 \mathrm{~A} \angle 0^{\circ}$.

\section{Forward Sweep}

The forward sweep traverses the graph using a depth-first search, starting at the slack bus $\left(v_{\text {slack }}\right)$, and updates the voltages at all other nodes $v \in \mathcal{V}$ reachable through enabled edges using KVL. Let $e \in \mathcal{E}$ be the enabled edge (cable) (i.e. $E N A B L E=1)$ that connects a pair of nodes $(v 1, v 2) \in \mathcal{V}$ (see Figure 3.14). Furthermore, let $v 1$ be an already updated node in iteration $k$ and let $v 2$ be the current investigated node. The voltage $U_{v 2}^{(k)}$ for $v 2$ can be obtained by calculating the voltage drop over $e$ :

$$
U_{v 2}^{(k)}=U_{v 1}^{(k)}-Z_{e} I_{e}
$$

where $U_{v 1}^{(k)}$ is the voltage at node $v 1$ in iteration $k, Z_{e}$ is the impedance of edge $e$ and $I_{e}$ is the vector of currents flowing through edge $e$ obtained in the previous iteration. 


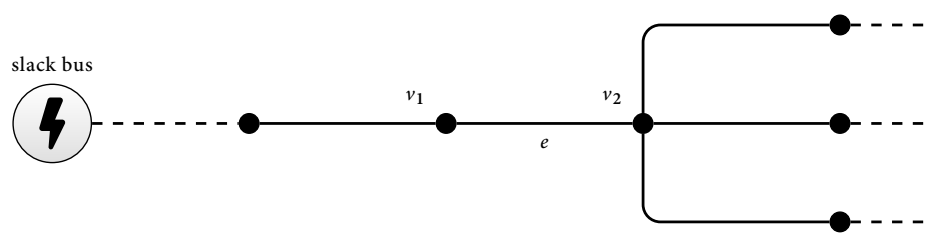

Figure 3.14: Part of a distribution grid model.

\section{Backward Sweep}

Currents are updated in the backward sweep, which follows the path in reverse order. Let $v 1, v 2$ and $e$ be the same nodes and edge as denoted in the forward sweep. Furthermore, let $I_{v 2}$ be the current flowing towards the load(s) connected to $v 2$, and let $e^{\text {out }}=e_{v 2} \backslash e$ be the set of edges connected to $v 2$, excluding $e$ (see Figure 3.14). According to KCL, the sum of all currents in a node must be equal to 0 and using this law we can find the current that flows through an edge. All edges in $e^{\text {out }}$ have already been visited in the current iteration of the algorithm. Therefore, edge $e$ is the only remaining edge that can supply $v 2$ of the current to satisfy this condition:

$$
I_{e}=\left(\sum_{g \in e^{\text {out }}}-I_{g}\right)-I_{v 2}
$$

where $I_{v 2}$ can be calculated, based on the voltage $U_{v 2}^{(k)}$ as obtained in the forward sweep, using the following relation:

$$
I_{v 2}=S_{v 2} / \overline{U_{v 2}^{(k)}}
$$

where $\overline{U_{v 2}^{(k)}}$ is the complex conjugate of $U_{v 2}^{(k)}$. The sum of all currents in vector $I_{e}$ must also be zero. The neutral conductor makes sure that this constraint is satisfied in LV grids. For the vector $I_{e}$ in three-phase four-wire LV we follow a similar notation as used with $U_{v}$ and write $\left.I_{e}=\left[I_{e}^{L 1}, I_{e}^{L 2}, I_{e}^{L 3}, I_{e}^{N}\right]\right)$. We can now find $I_{e}^{N}$ using the following relation:

$$
I_{e}^{N}=-I_{e}^{L 1}-I_{e}^{L 2}-I_{e}^{L 3}
$$

Distribution losses $P_{e}^{\text {loss }}$ are the result of the impedance in the cable and can be calculated using Ohm's law:

$$
P_{e}^{\text {loss }}=\left|I_{e}\right|^{2} R_{e},
$$

where $R_{e}$ is the real part of $Z_{e}$. 


\subsubsection{Convergence Criteria}

The load-flow algorithm stops after the convergence criteria is met, which is evaluated after each full sweep of the algorithm. The criteria is met when the difference between voltages in the current iteration $k$ and previous iteration $k-1$ is smaller than a predefined error $\epsilon$ for all nodes:

$$
|| U_{v}^{(k)}|-| U_{v}^{(k-1)}||<\epsilon \text { for all } v \in \mathcal{V}, \epsilon>0 .
$$

The algorithm can also be stopped after a maximum number of $k_{\max }$ iterations have passed.

\subsubsection{Other Energy Systems}

Similar to the device components, the presented components can be adapted to energy systems with other energy carriers. The infrastructure of heat, cold and natural gas networks can also be modelled using a graph. The conductors, modelled by edges, have to be replaced by pipes with an impedance (but without the hassle of the multiphase system and mutual impedances). Note that thermal systems are often modelled using equivalent electrical circuits. Voltages and currents can be replaced respectively with temperature and flow for heat and cold networks. For natural gas networks, a similar change can be done to flow instead of current and the energy density instead of voltage. Using this description, the flow problem can be solved using a suitable load-flow algorithm.

\subsection{CONTROL INFrastructure}

The cyber part of the CPS system consists of the information communication technology (ICT) system that manages (a part of) the devices within the microgrid and thereby manages the flow of energy within this network. The ICT system consists of two major components: control algorithms and communication links. These control algorithms often run on (embedded) computers and determine the actions that need to be taken to attain a certain target. This action can for instance be to change the state (consumption level) of a device or to request data from another controller. Communication links ensure that this exchange of information and commands can take place between control algorithms and/or devices.

Such a network of controllers and communication system can also be seen as a graph where the nodes represent the control algorithms that run on computers and the edges the links between the algorithms. Figure 3.15 shows an example of control structures. Many different topologies for such communication networks exists. A commonly used topology for DEM is a tree (or hierarchical) structure for its scalability and localization properties. Directed graphs are used for hierarchical control to indicate which node is the higher in the hierarchy. Other considered topologies are more dynamic, such as peer-to-peer networks. Systems may also 


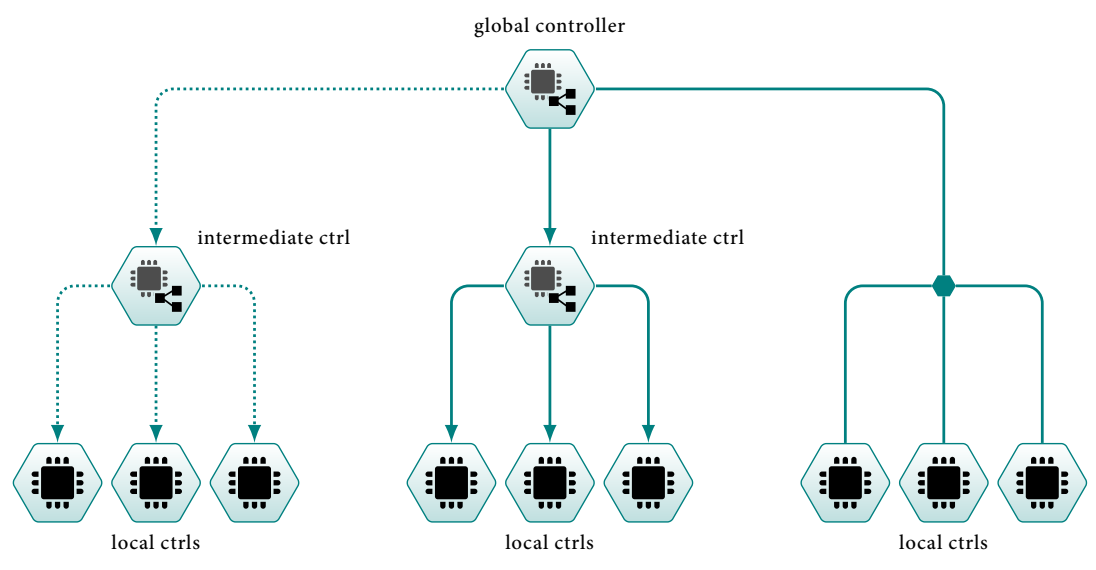

Figure 3.15: Three control topologies: a) on the left a top-down hierarchical control structure with uni-directional communication; b) in the middle a top-down hierarchical structure with bi-directional communication; and c) on the right a cluster of direct bi-directional controller to controller communication between any controller, symbolized by the small solid grey hexagonal node.

be mixed into hybrid systems where for instance each microgrid itself communicates using a peer-to-peer structure, but where these microgrids themselves are connected to each other using a hierarchical structure.

This subsection gives a brief overview of the ICT components for these communications networks whereas Chapters 4 and 5 provide more in depth detail on the proposed control structure and algorithms for smart grid control.

\subsubsection{Nodes: Controllers}

The nodes of the communication network represent controllers and the corresponding control algorithms need to be implemented and executed on a computer, somewhere. However, this does not mean that each node represents a separate physical computer. Within the models, a node merely is a control algorithm with inputs and outputs. Therefore, multiple algorithms may run on one physical system using multiple instances or virtualization. One physical system may therefore represent multiple nodes in one part of the graph, but also individual nodes that are not directly connected to each other. As such, the mapping of the control model onto physical systems has freedom to optimize the implementation for certain goals such as cost, reliability or energy usage. Furthermore, a system may also fail, which results in the removal of nodes and its associated edges.

Within control systems, these controllers influence the behaviour of the devices. Therefore, a controller may directly influence the behaviour of a device by changing its state, but also indirectly by sending incentives, such as prices or a desired profile 
to child controllers in a hierarchical control system. Often a distinction is made between device controllers and fleet controllers (often also called a cluster controller). Device controllers are directly associated to a physical device and translate incentives, using local algorithms, into control actions that change the state of the physical device. In hierarchical or centralized control, at least one fleet controller is required that sends the incentives to the device controllers. By doing so, a fleet controller can steer the fleet of devices into the right direction to attain a certain overall power value.

Multiple layers of fleet controllers are often introduced to preserve scalability. In such a case, each fleet controller can either forward incentives from a higher level, or optimize the behaviour of its fleet of devices independently.

\subsubsection{Edges: Communication Links}

Interaction between two control nodes goes through communication links, represented by an edge. These edges therefore indicate which nodes can directly communicate to each other. If hierarchy is required, then a directed edge can be used to express the relationship between nodes. Such a relationship is often described as a parent-child (or master-slave) relationship, where the parent imposes control onto its children. To distinguish between uni-directional and bi-directional communication within models, we use dashed edges for uni-directional communication (following the master-slave paradigm) and solid lines for bi-directional communication. Examples of control structures are given in Figure 3.15, where a small hexagonal node represents a hub that allows for direct interaction between nodes to avoid clutter of edges. Single communication links may also break, which results in a situation where a group of nodes is not reachable anymore. We speak of ICT-islanding in this case, in which one large cluster is split up in two or more individual clusters.

Multiple communication technologies, such as general packet radio service (GPRS) and optic fibre, are considered for control in smart grids. Each technology imposes restrictions on the data rate, reliability and latency that may be of influence. The models are technology agnostic and in theory, any communication technology can be used as long as it satisfies the requirements of the communication link as required by the control strategy. The models are also communication protocol agnostic, meaning that any protocol or implementation to exchange data between nodes can be used. Communication also does not necessarily need to be done via a communication network, but could also be function calls for instance.

\subsection{Interaction Between Components}

To create a full CPS, the individual components need to be tied together in such a way that information and properties can be exchanged. The three separate components form a triangle as depicted in Figure 3.16 in which the three sub-models can 

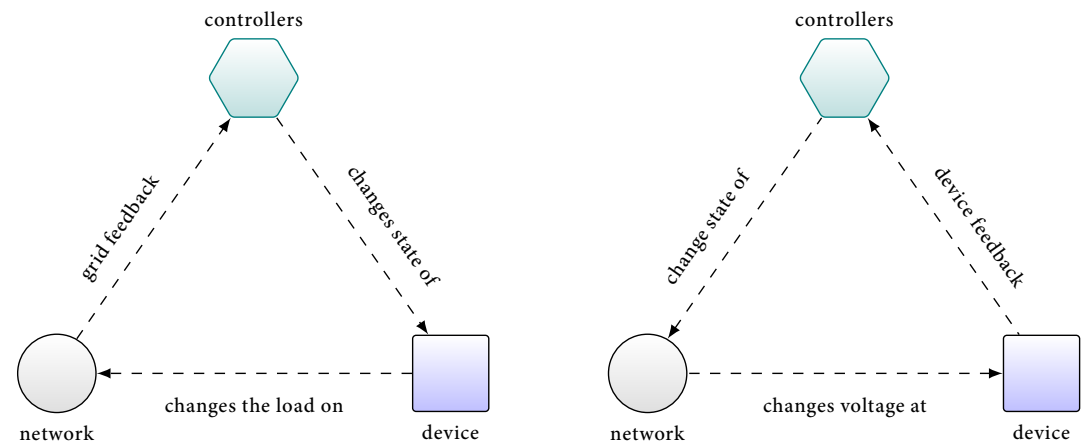

Figure 3.16: The three main model components (devices, network components and controllers) that form the complete CPS together with the interactions between these components in both clockwise direction (left) and counter clockwise direction (right).

directly change each others state. The physical system is formed by the combination of devices and controllers, whereas the controller infrastructure is the cyber part. As such, controllers change the state of the devices and thereby change the power consumption of the fleet of devices. This change results in a change of the state of the physical network as current flows and nodal voltages change. Using metering equipment, this new grid state can be fed back in the control system on which it may act to attain a certain target. Interaction is also possible in the counter clockwise direction, in which the controllers influence the state of network assets, such as changing the tap position on a transformer to change the supply voltage. This action results in different voltage levels as observed at devices, which in turn may provide this as feedback to their controller. This section covers the interaction between the individual components in the clockwise order.

\subsubsection{Controllers and Devices}

A controller $c t r l$, within a large structure of control nodes, can connect to a device $d$ using a one-to-one relation as depicted in Figure 3.17. Such a controller changes the state $s_{d}$ of the connected device and thereby the controller commands (dictates) what a connected device should do. Within a discrete time simulation, a controller can only change the state of a device once in each simulated time interval, whereas the real physical device may also have control rate limitations. The components are communication technology agnostic, but in practice the used communication technology imposes limitations to the maximum rate of control actions per unit of time.

The set of valid control actions $\Delta_{d}^{o}$ is given by the current device state $o_{d}$. Hence, the controller is required to obtain this state information to make proper actions or communicate information about the flexibility it can offer. As such, a controller 


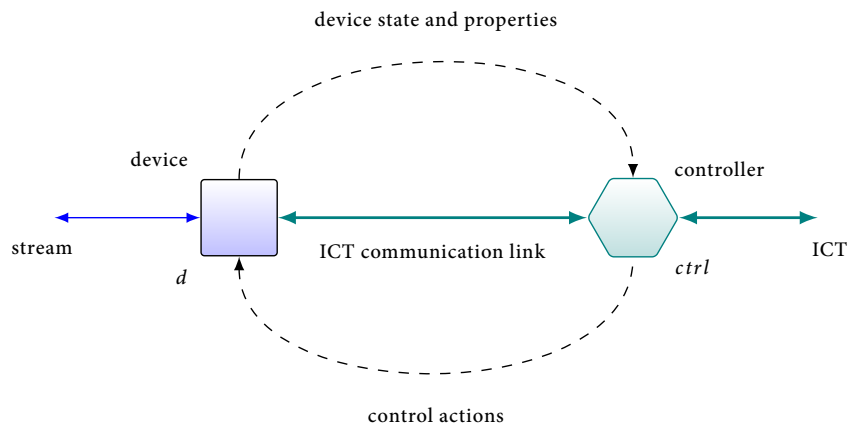

Figure 3.17: Interaction between a control node $(c t r l)$ and a device $(d)$.

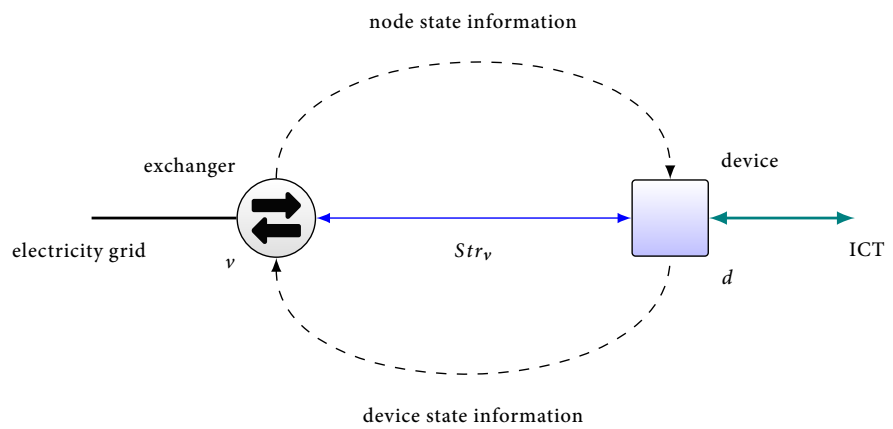

Figure 3.18: Interaction between a network node $(v)$ and a device $(d)$.

could for instance construct a valid bidding function based on the current state of the device. More advanced control strategies can use the device component for model predictive control (MPC) or to derive tailor made algorithms for planning based optimization such as [149]. Note that in this process the device component is leading. If a controller selects an invalid new state for the device, the device may override this command by either selecting the state that is closest to the desired state, or to ignore the command and continue with the current state.

The other way around, a device may also actively send information updates to the device controller based on local events. Such an event could for instance be a significant state update, e.g. a BEV that is connected to the charging station, a washing machine that has finished its job or a device that cannot maintain the desired state anymore. This allows the controller to actively use up-to-date information and act adequately when necessary. 


\subsubsection{DeVices AND Network}

Devices are usually connected to the grid using a socket or more advanced equipment such as a charging station. Within the model, depicted in Figure 3.18, this connection is represented by a set of streams $\operatorname{Str}_{v}$ associated to a network node $v$. Each stream $\operatorname{str}_{l,(v, d)}^{p} \in S t r_{v}$ specifies how much energy must flow through this stream as presented in Subsection 3.1.1. A load-flow algorithm can access this information through the exchangers, to which the devices are linked, to obtain the total load at this point in the network. This load can be translated into the current flowing towards the associated devices by using the nodal voltage at the exchanger. The voltage, and therefore current, is then updated in each iteration of the load-flow calculation. Note that all voltage dependent values of $S_{d}$ are specified using the nominal grid voltage $U_{\text {nom }}$ and that for each iteration $k$ of the load-flow algorithm the voltage supplied to the device is estimated by $U_{d}=U_{v}^{k}$.

A device may also have voltage measurement equipment and thus a device may read out the voltage level and, if applicable, the frequency of the associated node $v$. This information may be used by the device to change its state independently from an external controller, often to protect the stability of the system. An example of this is the operation of PV inverters which curtail the energy production in case the voltage or frequency exceeds a predefined threshold. Such an action can then lead to a notification to the connected controller as mentioned above.

\subsubsection{Network ANd Controllers}

The last link to make is the link between the physical network and the control structure as depicted in Figure 3.19. By its definition, a smart grid must provide system reliability, resilience and stability. In order to do so, the control system must ensure that the effects of the control actions keep the state of the electricity grid within limits. The network components provide an important part of this information in the form of limitations such as the ampacity of cables and the name plate power rating of transformers. The control structure can use this to ensure that the aggregated power consumption of a (sub)fleet of devices does not exceed these limitations for the considered part of the physical grid. In case of a radial LV grid and a hierarchical tree structure of controllers, this link becomes even stronger. The control structure can be setup in such a way that each layer of controllers represents a part of the physical grid. Each controller then incorporates the limits this part of the grid imposes and makes sure that its control actions stay (well) within these limits.

The network components can also be used for MPC to see what effects the proposed control actions have on the physical grid. This is done by setting the expected load on each of the network nodes and execute a load-flow calculation as simulation. These results are then used to verify whether the proposed control actions are feasible within the physical grid and by what margins. Such a verification may be to check if the delivered power quality to customers will be within regulatory limits. 


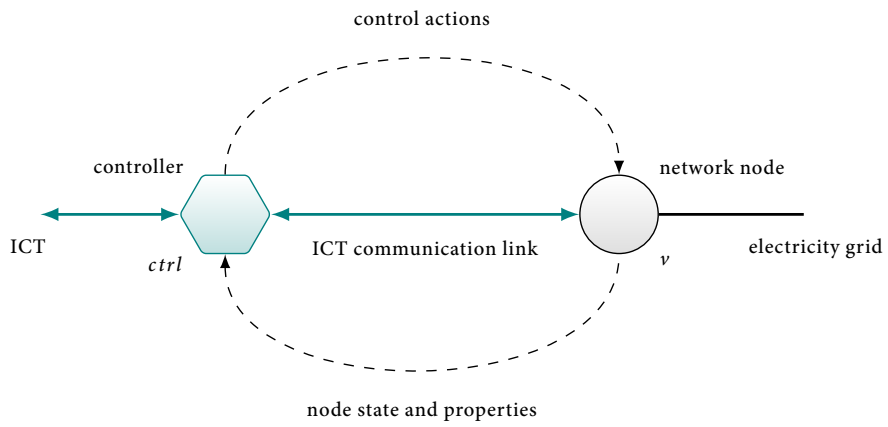

Figure 3.19: Interaction between a control node $(c t r l)$ and a network node $(v)$.

Furthermore, it can also check what margins are left to cope with deviations from the expectations such as those originating from devices that cannot be controlled.

\subsection{CONCLUSION}

In this chapter a model for smart grid control is described in detail. This model consists of detailed device components, extensive physical network components and the basics of control networks. All these separate components are generic and based on current practices. The novelty is in combining these three individual submodels into one integrated model that allows for CPS analysis and simulations of smart grids.

The basis of the model exists of generic device components that can be used to model the total energy consumption of a house or building. The device components range from simple components, such as load devices, buffers and converters, to combinations of these components using inheritance. This results in a flexible framework to define new devices and to extend the presented functionality. Each of the device components describes the behaviour of the device and the optimization potential that it can offer to a smart grid system.

A collection of devices, representing a building, is connected to the physical grid using streams. Within the physical grid model, the power consumption of the devices is translated into voltages and currents. As such, it is possible to perform load-flow analysis to study the effects of changing consumption and production behaviour on the physical grid. Grid properties, such as power quality and losses can be studied in detail. Furthermore, the grid structure can be reconfigured. The basic models are generic enough to support networks with other energy carriers.

The control system topology can be modelled separately and may follow the structure of the physical grid. Links with devices can be created to control and optimize the behaviour of the devices. Similarly, the grid components can be used to incorporate grid limitations at different levels to ensure that the control actions result 
in a stable and secure supply of energy to the end users (devices). Like in the physical grid model, connections may be disabled to study the effects of failing communication links on the control system.

The triangle formed by these three sub-models can be used in the complete CPS model to exchange information in both directions. By doing so, the interaction, limitations and dependencies between the components become clear, which results in a holistic view on a smart grid. Feedback from the physical model can be used by the control systems to adequately act on (unexpected) events in the grid, while the actions of the control system become visible in the physical domain.

The proposed model is generic and forms a solid basis for more advanced studies on smart energy systems. It is expected that studies on hybrid energy systems, where the proposed components are extended with other energy carriers, can be executed without fundamental changes of the overall setup. 


\title{
4 \\ Proactive Control Methodology
}

\begin{abstract}
This chapter describes the profile steering heuristic to optimize the overall power profile of a cluster of devices within the smart grid using model-predictive-control. This approach steers the cluster towards a desired profile using a device agnostic steering signal. These signals are distributed through a hierarchical and scalable tree, in which the leaves create the actual schedules. By doing so, parallelism among leaves can be exploited. The tree itself maps to the radial networks as described in the previous chapter, which allows the integration of local grid limits. The approach is extended to support multiple commodities and objectives, e.g. reactive power and phase balancing. Finally, an event-driven approach is introduced to deal with prediction errors in the profile steering algorithm, thereby allowing the algorithm to execute and realize the created planning.
\end{abstract}

In Chapter 1 we sketched the challenges in the electricity supply chain. Due to the intermittent nature of most renewable energy sources (RES), electricity may not be generated at times of demand such as done in the conventional power grid, and therefore, flexibility from the demand side is required. On the other hand, the electricity grid is challenged with the ongoing electrification on the demand side with the adoption of heat pumps and battery electric vehicle $(B E V)$. However, these distributed energy resources (DERs) such as a BEV and a heat pump offer flexibility which may be used to (partly) match production and consumption as shown in Chapter 3. By proper coordination, locally generated electric energy may be directly used locally, reducing the need for transport and thereby alleviate grid capacity issues.

Parts of this chapter are based on [GH:1], [GH:2], [GH:9], [GH:12] and [GH:13]. 
In the previous chapter we gave generic components for the smart grid infrastructure. This included a broad and generic model of the information communication technology (ICT) infrastructure that makes this smart grid possible. In this chapter we unveil a control methodology that utilizes this ICT infrastructure to manage and coordinate consumption and production of energy with the focus on the electricity grid in particular. To be effective, by the definition of the smart grid, such a coordination system must be able to steer a heterogeneous cluster of hundreds to thousands of devices within a microgrid while managing the long term energy system objectives.

In this Chapter we propose a decentralized energy management (DEM) approach that makes use of predictions to optimize energy flows in smart grids for future time intervals. The predictions allow the methodology to anticipate on expected future events and therefore we refer to this type of control as proactive control. Using these predictions in combination with optimization algorithms allows the system to find balance between meeting short- and long-term objectives. To accomplish this, we use an optimization heuristic called profile steering, which uses generic steering signals. This heuristic can be used in a synchronous and offline scheduling approach, as e.g. needed for the day-ahead market, but also in an asynchronous and online scheduling fashion for operational control.

The remainder of this chapter is organized as follows. In the next section we investigate the requirements for a DEM system to improve the operation of a smart grid as a whole. For this we derive key requirements and briefly review related work. The general control concept, based on these requirements and findings of related studies, is unveiled in Section 4.1. Subsequently, in Section 4.2 we present the profile steering heuristic utilizing this control concept to manage electric energy within a microgrid in a synchronized fashion. In Section 4.3 we build further on this methodology and introduce events to allow partial optimization for use in an online setting. We evaluate how this methodology meets the stated requirements and conclude this chapter in Section 4.4. Note, that results of the proposed control mechanism are presented in Chapter 7.

\subsection{REQUIREMENTS}

An energy transition towards the use of renewable energy is happening, which asks for an energy management system (EMS) as sketched in Chapter 2. This transition highly impacts the use of electricity and the electricity distribution systems, which is the focus of this thesis. But there are more energy carriers and distribution systems, such as natural gas and district heating systems. In order to optimize the efficiency of the total energy system, control over all system components must be considered. This asks for a multi-commodity energy management methodology that is able to combine the objectives of multiple interconnected energy systems. 
Within the electricity grid itself we can already define multiple commodities for active and reactive power. Furthermore, the three-phase distribution system can be seen as three separate networks that do influence each other.

In addition to these commodities, the system also must be able to impose control over a potential large cluster of thousands of devices within a portion of the electricity grid. Furthermore, the system has to deal with a wide variety of device controllers and operation constraints. Chapter 3 presented these device components and showed the potential of combining characteristics shared among different device types. Hence, the control methodology must be scalable in number of connected devices and the number of commodities. At the same time, it must also provide generic means to control heterogeneous clusters of devices.

The flexibility of the cluster as a whole may be used on electricity markets, such as the day-ahead market. To effectively trade on these markets, the system must be able to predict the electricity consumption and flexibility for several hours or even days into the future to optimize the fleet behaviour. However, this comes with a risk as the resulting schedule of control is optimized for the predicted flexibility constraints. As, predictions are never fully accurate, the constraints are different in reality. An EMS must therefore be robust against prediction errors and provide means to resolve issues that arise from these prediction errors. Furthermore, external market incentives may shape the electricity profile and potentially create large peaks in demand, e.g. when abundant energy is available generated by wind turbines. In such cases, the control system must respect physical capacity limitations of the distribution system.

Such an energy management and coordination system requires ICT to communicate the available flexibility and send incentives to change the operation of devices. However, the ICT infrastructure may show service interruptions from time to time. Therefore it is important that an EMS is robust to ICT service interruptions and should be able to continue on a local level to carry out the objective as good as possible. Therefore, next to global optimizations, more local nodes also must be able to perform local optimizations to resolve forecast errors.

However, it is not only the technical part of an EMS that matters, especially in residential (micro)grids. The potential to shape the electricity profile lies in the offered flexibility to the EMS. This flexibility has to be offered by users connected to the system and therefore depends on the willingness of users to provide this flexibility. This is often a trade-off between comfort in the broad sense, not necessarily resulting in discomfort, and some reward such as energy cost savings. Research has shown that users are willing to offer more flexibility to an EMS when the reward is clear and if the flexibility can be easily incorporated in their own schedule [106]. A reward per smart operation of a device is shown to be most effective over the long term. It is therefore important that the EMS is transparent to end-users in both the given reward for a smart operation and the proposed schedule. As electricity usage data contains valuable data about human patterns, the system must keep privacy sensitive data as local as possible. 
In short, the requirements for an EMS can be summarized as follows:

»Support for all commodities in the energy system (multi-commodity),

»Scale to many DERs in the smart grid (scalability),

»Control many different devices (heterogeneity),

» Predictable cluster operation (predictability),

» Respect physical limitations (feasibility),

» Robust against ICT failure (robustness to failure),

» Robust against forecast errors (robustness to errors),

» Transparent operation to end-users (transparency),

» Respect comfort of users (comfort),

"Respect the privacy of end-users (privacy).

\subsubsection{Related Work}

The aforementioned requirements largely align with the requirements that form the basis for the proactive three-step approach presented by Molderink [107], Bakker [8] and Bosman [15]. These three steps are prediction, scheduling and real-time control. Device level predictions are used to identify possible flexibility, which is then used to optimize the power consumption of a cluster. This optimization is done by sending differentiated price incentive vectors (i.e. all device controllers receive different price vectors) for the upcoming time period to the devices. These device controllers optimize their local schedules by minimizing the local costs based on these received price vectors. This approach is also designed with multi-commodity in mind as it is simple to add more price vectors that represent prices for the different commodities within the system. The device controllers then can optimize their schedules according to the applicable commodity price vectors. The main advantage of this scheduling approach is to prevent the control system from exhausting flexibility for short term objectives which result in extreme and expensive violations of long-term objectives.

However, this approach only focusses on the resulting energy profiles at global level and is agnostic to the physical infrastructure. The general assumption here is that an overall global flattened profile leads to a lower load in the network and in general a better power quality and quality of service. However, in [GH:14] and [GH:13] we have demonstrated that this is not always valid. The different price signals lead to an unbalanced load in space, resulting in local overloading of the grid and violations of the legal norms on power quality [113]. Furthermore it is noted that the price signals encourage extreme consumption on household level as device controllers prefer to consume as much as possible in periods of low prices and try to produce as much as possible in periods with high prices. As a consequence, these price steering signals do not provide enough controllability to the system. 
Since predictions are never completely accurate, proactive DEM has to deal with prediction errors. These can be both in the energy domain (e.g. underestimates of the energy production by PV) and the time domain (e.g. late arrival of a BEV). Events in real-time therefore may change the constraints that were considered during the scheduling phase, resulting in invalid device schedules. Hence, proactive DEM requires additional real-time control methods to resolve these prediction errors in order to follow the schedule as good as possible. Proactive DEM methods therefore often employ an online control method such as e.g. a double-sided auction [91] to control devices in real-time. This auction method considers all available assets to re-distribute the scheduled power value for the current or next interval. The objective is often to redistribute flexibility such that the scheduled power value is realized. However, this results in the risk that prediction errors on total energy consumption lead to large peaks when all flexibility is exhausted. Furthermore, the regular auctions do require the ICT system to be available for adequate control. Unlike scheduling based methods, double-sided auctions do not always offer transparent information to the end user. E.g. for a washing machine it is unclear when the washing machine will start, and thus will finish its operation, as this decision to start the device is based on the auction outcomes. Support of multiple commodities within these double-sided auctions is not straightforward [143]. Other approaches $[64,157]$ create a new planning each interval and could thereby incorporate these requirements, at the cost of requiring significant computation power.

\subsubsection{APPROACH}

To fulfil the requirements as stated in Section 4.1, we use a scheduling based approach as the cornerstone for our DEM methodology. The advantage of a scheduling based strategy is that it provides clearness to the users of such a DEM methodology. For example, system operators can use the scheduled electricity profile to plan maintenance, spinning reserve and act on the day-ahead market. On the other hand, prosumers are given more transparency as the system indicates how and when electricity will be used, gaining insight in when certain devices finish their operation. Gerards et al. have shown that scheduling a group of flexible devices within the smart grid context leads to an NP-hard problem [GH:12]. Therefore, a heuristic approach forms a proper choice to deal with scheduling a group of devices.

In the presented approach, a heuristic called profile steering is used to provide an efficient iterative scheduling process. The idea behind this heuristic is that we assume that we exactly know what power profile is desired. Therefore, we can use this desired profile to steer the device controllers directly instead of using indirect steering signals, such as prices. The device controllers then can optimize their flexibility to obtain a profile that is as close as possible to the desired profile, i.e. minimize the distance between the desired profile and the obtained profile, and communicate their profile back. This profile steering approach avoids the adverse effects of uniform prices as described, such as batteries that either charge or discharge at full power. We note that artificial price steering signals can still be used in this method 


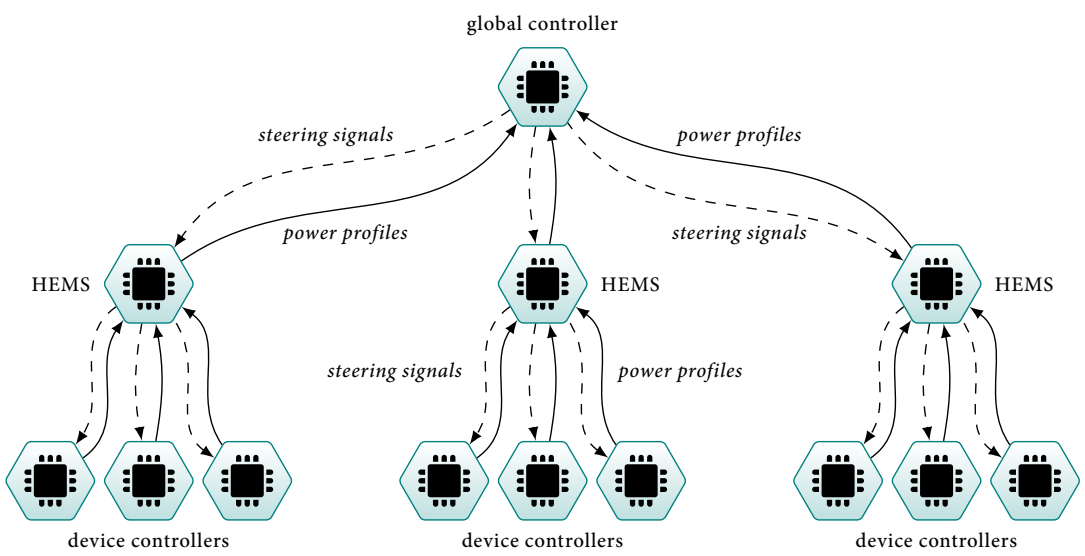

Figure 4.1: Hierarchical structure of controllers communicating steering signals down the tree and communicating resulting profiles upwards.

if desired. Profile steering can be applied in an hierarchical structure (see Figure 4.1) to manage a large heterogeneous cluster of device where parallelism is exploited to create a scalable approach. The same structure can be used to satisfy capacity constraints of the underlying physical infrastructure. Furthermore, multiple desired profiles can be sent to steer the power consumption for multiple commodities. Details on this profile steering heuristic are given in the next section.

Note that the above sketched scheduling approach heavily depends on predictions, such as weather predictions and human behaviour. In practice, such predictions on the device controller level are often unreliable and therefore may cause large problems to follow the schedule. Prediction errors lead to changing constraints, e.g. a BEV that needs to finish its charging earlier than predicted, with as a consequence that the original schedule is not feasible anymore. These errors have to be resolved somehow, but executing a new prediction and performing scheduling for each (small) deviation is too costly in terms of the required computational power. Furthermore, these prediction errors are often dampened and may cancel out over larger clusters of devices by the law of large numbers. Therefore, we utilize the hierarchical structure of profile steering to resolve prediction errors on a level where enough flexibility is available to do so. In this realization phase, profile steering is used to resolve infeasible schedules in an asynchronous and event-driven approach. In this way, device controllers can create a new schedule individually whenever it is necessary or desired to do so. Thereby, the required computational power is limited and spread across the devices, whilst the transparency and long-term objectives are still incorporated. 
Summarizing, our approach consists of two phases, namely a synchronous scheduling phase and an asynchronous realization phase. The first phase is used to create a schedule, considering all devices, for an upcoming horizon of time intervals. The second phase has the task to realize this scheduled power profile as good as possible, whereby the system must resolve prediction errors in a computationally efficient way.

\subsection{Synchronous Scheduling}

The first phase of our approach is a synchronous scheduling phase. It is synchronous in the sense that a schedule is created on a regular basis and considers all devices to optimize the flexibility for some time horizon into the future. Hereby a rolling horizon technique is used, which means that a new synchronous schedule is created already before the considered scheduling horizon of the previous schedule is passed. The resulting schedule and profile could for instance be used to act on markets, to verify that physical grid constraints are met or to plan maintenance. The created schedules are based on predicted power profiles and the flexibility offered by devices.

The challenge here lies in the coordination of a heterogeneous set of devices within a smart grid. As shown in Chapter 3, different classes of flexible devices exist, all with their own set of operation constraints. The set of operation constraints becomes increasingly complex in hybrid energy systems, because of the dependencies between the commodities. We choose to optimize the schedule of devices on the device controller level to avoid excessive communication of constraints to a central controller. This allows us to split the optimization process into smaller sub-problems that can be solved by tailor made optimization algorithms that satisfy the device constraints. A higher level controller is required to coordinate this process such that the set of devices as a whole optimizes towards a global optimum. Therefore, this controller sends steering signals, together with an objective function, to guide the planning process devices. In order to optimize their behaviour according to received signals, devices need to know their future flexibility. Therefore, device controller level predictions based on historical data are used.

To tackle scalability issues concerned with scheduling based DEM approaches, we consider a hierarchical tree of control nodes to exploit parallelism and reduce communication. Each control node within this tree can be connected to at most one parent. The device controllers (either embedded in the device, or as part of a home energy management system (HEMS)) form the leaves of this tree. Each of these controllers creates a schedule independently of the other controllers and sends this scheduled power profile to the following (higher) level node in the hierarchy. With a growing amount of devices, new levels of hierarchy can be introduced to distribute the required computation power over multiple nodes. This results in a layered control system that is not only scalable, but also strengthened against failure of communication as subtrees may operate independently. 


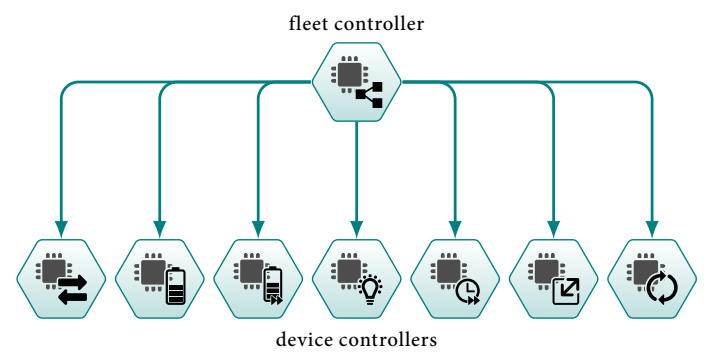

Figure 4.2: One top-level controller controlling multiple device controllers.

\subsubsection{Profile Steering Heuristic}

The basis for the profile steering heuristic consists of an initialization and an iterative optimization process, coordinated by a controller at the root of a control tree. Within the profile steering approach we distinguish two types of controllers: (sub)fleet controllers and device controllers. The fleet controller coordinates the optimization process, such that the overall power profile is optimized towards the system goals. The coordination is done through bi-directional communication between controllers. From the top level, steering signals are send downwards and end up at the devices controllers. The device controllers optimize their power profiles based on received steering signals and local (user) constraints. The resulting candidate power profiles are send upwards again to the higher level control nodes. We first consider a small setup of profile steering with two levels of hierarchy: one fleet controller at the top and some device controllers at the bottom, as depicted in Figure 4.2. From there on we gradually extend the basic approach of profile steering with more levels of hierarchy and multi-commodity support.

The goal of the fleet controller is to make sure that the power schedule of the fleet is optimized towards a predefined system objective, such as peak shaving or cost minimization. As argued, price steering signals with uniform prices often result in adverse behaviour with automated control and sufficient flexibility. Instead, we use a predefined desired profile $\vec{p}=\left[p_{1}, p_{2}, \ldots, p_{N}\right]^{T}$, which explicitly expresses what power profile the cluster of devices should attain for $N$ future time intervals. This means that this desired profile is a vector consisting of the desired power consumption values for a number of discrete time intervals in the future. It is likely that this desired profile cannot be completely attained due to limits of flexibility or differences between total generation and production. This produces a certain mismatch or distance between the desired profile and the resulting power profile $\vec{x}=\left[x_{1}, x_{2}, \ldots, x_{N}\right]^{T}$ after the optimization. This resulting power profile is the scheduled profile that should be realized by the system in the end. The system objective is to minimize the distance between the desired profile and power profile, which is expressed by a vector norm $\left(\|\vec{x}-\vec{p}\|_{*}\right)$, such as e.g. the Manhattan norm $(\|\vec{x}-\vec{p}\|)$. Within the scope of this thesis the Euclidean distance $\left(\|\vec{x}-\vec{p}\|_{2}\right)$ is used, which minimizes the squared deviations, and thus results in a preference to spread 
deviations. Minimizing the Euclidean distance aligns with the physical effects in the distribution grid that are linked to the quadraticly behaving losses with respect to the power consumption.

The profile steering heuristic starts with an initialization, initiated by the fleet controller, which desires to create a new aggregated schedule for the given cluster of devices. The fleet controller first asks each connected device controller $m \in\{1,2, \ldots, M\}$ to create an initial schedule based only on local constraints. Such a schedule may for instance schedule device operations greedy (e.g. run a washing machine as soon as possible), spread the power consumption as much as possible (e.g. spread the charging of a BEV) or optimize user comfort. This results in a power profile $\vec{x}_{m}=\left[x_{m, 1}, x_{m, 2}, \ldots, x_{m, N}\right]^{T}$ for each device controller $m$. The fleet controller receives and aggregates all these individual profiles to obtain the overall power profile $\vec{x}=\sum_{m}^{M} \vec{x}_{m}$. However, consider that the objective (e.g. minimize $\|\vec{x}-\vec{p}\|_{2}$ ) and desired profile $\vec{p}$ are already known. Hence device controllers can directly optimize towards the global objective upon initialization in order to obtain an initial solution that is close to this global objective. In this case the fleet controller communicates both $\vec{p}$ and objective to the connected device controllers.

After the initialization it is likely that individual deviations from the objective, such as peaks, may coincide at the global level. In an iterative process, device controllers are requested to alter their schedules to obtain a better overall profile with respect to the system objective. The mismatch at the fleet controller, called the difference profile, is now given by $\vec{d}=\vec{x}-\vec{p}$. This difference profile is communicated to all devices, which use this profile to calculate a new local desired profile $\vec{p}_{m}=$ $\vec{x}_{m}-\vec{d}$. The device controllers try to improve their performance by constructing a new feasible candidate power profile $\overrightarrow{\hat{x}}_{m}$ that minimizes $\left\|\overrightarrow{\hat{x}}_{m}-\vec{p}_{m}\right\|_{2}$. Each device controller calculates the improvement $e_{m}$ that is achieved by replacing the current power profile $\vec{x}_{m}$ by $\overrightarrow{\hat{x}}_{m}$ : e.g. $e_{m}=\left\|\vec{x}_{m}-\vec{p}_{m}\right\|_{2}-\left\|\overrightarrow{\hat{x}}_{m}-\vec{p}_{m}\right\|_{2}$, and communicates the obtained improvement $e_{m}$ back to the fleet controller.

The fleet controller collects all individual improvements and selects the device controller $m$ with the largest (positive) improvement $e_{m}$. This device controller is requested to replace its scheduled power profile by the candidate power and communicate how this changes its profile. The device controller responds with the difference profile $\vec{d}_{m}=\overrightarrow{\hat{x}}_{m}-\vec{x}_{m}$ and updates its own power profile $\vec{x}_{m}:=\overrightarrow{\hat{x}}_{m}$. The fleet controller uses the received difference profile to update its own power profile: $\vec{x}:=\vec{x}+\vec{d}_{m}$. This operation improves the total profile, i.e. it improves the objective value. This also results in a new difference profile $\vec{d}$ at the fleet controller. Another device may have a significant improvement based on this new difference profile. Hence we repeat this process iteratively until none of the candidate profiles result in significant improvements or a predefined maximum number of iterations $k_{\max }$ have been exhausted. Note that only one device controller is selected per iteration to prevent possible oscillation and overshoot problems. An example of this process is shown in Figures 4.3 and 4.4. The details of the algorithm are presented in Algorithm 2. 

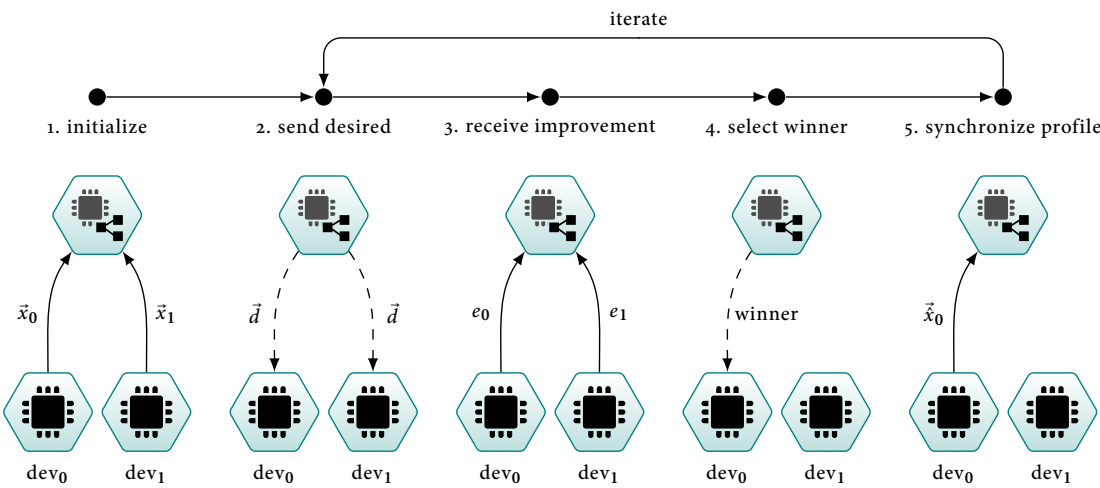

Figure 4.3: Schematic overview of the profile steering algorithm.

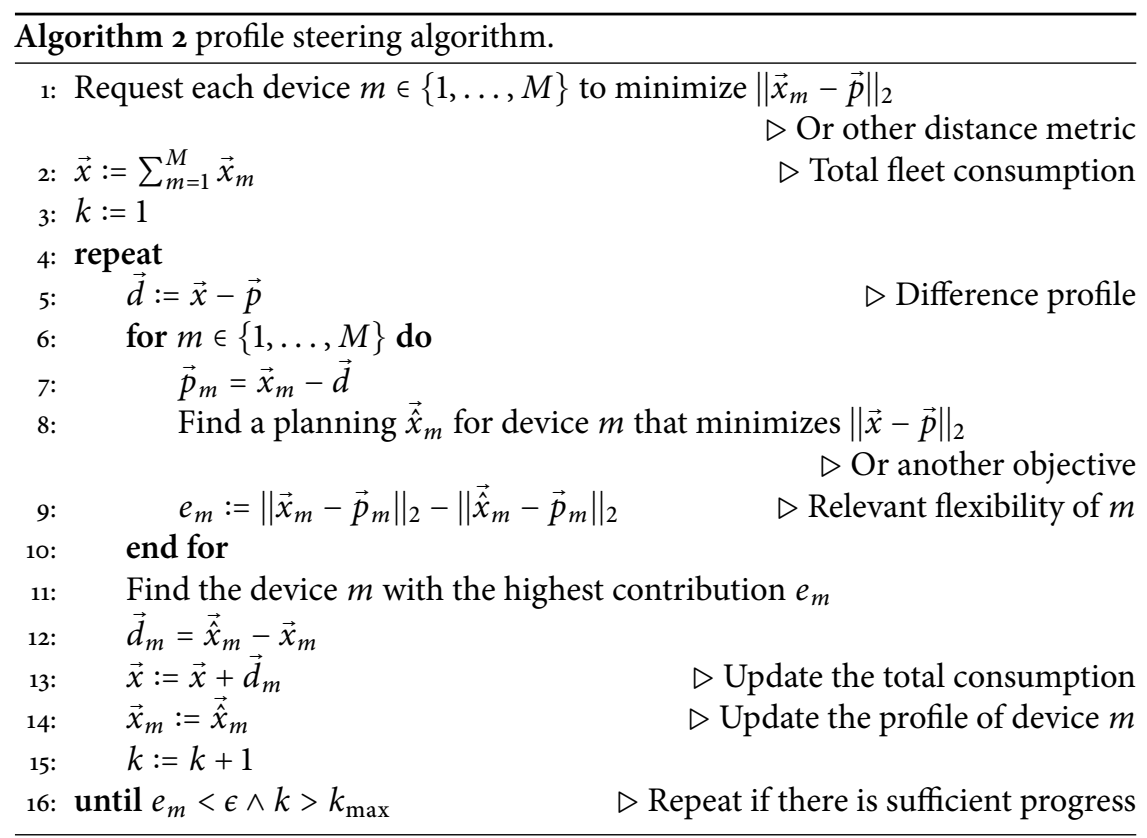

In this approach, the optimization algorithms are implemented at the leaf nodes of the control model. As a result, the optimization process benefits from the inherent parallelism as all device controllers receive the same steering signals simultaneously. This implies that the approach in principle is scalable. At the same time, the approach also solves the privacy issue partly as flexibility information is kept local and complete profiles are only communicated during the initialization. Note that further privacy measures, such as adding obfuscation, are advised. 


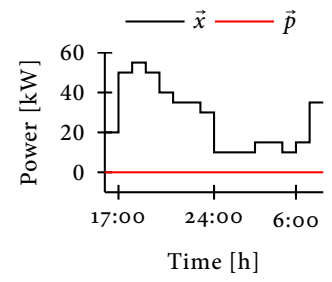

(a) Fleet controller

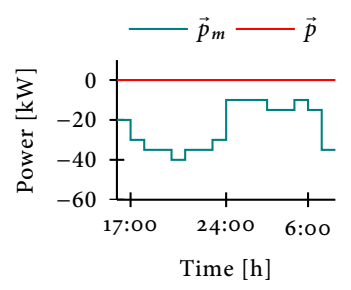

(d) BEV desired

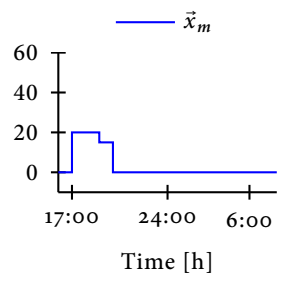

(b) BEV profile

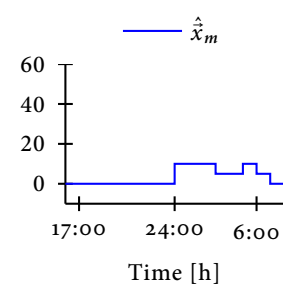

(e) BEV candidate

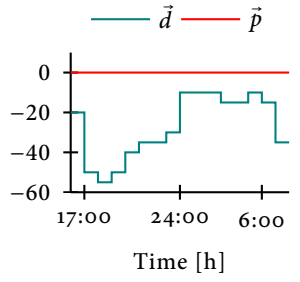

(c) Incentive to BEV

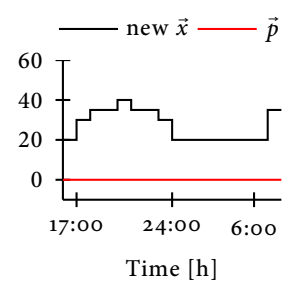

(f) Fleet controller

Figure 4.4: Example of profile steering with a BEV arriving at 17:00 that has a charging deadline at 7:0o the next day and energy demand of $55 \mathrm{kWh}$. The original state of the fleet controller is depicted in (a) and for the BEV in (b). The fleet controller sends out an incentive (c), for which the BEV produces its own desired profile (d). The resulting (and winning) candidate profile from the BEV is shown in (e), which results in an updated profile at the fleet controller (f).

\subsubsection{Hierarchy}

Characteristic to the profile steering approach is the coordination through bi- directional communication between the fleet controller and the device controllers. The steering signals are used by the fleet controller to guide the devices. The device controllers in turn respond with the resulting profiles or the achieved improvement, but other details about the devices do not need to be communicated. The fleet controller does not need to know how these profiles are obtained, it only needs to receive the information required to construct an aggregated power profile for its fleet. Hence, the communication and fleet controller are agnostic to the lower level controller implementation. This makes the system flexible to integrate a heterogeneous cluster of devices.

Since the fleet controller is agnostic about its child controllers, one or all of the children may as well be a fleet controller that implements the profile steering algorithm for its children. As a fleet controller depends on the device controllers to create a schedule, the newly added fleet controller also adds a new level within the hierarchical structure, with the root fleet controller as parent and one or multiple device controllers as its children. Hence we speak of a subfleet controller as it controls 
a part of the fleet of devices. Compared to the fleet controller, the subfleet controller is required to accept and forward steering signals from its parent towards its children. Likewise, it needs to communicate back the resulting cumulative power profile of its children to its parent.

\subsubsection{Profile BookKeEPing}

Since a subfleet controller also implements the profile steering algorithm, it may run multiple iterations before it sends a result to its parent controller. Especially during the initialization it may be useful to use the subfleet controllers to directly optimize small clusters of devices, such as each household, according to their flexibility. This approach may significantly reduce the number of iterations in the iterative process as shown in simulations [GH:12]. Also during the iterative process, the subfleet controller may choose to execute multiple iterations before submitting the resulting power profile to its parent. However, this also means that the subfleet controller must select device controllers that commit their updated power profiles. This introduces a problem when the subfleet controller itself is not selected by its parent controller. In such a case, the aggregated profiles of the children of a subfleet controller differs from the profile known at the subfleet controller itself.

Therefore, additional bookkeeping is introduced that allows control nodes to revert their power profile according to the outcome of higher level (sub)fleet controllers. Instead of only one stored candidate power profile, each node now has as much candidate power profiles as there exist levels above this node in the control hierarchy. Consider an example with 3 levels. As result let $H_{m}$ express the hierarchy level of a node $m$. Then, for the example, each device controller has $H_{m}=2$, subfleet controllers have $H_{m}=1$ and the root fleet controller has $H_{m}=0$ (see Figure 4.5). Now, let $\overrightarrow{\hat{x}}_{m, h}$ be the candidate profile of node $m$ committed at the request of the controller on level $h \in\left\{0,1, \ldots, H_{m}\right\}$. After initialization, all these candidate power profiles are filled with the same initial scheduled profile $\vec{x}_{m}$. During the iterative phase each device controller $m$ constructs a candidate profile, which will now be stored in $\overrightarrow{\hat{x}}_{m, 2}$. Now, in case device controller $m$ is selected to commit the candidate profile by its parent subfleet controller of level $H=1$, it will copy the candidate profile to a higher level (i.e. a lower index), $\overrightarrow{\hat{x}}_{m, 1}:=\overrightarrow{\hat{x}}_{m, 2}$. Likewise, the subfleet controller will update its own candidate profile. Now, if the fleet controller selects the whole subfleet to commit its profile, all nodes in the subtree will update their settled power profile, $\vec{x}_{m, 0}:=\overrightarrow{\hat{x}}_{m, 1}$. If the candidate power profile of a subfleet is not selected, the whole subfleet has to revert the candidate power profiles to keep the profiles at each level synchronized. If the fleet controller selects another branch, the unselected branches revert their candidates the other way around: $\overrightarrow{\hat{x}}_{m, 1}:=\overrightarrow{\hat{x}}_{m, 0}$ and additionally for the device controllers $\overrightarrow{\hat{x}}_{m, 2}:=\overrightarrow{\hat{x}}_{m, 0}$.

This approach can be generalized for any number of levels in the hierarchy. Upon the selection of a candidate by a control node of a hierarchical level $h$, all underlying child nodes in a subtree (with $H_{m}>h$ ) perform the copy process $\overrightarrow{\hat{x}}_{m, h}:=\overrightarrow{\hat{x}}_{m, h+1}$. Upon a revert request, the opposite copy is performed for all lower levels control 


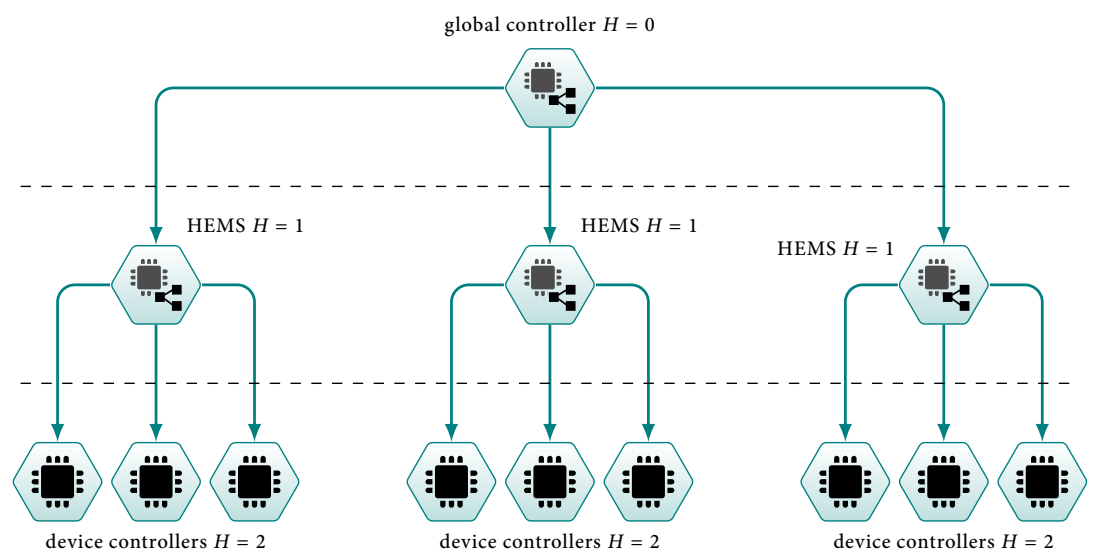

Figure 4.5: Overview of the hierarchical structure with the different levels of device, subfleet and fleet controllers.

nodes in a subtree $\overrightarrow{\hat{x}}_{m, h_{*}}:=\overrightarrow{\hat{x}}_{m, h}$ for all $h_{*} \in\left\{h, \ldots, H_{m}\right\}$. Hence, for any controller steering signal the level $h_{m}$ of the initiating controller has to be communicated downwards and may not be altered by intermediate nodes. Furthermore, notice that only the highest level of control (i.e. $H_{m}=0$ ) controls the fleet and thus has the final control over which profiles are accepted to compose the final scheduled profile.

Note, that the introduced hierarchy can be used to partition the scheduling problem, resulting in a scalable approach. As all subfleet controllers implement the profile steering algorithm, each subfleet controller can optimize its subtree without the need of a higher level controller. This is a useful property as it allows segments of the system to continue operation if the communication fails, making it robust against failure of a single node. It also partially provides a solution to the privacy issue as profiles are aggregated on each level, hiding the information of lower level control nodes. This aggregation is comparable to the information that can be obtained through measurement equipment within the network, e.g. at the transformer. In addition, complete profiles only need to be communicated once, as after the initial phase only the differences have to be communicated. On the other hand, devices controllers optimize their potential and only communicate the resulting profile, keeping optimization specific constraints local.

Partitioning the problem into multiple subtrees may be done on basis of a maximum number of controllable nodes per subfleet. However, the hierarchical tree structure matches the radially operated structure of the majority of physical low voltage $(L V)$ distribution grids in the Netherlands. Hence, there exists a natural mapping from distribution grid infrastructure to control structure, shown in Figure 4.6. In a bottom-up approach, device controllers that are associated to devices within a household may be assigned to a specific subfleet controller for the house, often 


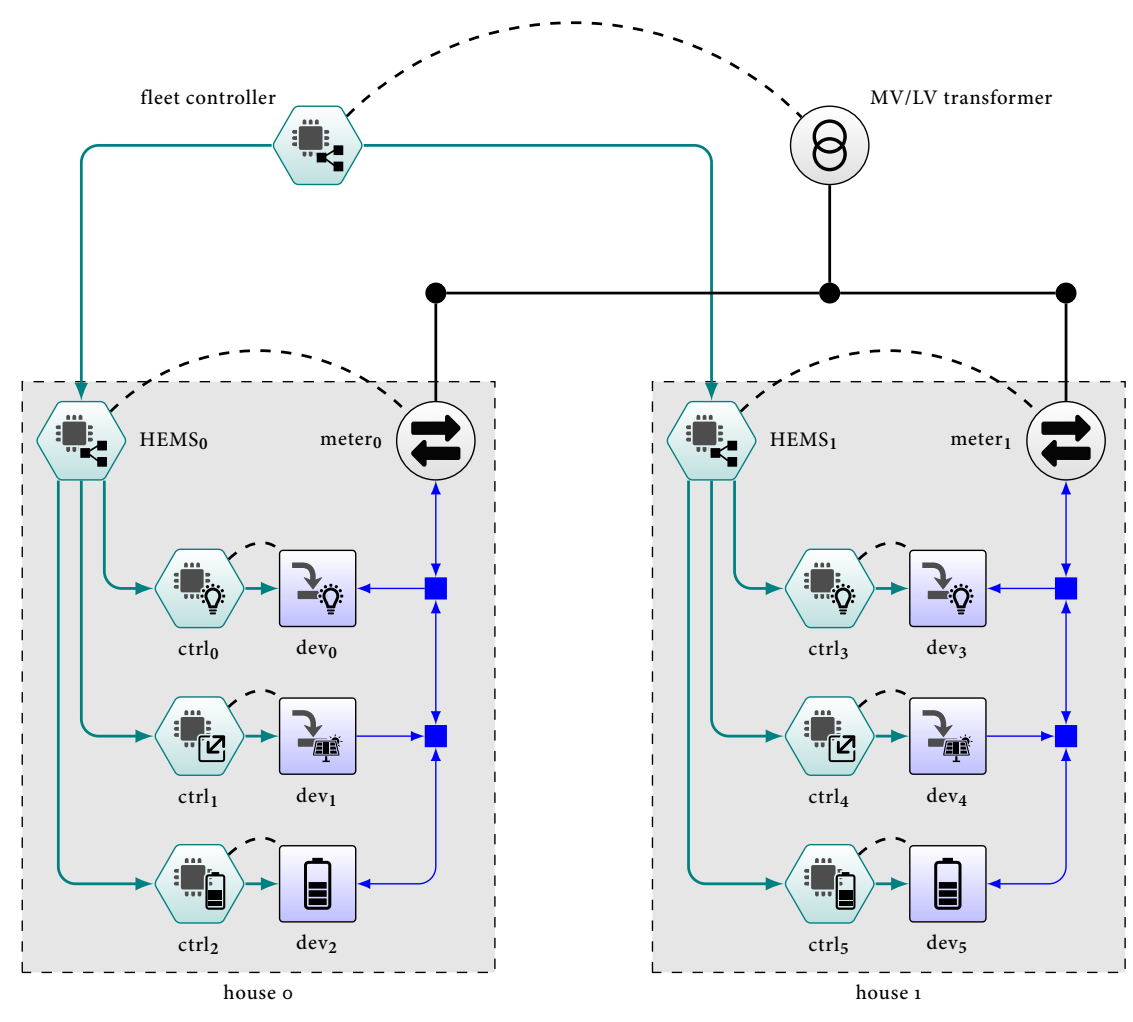

Figure 4.6: Alignment of the hierarchical tree structure of the profile steering approach with the radial structure of the distribution grid.

referred to as HEMS. Then, within a street, houses often share the same feeder or branch such that the HEMS of these households can be grouped together in a higher level subfleet controller. Finally, the controllers associated to each feeder can connect to the fleet controller at MV/LV level. Higher levels, such as the medium voltage $(M V)$ grid can be incorporated in a similar fashion. Such a partition is not only limited to Dutch LV and MV grids, but also across Europe and other continents that use radially operated distribution networks. For example, in a United States (US) grid households can be grouped by pad-mount or pole-mount transformers. Then, all controllers associated to these transformers on one single-phase feeder can be grouped by a higher level controller.

\subsubsection{Local Power Limits}

With the established mapping between control and physical infrastructure, the control system can also take local capacity limitations into account during the optimization. Such limits are for example the connection capacity of a household 
(e.g. a single phase 40 A connection) or fuses installed at the secondary side of a transformer to ensure a safe and rapid disconnection upon short-circuit faults for instance. Such limitations are commonly referred to as congestion points. By adding these local limitations as a constraint to the scheduling problem, a schedule that fits within these grid limitations can be obtained. Note that these limits are, in contrast to the power profiles used in our approach, often based on a maximum current (in either direction). Since currents depend on the resulting voltage we have a non-linear relation and hence the currents can only be obtained using loadflow simulations. Therefore, it is hard to efficiently incorporate these current limits. Instead, the limits may be transformed into power limits by assuming a constant voltage, e.g. the nominal voltage. Slightly stricter limits may be used to provide headroom to deal with inaccuracies on this end, as well as unincorporated distribution losses. Furthermore, load-flow simulations may be executed to check whether a schedule will indeed stay within the physical bounds.

The physical limitations can be expressed as constraints to the scheduling problem. Let $\vec{b}^{\text {min }}$ and $\vec{b}^{\text {max }}$ be vectors that indicate the lower and upper limit for power flow in each discrete time interval at a (sub)fleet controller. The scheduled (aggregated) power consumption $\vec{x}$ at this (sub)fleet controller must satisfy these limits, i.e. we have $\vec{b}^{\text {min }} \leq \vec{x} \leq \vec{b}^{\text {max }}$. Therefore, we need to adapt the profile steering algorithm to satisfy these limitations.

Initially no schedules are known and thus it is not possible to check feasibility. However, it is important to create already in the initial phase of the profile steering algorithm a feasible schedule. Therefore, we let each device controller create an initial schedule and then perform a feasibility check. The algorithm can continue to the iterative process as described if the initial schedule is indeed feasible. In case of an infeasible initial schedule (i.e. it violates the limits) we first need to perform another, intermediate, iterative process to obtain a feasible schedule. For this, the profile steering algorithm can be applied with a different objective that aims to create a schedule that maximizes the distance to both bounds, e.g.

$$
\min \left\|\vec{x}-\left(\frac{\vec{b}^{\min }+\vec{b}^{\max }}{2}\right)\right\|_{2} .
$$

Within the normal iterative process of the profile steering algorithm we now also need to consider the limitations to ensure that a feasible schedule is not replaced by an infeasible schedule. In this phase, the (sub)fleet controller knows the aggregated power profile $\vec{x}$ of all its children. We have to ensure that this child does not change its schedule more than the difference of the current aggregated profile and the given bounds. For this, the (sub)fleet controller communicates the difference between the bounds and the current aggregated schedule to a child, i.e. $\overrightarrow{\hat{b}}^{\text {min }}=\vec{b}^{\text {min }}-\vec{x}$ and $\overrightarrow{\hat{b}}^{\max }=\vec{b}^{\max }-\vec{x}$. A child $m$ now can add its own power profile to these received bounds, to obtain the local limits $\overrightarrow{\hat{b}}_{m}^{\text {min }}$ and $\overrightarrow{\hat{b}}_{m}^{\text {max }}$ that a new candidate power profile must satisfy: 


$$
\begin{aligned}
& \overrightarrow{\hat{b}}_{m}^{\min }=\overrightarrow{\hat{b}}^{\min }+\vec{x}_{m}, \\
& \overrightarrow{\hat{b}}_{m}^{\max }=\overrightarrow{\hat{b}}^{\max }+\vec{x}_{m} .
\end{aligned}
$$

A child in this context may also be another subfleet controller with associated power limits that need to be taken into account. As the power profiles must satisfy both local and higher level limits, the stricter limits have to be used within the algorithm. The details of the algorithm are presented in Algorithm 3.

\subsubsection{Multi-Commodity}

The presented profile steering approach only works with a single vector that expresses power profiles, which can be viewed as a single commodity. However, often there are multiple energy commodities that can be considered, such as electricity, heat and gas. Within alternating current $(A C)$ electricity grids the power consists of an active power component and a reactive power component. Another example of multi-commodity usage within the electricity grid is the three-phase system, for which a balance is desired to minimize losses and improve power quality as discussed in Chapter 3. In this case, the commodities represent different channels instead of different energy carriers. Note, that incorporating reactive power in the presented approach is straightforward with the use of complex numbers. As the 2-norm is also defined for complex numbers, all real values in the algorithm can be replaced by complex numbers. For the three phase system this is not as straightforward as it consists of three separate energy streams that need to be controlled. In the following we discuss how the presented approach can be adapted to incorporate support for multiple commodities.

The profile steering approach can be extended with multi-commodity support by communicating multiple profiles simultaneously, where each profile represents a commodity. In case of the three phase systems one can define three commodities that represent these phases. This approach is not limited to electricity, heat and natural gas can also be added for example. To keep the algorithm generic, we denote the number of commodities with $C$ and the set of commodities with $\mathcal{C}=$ $\left\{c_{1}, \ldots, c_{C}\right\}$. Any profile vector for an individual commodity $c \in \mathcal{C}$ is now indicated by a superscript, e.g. $\vec{x}^{c}=\left[x_{1}^{c}, x_{2}^{c}, \ldots, x_{N}^{c}\right]^{T}$ and $\vec{x}_{m}^{c}=\left[x_{m, 1}^{c}, x_{m, 2}^{c}, \ldots, x_{m, N}^{c}\right]^{T}$. In essence, this means that the original profile vectors are replaced by profile matrices. Hence, for sake of clarity, the previously defined notation for the profiles is changed into capitals, e.g. $\vec{x}$ becomes $\vec{X}$ and $\vec{x}_{m}$ becomes $\vec{X}_{m}$. Herein, the rows represent the time intervals and the columns represent commodities, e.g.

$$
\vec{X}=\left[\begin{array}{cccc}
x_{1}^{c_{1}} & x_{1}^{c_{2}} & \ldots & x_{1}^{c_{C}} \\
x_{2}^{c_{1}} & x_{2}^{c_{2}} & \ldots & x_{2}^{c_{C}} \\
\vdots & \vdots & \ddots & \vdots \\
x_{N}^{c_{1}} & x_{N}^{c_{2}} & \ldots & x_{N}^{c_{C}}
\end{array}\right], \vec{X}_{m}=\left[\begin{array}{cccc}
x_{m, 1}^{c_{1}} & x_{m, 1}^{c_{2}} & \ldots & x_{m, 1}^{c_{C}} \\
x_{m, 2}^{c_{1}} & x_{m, 2}^{c_{2}} & \ldots & x_{m, 2}^{c_{C}} \\
\vdots & \vdots & \ddots & \vdots \\
x_{m, N}^{c_{1}} & x_{m, N}^{c_{2}} & \ldots & x_{m, N}^{c_{C}}
\end{array}\right] .
$$




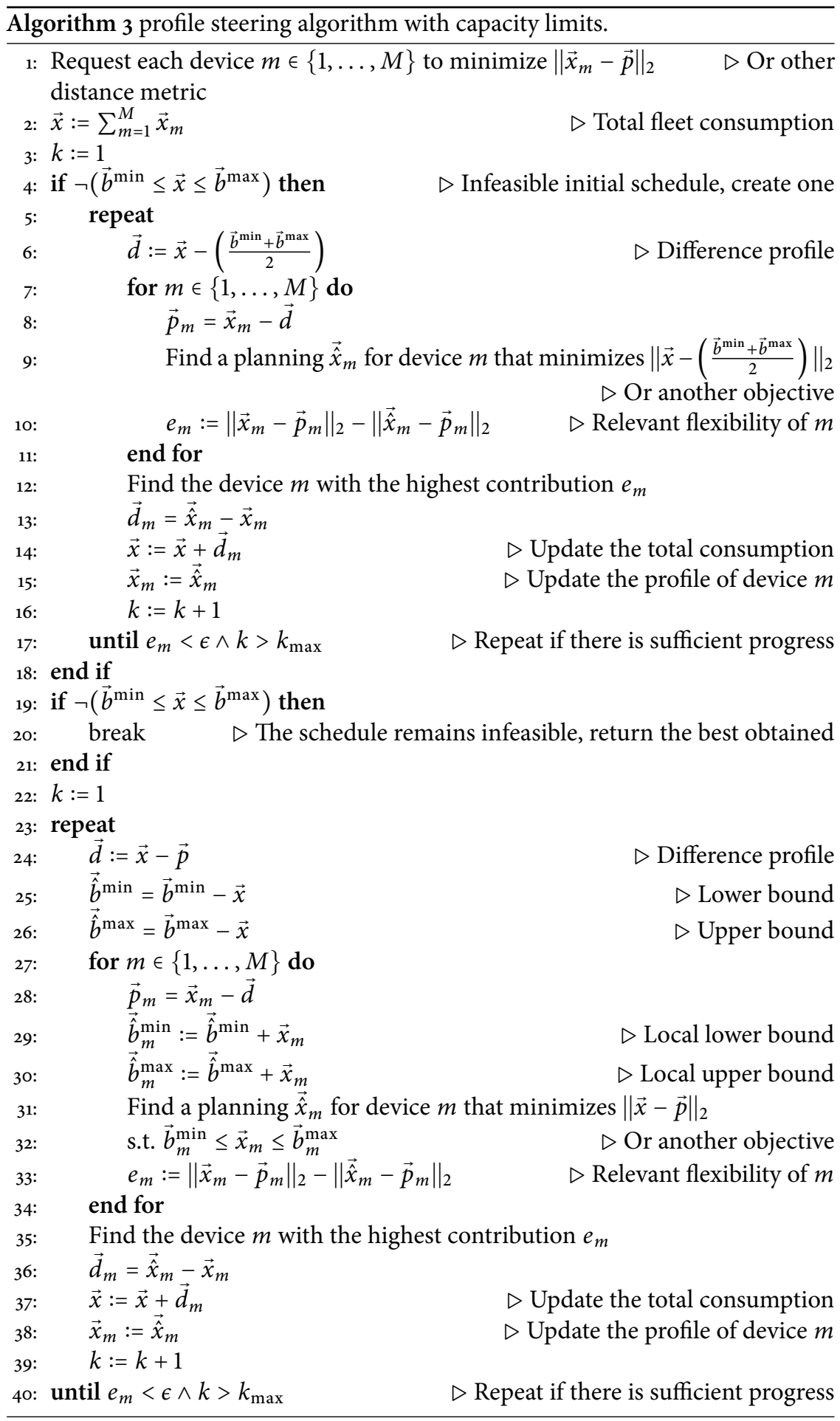


Instead of minimizing the distance between a power profile vector and the desired profile vector, we now need to do this over all commodities $c \in \mathcal{C}$. Hereby, in certain scenarios, the final profile of one commodity may be more important than the profile of other commodities. Therefore, we introduce weights $W=\left\{w_{1}, \ldots, w_{C}\right\}$, where $w_{i}$ expresses the preference of the $i^{\text {th }}$ commodity. This can be combined into a vector norm (see Subsection 4.2.1) leading to the following objective when using the Euclidean norm:

$$
\min \sum_{c=1}^{C} w_{c} \cdot\left\|\vec{x}^{c}-\vec{p}^{c}\right\|_{2} .
$$

We note that also other optimization objectives are possible for multiple commodities. In particular, an ordering may be made to first optimize towards a certain objective, such as to minimize total electricity import and export, and then use the remaining flexibility for secondary orthogonal objectives. Such a secondary objective may be to balance the three phase AC electricity system, or balance reactive power.

Except for the switch from vectors to matrices, nothing significantly changes for the fleet controller. This is due to the fact that the fleet controller only coordinates and does the overall bookkeeping of the profiles, whereas the device controllers perform the actual optimization. It is likely that each device can only consume/produce energy for a subset of the commodities, hence other commodities can be neglected by the device controller $m$, i.e. the $\operatorname{set} \mathcal{C}_{m}$ of relevant commodities is only a subset of $\mathcal{C}$.

Originally, the improvement $e_{m}$ by device controller $m$ was given by the amount it can reduce the distance to the objective when offering the load profile $\vec{x}_{m}$ instead of $\overrightarrow{\hat{x}}_{m}$. In the multi-commodity case, we decompose the overall improvement into multiple improvements $e_{m}^{c}$ for each commodity $c \in \mathcal{C}$, resulting in:

$$
e_{m}=\sum_{c=1}^{C} e_{m}^{c}=\sum_{c=1}^{C} w_{c} \cdot\left(\left\|\vec{x}_{m}^{c}-\vec{p}_{m}^{c}\right\|_{2}-\left\|\overrightarrow{\hat{x}}_{m}^{c}-\vec{p}_{m}^{c}\right\|_{2}\right)
$$

The fleet controller now selects the device controller with the largest overall improvement $e_{m}=\sum_{c=1}^{C} e_{m}^{c}$. To reduce the data communication, the selected device controller $m$ should communicate only the candidate profiles of the commodities in $\mathcal{C}_{m}$. The details of the algorithm are presented in Algorithm 4. Note that this algorithm reduces to the algorithm presented in Subsection 4.2.1 when $C=1$ and $W=\{1\}$ are used. The previously presented capacity limits can be incorporated into the multi-commodity profile steering algorithm by defining and applying capacity constraints for each commodity in the algorithm.

Since the device controllers determine and communicate the optimal profile themselves, they can directly incorporate local constraints on the dependencies between commodities. Hence, there is no need to communicate these dependencies. This 


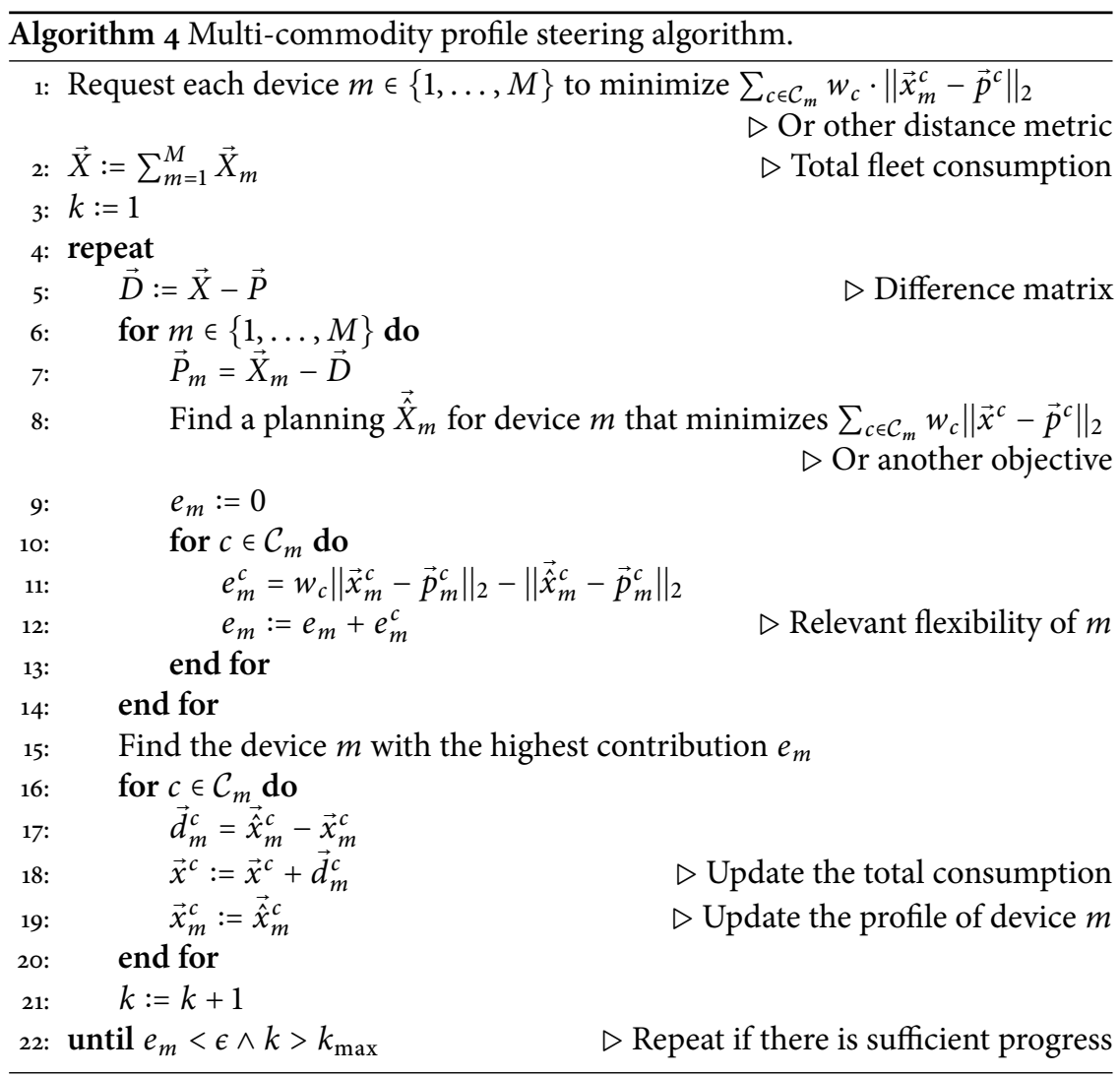

results in a optimization heuristic that scales linearly with the number of commodities. So for $C$ commodities, we have at most $C$ times as much data to be communicated per iteration.

\subsubsection{Device Level Scheduling}

Eventually the steering signals end up at the leaves of the control structure. These leaves represent the device controllers that actually obtain the power profiles. A specific device controller is defined for each device presented in Chapter 3 (see Figure 4.7). Some of these devices are static, uncontrollable, loads as mentioned in Chapter 3 and offer no flexibility. Hence for these devices only a predicted power demand can be communicated. The other devices, such as buffers and timeshiftables, have some flexibility in their power usage or time of power usage that allows for power usage shifting or reduction. Based on the received steering signals, a device controller can optimize the potential of such devices within the scheduling horizon. Again, the system must anticipate on future events and thus predictions on future energy usage of these devices are also required. In addition, some devices, such as 

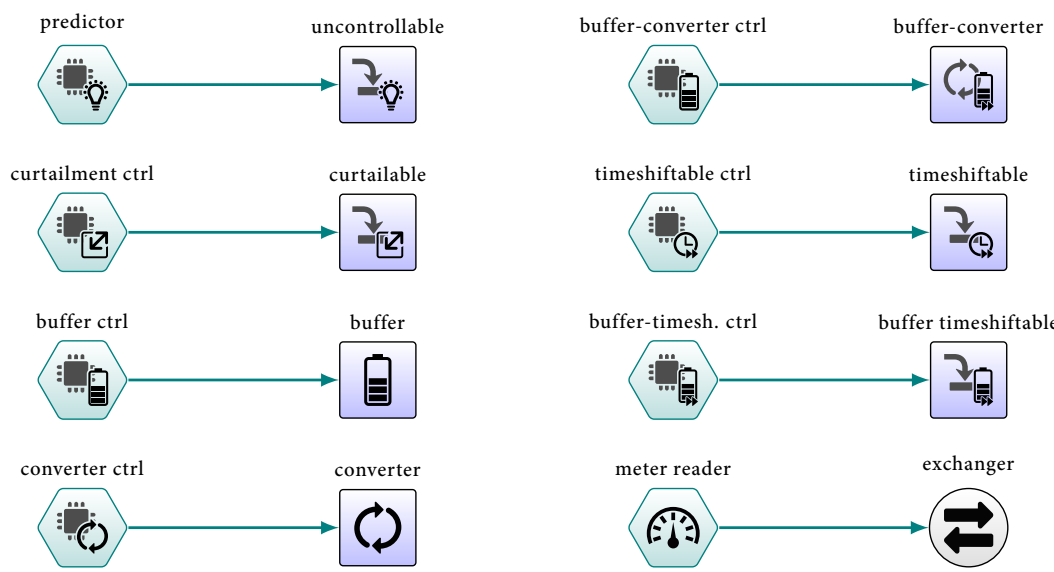

Figure 4.7: The different devices and their respective device controller.

a $\mathrm{BEV}$, are not continuously available, which results in additional constraints that reduce the flexibility. Thus predictions also need to incorporate constraints such as arrival and departure times.

To obtain the power profiles of flexible devices in response to given steering signals, optimization algorithms are required that schedule devices while respecting user and device specific constraints. In case of a timeshiftable device, such as a washing machine, this results in an arrival time and deadline as device runtime constraints. Furthermore, the washing program is assumed to be known, such that the total runtime is known and a latest starting time can be derived. This results in a finite, and generally small, number of feasible starting times since discrete time intervals are used within the optimization. All possible options can be explored to determine the optimal starting time. Other devices, such as buffer devices or those inheriting from the buffer class, are more difficult to schedule. These devices can often freely choose their power consumption and total energy consumption or production, resulting in an infinite number of feasible schedules. Efficient algorithms to optimize power profiles for some of these devices using profile steering are presented by van der Klauw [148]. He provides a linear algorithm for BEV scheduling and a quadratic algorithm for buffer scheduling with respect to the number of intervals considered.

Flexible devices that are used irregularly, such as electric vehicles, may result in large prediction errors if an approach is taken where the predicted availability is binary, meaning that the start and end times of the availability is predicted. Some form of stochasticity should be incorporated in the used availability interval. As one possible realization we use a weighted averages approach based on the flexibility of the previous 4 same days of the week. The scheduling problem of timeshiftable is then split up in four scheduling problems that use each a fraction of the device capabilities. The resulting schedules are combined to obtain one lumped scheduled power profile for a device. So, e.g. for a BEV we schedule a half BEV using the 
flexibility of previous week, a quarter of 2 weeks ago and two times an eighth of the flexibility of 3 and 4 weeks ago. The half BEV is then scheduled using the algorithm by van der Klauw [150], but with only half the energy demand, half the charging power and half the battery capacity and state of charge $(\mathrm{SoC})$ with respect to the

BEV model. Similar rescaling is used for the other parts. Finally, the resulting profiles of all these partial devices are aggregated to get an estimate on the total electricity consumption and how the flexibility might be used.

\subsection{AsynCHRONOUS REALIZATION}

The presented proactive profile steering approach for control in smart grids heavily depends on predictions of energy usage and available flexibility. In essence this means that quite often human behaviour has to be predicted as predictions are created at the device controller level. However, predicting behaviour of a single device is generally hard due to irregular activities, resulting in non repetitive behaviour. This does not only affect the moment that a flexible device becomes available, such as the arrival of a BEV, but also the total energy demand. In addition, weather prediction inaccuracies may also result in large prediction errors on total local electricity generation. Thus, the presented control mechanism must be extended to make it robust to deal with prediction errors in both the time and the energy domain.

The second phase of the methodology is concerned with realizing the scheduled power consumption of a fleet and resolving prediction errors while respecting local constraints. The chosen objective for this realization is to follow the original scheduled power consumption as close as possible as this may be the schedule that is traded on energy markets. We call this realization of the scheduled power profile operational control, for which we use the profile steering concepts. However, due to the complexity of the scheduling problem, a complete rescheduling operation for the whole fleet of devices for each time interval or for each observed disturbance (e.g. deviations from the schedule) is too costly in terms of the required computational time. Furthermore, such a solution is not scalable and may result in a situation where the system cannot provide a solution in time.

We use an asynchronous approach where only a subset of the fleet is scheduled or rescheduled at a time to resolve deviations. This in contrast to the scheduling phase where all devices are scheduled at synchronized moments in time. The basic idea of the approach is to deal with prediction errors by scheduling a device when there is enough confidence that constraints and parameters will not (significantly) change anymore. A schedule is reliable when constraints, e.g. a deadline for a washing machine, and parameters, e.g. the requested charge of a BEV, are unlikely to change. For example, a reliable schedule for a BEV can be created upon the event of arrival. From that moment on, the start time, end time and requested charge of the device, are known and unlikely to change. Therefore, the synchronized scheduling phase is used to estimate what profile may be attained. 
The sketched concept results in a partial scheduling problem in which only a small subset of device controllers is used and hence it leads to lower computational time. Such partial scheduling can be done upon an event, such as the arrival of a BEV. Likewise, device controllers may also commit updates on their predictions, such that more recent and often more accurate predictions can be used to schedule flexible devices that trigger an event afterwards. This results in an ever evolving system with up-to-date information where each event provides a possibility to react to the latest information. Since the approach uses scheduling and predictions, it can be seen as model predictive control (MPC) and by design pursuits both short-term and long-term objectives, thereby avoiding extreme behaviour. It also reduces the risks involved with failing communication systems as devices controllers store an accurate schedule for hours into the future that can be followed. The following subsections discuss the considered types of events and how these can be handled using profile steering while satisfying user comfort and transparency concerns.

This section covers the basic event-driven profile steering approach, but the presented extensions to support hierarchy, power limits and multiple commodities can also be applied to this approach to extend the capabilities.

\subsubsection{EvENTS}

Without events, there would be no partial (re)scheduling and hence there are no means to solve prediction errors. Thus, the asynchronous scheduling based approach for operational control depends on events to come in regularly. One important aspect is that one single device often has not enough flexibility to resolve all mismatches. However, since device controllers can react after each other in arbitrary order, gaps left by the previous events can be filled by other devices. This results in an evolving system where deviations from the schedule may appear and subsequently be resolved by other devices. The amount of events, and accompanying flexibility, determines the ability of the control system to resolve prediction errors. Hence, a trade-off must be made between the frequency of events and processing power, based on the system objectives. These events can be triggered by both (sub)fleet controllers and device controllers. In the following we specify the different types of events and roles we use for our approach.

The objective of (sub)fleet controllers is to maintain a given target profile and control a fleet of device controllers to achieve this. This implies that each (sub)fleet controller has enough flexibility in its subtree to make sure that it is able to sufficiently cancel out prediction errors. As a result, in most cases the HEMS can therefore not act as a (sub)fleet controller under normal (e.g. non islanding) conditions as depicted in Figure 4.8. Within the operational control phase, it is the task of the (sub)fleet controllers to manage that the scheduled profile is realized by the device controllers that signal events.

Two new vectors are introduced to account for these deviations. The original settled power profile $\vec{x}$ after the synchronous scheduling phase is copied into a new scheduled profile $\vec{q}:=\vec{x}$. Furthermore, the (sub)fleet controller needs to keep track 


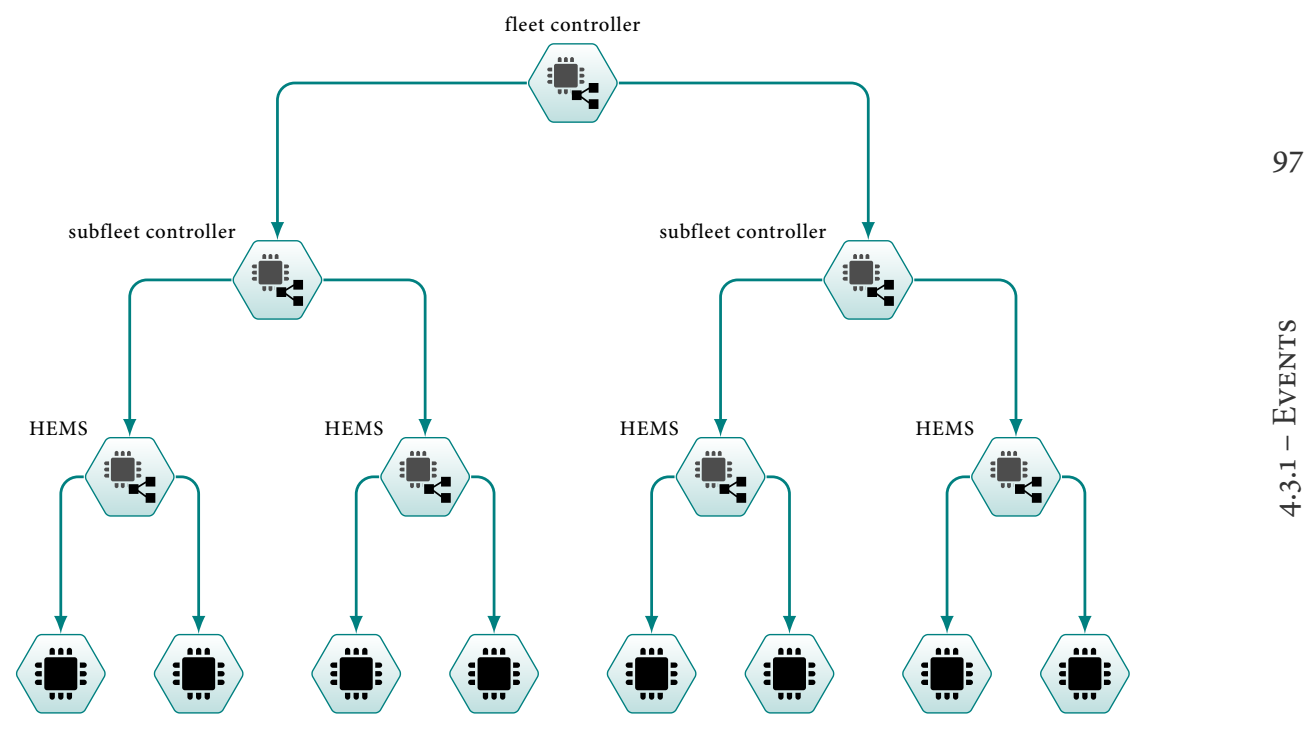

Figure 4.8: Hierarchical profile steering approach with event-based scheduling. Note that only higher level controllers to act as (sub)fleet controller.

of the already fixed and reliable schedule, which is expressed by the committed profile $\vec{r}=\left[r_{0}, r_{1}, \ldots, r_{N}\right]^{T}$. In case too large deviations occur between $\vec{q}$ and $\vec{r}$, the (sub)fleet controller can initiate a partial rescheduling round to redistribute the flexibility better in time and space to resolve potential issues. This rescheduling can be triggered when either the past observations or future trends show a significant deviation from $\vec{q}$.

There are two important device control types to distinguish. The first class of devices is based on user interaction, such as a BEV or white goods. These devices require manual operation by the end-user, before the device starts and to specify when the device has to be finished. As an example, consider a washing machine where the user needs to manually fill the device and empty the device again after it is finished to avoid that the wet wash is kept too long in the device. This requires the end-user to be available at those two moments in time. This is only possible if the user knows when the device will finish its operation. Control over such a device may therefore heavily intervene with the agenda of the end-user. As a result, rescheduling of these devices should only be considered if the end-user agrees to do so. Furthermore, the manual operation of making the device available to the control system results in a high risk for prediction errors as it means that the device synchronizes with human behaviour. Therefore, after the synchronous scheduling phase the committed profile for such a device controller $m$ is defined as $\vec{r}_{m}=[0,0, \ldots, 0]^{T}$, i.e. its schedule is considered as unreliable. 
Devices that are always connected to the grid are considered to be always available to the control system. Devices such as batteries, heating with a heat buffer or curtailable solar panels belong to this category. Unlike the manually operated devices, these devices have less to no impact on the comfort of end-users and depend less on human behaviour. Therefore, the schedules created during the scheduling phase are considered reliable and hence we use the scheduled power profile for such a device controller $m$ as committed profile, i.e. $\vec{r}_{m}:=\vec{x}_{m}$. Furthermore, as rescheduling of such devices does not intervene with user comfort such that these devices may be used for partial rescheduling. However, to ensure that the dynamics of the system are preserved, events have to be triggered regularly to keep these device controller schedules up to date. The simplest form is a regularly occurring update based on a timer. However, more significant events may be added such as thermostat setpoint changes or when a certain SoC is reached. The system may also deal with mismatches between the device model and the physical behaviour by rescheduling (through an event) when the mismatch between the measured and scheduled SoC is large.

The events differ for each device:

» Uncontrollable device: Updated prediction;

»Curtailable device: Updated prediction;

"Buffer device: Deviation from planning, timer expiration, (almost) empty, (almost) full;

» Converter device: Updated prediction, setpoint change (e.g. thermostat);

» Buffer-Converter device: Deviation from planning, timer expiration, (almost) empty, (almost) full, updated prediction, setpoint change (e.g. thermostat);

» Timeshiftable device: Ready, cancellation;

"Buffer-Timeshiftable device: Arrival, departure.

\subsubsection{Event-Based Device Scheduling}

Rescheduling a single device on the basis of an event is done by the (sub)fleet controller. We use an example (Figure 4.9) with a BEV $m$ arriving at 17:00 and departing at 6:00 the next day, with a total demand of $50 \mathrm{kWh}$ to clarify this process. We assume that this device is still unscheduled, e.g. $\vec{r}_{m}=[0,0, \ldots, 0]^{T}$. Upon arrival, device controller $m$ triggers an event and requests an updated desired profile $\vec{d}$ from the fleet controller.

The fleet controller should realize the scheduled profile $\vec{q}=\left[q_{1}, q_{2}, \ldots, q_{K}\right]^{T}$, where $K$ indicates the number of remaining scheduled intervals $(1 \leq K \leq N)$. To keep track of the confirmed device controller schedules a committed overall profile $\vec{r}$ is kept locally at the fleet controller (Figure 4.9a). The objective is to minimize the Euclidean distance between this committed overall profile and the scheduled profile 


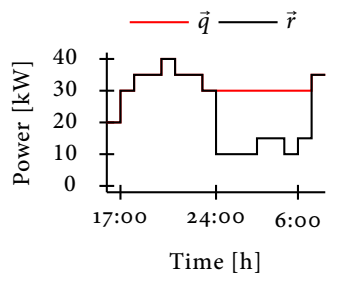

(a) Fleet controller

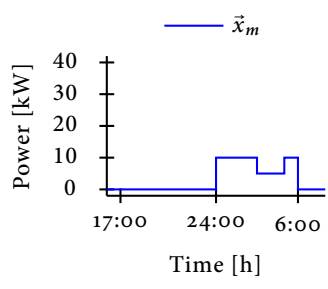

(d) BEV planning

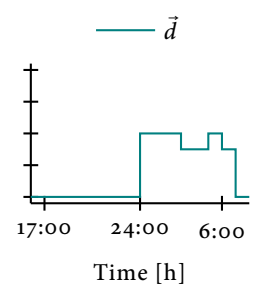

(b) Data to BEV

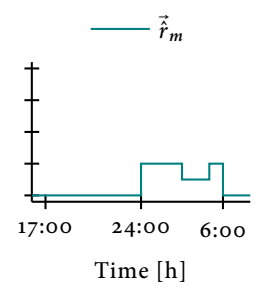

(e) Data to fleet controller

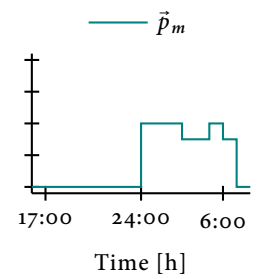

(c) BEV desired profile

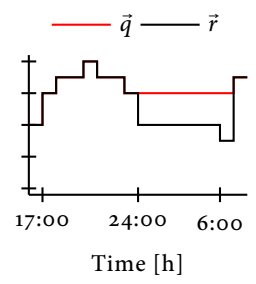

(f) Fleet controller

Figure 4.9: Example of event-based scheduling with a BEV arriving at 17:00 that has a charging deadline at 6:0o the next day and energy demand of $50 \mathrm{kWh}$ without a current schedule. based on the original planning (a) the fleet controller sends an incentive to the BEV (b), resulting in a local desired profile for the BEV (c). Based on this information, the BEV creates a schedule (d) and sends this to the fleet controller (e). Finally, the fleet controller updates its profile (f).

$\left(\|\vec{q}-\vec{r}\|_{2}\right)$ in order to follow the original schedule $\vec{q}$. Hence we send $\vec{d}=\vec{q}-\vec{r}$ to the device controller $m$ as desired profile since it exactly expresses the gap in the profile that needs to be filled (Figure $4.9 \mathrm{~b}$ ). In this example, there is still a large valley to be filled during the night.

Device $m$ first adds its own committed profile $\vec{r}_{m}=\left[r_{m, 1}, r_{m, 2}, \ldots, r_{m, K}\right]^{T}$ to the received signal, resulting in $\vec{p}_{m}=\vec{d}+\vec{r}_{m}$ (Figure 4.9c). Note that the local committed profile may be zero (such as in the example) or filled with a (partial) profile as a result from previous events (e.g. an already scheduled battery). The device controller then optimizes its profile according to the objective, which in our example is to minimize the Euclidean distance between its own power profile $\vec{x}_{m}=\left[x_{m, 1}, x_{m, 2}, \ldots, x_{m, K}\right]^{T}$ and $\vec{p}_{m}$ (i.e. minimize $\left\|\vec{x}_{m}-\vec{p}_{m}\right\|_{2}$ ) while satisfying the (updated) user constraints (Figure 4.9d). Since constraints are unlikely to change, the resulting schedule is considered reliable and realized. Hence the device controller can commit the new schedule and notify the fleet controller of the change in profile $\overrightarrow{\hat{r}}_{m}:=\vec{x}_{m}-\vec{r}_{m}$ (Figure 4.9e). The fleet controller now obtains a new committed profile: $\vec{r}:=\vec{r}+\overrightarrow{\hat{r}}_{m}$ (Figure 4.9f). Finally, the device controller updates committed profile: $\vec{r}_{m}:=\vec{x}_{m}$. Similarly, a subfleet controller within the hierarchy also sends its update of its committed 

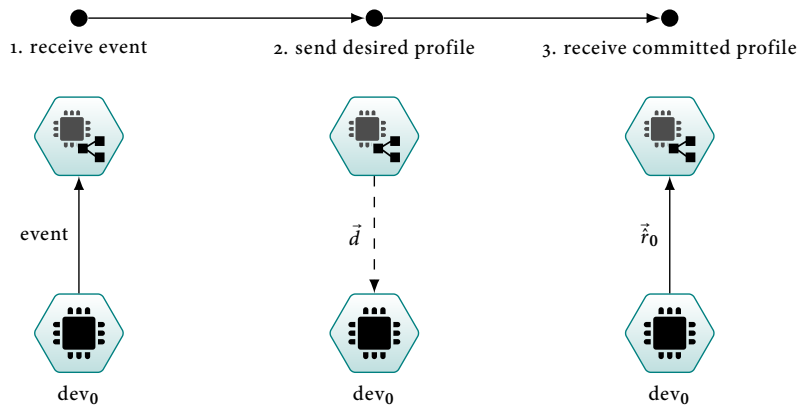

Figure 4.10: Schematic overview of the profile steering algorithm.

profile upwards to higher level (sub)fleet controllers, such that the whole branch knows the new status. The details of the algorithm are presented in Algorithm 5 and is depicted in Figure 4.10.

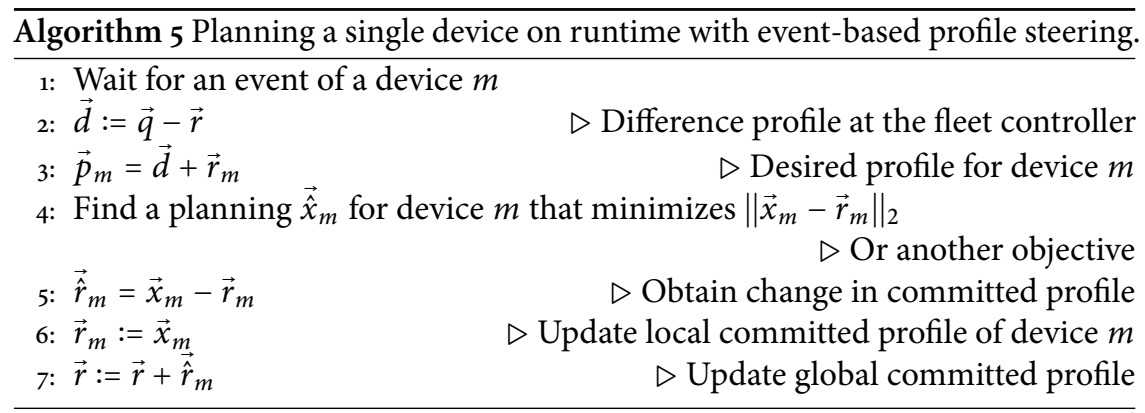

In case the difference between the committed and scheduled profile at a subfleet controller is zero or sufficiently small the original schedule for this subfleet controller is already realized by commitments of its children. However, with a scheduling request of one device, this match between original schedule and realized profile may be undone. Furthermore, mismatches on higher level (sub)fleet controllers may still exist. In such case, the first subfleet controller propagates the event to a higher (sub)fleet controller. This allows the system to balance problems on a higher level such that electricity usage and flexibility can be redistributed across subtrees.

All device events are handled in order and only one single device is considered at a time. Also, scheduling a single device in our methodology is a single shot operation that does not require several iterations and, depending on the device type, only one to few of these events are expected on a daily basis. Furthermore, the resulting device schedule to be followed spans multiple time intervals and thus improves the robustness against loss of connection in the time between events. 


\subsubsection{Profile Updates}

In addition to the control over the flexible assets, we are left with the inflexible load and generation from RES (we do not consider curtailment). Since there is nothing to be controlled, we consider their respective predicted profiles to be realized (confirmed) immediately in the first phase of our method. Load and production forecasting controllers may update their predicted profiles during the operation control phase. This results in a different profile that is expected to be realized. So these controllers regularly send an updated $\vec{r}_{m}$ to the (sub)fleet controller that expresses the difference between the new prediction and the previous prediction. In that way, more accurate predictions for, e.g. solar production can be incorporated. Flexible devices that request a new schedule after such updates can then directly incorporate these predictions in their own optimized profiles.

The same approach as previously mentioned is used to propagate these updates on the committed profile to higher levels of fleet controllers. To limit the amount of communication traffic, updates from subfleet controllers may be delayed until significant (accumulated) changes occur. Profile updates are also applicable to devices that would like to cancel their schedule, such as an suddenly departing BEV. In that case the fleet controllers are notified of this change, which often results in a reduced total energy consumption.

\subsubsection{Rescheduling}

The main goal for the second phase is to resolve prediction errors that occur on the device level while maintaining the settled power profile on the global scale. However, large mismatches between the scheduled profile and the committed profile may arise. These may not be resolved by (re)scheduling a single device as presented. Instead, the flexibility of a larger cluster of devices may be required to resolve problems. This boils down to executing a new scheduling phase using the profile steering algorithm from a higher level (sub)fleet controller.

When a rescheduling is triggered, a scheduling operation as described in Section 4.2 is executed. This does not need to be a complete rescheduling. This request for rescheduling can be triggered by a subfleet controller and thus a partial rescheduling can be performed for a subtree. The objective for an intermediate reschedule operation is still to realize the scheduled power profile from the scheduling phase. Hence, the scheduled profile is the desired profile in this case and thus $\vec{p}$ can be replaced by $\vec{q}$, resulting in an optimization objective to minimize $\|\vec{x}-\vec{q}\|_{2}$ for example. The result of the rescheduling is an updated realized profile, the original scheduled profile $\vec{q}$ must be preserved as it is the settled schedule to which all deviations made in real-time must be evaluated.

The decision by a (sub)fleet controller to perform a rescheduling can be based on the mismatch between the scheduled (objective) profile $\vec{q}$ and the committed profile $\vec{r}$. A rescheduling can be triggered in case the distance between these two is too large. Since parts of the mismatch may be filled in future events, the approach 
should weigh the near future intervals as more important in comparison to far future intervals. If the mismatch between the scheduled profile and the actual measured power in past intervals show large mismatches as well, without a trend of improvement, rescheduling can be triggered.

Slight changes also exist on the device controller level rescheduling within this approach. As mentioned earlier in this section, for some devices a rescheduling should be only considered with consent of the end-user, such as with the devices that belong the timeshiftable class (i.e. washing machines and electric vehicles). Within a rescheduling operation, the devices that are not allowed to be rescheduled can be partly considered as static, uncontrollable, devices for the already started operations. To be more precise, an already scheduled job of such a device controller $m$ should not be rescheduled and thus the static committed profile $\vec{r}_{m}$ for this job should be communicated as if it were an uncontrollable device.

\subsection{CONCLUSION}

In this chapter we presented a proactive profile steering DEM approach for distribution grids. The approach consists of two phases, namely a synchronized scheduling phase and an asynchronous event-driven phase for operation control. The first phase uses predictions to optimize the expected potential of a fleet of devices within the distribution grid using the profile steering algorithm. This schedule based on predictions comes with the risk of prediction errors, resulting possibly in an infeasible schedule. Therefore, the second event-based phase uses profile steering to resolve prediction errors by (re)scheduling a subset of devices based on events, such that not only the current status of the grid is considered, but also the future state. The use of MPC makes the operation of the smart grid predictable, satisfying the predictability requirement. The basic profile steering algorithm can easily be extended with support for multiple commodities by extending the number of communicated profiles to satisfy the multi-commodity requirement.

The control tree consists of a hierarchical tree with the possibility to add multiple layers of fleet controllers that implement the profile steering algorithm. The leaves of this tree represent the device controller that are steered to a certain system objective by the use of bi-directional communication with higher level controllers. Therefore, parallelism is exploited by the distribution of the scheduling problem over multiple control nodes. This approach therefore satisfies the scalability requirement. Reusing the profile steering algorithm on each level of the tree also allows other levels to independently optimize a subtree. This is a useful feature as it makes the system robust to failure of higher level control nodes, satisfying the robustness to failure requirement. A further advantage of the tree structure is that it provides a natural mapping from the control structure to the physical grid structure. Local capacity limitations can be taken into account by several levels of (sub)fleet controllers. This allows the profile steering algorithm to create feasible schedules with respect to the physical infrastructure and hence the feasibility requirement is satisfied. 
Instead of using generic price oriented steering signals, the profile steering approach directly steers a fleet of device controllers by the use of an explicit desired profile. This profile is based on the objective for the fleet of devices. Compared to price based incentives, such as time of use (ToU), this desired profile results in better controllability as the costs of a profile are evaluated on the basis of the deviation from this desired profile. Furthermore, this profile-based steering signal is generic and applicable to any type of lower level device controller or fleet controller. Thus the approach satisfies the heterogeneity requirement and is flexible to support future smart grid technologies.

Scheduling of a device is done on the local level using tailored optimization algorithms for the specific device class, taking both device constraints and user-defined constraints into account. Privacy sensitive information is kept locally with these algorithms as only the resulting profiles are communicated in the first round. Afterwards, only mutations to this profile are communicated and only for the subtree that provides the best improvement. Furthermore, the aggregation of data at the intermediate nodes hides more localized data. The profiles at these levels do not differ from the data that can be obtained by measurements on the physical grid on these levels. Therefore, the presented approach does respect the privacy requirement.

An asynchronous event-driven modification of the profile steering algorithm is presented for operational control in order to resolve prediction errors and satisfy the robustness to errors requirement. With the use of events, this system is able to resolve significant deviations from the desired schedule or prediction at the moment it happens or is about to happen. On the other hand, it avoids the use of communication under normal conditions. The use of profile steering to resolve prediction errors also ensures that trade-offs between resolving short-term and long-term objectives are made.

The event-based approach also allows to schedule devices when they become available, such as a BEV or white goods. At this point it is unlikely that constraints will change and thus such a schedule can be created with great confidence. In a practical setting, this approach can communicate the proposed schedule to the owner of the device. As a result, a tangible proposition to the end-user can be made that specifies what flexibility is traded for what compensation. The offer can then be accepted or refused, resulting in a transparent operation of the control system to fulfil the transparency requirement. This also improves the comfort perceived by consumers as more control can be offered by the presented approach, especially for intrusive appliances. In addition, the optimization process takes user-defined constraints into account, thus the approach satisfies the comfort requirement. Note that the scheduling-based approach itself already provides a transparent operation to other parties, such as a distribution service operator (DSO).

The presented approach in its current form relies heavily on the tree hierarchy, which maps natural to the structure of most distribution grids. However, not all networks may necessarily be operated radially. There exist also meshed networks or ring structures. We believe that the event-based profile steering approach may 
be adapted to these structures as well. Hierarchy may be omitted on certain levels, such as on the house controller level, by allowing communication between control nodes of the same level. In such a case, fractions of difference profiles may be communicated to neighbouring nodes, which can respond and forward remaining problems to their neighbours. Such an approach could stabilize a meshed or ring network in a similar fashion as waves fade out in water after a rock is thrown in it.

Two situations remain in which the presented approach may not result in adequate control of smart (micro)grids. The first is an islanded setting in which fast and real-time control is necessary to keep the grid stable. In such a case even the eventdriven approach taken in this chapter may be not fast enough for this time-critical scenario. Nor is it likely that a single device has the flexibility to restore the balance. The second situation is a situation where communication infrastructure may fail for a longer time period and historical data may not provide enough guarantees to provide a stable service. A second control methodology for these situations is presented in the next chapter. That approach may be complemented with the profile steering mechanism as presented in this chapter. The performance of this control mechanism is evaluated in Chapter 7. 
106 


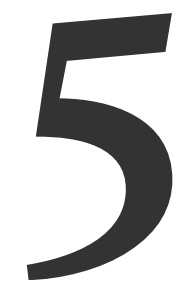

\title{
Active Control Methodology
}

\begin{abstract}
In the previous chapter we presented the profile steering algorithm to schedule a cluster of devices. However, this algorithm is unsuitable in certain conditions, such as in the islanded mode of a microgrid, as the creation of a plan may take too much time. In this chapter we extend the double-sided auction approach as an alternative where a local market is created for demand and supply matching. This control mechanism also employs a tree structure, is scalable, and can incorporate local limitations. The mechanism is extended to ensure that demand and supply matching is always possible in islanded grids by supporting load shedding and curtailment. Furthermore, a proportionalintegral-derivative controller (PID) controller is integrated in this approach to reduce the communication of the used demand functions to increase the rate with which new setpoints can be communicated. We also present a mechanism in which a local market can be created when the communication networks fail. Herein, the local grid is used as a communication channel instead to avoid grid overloading. A local market clearing price is derived from local grid measurements to control devices and ensure that no overloading occurs.
\end{abstract}

In the previous chapter we introduced a proactive control mechanism using the profile steering approach. This approach is suitable for both scheduling and active (operational) control within smart grids. However, the iterative planning oriented approach taken in Chapter 4 is rather time consuming. Especially during the planning phase, where the operation of all devices in the microgrid for several hours into the future is considered, in practice the creation of schedules can take a few minutes. Furthermore, the profile steering approach depends on communication technology being available and may have to communicate quite some data during the planning phase. Overall, the profile steering approach is tailored to provide a steady power profile over longer time spans.

Parts of this chapter are based on [GH:3] and [GH:6]. 
The time required for the profile steering algorithm to perform (re)scheduling may not be available in a microgrid under certain circumstances, such as islanding. Production and consumption of energy must be balanced at all times in an islanded microgrid, and hence a fast acting control mechanism is required. Another example is handling the rapid fluctuating production of photovoltaic $(P V)$ panels due to clouds moving over. Although the total amount of energy produced by PV systems may be predicted accurately, the exact time of clouds moving over is impossible to predict. In such demanding situations a control system must be able to react nearly instantaneously to keep energy balance within the microgrid. Such large fluctuations may also demand the flexibility of more than one device. Therefore, it is important to be able to control multiple devices simultaneously, such that the problem at hand can be distributed among the devices within a cluster. We refer to control systems that are able to react instantaneously to these changes in demand as active control methodologies. This has as a consequence that due to their time restrictions, no predictive control is possible.

The remainder of this chapter is organized as follows. Section 5.1 discusses the requirements of an active control methodology for microgrids must meet. Related work in the field of control methodologies is addressed in Subsection 5.1.1. The foundation of an active control methodology that suits our requirements is presented in Section 5.2. Consecutively, this foundation is used for islanded microgrids in Section 5.3, and for grids where information communication technology (ICT) communication systems fail in Section 5.4. Finally, this chapter ends with conclusions in Section 5.5. Note, that results of the proposed control mechanism are presented in Chapter 7.

\subsection{REQUIREMENTS}

The goal of an active control methodology is to nearly instantaneously control a cluster of devices to maintain a certain target power value for the whole cluster of devices. This target can be a predefined power value, such as the result of the planning phase as presented in Chapter 4, but also global balance of consumption and production. Within islanded microgrids, such a balance between production and consumption is essential to prevent the power system from collapsing. Thus an active control system must be able to find a balance between production and consumption at all times.

Within islanded microgrids, we envision a system where at least one generator or battery inverter is not directly controlled by the control system, but by an embedded governor. This governor uses local measurements that are fed into a control system such as a droop controller. Such a system is the conventional way of stabilising a microgrid and is common practice. However, with controllable domestic appliances more options to shape the grid arise. By properly coordinating and controlling a fleet of devices, these devices can reduce both the load and ramp rates that need to be stabilized with one or more backup generators. As a result, 
the required power rating of such generators is reduced. Furthermore, the active control system needs to take latencies into account as most domestic appliances do not react instantaneously after receiving control signals. Due to the different types of devices, a device agnostic method for control is required to be able to use all available flexibility.

Since balance is critical for islanded microgrids, the system must be able to find balance at all times. This requirement may conflict with the comfort demanded by the end users at times when not enough energy is available or produced to meet the demand for energy. It is likely that at some point in time in an islanded grid load shedding or production curtailment is required as a last resort to maintain balance. But even before the microgrid runs out of energy, it may be wise to start with load shedding earlier to conserve some energy for the future. One may trade current comfort for the availability of energy in the future. An example is to change thermostat setpoints to reduce energy consumption for heating or cooling. The saved energy can be used to ensure that essential devices, such as refrigerators and lighting, get their energy in the future. Especially in temporary islanded microgrids, e.g. after a disaster, it may be uncertain when the grid is reconnected again.

As sketched in the introduction, the supply of electrical energy is crucial for our society. Therefore, the smart grid should also function when critical infrastructure fails. A newly introduced critical dependency of the smart grid, is the dependency on communication technology. Therefore, the control system must be able to find a safe state for the grid when no communication is available. Local observations of the voltage and/or frequency in the grid can assist in this task since they embed information of the state of the microgrid. This information can be fed to a control system to make local decisions and thereby prevent dangerous situations for the microgrid.

Summarizing, the requirements for the active control system in (islanded) microgrids are:

» Fast control actions (instantaneous)

»Control many different devices (heterogeneity),

» Fall-back solution in case loss of communication (fail-safe)

» Match production and consumption at all times (balancing)

» Keep ramp rates limited (stability)

Note that most requirements are parameters, which depend on the size of a microgrid, available devices and backup generators installed.

\subsubsection{RELATED WORK}

Since the early days of alternating current $(A C)$ electricity grids, there has been control to stabilize the supply of electricity at a relative stable grid frequency as presented in Chapter 2. Demand and supply has been matched in electricity grids 
using droop controllers which act on the measured grid frequency. In fact, the first electricity grids were what we call microgrids today and hence these proven control methodologies could be applied for microgrids [6o]. However, in modern microgrids there also exist various devices which can only be controlled by an external system instead of local measurements. More importantly, most devices do not offer a continuous range of power states, but only a limited, discrete set. Hence a new solution is required to allow novel devices to participate in balancing the microgrid.

The power grid has similarities with other systems, such as the internet. In the internet data is distributed, which can be seen as an analogue to the power that has to be distributed in the electricity grid. Thus solutions might be borrowed from these technologies as suggested by Keshav and Rosenberg [85]. Hermanns et al. $[65,66]$ have studied communication network technologies to avoid over-frequency issues with PV. The authors show that such an approach also works for PV within the power grid. Hereby the PV generation is curtailed when the frequency exceeds $50.2 \mathrm{~Hz}$. In their work only the generation side is considered and not the demand side. The addition of a communication layer to the power grid enables the system to communicate the local balance between production and consumption in grid connected mode. Stüdli et al. [140] show that an additive increase, multiplicative decrease (AIMD) control strategy performs well when charging battery electric vehicles (BEVs), but this method still requires communication of the global power consumption or production in the grid. However, in islanded microgrids, this communication can be replaced with the frequency. Monshizadeh et al. [111] show that this is possible with a master-slave method where one generator controls the grid frequency and uses this as a steering signal to control the power output of other generators in a microgrid. The slave generators change their power output according to the grid frequency. This is seen as a form of distributed control.

Frequency based control methods are not directly applicable to decentralized energy management (DEM) in grid connected microgrids. First of all, the frequency is a global measure and therefore does not reflect the local state of the grid. Secondly, most consumer devices do not offer a continuous range of power options. Iacovella et al. [72, 73] have studied the potential of using droop-control like strategies in residential grids to avoid under- and over voltage problems. In their approach, the frequency is replaced by the local voltage, which reflects the local state of the grid better. Furthermore, the linear relation is replaced by discrete points at which a device is forced to switch on or off based on the voltage. This discrete point depends on priorities of the device, which are user defined. Experiments by D'Hulst et al. [32] show that this system has potential.

Other demand and supply balancing problems, such as in economics, are often solved through auctions. As shown in Chapter 2, the double-sided auction is an often used approach within electricity grids. As an example, the PowerMatcher [91] is an device agnostic control method that is able to find a momentary balance of demand and supply within an electricity grid. Herein, the communication is 


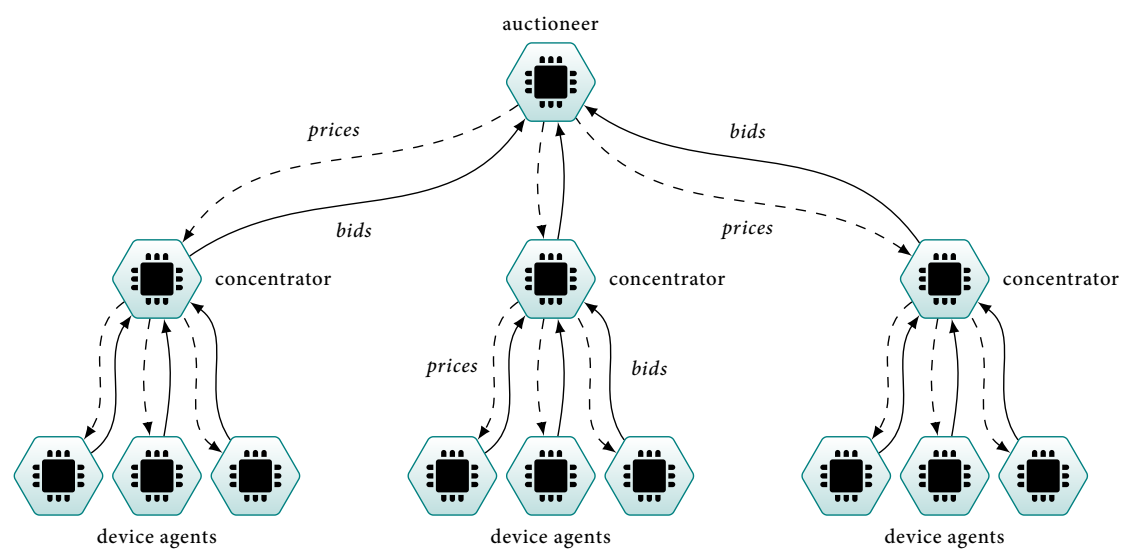

Figure 5.1: Hierarchy of controllers within a double-sided auction with the lower level controllers (agents) sending demand function upwards and the top level controller (auctioneer) selecting a market clearing price and communicating this price downwards.

limited and no iterations are required, resulting in a control system that is able to react nearly instantaneous to changes.

\subsection{CONCEPT}

Within this work we choose to base our active control system on the double-sided auction as found in literature, see e.g. [91]. The double-sided auctions have a lot in common with conventional droop control, and thereby provide the flexibility to implement the other mentioned related mechanisms into this control system. In this section we will first give a general introduction to double-sided auctions. Subsequently, we present extensions to the double-sided auction concept for control in islanded microgrids and for situations where the communication network fails.

To control the operation of a device, some external steering signal must be applied to the device. All devices can change their behaviour based on the received signals and thus the system is device agnostic. As all devices are addressed, the control system can send out new steering signals to react quickly to events occurring in the power system. However, the exact reaction of the devices to a new steering signal is not known when there is only communication from the controller to the devices. Thus, the controller needs to know the response of the devices to a new price steering signal. Only then the control system can select a price that balances the grid or limits the ramp rate.

Within market based approaches, this is done by using a double-sided auction. Within such an auction, the controller (auctioneer) asks all devices to construct 
and communicate a bid function that expresses how much power they buy/sell for a given price. An auctioneer can then select a market clearing price which clears the market (see Figure 5.1 for the communication). Within power systems, the market clearing price can be chosen such that the reaction of the devices fulfils the needs of the technical system in terms of balance and ramp rates. By enforcing bid options for completely turning off consuming appliances at high prices and curtailing all production at low prices, forceful curtailment and load shedding is possible to ensure that balance in demand and supply is possible in all cases.

In order to maintain stability in islanded microgrids with a (small) backup generator or battery pack, the market can also be cleared with a small surplus or shortage of energy. Based on the properties of the backup system and its governor, this method may be used to indirectly control this backup system. In case of a market clearing with shortage, the generator will fill this gap by supplying this shortage. In case the backup system has a battery system, a surplus of energy will be consumed by this backup system. This way, the control system can manage the state of the backup system without the need for direct communication.

Integration with conventional controllers, such as droop controllers, using such a double-sided auction is also straightforward as the bid functions are similar to droop curves. Devices can directly act as conventional droop controlled loads and generators to assist in finding power balance when the local frequency, indicating this balance, is translated into a clearing price. This makes it possible to use the system for communication-free control where the market is cleared locally (e.g., on the building level) using local measurements.

\subsubsection{Demand Functions}

We use demand functions to exchange information about the willingness of devices to consume or produce energy. A demand function $b(p)$ is a monotonically decreasing function that relates a price $p$ to a power value $P$. Within our approach we do not differentiate between supply- and demand side bids, but allow demand side bids to specify a negative demand to indicate production of electricity. However, there exists one special demand function, namely the clearing function, which expresses the willingness of the microgrid to import or export electricity. Note that, in this thesis, we use the price as an artificial steering signal to control the fleet of devices instead of the real energy price. The price therefore indicates the deviation from the desired behaviour of the cluster.

Restrictions on the structure of the demand functions are imposed to limit the worst-case amount of data that has to be transmitted by each node such that the system can operate within the bandwidth offered by the communication system. Therefore, we limit the set of price points used to construct a demand function to integer values. Furthermore, the market is characterized by a minimum price $p_{\min }$ and maximum price $p_{\max }$. We use a symmetric market in which $p_{\max }=-p_{\min }$ and 0 is the centre price point. 


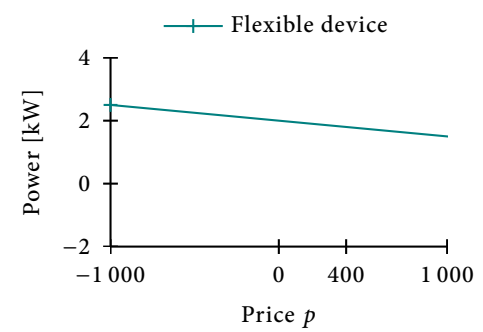

(a) Flexible device

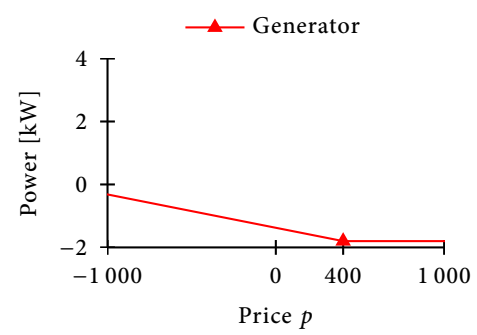

(c) Generator

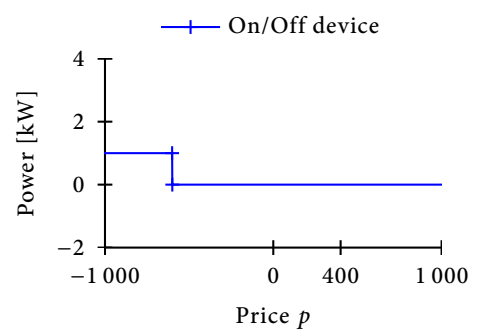

(b) On/off device

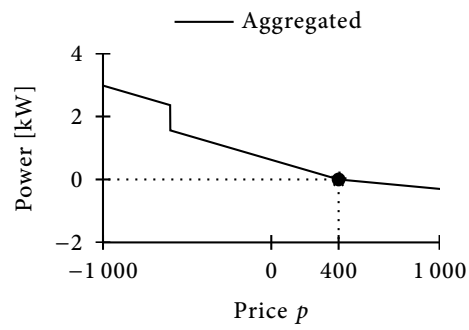

(d) Aggregated

Figure 5.2: Example of demand functions for three types of devices and the aggregated demand function with a power equilibrium at $p=400$

The demand does not need to be specified for each price point within this price spectrum. More precisely, $b(p)$ is characterized by the values for a finite subset $\mathcal{P}=\left\{p_{1}, . ., p_{N}\right\} \subset\left[p_{\min }, p_{\max }\right]$. For $p \in \mathcal{P}$, the value $b(p)$ is directly given for a price $p$. The corresponding demand for a price $p \notin \mathcal{P}$ is found using linear interpolation between the two neighbouring price points $p_{a}<p$ and $p_{b}>p$.

$$
b(p)=b\left(p_{a}\right)-\left(\left(\frac{b\left(p_{a}\right)-b\left(p_{b}\right)}{p_{b}-p_{a}}\right) *\left(p-p_{a}\right)\right)
$$

In case two neighbouring points do not exist, ie. if $p<p_{1}$ or $p>p_{N}$, the corresponding demand is given by the closest defined demand value, i.e. by $p_{1}$ or $p_{N}$ respectively. Bids of multiple devices can be added (aggregated) as adding two valid demand functions $b_{1}(p)$ and $b_{2}(p)$ result in a valid function $b_{3}(p)=b_{1}(p)+b_{2}(p)$. Examples of demand functions are given in Figure 5.2.

We refer to these demand functions as continuous demand functions and provide means to describe devices with a continuous operating power range, such as buffers, using only a few price-power points and thereby reducing the data that needs to be transmitted. However, not all devices offer this type of flexibility, some devices, such as on/off devices, only offer a limited number of discrete power values. This 
inherently introduces discontinuities in the demand function. Hence the function should support discontinuities as well. The continuous demand functions can be used for these type of devices by adding two restrictions. Firstly, we restrict $\mathcal{P}$ to integers. Secondly, devices with discontinuities round the received price signal to the nearest integer at the device level. This way, devices can explicitly specify what power they consume, based on possible device states, for what price. With this method, we can control a mix of continuous and discrete devices using the same demand function framework.

As mentioned, the control method must also be able to enforce curtailment and load shedding to ensure that a balance between production and consumption can be found in islanded microgrids. However, this requires the option to violate enduser constraints and therefore this option should be avoided if possible. To do so, we add a curtailment zone to the lower end of the price spectrum $\mathcal{P}_{\text {curt }}$ by defining a minimum comfort price $p_{\min }^{\text {comf }} \geq p_{\min }$, and by this we specify the curtailment zone by $\mathcal{P}_{\text {curt }}=\left[p_{\min }, p_{\min }^{\text {comf }}\right]$. Producing devices are required to curtail their production based on the price, with total curtailment at $p_{\text {min }}$. Likewise, we define a load shedding zone $\mathcal{P}_{\text {shed }}$ by introducing a maximum comfort price $p_{\max }^{\text {comf }} \leq p_{\max }$ , resulting in the load shedding zone $\mathcal{P}_{\text {shed }}=\left[p_{\max }^{\text {comf }}, p_{\max }\right]$. In this zone, devices need to offer options to force load shedding and thereby violating user constraints with a power consumption of 0 at $p_{\max }$. Using this approach, it is ensured that no comfort constraints are violated for a selected price that falls within the comfort zone $\mathcal{P}_{\text {comfort }}=\left[p_{\min }^{\text {comf }}, p_{\max }^{\text {comf }}\right]$. This extension to the demand functions is depicted in Figure 5.3.

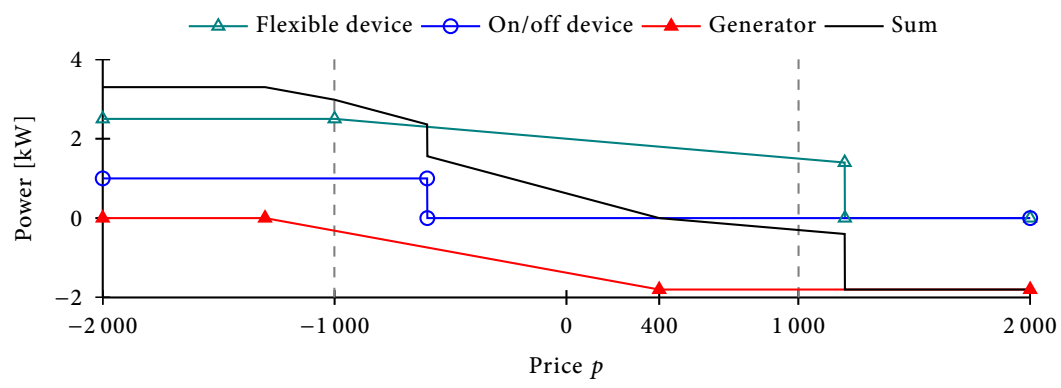

Figure 5.3: Three demand functions and their sum with a power equilibrium at $p=400$ and options for production curtailment and load shedding zones, with $p_{\min }^{\text {comf }}=-1000$ and $p_{\max }^{\text {comf }}=1000$. 


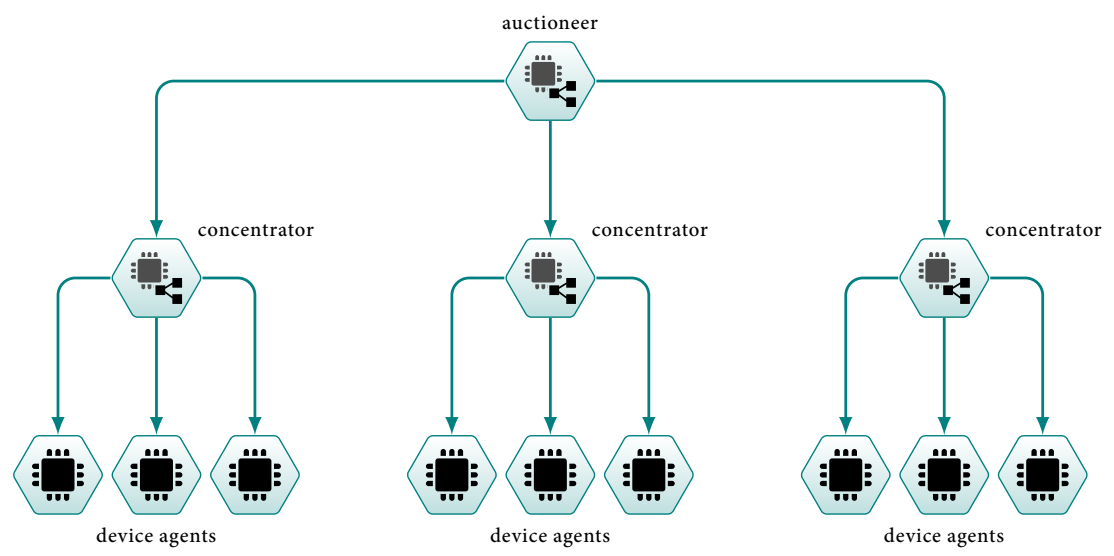

Figure 5.4: Hierarchical structure of a top level auctioneer, intermediate concentrators and lower level device agents.

\subsubsection{Hierarchical Control Structure}

The active control system consists of a hierarchical structure of interconnected controllers in a tree form. This results in a highly scalable distributed control system. The controllers represent particular levels in the physical distribution grid, e.g., devices, houses and feeders. There exist three types of controllers within an auction based system:

" The auctioneer at the top receives all bidding function and determines the market price based on the received bids.

" The device controllers at the bottom (often referred to as agents) that create demand functions on behalf of the device and end-user.

"And concentrators, intermediate nodes that aggregate demand functions from lower level controllers and propagate these aggregated functions to the next, higher, level. Received price steering signals are propagated downwards.

This structure is depicted in Figure 5.4. Along the communication links, demand functions are send upwards from the devices, via the concentrators, to end up at the auctioneer. The price, which is a steering signal, is send in the opposite direction, starting at the auctioneer and is propagated towards the devices.

\section{Device Controllers}

Each device controller needs to construct a demand function based on the current state of the device and comfort constraints. Kok [91] presents methods to define proper bidding strategies for several devices and Toersche has experimented with 
several bidding strategies for heat pumps [143]. In general, devices should bid according to their need to consume or produce energy and avoid risks of violating user constraints. For example, a BEV, should increase the price it is willing to pay for energy when the charging deadline approaches and the state of charge (SoC) setpoint is not reached yet. At a certain point, a device may run out of flexibility to meet comfort constraints and therefore has to take any price for the required demand within the comfort zone. An example is a BEV that has to charge at maximum power to meet the SoC constraints by a given time. We refer to this state as a must-run state. Furthermore, demand functions can be adapted in such a way that they express the priority of a certain device over others. By fine tuning the bidding strategies, a desired behaviour can be programmed, such as charging a BEV has priority over a battery system in case of low prices when abundant energy (e.g. from PV systems) is available.

\section{Concentrators}

The concentrators aggregate the received demand functions from $N$ lower level controllers $\left(b_{1}(p), b_{2}(p), \ldots, b_{N}(p)\right)$ and pass the resulting aggregated demand function $b_{\text {agg }}(p)=\sum_{i=1}^{N} b_{i}(p)$ to the next concentrator in the hierarchy of the distributed control tree. Algorithms exist to aggregate demand functions efficiently using a hierarchical tree. [5].

Just like the controllers presented in Chapter 4, the concentrators can also represent levels in the physical grid structure. Within the auction mechanism, capacity constraints can also be integrated. Consider an aggregated demand function $b_{\text {agg }}(p)$ and a capacity constraint $\left|P_{\max }\right|$ for the concentrator. To ensure that local limitations are not exceeded, the absolute demand for a given price $p$ may not exceed this limit and thus the concentrator must propagate a different demand function $\bar{b}_{\text {agg }}$ which satisfies the capacity constraints $\left|\bar{b}_{\text {agg }}(p)\right| \leq P_{\max }$ for all possible prices $p \in \mathcal{P}$. When the prices are propagated downwards, the concentrator changes the received price $p$ to $\bar{p}$ such that $\left|b_{\text {agg }}(\bar{p})\right| \leq P_{\max }$. Subsequently, $\bar{p}$ is propagated downwards to the children and so the capacity constraints are not violated (see Figure 5.5). Other transformations on the aggregated demand functions by the concentrators are also possible. E.g., a penalty can be added which expresses the grid losses, such that these losses are compensated by the auctioneer. These mechanisms are described in detail by Kok [91] (Chapter 7).

\section{Auctioneer}

The auctioneer is situated at the root of the control tree and can be seen as an extended version of the concentrator and inherits all functionality of the concentrator. This auctioneer, of which only one exists, is in charge of the fleet of devices by selecting the right stimulus based on the aggregated bid $b_{\text {agg }}(p)$. This stimulus is in the form of a price which we call the market clearing price $(M C P)$. The selected MCP is communicated back to all devices through the tree, which subsequently change 


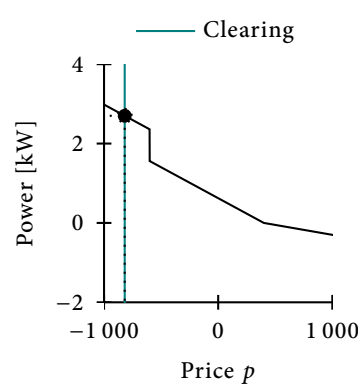

(a) Original function

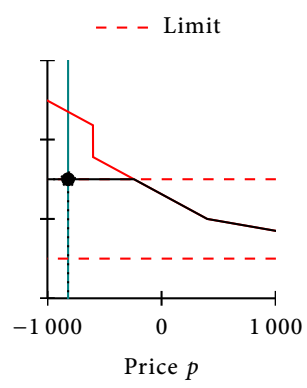

(b) Auctioneer

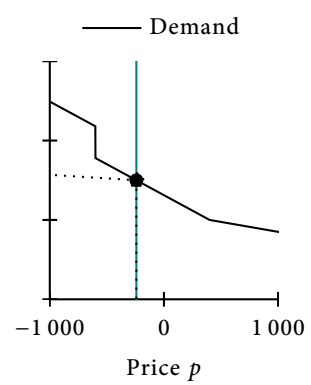

(c) Clearing price

Figure 5.5: Example of market clearing with capacity constraints at the concentrator level. The original aggregated demand function (a), for which the demand at fixed $p=-818$ exceeds the capacity limit of $1 \mathrm{~kW}$ in the example. Therefore, the demand function that is sent upward to the auctioneer is capped at $1 \mathrm{~kW}(\mathrm{~b})$. The prices sent downwards, to the device agents, are altered to ensure that the demand does not exceed capacity limits (c).

their energy consumption/production based on their previously communicated demand function.

The economic background of the MCP is that it is the price for which the demand equals the production. To guarantee that such an MCP always exists for a smart grid, implies that there should be enough generation at all times in the local grid to satisfy this equilibrium. Since microgrids are often connected to the national power grid, the generation may also (partly) come from generation units connected somewhere in this national grid. To express the willingness to import (export) energy from (to) the national grid, the auctioneer may add a clearing demand function $\breve{b}(p)$. Subsequently, this clearing demand function $\breve{b}$ added to the received demand function $b_{\text {agg }}(p)$ to obtain $b_{\text {auction }}(p)=b_{\text {agg }}(p)+\check{b}(p)$.

The exact clearing demand function depends on the objectives of the auctioneer (e.g. peak shaving, optimizing self-consumption) or whether the microgrid is islanded or not. Three kinds of clearing demand functions exists [143] (Figure 5.6):

" Forced clearing price: The market is cleared at a fixed price $p^{*}$, which is indicated by a clearing demand function $\breve{b}(p)$ that takes the value $\infty$ for values of $p<p^{*}$ and $-\infty$ for values of $p>p^{*}$.

" Forced demand clearing: The market is cleared at a fixed demand $D$ (import/export), which is indicated by a clearing demand function $\breve{b}(p)=-D$ for all $p$.

" Proper market clearing: The market is cleared using a clearing demand function $\breve{b}$ that provides elasticity to import more energy during periods of high load and export more energy in periods of high production. 


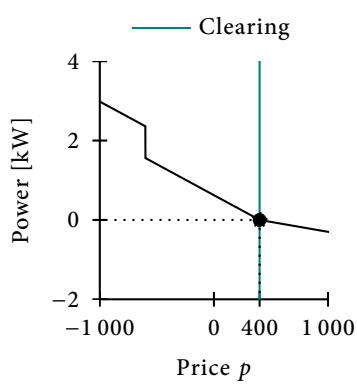

(a) Forced clearing price

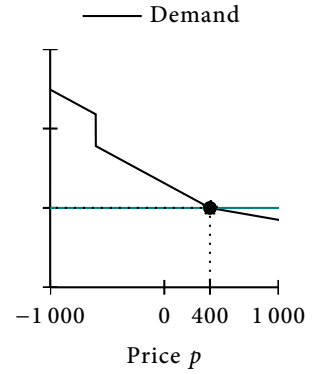

(b) Forced demand

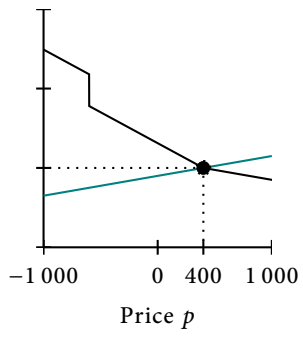

(c) Proper clearing

Figure 5.6: Example of market clearing functions for three types of market clearing.

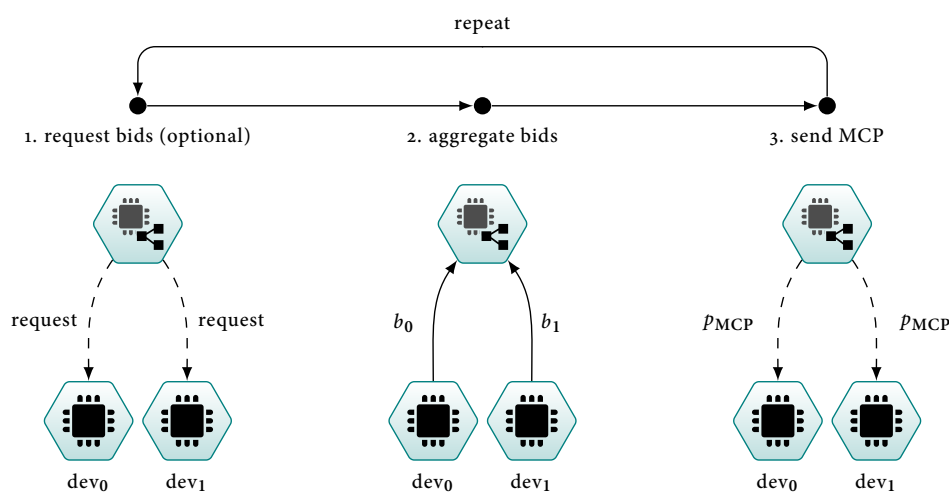

Figure 5.7: Schematic overview of the communication flow with double-sided auctions.

Note that we use demand functions only and denote supply as negative demand.

The auctioneer clears the market by selecting a price $p_{\mathrm{MCP}}$, such that $b_{\text {auction }}\left(p_{\mathrm{MCP}}\right)$ $=0$. This $p_{\mathrm{MCP}}$ may be restricted by a minimum $p_{\mathrm{MCP}}^{\min } \geq p_{\min }$ and maximum $p_{\mathrm{MCP}}^{\max } \leq p_{\max }$, such that $p_{\mathrm{MCP}}^{\min } \leq p_{\mathrm{MCP}} \leq p_{\mathrm{MCP}}^{\max }$. This gives the auctioneer the possibility to restrict the prices such that load-shedding or curtailment does not occur in undesired situations, such as when the microgrid is operated in grid connected mode.

In case no $p_{\mathrm{MCP}}$ exists for which $b_{\text {auction }}\left(p_{\mathrm{MCP}}\right)=0, p_{\mathrm{MCP}}$ is chosen such that it minimizes the difference to the objective, i.e. $p_{\mathrm{MCP}}=p_{\mathrm{MCP}}^{\max }$ if $b_{\text {auction }}\left(p_{\mathrm{MCP}}^{\max }\right)>0$ and $p_{\mathrm{MCP}}=p_{\mathrm{MCP}}^{\min }$ if $b_{\text {auction }}\left(p_{\mathrm{MCP}}^{\min }\right)<0$. Optionally, load-shedding or curtailment may be considered to obey grid constraints in such a case. The flow of actions is depicted in Figure 5.7. 


\section{Bid Updates}

The demand for energy by devices changes over time and thus demand functions also change over time. As an example, uncontrollable devices are price takers and need to update their bid as demand or production changes (e.g. a computer being turned on). This may result in a tremendous rate of updates due to the events that happen within the microgrid and thereby a vast amount of data that has to be transmitted. Furthermore, on each update, the auctioneer must determine a new MCP and propagate this signal down the tree. A time limit can be introduced to limit the transmission of data by only sending updates at a predefined rate.

Another solution is to only send updated demand functions if there are significant local changes and to accept small deviations (mismatches) in power. Only after significant changes to the demand function, an updated demand function is communicated to the parent controller. Likewise, concentrators can wait till subsequent updated bids from child controllers result in a significant change. On the other hand, the auctioneer can choose to update the MCP in case of a significant price change. Within this work we take the absolute difference between the new candidate demand function $b^{\prime}$ and the current active demand function $b$. The demand function is then updated if $\sum_{p_{i} \in \mathcal{P}}\left|b\left(p_{i}\right)-b^{\prime}\left(p_{i}\right)\right|>\epsilon$, where $\epsilon$ is a configurable parameter. A small $\epsilon$ results in a higher rate of updates. This solution has the advantage that significant updates are sent as soon as possible, such that large deviations are addressed directly instead of waiting for the next time slot. It may be combined with the clock based approach to limit the maximum rate of updates, such that the worst-case data throughput can be determined.

\subsection{Online Control}

The double-sided auction mechanism provides a light-weight method to balance production and consumption. The advantage over the profile steering approach is that the auction does not require several computational intensive optimization iterations. At the same time, it is able to consider all assets within the microgrid. It is therefore suitable to (re)dispatch available flexibility nearly instantaneously to resolve fluctuations in the grid. However, by itself, it does not incorporate predictions and planning and the market clearing output only depends on the objective power value of the auctioneer. Therefore, double-sided auctions only clear the power market for a given moment in time. However, the desired power value may come from external input, such as the global planning as presented in Chapter 4 . 
In this section we unveil control strategies using double-sided auctions for residential microgrids. Both the islanded and grid connected modes of operation are considered in which the clearing function of the control system differs. The objective in the islanded microgrid setting is to keep balance between production/consumption as it directly influences the stability of the microgrid. In this case we add a PID controller to the double-sided auction to quickly steer towards a balanced situation while resolving demand function mismatches. The objective for grid connected microgrid is often to attain a certain power profile, e.g. one that is agreed on the power markets. In this case, we combine the double-sided auctions with the strategy presented in Chapter 4.

\subsubsection{Global Market Clearing}

First we consider the case in which the microgrid is connected to the regional and/or national distribution and transport grid. In this case, the microgrid can import a deficit or export a surplus of electrical energy from/to the microgrid. For the microgrid, there may be (monetary) incentives to consume as much energy as possible at certain times with low to negative energy prices, whereas time periods of relative high energy prices may exist where it is beneficial to export energy. However, the import or export of power is constrained by physical limitations of the microgrid under consideration. The auctioneer is in charge of controlling the exact amount of energy that is imported and/or exported by determining the MCP, based on the objective function $\breve{b}(p)$, which defines the willingness to import or export energy as mentioned in 5.2.2. Note that $\breve{b}(p)$ may vary over time.

The simple approach is to clear the market for a given power value. However, since the method does not incorporate prediction and planning, the market may be cleared at an average power level that is either too high or too low. As a consequence, devices exhaust their flexibility to keep up with the desired power profile at the auctioneer, resulting in a moment in time where no flexibility is left. Such behaviour results in high power spikes (either negative or positive) or unnecessary discomfort in the form of load-shedding and/or curtailment. As high penalties may be associated with these peaks and discomfort, the approach has the risk to end up with high system costs.

To overcome this problem, we propose to guide the auctioneer by the profile steering approach as presented in Chapter 4 to incorporate prediction and planning. By doing so, the global planning is directly integrated in the auction mechanism, and the predictions are indirectly incorporated as they form the basis of this global planning. The auctioneer can devise a clearing demand function $\breve{b}$ based on the planning outcome. This implies that the auction mechanism is used to extend the profile steering approach with real-time control. This planning guided auction approach is also studied by Molderink et al. $[109,110]$ and compared to other approaches such as a local, domestic, integer linear program (ILP) to resolve prediction errors. Their findings are that the auction is capable of re-distributing the planning error efficiently as it considers all flexibility in the fleet. 


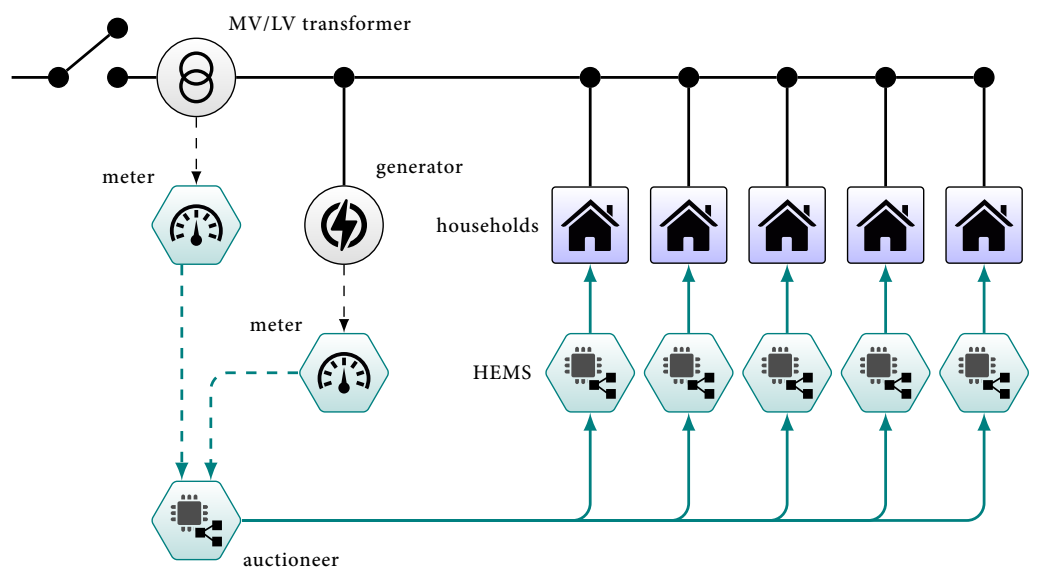

Figure 5.8: Schematic overview of a microgrid in islanded mode with a backup generator governed by a droop controller to stabilize the grid.

Within our combination, we stick to a simple approach of using external data at the auctioneer. This external data is either the resulting planning using profile steering or the realized profile in the event based approach. Both the global plan $(\vec{x})$ and realized profile $(\vec{r})$ can be used as input to define $\breve{b}(p)$ for each time interval. Two clearing approaches are considered. The first is forced demand clearing, i.e. $D=-\vec{x}$ (note that $\vec{x}$ can be exchanged for $\vec{r}$ here). The other option is proper market clearing based on the plan where $\breve{b}(0)=-\vec{x}$ ( 0 being the centre of the price spectrum) and elasticity is introduced by linearly scaling the planning at the end points to compensate for prediction errors, e.g. $\breve{b}(-1000)=-\vec{x}+0.1 \times|\vec{x}|$ and $\check{b}(1000)=-\vec{x}-0.1 \times|\vec{x}|$. This could be a simple linear function or a more clever function. In Chapter 7 we compare the performance of these approaches with the profile steering only approach.

\subsubsection{IsLanded Grid CONTROL}

This market based approach can also be used in islanded operation of a microgrid as depicted in Figure 5.8. Due to the disconnection from the main grid, the microgrid must find balance between production and consumption at any given time. Therefore the auctioneer has only one option: clear the microgrid at exactly this balance such that $b_{\text {auction }}\left(p_{\mathrm{MCP}}\right)=0$. Local measurements, at a central point in the microgrid, are used to measure the current state, e.g. frequency of the microgrid. This information can be used as input for the auctioneer to change the MCP. Using this generic control approach allows us to incorporate various domestic devices in the process of balancing an islanded grid.

The downside of using these consumer devices is that they usually only have limited options in terms of controllability compared to conventional generators. Most 
devices offer only two operation states: on or off. Other devices, may only offer a limited number of modulation steps. Therefore, this balance may not exactly exist. Furthermore, it is not guaranteed that these consumer appliances give the exact balance since these appliances lack internal feedback systems. Hence, these devices cannot guarantee that they achieve an exact power value as desired and therefore balance is not guaranteed. Furthermore, the various consumer grade appliances do have different operation characteristics, communication protocols and response times. This response delay is usually a couple of seconds. Within grid-connected mode, these limitations are not a problem as centralized power plants make up for small deviations. However, in microgrids, absolute balance is crucial and these limitations have a bigger impact and may result in a collapse of the islanded microgrid.

In the islanding scenario, the previously mentioned load shedding and production curtailment zones are active if these are required to maintain this balance. Together with the balancing system, the auctioneer may choose to perform energy rationing in which user comfort is traded for a longer uptime of the grid for emergency energy usage. Providing electricity to refrigerators, lighting, water pumps and sewage pumps has generally a higher priority than equipment such as heating, ventilation and air conditioning (HVAC) systems or charging a BEV.

\section{System Delays}

Within this system, various processing and communication delays exist that need to be taken into account. The implemented control system is extended with the following delays by means of a buffer:

" $T_{\mathrm{dc}}$ : The communication delay between two control nodes. With the current state of communication networks this delay is usually small $(<10 \mathrm{~ms})$.

" $T_{\mathrm{dm}}$ : The measurement data obtained from a central place in the microgrid may be delayed, introducing a mismatch between the measured consumption and the actual consumption.

» $T_{\mathrm{dr}}$ : The reaction time of devices between receiving a signal and changing the power consumption of the device to the desired setpoint. It may take seconds for devices to act on the given signal or the device applies a smoothed curve towards the new setpoint. For example in a previously conducted experiments [GH:11], it was observed that $T_{\mathrm{dr}}$ for a Renault ZOE electric vehicle is approximately 4 seconds.

All these delays in the system aggregate to $T_{d}$. This delay specifies the total delay between the moment a measurement sample is taken and the controlled devices have updated their consumption. In addition, certain consumer devices may also restrict the control frequency at which they accept new control signals, denoted by $T_{\mathrm{da}}$. These devices limit the control frequency of the system severely, possibly reducing the effectiveness of DEM methodologies for islanded microgrids. 
As many different devices exist in a residential microgrid, not all devices necessarily need to receive a new steering signal simultaneously. Instead, devices may receive new steering signals using a round-robin scheme. In this scheme, devices or controllers receive a new steering signal in alternating order. The advantage is that a part of the fleet is always available to receive a new signal to compensate for the observed errors quickly. The round time of the round-robin scheme must at least be equal to the highest $T_{\mathrm{da}}$ among the devices.

\section{Dealing With Delays}

As mentioned earlier, the auctioneer uses, besides the aggregated demand function, additional measurement information in islanded mode. This additional information is the last measurement sample $y(t)$ at time $t$ at the common measurement point. The objective of the auctioneer is to minimize the difference between $y(t)$ and the target power value based on the auction outcome $r(t)=b_{\text {auction }}\left(p_{\mathrm{MCP}}\right)$.

Usually, no difference between $y(t)$ and $r(t)$ should occur as the received demand functions specify the reaction to a new MCP. However, because of the time delays, devices may not yet have changed their consumption according to the prior steering signal whenever a new measurement sample is obtained. It is because of these time delays that $y(t)$ lags behind $r(t)$. Hence, there is an error $e\left(t_{k}\right)$, given by $r\left(t_{k}\right)-y\left(t_{k}\right)$. Based on this error, the auctioneer can change the MCP to make up for this error. However, this introduces the risk of overcompensation by the control system, which may result in instability.

To overcome this problem, we implement a discrete PID controller to stabilize the double-sided auction mechanism within time critical islanding situations. The general formula of a discrete PID controller is:

$$
u\left(t_{k}\right)=K_{p} e\left(t_{k}\right)+K_{i} \sum_{j=1}^{k} e\left(t_{j}\right) \Delta t+K_{d} \frac{e\left(t_{k}\right)-e\left(t_{k-1}\right)}{\Delta t}
$$

where $K_{p}, K_{i}$, and $K_{d}$ denote the coefficients for the proportional, integral, and derivative terms of the controller and the discrete samping time is denoted with $\Delta t$. The resulting output $u\left(t_{k}\right)$ for time interval $t_{k}$ is the new steering signal which is used instead of $r\left(t_{k}\right)$ to determine the next MCP, such that $u\left(t_{k}\right)=b_{\text {auction }}\left(p_{\mathrm{MCP}}\right)$.

Due to the time delays in the system, the error at the time that devices react is different than at the moment the steering signal was sent. Therefore we compensate using a simple linear extrapolation such that $e\left(t_{k}\right)$ is replaced by:

$$
e\left(t_{k+T_{d}}\right)=r\left(t_{k+T_{d}}\right)-y\left(t_{k}\right)+\frac{T_{d}}{\Delta t}\left(y\left(t_{k}\right)-y\left(t_{k-1}\right)\right) .
$$




\subsection{Communication-Free Control}

Up to this point the focus has been on control of smart grids using ICT technology. This ICT infrastructure is the foundation that allows the exchange of information and efficient coordination between appliances in the microgrid. However, this also adds more vulnerability to the system in the form of a second piece of network infrastructure that may malfunction. Additionally, ICT based control also adds the risk of being remotely accessible using software exploits. Malicious software may be installed that alters control signals to change the behaviour of the system, with the possibility to control millions of domestic appliances. Dangerous situations, e.g. a blackout, may be created. Hence, ICT introduces a new vulnerability to the system and an alternative way of control to fall back onto is desired to prevent overloading of the grid, dangerous situations or blackouts [138].

In case the communication fails, the electricity grid still provides valuable information about the state of the grid, which is accessible by using measurement equipment. The local supplied voltage contains information on the local balance between consumption and production of electricity. A relative low voltage indicates a relative high load, whereas a relative high voltage indicates a relative high production of electricity. These voltage rises and drops are caused by the resistance in cable sections of the grid and depend on the flow direction of the current. In case the microgrid is connected to the main grid, the instability of the supplied voltage at the transformer due to upstream events in the medium voltage grid also have to be taken into account.

A second indicator for balance in the grid is the frequency which drops when the load is high and rises when the generation increases. However, the frequency is synchronized in a grid and can therefore only be used as indicator for local balance if the considered microgrid is operated in islanded mode. If the characteristics of the backup generator is known, i.e. the droop control characteristics, the observed frequency deviation can be translated directly into a power mismatch. Unlike the voltage, the frequency is not location dependent.

\section{System Setup}

To make use of this local grid information during a period without communication, measurement equipment is required to obtain the grid frequency and voltage. This equipment needs to be connected to the home energy management system (HEMS). This leads to a separate hardware module for the HEMS which can be used to determine local, household, control signals. Subsequently, the HEMS communicates this steering signal to the devices using the local (home) area network. A connection to the smart meter is also required in order to track the local consumption (or production). The system setup is depicted in Figure 5.9. Note that the equipment may also be used to enhance the robustness of smart grid control systems to malicious steering signals, e.g. a request for more power consumption when the local voltage is very low, indicating a high load. 


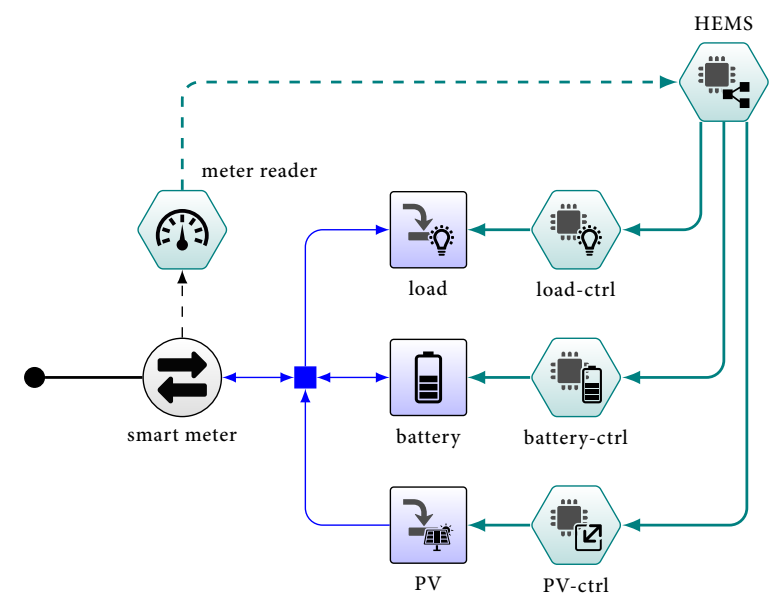

Figure 5.9: Schematic example of a from the internet disconnected household with several appliances and controllers and a HEMS that uses local measurement data to stabilize the grid.

In case of a failing communication network, the MCP cannot be communicated by the auctioneer. Therefore, a suitable method to locally determine a MCP is required. A possible approach is to translate the local information into a local (household) MCP which is sent to the devices to control the consumption/production. Local measurement data, such as the frequency, may be used to determine a local MCP. It remains to define a function which translates each input sample of the local measurement to a corresponding local MCP. Since it is a local market clearing, we refer to this clearing price as the local clearing price $(L C P)$ instead. In the following the process of determining a LCP based on local information is described in detail.

\subsubsection{Local Clearing Price}

It is important to keep the LCP close to the centre of the price spectrum as this indicates that the situation is normal and devices can continue their normal operation. Based on historical data, an average of the measured information (e.g. voltage or frequency) is determined. We denote this average value by $\mu$ and assume that it reflects the aforementioned normal behaviour. In general, $\mu$ can be used as the setpoint $r$. If the actual measured value $y$ equals $r$ the situation is normal and the LCP is set to the centre of the price range. To avoid control actions on small deviations from the target, a deadband is introduced. Such a deadband ranges from $r_{\mathrm{DB}}^{-}$to $r_{\mathrm{DB}}^{+}$and is used to translate multiple measurement values to the same LCP, i.e. all measured values $y \in\left[r_{\mathrm{DB}}^{-}, r_{\mathrm{DB}}^{+}\right]$are translated to a LCP of 0 . The deadband itself indicates the range in which the system operates normally and within safe margins. This type of control is very similar to a droop controller. Measurement values outside the deadband are mapped to the rest of the price spectrum. More 
precisely, we define an upper limit $r_{\max }$ and a lower limit $r_{\min }$ which are mapped to $p_{\max }$ and $p_{\min }$ respectively. These limits may represent the limits of the local regulations, such as the EN-50160. All other values of $y$ that lay outside the deadband, but inside these limits, are mapped linearly to the rest of the price spectrum, i.e. values from $\left[r_{\min }, r_{\mathrm{DB}}^{-}\right]$are mapped linearly to $\left[p_{\min }, 0\right]$ and values from $\left[r_{\mathrm{DB}}^{+}, r_{\max }\right]$ are mapped linearly to $\left[0, p_{\max }\right]$. Measurement values that exceed $r_{\max }$ are mapped to $p_{\max }$ and values less than $r_{\min }$ are mapped to $p_{\min }$.

To avoid oscillation, we propose to use an incremental strategy which only increases or decreases the LCP based on the current LCP and the deviation from the local target value $r$. When these incremental steps are small enough, a cluster converges to a stable situation without overshoots. The LCP is increased or decreased based on the error $\epsilon$ between the setpoint and the measurement data $(\epsilon=r-y)$ and a multiplier $\alpha$, such that $L C P:=L C P+\alpha \epsilon$. This multiplier $\alpha$ can differ between households to reflect the local effects of the physical location. For example the physical location of the house in the network has influence on the magnitude of observed voltage fluctuations. Both $r$ and $\alpha$ may be defined using extensive models or sensitivity analysis such as described by Weckx et al. [164].

The second potential problem to solve is the danger of synchronized actions by all devices in a microgrid. If all devices respond at the same time, the aggregated change in demand can be too large. This results in dangerous overshoots of demand or production. Hence, a desynchronized system is desired in which households can respond in an arbitrary order and thereby take each others actions into account. Such behaviour results in a system that slowly converges towards a stable state. This desynchronization is achieved using a probabilistic back-off timer as used in wireless communication networks. After performing an action, households wait a certain amount of time before taking a new measurement sample and performing actions if required.

As we require a symmetric approach for both consumption and production, we extend the presented mechanism with two back-off timers: one to increase the LCP $\left(T_{\text {poll }}^{+}\right)$and one to decrease the LCP $\left(T_{\text {poll }}^{-}\right)$. After one of those timers expires, a new measurement sample is taken and based on this sample the LCP may be updated. When the measurement sample falls within the defined deadband $\left(r_{\mathrm{DB}}^{-} \leq y \leq r_{\mathrm{DB}}^{+}\right)$ the LCP is updated slowly towards the centre of the defined market. Otherwise, $p_{\mathrm{LCP}}$ may only be decreased if the $T_{\text {poll }}^{-}$timer expired, and only increased when $T_{\text {poll }}^{+}$expired.

Within communication networks, the exponential back-off counter and timer depend on the number of collisions, which indicates the congestion on the channel. For power grids, there are no collisions to be counted. Therefore we need a substitute to determine the maximum size of the random back-off time. The LCP is an indicator for the demanded flexibility and therefore an indicator for the congestion in the grid. Hence, we choose to determine the maximum back-off time using the selected LCP, namely $p_{\mathrm{LCP}}$. The maximum back-off time $T_{\text {poll }}^{+}$is selected by adding a random time between 1 and $2^{\kappa+\vartheta}+1$ time intervals to the current time interval 


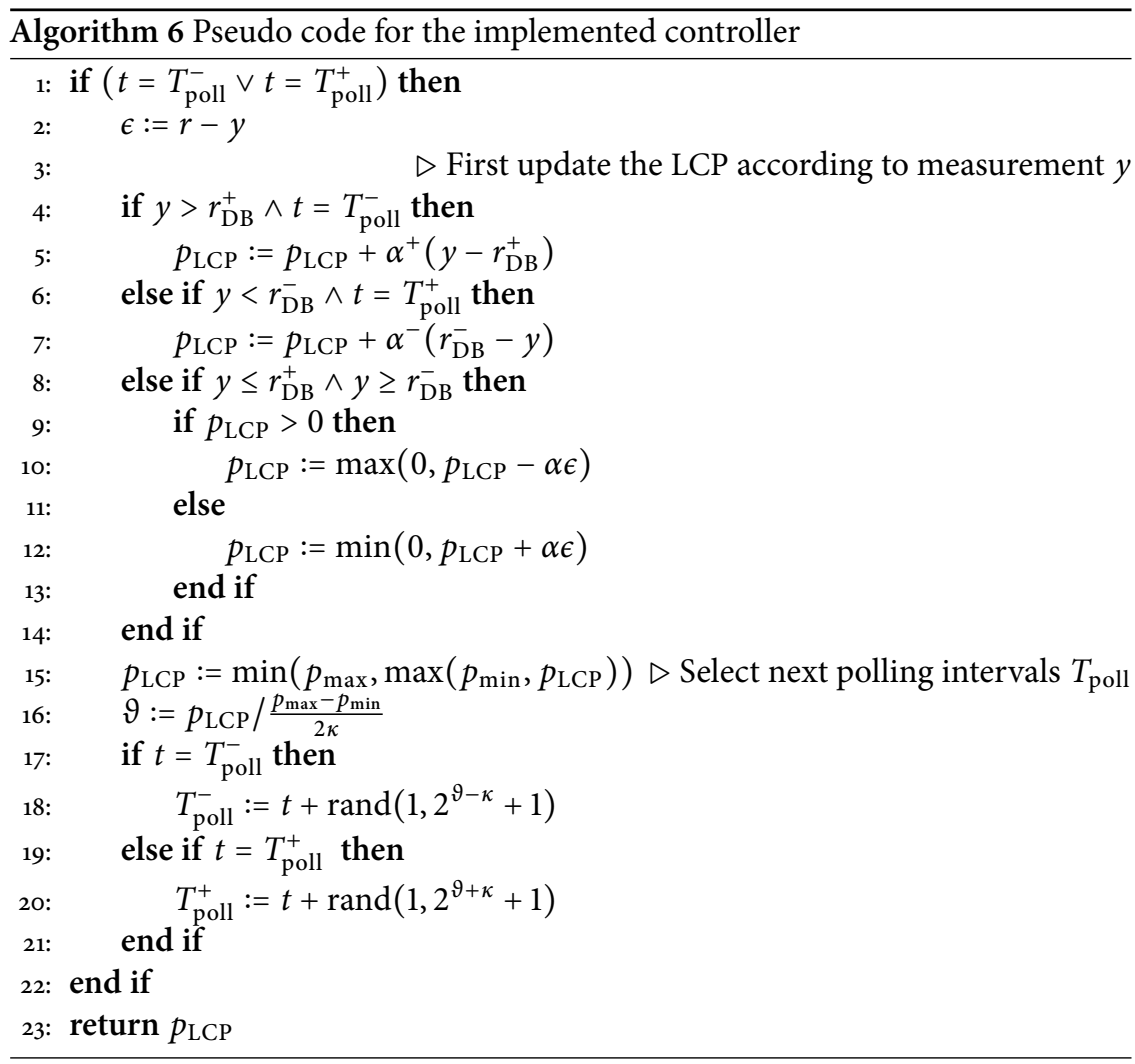

$t$, where $\vartheta=p_{\mathrm{LCP}} / \frac{p_{\max }-p_{\min }}{2 \kappa}$ and $\kappa$ is a parameter. Likewise, for $T_{\text {poll }}^{-}$a random back-off time between 1 and $2^{\kappa+\vartheta}+1$ time intervals is selected and added to current time interval $t$.

A symmetric market is used $\left(p_{\max }=-p_{\min }\right)$ with the nominal value placed at zero. This choice results in the desired behaviour where households have a higher probability to change $p_{\mathrm{LCP}}$ back into the direction of the nominal 0 and a lower probability to deviate more from the nominal LCP. This can be seen as a prioritizing mechanism which balances the LCPs of all households, e.g. households with a LCP that slightly deviates from the nominal have a higher probability to change their LCP to resolve the problems in an unbalanced situation. The presented method is described in Algorithm 6. 


\subsubsection{Voltage Based Control}

The distributed control mechanism outlined above is used to balance a smart grid based on local voltage measurements. We use the local voltage $U$ measured between phase and ground as input for $y$ in this method, whereas the relevant parameters are obtained during a training period. The objective of the controller is to stabilize the locally measured voltage level around the historical average. Using this local historical data, each controller determines the average measured value $\mu$, which is the target to maintain for the local controller, and the standard deviation $\sigma$, which is a measure for the stability of the voltage at that particular location in the grid. To find suitable parameters for increasing and decreasing the clearing price, the measurement samples are split up into two sets: The set of values below and above $\mu$. For each set, the average and standard deviation is determined, resulting in $\mu^{+}$ and $\sigma^{+}$for the set above $\mu$ and $\mu^{-}$and $\sigma^{-}$for the set below $\mu$.

Note that the voltage supplied over the medium voltage (medium voltage $(M V)$ ) grid can fluctuate quite a lot. When provided with historical data of these fluctuations, controllers can partly compensate their own measurements. These fluctuation profiles are provided beforehand or updated in times when communication is possible. The measurement samples are then compensated with the expected deviation from the nominal $230 \mathrm{~V}$ at the transformer. The used deadband $r_{\mathrm{DB}}$ depends on whether the MV fluctuations are taken into account or not. With a constant supply of voltage to the low voltage ( $\mathrm{LV})$ grid, we chose $r_{\mathrm{DB}}^{+}=r_{\mathrm{DB}}^{-}=\mu$ to incorporate local effects due to the physical location. When the MV voltage supply is taken into account, the deadband is changed to $r_{\mathrm{DB}}^{+}=\mu+\sigma^{+}+\sigma_{\mathrm{T}}$ and $r_{\mathrm{DB}}^{-}=\mu-\sigma^{-}-\sigma_{\mathrm{T}}$, where $\sigma_{\mathrm{T}}$ is the standard deviation between the expected and real voltage deviation at the transformer. The wider deadband is used as a filter to avoid control actions based on the global fluctuations, which in essence is noise to our approach. The drawback is that local, valuable, information is also filtered out of the measurement signal. Therefore, the system will allow for larger power deviations and thus sacrifice peak shaving performance

\subsubsection{Frequency Based Control}

The frequency is synchronized within the network, so all customers measure the same signal and hence no location specific parameters need to be configured. We envision this system to run in a master-slave setting as proposed by Monshizadeh et al. [111]. In this approach, one generator sets the reference frequency, whereas the other generators change their power output based on this frequency. Hence, the grid frequency is used as a steering signal indicating the microgrid balance. The proposed method can utilize this frequency signal to adjust the local clearing price such that domestic appliances can help to restore the balance. The relevant parameters $\mu, \sigma, \mu^{+}, \sigma^{+}, \mu^{-}$and $\sigma^{-}$must be obtained through system analysis of the backup solutions installed in the grid. Based on their response characteristics, stable parameters can be derived. 


\subsection{Conclusion}

In this chapter we have presented two control methodologies for two different settings of a microgrid. The first is the islanded case, in which balance between consumption and production must be maintained at all times. Fast and accurate control is more important in such a case than long term optimization. The other scenario is a case where the communication network, which is essential for coordinated control, malfunctions. Due to the dependence on energy in our society, such a failure may not lead to a standstill of our daily lives and economy. For both cases, the profile steering approach in its basic form is not suitable as planning iterations will take too long and local schedules are only valid for a limited amount of time.

To protect the smart microgrids in these scenarios from a failure and outage, a second control mechanism based on double-sided auctions is introduced. These auctions only depend on the current state of the device and requires limited communication using generic demand functions. Since devices specify how they react to certain steering signals, the control system can directly choose the correct steering signal based on the objectives of the microgrid, thereby satisfying the instantaneous control and heterogeneity requirements. This process may be guided by utilizing the planning given by the profile steering approach. Furthermore, in islanded operation, the auctioneer can clear the market based on stability aspects by guaranteeing balance, even when this violates user comfort constraints. Similarly, the clearing price can be selected to avoid steep ramp rates, resulting in a solution that satisfies the balancing and stability requirements.

The demand functions can be constructed in such a way that forceful load shedding and curtailment can be included to ensure balance in the microgrid remains. This allows the system to achieve trade-offs between comfort and a longer emergency supply of electricity. In scenarios where the ICT network fails, the same auction mechanism can be used. As the used demand functions show similarities with conventional droop control, domestic devices can contribute in solving the balancing problem. Local observations of the voltage or frequency can be used to set a local clearing price. With the addition of proven concepts from communication networks, the energy consumption or production can be spread across all households without communication, satisfying the fail-safe requirement.

The proposed auction system thereby provides an efficient way to meet the requirements stated in the beginning of this chapter and adds a control system to control critical scenarios. We do note that the double-sided auctions have (scalability) limitations when it comes to multi-commodity management and reactive power control. The performance of the presented control mechanisms is evaluated in Chapter 7 . 


\title{
Simulation AND DEMONSTRATION PLATFORM
}

\begin{abstract}
This chapter presents implementation details of two tools that have been developed to evaluate the performance of energy management systems. The first tool is a standalone artificial load profile generator (ALPG) to create use-cases with explicit information on available flexibility. The second tool, called DEMKit, is a simulation and demonstration framework. Both tools can be used together to form a tool chain for smart grid studies. The ALPG uses high level residential statistics as input and has configuration parameters to change the penetration of emerging distributed energy resources (DERs). Power profiles of households and devices are generated from this data. Simulations of models are performed to create an occupancy profile of the inhabitants, which forms the base to determine when loads are switched on and off. This results in a load profile that is consistent with the behaviour of the persons in the household. Additionally, flexibility information is provided explicitly using generic components to allow for a direct comparison between decentralized energy management (DEM) approaches that exploit this flexibility. DEMKit implements the components and control systems presented in the previous chapters. Together with the output provided by the ALPG, this leads to a complete model of a smart grid. Due to the modular setup of DEMKit, different control systems and device models can be used. Using the tool, the effects of control systems on the physical grid can be evaluated. Furthermore, off-the-shelf home automation systems can be linked to the platform to allow rapid prototyping.
\end{abstract}

This chapter describes the tools developed to evaluate the performance of control approaches in smart grids on the physical grid infrastructure. The first tool is a

Parts of this chapter are based on [GH:5] and [GH:8] . 


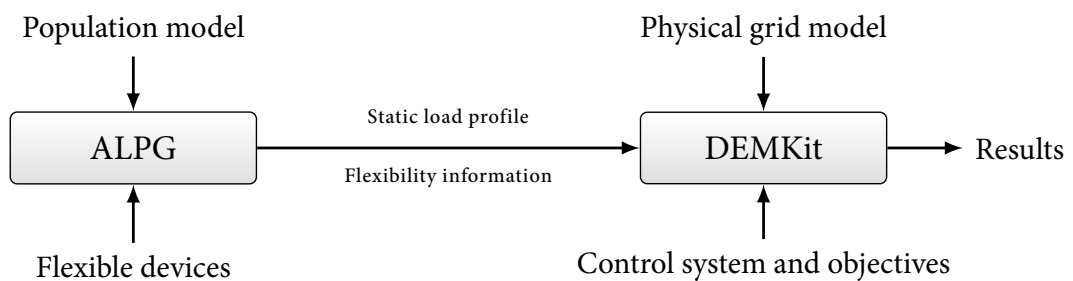

Figure 6.1: Diagram of the ALPG and DEMKit tool-chain.

standalone artificial load profile generator (ALPG) for residential areas, which generates household load profiles based on population statistics. In addition, this tool explicitly generates flexibility information, e.g. arrival and departure times of battery electric vehicles (BEVs). The second tool is a software platform to evaluate different scenarios and control strategies in both simulations and small-scale experimental demonstrations. Combined, the profile generator and the simulator can be used as a decision support tool for the implementation of smart energy systems.

The ALPG models different types of households based on energy usage of typical households. To generate profiles, the tool simulates a simplified model of users to derive activities and household occupancy profiles. This data is used to construct a power profile, including reactive power, and relevant flexibility information for DEM methodologies. In this way, a consistent power profile is constructed as both the profile and flexibility information depend on the household occupancy profile and activities.

The resulting profiles and data can be imported into the DEMKit simulation and demonstration tool. The components presented in Chapter 3 and the control approaches presented in Chapters 4 and 5 are implemented in this tool, resulting in a flexible and extensible framework for DEM research. Simulation functionality is developed on top of the components in order to orchestrate the coordination between the different components. Results are written in a time series database and interfacing with the OpenHAB home automation platform [121] is possible to perform rapid demonstration prototyping.

The remainder of this chapter describes the two tools, which together form a tool chain (see Figure 6.1) to perform simulation studies on smart grid control systems. The ALPG is presented first in Section 6.1 and the simulation and demonstration framework is presented in Section 6.2. For both tools, first the requirements and related work are presented, followed by details and design choices. The last section concludes the chapter. Simulation results of both tools are presented in the next chapter. 


\subsection{Artificial Load Profile Generator}

This section discusses the implementation details of the ALPG ${ }^{1}$. We start with the requirements for such a tool and a discussion of related work on demand profiles generators and point out shortcomings of available solutions. Subsequently we give an overview of the implemented tool, the required input and how realistic load profiles and flexibility information are derived from this.

\subsubsection{REQUIREMENTS}

To avoid grid overloading and power quality issues, flexibility offered by devices can be exploited by DEM systems. As such control systems rely on the flexibility offered by residential users and installed devices, it is essential to know what flexibility is available to the system. Therefore a tool to obtain realistic profiles and flexibility information is required to evaluate the performance of control systems. Creating a stand-alone tool for this purpose has the advantage that it creates the opportunity for other DEM simulators to use the resulting output data and compare each other's performance

The availability information of devices is usually expressed in start times (at which a device becomes available), deadlines and the amount of energy a device demands. This data is generally not easily obtainable. Measurement data merely consists of the aggregated electricity demand of a household and therefore lacks information about the available flexibility. Even if individual devices are measured, it is still unknown what their deadline was and whether a certain minimum (lower) demand of energy could have been sufficient to satisfy the end-user comfort constraints (e.g., a 50\% state of charge for a BEV). Furthermore, the considered use cases lay in the future, such as the development of new residential areas or to assess the impact of certain energy targets. We choose to use high level demographic statistics as an input to obtain reasonably accurate data with limited configuration effort. These statistics can easily be adapted to cover future scenarios. A part of this flexibility information depends on actions of users, such as preparing a washing machine or connecting a BEV. Therefore, this information should be consistent with the rest of the household profile and occupancy. Furthermore, the relevant flexibility information must be delivered as a separate output, in the form of constraints, such that optimization algorithms can use the provided information.

To specify the time granularity of data, we note that e.g. power quality regulations, such as [113], often 10-minute averages are used, whereas certain electricity markets are operated in 15 minute blocks. Furthermore, on a household level, short power usage peaks, such as from kettles, often have a duration of only one or two minutes. Similarly, energy production fluctuations from photovoltaic $(P V)$ panels may occur within a minute. Therefore, to preserve these shorter peaks in the load profile, we choose to output the data in discrete time intervals of one minute.

\footnotetext{
${ }^{1}$ The ALPG is available at: https://github.com/GENETX/alpg
} 
Summarizing, the requirements for the ALPG are as follows:

» Applicable for multiple DEM approaches (Versatility);

» Limited required configuration effort (Configuration effort);

" Explicit and generic flexibility information (Flexibility);

» Relative high accuracy of generated data (Accuracy).

\subsubsection{Related WORK}

Predicting and creating energy demand profiles for residential areas is a well studied field within power engineering. Such demand profiles usually consist of the aggregated demand profile for a group of households, where the large number of households helps to obtain realistic profiles. Jardini et al. [80] show that on this aggregated level, accurate forecasts for residential areas can be made. These forecasted profiles are also used to design and size distribution grid assets, or to investigate how to trade on the energy market. Such demand profiles are used to estimate the flexibility that the supply side has to offer. However, with the transition to renewable energy the demand for flexibility, and how this flexibility can be utilized, on the demand side is growing.

Where these aggregated profiles are sufficient for this high level consideration, within research on residential smart grids and DEM methodologies, the focus and modelling is usually on a much finer scale: that of individual devices within households. This asks for load demand profiles that explicitly specify consumption patterns of individual devices and households. In this context, obtaining household consumption measurements is generally not that hard. These are available in field tests (e.g., [GH:11]), or in online databases such as provided by Pecan Street inc. [123]. It is even possible to extract usage of individual devices, such as washing machines and BEVs, from an aggregated power consumption profile provided by smart meters using load disaggregation algorithms (see e.g. [GH:15] and [141]).

Pipattanasomporn et al. [125] have investigated the potential for DEM in United States (US) households using measurements. They identified a total of six major devices, suitable for DEM programs, and provide measurement data to construct residential load profiles. Kong et al. [94] propose a load profile generator that incorporates usage patterns derived from inhabitant simulations. Pflugradt et al. [124] describe a novel load profile generator that uses psychological models for user behaviour. The generator combines a solid model with an extensive set of measurements of individual devices. However, this tool is not easy to uses as it takes quite some time to set up a model due to the vast number of provided options. Another profile generator is given in [128], but also lacks flexibility information and lacks accuracy.

All these approaches require a lot of user input for the purpose of evaluating a DEM approach. Another drawback is that these techniques do not specify the exact degree of freedom these devices offer. Obtaining this data from a field test is tedious 
and costly. One would need to equip a large group of households with smart devices and measurement equipment. Another approach is to spread questionnaires to map the flexibility. Such an approach is taken by Stamminger [139], where the usage distributions for various devices through Europe are outlined.

Claessen et al. [23] use a generic way of specifying flexibility in their model to compare the performance of the TRIANA methodology [108] and the Intelligator methodology [155]. The general structure of the dataset satisfies the requirements and the research results show that such a dataset can be used by multiple DEM methodologies if it is structured well. However, this is a static, tailor made, use-case for the considered evaluation and thus offers no means to generate other use-cases.

\subsubsection{OverVIEW}

As all approaches mentioned above are either incomplete, inflexible or require too much modelling effort, we decided to develop our own ALPG in Python to evaluate DEM approaches. The profile generator uses a bottom-up approach that initially specifies for each household the available flexible devices, photovoltaic (PV) installations and batteries. Based on the configuration, the behaviour of individual inhabitants is simulated to obtain an occupancy profile. The occupancy profile is used to create consistent profiles for the devices, meaning that devices that require user interaction can only change their state when a person is at home. For flexible devices the usage patterns are also generated using the household configuration and it is guaranteed that the start times are synchronized with the occupancy profile. The available flexibility is specified using four flexible device classes presented in Chapter 3: Timeshiftables, buffer-timeshiftables, buffers and curtailables. The inflexible electricity profiles are categorized in the following categories: stand-by load, consumer electronics, lighting, inductive devices, fridges and other. These individual profiles are scaled in magnitude to reflect the annual electricity consumption. This makes it easy to alter the profile when external factors lead to a change in electricity usage, e.g. the adoption of LED lighting. Furthermore, power factors are assigned to obtain reactive power profiles as well. Some more information on these inflexible device categories are given in Table 6.1. These numbers are based on [40], [142] and analysis of measurement data obtained in the Lochem smart grid test site [GH:11].

The simulation components consists of multiple classes that each represent a part of the model, for which an overview of the structure is given in Figure 6.2. This makes the software flexible to be extended in the future. The following classes are implemented:

Persons: This class defines the behaviour of a person by generating and storing default patterns, such as, wake up times and arrival times from work. It sets parameters for activities such as sporting days, home working days, and the travel distance to work. An uncertainty variable is available to make the person more stochastic. 
Table 6.1: Uncontrollable device categories

\begin{tabular}{r|cc}
\hline Category & \% of annual consumption & Power factor range \\
\hline Stand-by & $17-25$ & $0.75-0.85$ capacitive \\
Electronics & $8-12$ & $0.99-1.00$ capacitive \\
Lighting & $3-6$ & $0.99-1.00$ capacitive \\
Fridge & N/A & $0.55-0.65$ inductive \\
Inductive & N/A & $0.70-0.90$ inductive \\
Other & N/A & 1.00 \\
\hline
\end{tabular}

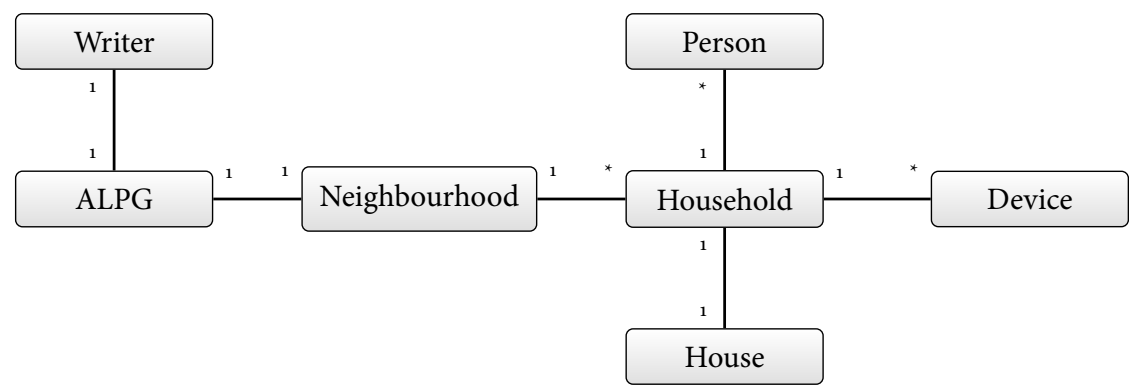

Figure 6.2: Class diagram of the ALPG.

Devices: This class represents the devices in a household and stores data about the information. For the inflexible loads, such as refrigerators, vacuum cleaners, lighting, models exist that specify the behaviour of these devices. Furthermore, for the flexible devices, flexibility information is stored in this class.

House: The House class stores information about the orientation of the roof to determine the PV generation based on the position of the sun and recorded irradiation data for a given location.

Households: The Households class contains various types of households with corresponding Persons, Devices and Houses, including annual power consumption values. This class is used to collect data of all devices and is in charge of bookkeeping the Devices attached to the household.

Neighbourhood: The Neighbourhood class contains information about the households in a residential area. Furthermore, it is in charge of distributing the available (PH)EVs, batteries and PV setups over the households.

Writer: The Writer class provides functionality to format the resulting output in suitable configuration files for DEM simulation software, such as DEMKit.

ALPG: The ALPG class contains references to all objects in the model and controls the generation of profiles. 
Table 6.2: Predefined household configurations

\begin{tabular}{r|cc}
\hline Name & Annual consumption & Persons (Adults) \\
\hline SingleWorker & $1610-2410 \mathrm{kWh}$ & $1(1)$ \\
DualWorker & $2660-4060 \mathrm{kWh}$ & $2(2)$ \\
FamilyDualWorker & $3460-7060 \mathrm{kWh}$ & $3-6(2)$ \\
FamilySingleWorker & $3460-7060 \mathrm{kWh}$ & $3-6(2)$ \\
FamilySingleParent & $2600-6200 \mathrm{kWh}$ & $2-5(1)$ \\
DualRetired & $2660-4060 \mathrm{kWh}$ & $2(2)$ \\
SingleRetired & $1610-2410 \mathrm{kWh}$ & $1(1)$ \\
\hline
\end{tabular}

\subsubsection{InPUt DATA}

The major problem for generating residential load profiles is either the lack of configurability or the burden of collecting and analysing enormous amounts of data to create models (which would result in more accurate and sophisticated profiles). However, such a degree of detail is not strictly required for the evaluation of DEM approaches. Instead, we focus on a minimal set of in general easily obtainable parameters and statistics (e.g. from surveys or census data) that result in decent load profiles.

These parameters for the model can be configured in the config.py-file, which provides options for the penetration of certain emerging technologies and the household types in the neighbourhood. The following parameters must be provided:

» Generation parameters: The number of days to be simulated and the randomization seed.

" Penetration of emerging technologies: This includes the percentage of households owning a BEV, battery storage and rooftop mounted PV.

» Power consumption of various devices: Power ratings and, if applicable, battery capacities for these emerging technologies have to be specified. Most of these values can be obtained through data sheets. Consumption levels of demanding devices, such as e.g. induction stoves, have to be provided as well

" Geographical location of the neighbourhood: The geographical location, which is used to obtain sunrise and sunset times

" Household types in the neighbourhood: the number and types of households are configured by selecting the number of each predefined household type. These predefined households are tabulated in Table 6.2 and include, amongst others, families and single households. These values are based on [19] and [142].

"Predictability of persons: The amount to which the behaviour of inhabitants is predictable can be configured to allow some deviation in the number 
of random events. These events represent randomly adding or skipping actions from the standard behaviour pattern. This makes it possible to evaluate the robustness of DEM approaches to prediction errors.

Next to the parameters defined in the configuration file, also other classes may be extended to better reflect local behaviour and scenarios. The Persons class can be inherited if person profiles need to be changed or new default profiles of persons are required. This includes for example changing the default distributions for wakeup times. Furthermore, new devices can be derived from the Devices class, which contains the generic device subclasses and their flexibility parameters. Since high level data is used, instances of houses, persons and devices have to be created based on the input data by the ALPG. Therefore, truncated Gaussian distributions are used to select parameters for these instances. These are part of the component models, and therefore found in the code itself.

\subsubsection{Simulation and Generation}

The program runs by executing profilegenerator.py. This starts the initialization of the components and the selection of values from predefined distributions, after which the simulation of households starts to produce profiles and flexibility data.

\section{Generation}

The components are instantiated initially when executing the ALPG using values from the input parameters. Parameters for households, persons, devices, etc, are chosen from a Gaussian distribution. For each individual household the presence of devices such as dryers and dishwashers is determined by probability, which depends on the type of household. Furthermore, the annual power consumption for some of the uncontrollable load categories is chosen using a truncated Gaussian distribution, in which the mean value represents the average consumption per static load category for the given type of household and in combination with the number of adults and children.

Within the household generation, the number of children and the age of each inhabitant is chosen using a bounded uniform distribution. All generated persons are stored in a list, in which the first person is always an adult. For this person, the driving distance to work is chosen using a Gaussian distribution for which the mean and variance can be configured. This value is zero for those without a job.

An occupancy profile is generated using a simple behavioural model. This model is configured using mean times for general events that change the state of a person to either active (being home), inactive (e.g., sleeping) or away (e.g., to work). The exact times for inhabitants are chosen using a truncated Gaussian distribution. Days with regular events, such as sporting activities, washing days and home working, are also selected based on the person model. 
After the individual households and the corresponding persons are established, they are assigned to a random house in the grid. Next, the devices with specific penetration levels are distributed over the households to control the penetration of these devices.

" PV setups are randomly distributed over the households and the orientation of the roof is randomly chosen within predefined bounds.

" The selected amount of battery storage systems is spread over the houseseholds with a PV setup, such that they can increase their self consumption.

"The BEVs are distributed over the households with the largest commute distance. Note that the current implementation is limited to only one BEV per household.

\section{Simulation}

After all components are instantiated, a simulation is started. Within this simulation, the behavioural model of each component is used to simulate its actions during a day. For persons, this results in an occupancy profile, whereas a static load profile or flexibility information for devices is created. To avoid high memory usage, each house is simulated individually and written into an output file.

The simulation for a household consists of two parts: first the persons in the household are simulated to obtain the occupancy profile, and afterwards the device behaviour is simulated. This order is chosen, since the behaviour of the inhabitants of the household is leading for interactions with devices. The simulation of persons distinguishes between weekend days and workdays. During the weekends, the weekend schedule of persons is simulated to obtain their occupancy profile. A working day is simulated on working days, except on a day off, for which also a weekend schedule is simulated. The exact activity event times are randomized. Other random events (e.g., shopping) are added to the occupancy profile. In the weekends there is a higher probability that the whole family may leave, e.g. to visit relatives. These events synchronizes the individual occupancy profiles.

The simulation process for the devices is as follows:

" The static stand-by profile is always applied to the load profile. On top of this stand-by profile, the individual freezers and refrigerators are simulated.

" Electronic equipment, such as computers and televisions, are activated using a probability function, which depends on the number of active inhabitants. Each person that changes its state to active can trigger a device to be turned on, which results in a power consumption time series. This time series profile is scaled in magnitude during the post processing step to match the annual power consumption for electronics. As soon as a person leaves the house again, certain devices are turned off with a given probability. The simulation ensures that no static load devices are left on when nobody is at home. However, flexible devices, such as timeshiftables, do have the option to operate. 
" Power consumption for ironing and vacuum cleaning is added approximately once per week.

"For cooking, the highest probability is assigned to cook using the stove, but there are chances that the oven or microwave is used instead. Based on the chosen device for cooking, the simulation decides whether the exhaust hood is turned on or not. Coffee makers and (electric) kettles are turned on randomly when at least one person is active. Lighting is turned on approximately 30 minutes before sunset.

" The start times of the washing machine are chosen based on the occupancy profile, available devices and preferred washing days of a person. A measured profile from a washing machine is available, which determines the minimum runtime and therefore the minimum end time. The deadline is chosen on basis of the minimum runtime and the occupancy profile. The simulation ensures that no start and end times overlap and that all deadlines can be met by the device. The same process is used for the dishwasher.

» BEVs are activated as soon as their owner gets back home from work, unless a random event is scheduled later in the evening for which the car is used. The car has to be charged before this person leaves to work the next day. The required charge is based on the driving distance with an average energy consumption of $1 \mathrm{kWh}$ per $5 \mathrm{~km}$, with a variation to this value to reflect driving conditions and behaviour. The energy requirement is slightly increased during the winter months and reduced during the summer, to reflect the effect of different indoor and outdoor temperatures on the battery performance as shown in [99]. Other random trips, such as family outings, are included in the BEV usage pattern. The simulation ensures that no start and end times overlap and that all deadlines can be met by the BEV.

\section{Post processing}

When all usage patterns are determined, the static load profiles are post-processed. First, the lighting, stand-by and electronics profiles are rescaled in magnitude to reflect the annual consumption for these consumption categories. Such a rescaling is applied to all categories to obtain a reactive power profile.

\subsubsection{Output Data}

The output of the ALPG consists of two major parts: The flexible part and the inflexible part. The latter is stored in comma separated values (csv) file that specifies the average power consumption in watts for each minute for each household. The rows represent the minute intervals in ascending order and each column represents a household in ascending order. Likewise, a csv file with the reactive power profile is stored. Examples of output load profiles are given in Figures 6.3a (no optimization used) and 6.3b (with optimization). 


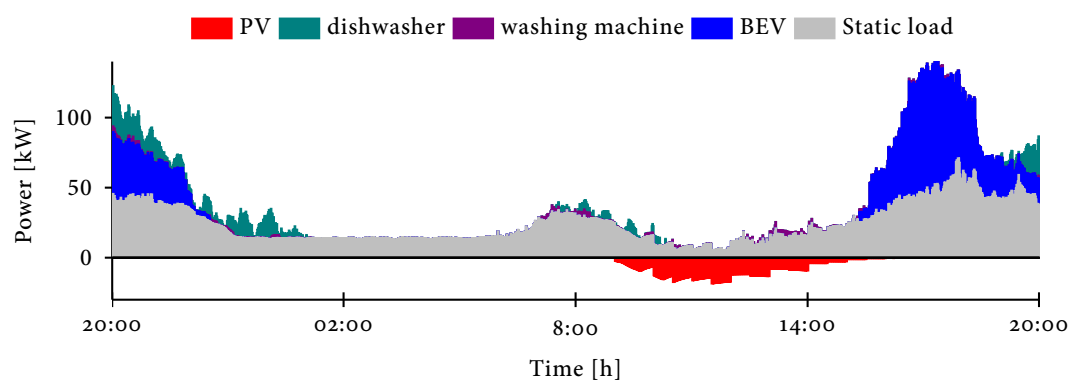

(a) Without optimization

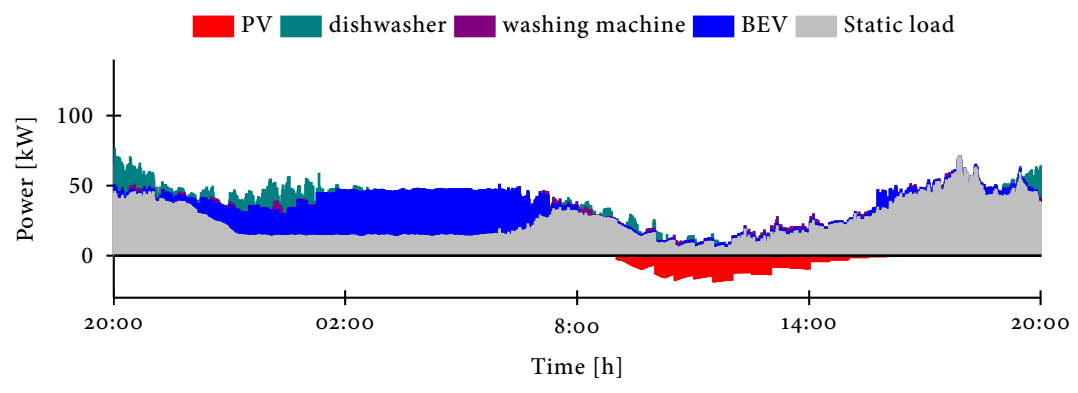

(b) With optimization

Figure 6.3: Resulting power profiles based on ALPG output.

For the flexible devices we do not want to create a huge variety of different output files to specify these devices. Therefore, we specify a restricted set of flexibility classes and for each of these classes we specify which data has to be provided. The individual devices are assigned to one of these classes. This limited amount of device classes asks only for a limited number of corresponding optimization algorithms in DEM approaches. Such an approach is the DEMKit platform presented in the next section, but also EF-Pi [51] uses a similar set of devices.

The following device classes, as presented in Chapter 3, are used. For all classes also the EF-Pi equivalent is given:

" Uncontrollable: e.g., stand-by usage and electronics. The output of the static load devices is stored in a list with the average power consumption for each interval. Resulting output is provided in the format as described in Subsection 3.1.2. The equivalent class in EF-Pi is the Uncontrollable.

»Curtailable: e.g., PV. This class specifies a fixed consumption or production profile and the amount of power that can be curtailed. Resulting output is provided in the format as described in Subsection 3.1.3. The equivalent class in EF-Pi is the Uncontrollable. 
" Timeshiftable: e.g., washing machines, dryers and dishwashers. Real measurement data is used to obtain a static consumption profile in watts. The use of timeshiftable devices is given by a list of jobs that have both an arrival time and deadline in seconds. The static consumption profile of the device should be finished before the deadline and not started before the arrival time of each job. Resulting output is provided in the format as described in Subsection 3.1.7. The EF-Pi equivalent for this class is the Timeshifter.

" Buffer-Timeshiftable: e.g., BEVs. The flexibility is specified by jobs with a start time, deadline (both given in seconds) and required energy demand in watt-hours. These devices have a fixed maximum power consumption in watts and buffer capacity in watt-hours. Resulting output is provided in the format as described in Subsection 3.1.8. The equivalent EF-Pi device class is the Buffer.

» Buffer: e.g., a battery or hot water buffer. The specification gives a maximum power consumption or production level in watts and capacity in watt-hours. Resulting output is provided in the format as described in Subsection 3.1.4. The equivalent class in EF-Pi is the Buffer.

The ALPG provides output data using minute based intervals. This is detailed enough to see short term peaks and dynamics, resulting from devices such as kettles, but makes it also possible to analyse the effect of using longer term schedules based on more aggregated time intervals, usually 15 minute intervals, on the resulting profile when applying real-time control. As a final result, the ALPG is a versatile tool to provide input data for DEM approaches. The same data can also be used to compare multiple DEM approaches based on one use-case. A comparison between generated profiles and real measurement data is made in Chapter 7.

\subsection{DEMKIT}

To evaluate the performance of the presented control systems, considering the models from Chapter 3, a simulator and demonstration framework called DEMKit has been developed. The goals of the framework is not only to perform simulation studies, but also to provide the possibilities for co-simulations and small demonstrators. In the following, the simulation control logic and hardware interfaces are discussed and details are given how co-simulations can be performed using the developed framework. The following subsections present related work and motivate why this framework was developed. Subsequently the overall framework and subcomponents, such as devices and controllers, are discussed.

\subsubsection{REQUIREMENTS}

The goal of the simulator is to study use cases by modelling individual devices, which make up a household or a building. Subsequently, it should be possible to connect multiple buildings to a physical (micro)grid for up to a few hundred households or buildings. On top of these physical components, a digital control system 
can be modelled, resulting in a cyber-physical simulation tool. To accommodate the research on different electricity grids, control strategies and scenarios, a flexible and extensible framework is required. We see the components presented in Chapter 3 as the main building blocks for such a simulation framework. The motivation for this choice is that the explicit separation between physical models and control methods makes it possible to easily swap control strategies or device components with different granularities of detail. Therefore, the tool has to provide a package of components for efficient and effective research on DEM methodologies, such that new ideas and concepts can be tested easily. Furthermore, the separation between device and control should also allow for a smooth transition from a pure simulation based approach to a small demonstrator where device components can be replaced by their real counterparts to perform demonstrations. For this purpose the framework must provide the possibility to interface with hardware. Preferably offthe-shelf hardware should be integrated to allow for rapid prototyping. We choose to rely on an external database and feature rich third-party tools for analysis of the resulting simulation data.

Measurement samples are considered to be processed in a rather high frequency, so we choose the maximum frequency to be $1 \mathrm{~Hz}$ (an interval length of 1 second). Since the sampling rate of data may vary across devices and dataset, we require the possibility to have an adjustable interval length and the possibility to use different interval lengths where resampling is executed upon simulation. The simulation interval lengths can therefore also be changed to trade accuracy for simulation time.

In the end, the focus is on the resulting data produced by the simulation tool. Since every single component is modelled individually, large quantities of output data can be expected for a typical microgrid setting with hundreds of devices, controllers and grid components for each simulated time interval. Hence, not only a proper method for storage of all this data is required, but also a tool chain that allows for convenient analysis of the resulting data.

Summarizing, the requirements for DEMKit are as follows:

» Decoupled control system and physical system simulation (Decoupling);

"Extensible with new technologies and methodologies (Extensibility);

"Support prototyping and demonstration using hardware (Demonstrators);

» Fast agile prototyping to support research (Agility);

» Detailed simulation output on various levels (Detail).

\subsubsection{ReLATED Work}

The energy transition demands tools to evaluate the effectiveness and (economic) feasibility of considered solutions to provide a clean energy supply chain. With options in generation, control systems, grids, energy mixes, etc, the search space for 
such solutions is often very large. Various modelling software and simulation solutions exist to guide the policy makers in this process. A comprehensive overview of available software tools for decision making is published in [26]. These tools range from energy simulations on a regional or even national scale (e.g. EnergyPLAN [41] or Energy Transition Model [127]) to small scale models (e.g. EnergyPRO [39]). Gridlab-D [20] for example is a tool that is specialized in simulating the effects of the energy transition on the physical transmission and distribution grids. The considered energy carriers, timestep size, control systems and optimization methods also hugely differ between all these tools.

With our focus on evaluating small microgrids with up to a few hundreds of households or other buildings, the above mentioned tools do not satisfy our requirements. We are interested in an in-depth, bottom-up approach with a focus on a cyberphysical simulations. HOMER [71] is a tool that allows for detailed modelling of microgrids. It also incorporates deferrable loads, buffers and accompanying control and optimization modules. However, the software is closed source and the exact optimization algorithms are not disclosed. But this is an essential requirement to study the effects of control mechanisms on the physical grid. On the other side also some specific distribution grid simulators exist, created to guide network planners in the process of designing new grids. However, these tools in general do not model the device level in sufficient detail.

A fruitful solution to perform cyber-physical simulations is to combine domain specific tools. The Mosaik framework [131, 134] framework, written in Python, offers basic simulation functionality to add components, such as devices and controllers, to a simulation model. Furthermore, it offers various interfaces to integrate Matlab functions or to communicate with the load-flow simulator PyPower for grid analysis [102]. Compared to all other simulators, Mosaik provides merely a framework for simulations and thereby does not provide an extensive library with device components and controller components.

In previous work at the University of Twente already a simulator has been developed by Molderink [107] and Bakker [8], for which the requirements largely align with ours. Another, separate, implementation was developed for demonstration within a field test [9]. With a tailor-made simulator, framework overhead is omitted, resulting in a light-weight simulator able to efficiently simulate larger use-cases. Furthermore, this approach gave the developers the complete implementation freedom as no limitations of some framework had to be considered. To further speed-up the simulations, the tool did not rely on external tools and interfacing overhead. This approach was later followed with the integration of more advanced grid components and a load-flow solver [GH:14]. Another prominent advantage of such integration became clear as it allowed a tight and flexible integration of control and the physical grid. 


\subsubsection{StRUCTURE}

After evaluation of all possible options, we decided to continue the path of developing our own simulator. The main motivators are that the expertise and reference code was already available, reducing the effort required to build a simulator from scratch. Thereby, we also maintain the full flexibility to implement the simulation and co-simulation as we intended to do. After an extensive code review we decided to rewrite the simulator as the code of the original simulator had become cluttered through several research projects and prototypes. Furthermore, some design choices hindered the implementation of newly developed concepts.

The focus of the new code base is to provide an agile platform for research and rapid prototyping for real-world validations, hereby extending the aim of the previous simulator. The platform is written in Python to benefit from dozens of scientific packages and object oriented programming structures. On the other side, the software does not need to be compiled and Python is supported on multiple operating systems for both desktops and embedded computer systems. This helps to achieve an ecosystem where simulation cases can gradually be developed, fine tuned and finally copied onto a real system. Various proof-of-concept iterations can be implemented and feedback can be incorporated in an early stage of development. Since simulation and demonstration share the same code-base, measurements from a test can be imported to re-simulate and resolve potential issues for a new prototype. We call the developed platform DEMKit, which is short for DEM toolkit.

The main reason for the new simulator is that we decided to follow a strict cyberphysical separation approach. As a result, the device components and behavioural description are separated from the control components. This separation allows us to easily swap devices or controllers as motivated in Chapter 3. As a consequence, both the optimization algorithms and devices can have different models. This allows for instance to use a simplified model for optimization to reduce computation time, but to test the effect of using optimized control actions resulting from the simplified model on a more advanced device model or the actual physical device. The latter is also one of our key requirements as we wish to use the tool for co-simulation and small scale demonstrators. On the control hierarchy itself we also changed the structure. The original simulator implemented different model levels, such as houses and the grid. As a result, devices could only be added at the house level. To allow different structures and allow the installation of grid assets on other control levels, we removed this levelled structure. It is replaced with a modular structure that allows for other structures and flexible modelling, as long as the implementation of controllers support this.

Despite all these architectural changes, various basic principles from the original simulator have been preserved. Most notable is the discrete time simulation, which uses a similar interface of handling the time synchronization as in the previous simulator. One central entity, to which all components are attached, coordinates the simulation flow and distributes the time progress to all these components. Therefore, similar functions are implemented to handle the initialization process and 
simulation of the components, including resampling to support mixed time bases. Furthermore, functionality to trigger predictions, optimization and control are also implemented in the controllers.

The choice to rewrite the simulator also allowed us to change from $\mathrm{C}++$ code in the original simulator to an implementation in the Python 3 programming language. The main advantages and reasons for this choice are:

" The focus is on performing research and developing proof-of-concept implementations. Practical experiences with the original simulator showed significant struggling with the steep learning curve, dependency errors, compilation process and time consuming implementation of low level functions. Due to the wide support of Python and numerous available libraries, such proof-of-concept implementations can be developed rapidly.

"As the research field is multidisciplinary, Python is generally easier to learn such that researchers with basic programming experience can contribute.

»Python is also supported on embedded hardware platforms without the need for recompilation, which also become increasingly powerful. This justifies the performance penalty between a lower level language, such as $\mathrm{C}++$, and Python. Compared to other solutions, such as implementations in Matlab, Python is an object oriented programming language that allows for a clear implementation of complex structures such as the developed simulation and demonstration platform.

"The focus is solely on the implementation of the components and control algorithms. As a result, no user interface is implemented and external tools are used where applicable.

\subsubsection{FRAMEWORK}

The general framework of the DEMKit software consists of classes and interfaces to external tools, together with a library of components. These components include devices, grid assets and controllers. The framework provides the tools to instantiate instances of these components and link them together such that the models can interact with each other and with the simulation or demonstration environment. A class diagram of the structure is depicted in Figure 6.4, where the symbols as introduced in Chapter 3 symbolize the implementation of these models within the DEMKit framework.

\section{Configuration}

Python scripts are used to create and configure a model of a neighbourhood. The configuration script is passed as an argument to DEMKit on the command line tool. Such a model consists of instantiations of the individual device components, grid assets and control components which are available within the DEMKit components library, which is discussed in the next subsection. Within the configuration 


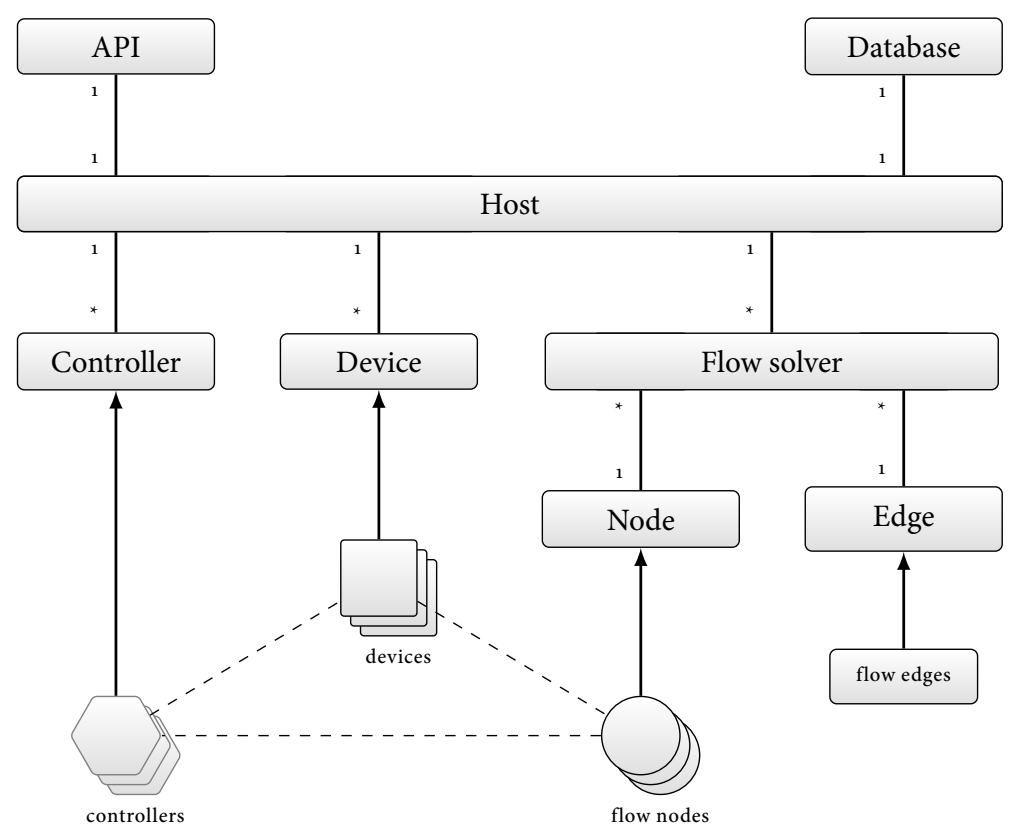

Figure 6.4: Class diagram of the DEMKit platform.

file, the desired components from this library can be imported and used. All these components have a link to the DEMKit environment, such that components can interact. Components can also create connections, in the form of object references, to other instantiated components to perform the interactions as described in Chapter 3. Examples are connections between controllers to create a tree structure, or the link between a controller and a device component for control. Components that require a connection to another component enforce this through a mandatory parameter in the instantiation function. Subsequently, the default parameters of the individual components can be changed, such as e.g. the capacity of a buffer. Environment parameters, such as the number of simulation intervals and the database to write results to can be configured.

The output of the aforementioned ALPG can be used to model the households in a neighbourhood. Subsequently, the household models can be connected to a node within the physical grid component. On the other hand, optional controllers can be connected to the devices within the household to perform energy profile optimization. The use of Python scripts for configuration also allows for convenient modelling of complex systems, such as e.g. a synthetic low voltage $(L V)$ network. 


\section{Host System}

The most notable class of the DEMKit framework is the Host-class, which represents the system on which the framework is executed. Dependent on the purpose, a different selection of host system functionality is instantiated. An interface to store data into a database is included for all use cases, but the simulation flow is only included for a simulation case, while an HTTP REST application programming interface (API) is instantiated for demonstrators. This use-case dependent instantiation reduces the overhead by only using the required functionality. Functionality can therefore be gradually included for a step-wise transition from a pure simulation based setup towards a co-simulation environment with real hardware.

All instantiated components have a reference to a singleton instance of the host class and vice versa. This allows the host to interact with instantiated components such as forwarding received messages from the API. This also works the other way around, as components can interact with the framework to write data, display messages or expose information through the API. More importantly, the host also performs function calls to signal important events, such as a (simulated) startup and shutdown of the system, and the time progress in case of a simulation. Based on these events, individual components can perform actions such as an initialization or write final results to the database.

\section{Data Storage}

To store the massive amounts of data generated by thousands of instantiated components for thousands of intervals, a database is used. We have chosen to use a time-series database as both simulation data and measurement data is produced in discrete time series. From the available time series databases, we have chosen to use InfluxDB [76] due to its ease of use and the availability on all major desktop operating systems and embedded architectures. This database does not require predefined data tables, allowing users to conveniently log new types of data on the fly through the web based API. A database class is created to interface with the database, which may be replaced to support other databases in the future. A function is available to push values, linked to tags, from the components objects to the database class instance. To limit the performance penalty of writing data trough the InfluxDB API, we buffer all data that has to be written to the database. Only when this buffer exceeds a predefined number of characters the data is send to the database and the buffer is cleared.

To access and visualize the resulting data, another software tool, Grafana [58], is used. This software provides functions to aggregate data from multiple time series, as well as tools to calculate e.g. mean values, or filter the 95-th percentile. The tool also provides a convenient user interface which lists all logged data tags to construct queries. Grafana is also available for all major operating systems. 


\section{Application Programming Interface}

An hypertext transport protocol (HTTP) representational state transfer (REST) API is implemented to communicate with the framework in co-simulation environments with Javascript object notation (JSON) to communicate data. The API exposes functionality for external time progress and communication to instantiated components in the framework. Time advancement synchronization is performed from an external tool which indicates the time progress by posting a time tick. Internal instantiated components in the software can be accessed externally by addressing them via unique names. Components can extend the functionality of the API too to expose functionality such as the internal status of a device component. The controllers expose functionality through the API in order to support distributed control over several physical systems. An intermediate layer has to be added which translates internal function calls into API calls to the external system. This abstraction layer allows the use of the same controller components as used in a pure simulation environment.

\subsubsection{COMPONENTS Library}

A model of a residential microgrid, can be constructed by instantiating different device, grid and controller components. The individual components as presented in Chapter 3 are implemented in the DEMKit framework library.

\section{Device Models}

Within simulations, generic device components are available that describe the behaviour of a device and customizable parameters. All device implementations inherit from a common class, which implements the minimal required functionality for a device. Each device at least expresses its current (complex) power consumption for each commodity through a variable, such that a device can be connected to the physical grid model. Optionally, device components can also expose internal states towards the attached controller. Each instantiation also acts as a storage container for relevant flexibility information, which can be accessed by external controllers to optimize the operation of the device. This information, and the relevant parameters of a device, can be configured directly as these are all public. These parameters often also result in constraints for optimization, such as the buffer capacity or time intervals in which a BEV is connected.

The device components describe the behaviour of a device without external control, i.e. only internal device logic is defined. Within simulations, this device behaviour is simulated by a discrete time progress, triggered through the timeTick function call. Hereby, as basis often a greedy strategy is used, e.g. start the timeshifter as soon as it becomes available or charge a BEV as fast as possible. Furthermore, human behaviour is implicitly modelled within these components. For example, a washing machine is modelled as a timeshifter and requires a static time series load profile, together with a list of start and due times, which represent the human- 
device interaction. Each device also contains a list of planned power values, which may be filled by the external controller.

If a controller specifies a planned power value for the current time interval, the device has a preference to bring itself in a state that satisfies this planned power value. However, the device behaviour model is leading, meaning that a device will not follow the planned value when it is unable to do so. An example is an empty battery which is expected to inject power. Since there is no charge left, the battery cannot comply and executes the best possible option in this state by setting its power consumption to $0 \mathrm{~W}$.

\section{Grid Models}

Power consumption of multiple devices can be aggregated into one value through a meter component. This meter component is linked to a node in the flow model. Such a flow model consists of a graph, which represents the physical energy distribution network. Hereby, a generic representation of vertices and edges can be used for e.g. electricity grids, heat networks and natural gas distribution infrastructure. Connected to this graph is a load-flow solver to calculate the steady state within the given grid.

Models of LV cables, derived from the edge class, are implemented within the framework, together with nodes representing the three bus types. A load-flow solver for three-phase four-wire unbalanced low-voltage electricity distribution networks is currently implemented as presented in Chapter 3. This solver reads out the consumption data of the meter components to determine the voltages and currents in the network. The load-flow problem is solved every discrete time step to obtain a steady state of the network, which then can be used as input for control actions in the next discrete time interval. This data can be accessed through public variables. Also, voltage information is forwarded to devices, such that e.g. PV inverters can stop production if the local voltage exceeds a predefined upper limit.

\section{Controllers}

Control systems form the cyber-part of our simulation environment. All the data processing, evaluation, optimization and control actions to be executed are simulated in control components. Based on the type of control, a base class may be implemented, from which all other control components are derived, but in contrast to the physical part, no mandatory interface for controllers is implemented. Instead, all controllers need to implement the generic framework interface to allow interaction with the rest of the environment and to receive simulation specific triggers. Furthermore, controllers that influence the behaviour of devices can use a standard interface to write planned control actions into the device's planning array.

Two control strategies are implemented in the current version of the DEMKit framework: the profile steering approach presented in Chapter 4 and the double-sided auction presented in Chapter 5 . In both these approaches, the control structure is 
formed by a tree, in which the top level (root of the tree) coordinates all control actions and steers the fleet. This controller structure is formed by object references between the instantiated control components in the configuration. The lower level (leaves) form the device controllers and have a significant different implementation then all intermediate nodes. Most functionality, such as the device specific optimization algorithms and the demand functions, are implemented in a separate library for re-use. All functions required for control, such as performing predictions or constructing demand functions, are implemented in the control level to keep the strict separation between device components and control. The device controllers have references to the controlled device(s), in order to obtain the device constraints that need to be satisfied by control actions.

Alike devices, all controllers also receive a timetick during simulations to progress time. However, the dependency checking is done on the control level. Since we only deal with tree structures, a parent/child reference structure (with a maximum of one parent per controller) is used and only controllers without a parent, which in our case is the root controller, act on this timetick signal. Other control structures, such as a meshed structure, are possible by implementing different dependency checking mechanisms or arbitrary ordering of control components.

\subsubsection{EXECUTION}

The DEMKit platform is executed from the command line by running demkit.py using Python 3. This script requires the used configuration file to be passed as an argument on the command line. The tool first includes mandatory libraries and sets the path to the configuration file directory, such that file references within configuration files can be relative. Subsequently, it loads the configuration script and imports the used instantiate parametrized components. All components are then instantiated, initialized and parameters are set. Lastly, a connection to the database is established and the API is started in case of a co-simulation environment.

After the complete model is built and all internals are initialized, the platform signals the startup-command to all components. Based on this signal, devices can perform some last initialization, such as validating non default parameters for correctness. Likewise, controllers can perform an initial prediction and planning. After all components have reacted to this startup signal, the environment is ready to commence normal operation, such as (co-)simulation. A similar shutdown signal is broadcast over all components when the execution comes to an end. This allows components to store final results and, if necessary, disconnect in a proper manner.

\subsubsection{Simulation}

Within a simulation, the simulationHost provides the simulation logic. After the initialization is finished, the host starts a for-loop to simulate time progression based on the configured simulation timestep size and number of intervals. Within this loop, the timeTick function of all components is called in each iteration of the 
for-loop. Furthermore, in each iteration, the simulation timestamp is increased by the stepsize and this time is passed as function argument. This results in a linear time series simulation, where each component can update its state based on the selected state in the previous interval.

Since there is a dependency between the flow simulation and devices, the order in which the components are execute in a simulation step is important. Therefore, timeticks are distributed first to the controllers, which can alter the behaviour of the device if desired. Subsequently, all the devices receive the timetick to advance in time and update their internal state and power consumption. In this stage, devices can also signal events to their controller, such as to request a (re)planning based on local changes. After all the device components received the timetick, the load-flow simulation is performed as this power consumption is required by the physical grid model.

\subsubsection{Co-Simulation}

Next to running simulations, DEMKit can also be used to control real devices or interface with other simulation based tools. This mixed operation is referred to as co-simulation. We specifically focus on co-simulation with real-hardware, but the following concepts can also be used for interaction between multiple simulators, or distributed control with multiple instances of DEMKit.

Within co-simulations and demonstrations time synchronization between the simulated part and the real world is required. Therefore, the API provides an interface to signal time progress from an external source, in order to synchronize the simulation with the real hardware. Device components that are to be replaced by their physical counterparts need to be exchanged for device connector components. These components need to translate internal control setpoints and actions into API calls supported by the device that is to be controlled. The separation between controllers and devices in our implementation allows the use of the same controllers and optimization code in both the simulation case and co-simulation environment.

To control physical devices from the DEMKit environment, a set of device connectors is implemented which interfaces with devices connected to the OpenHAB home automation platform [121]. More precisely, it interfaces with so-called items in OpenHAB, which represent properties, setpoints and parameters of a physical device. A set of these items represents one physical device (called a Thing in OpenHAB), where some items represent a readable state, such as the measured temperature, and others an influenceable state, such as a power consumption setpoint. These items communicate with the thing (device) through channels. An example of this setup is the software driver for a BEV (the thing), which exposes, amongst others, channels to read the state of charge ( $\mathrm{SoC}$ ) and power consumption setpoint. Items are linked to these channels, such that the BEV can be controlled. 


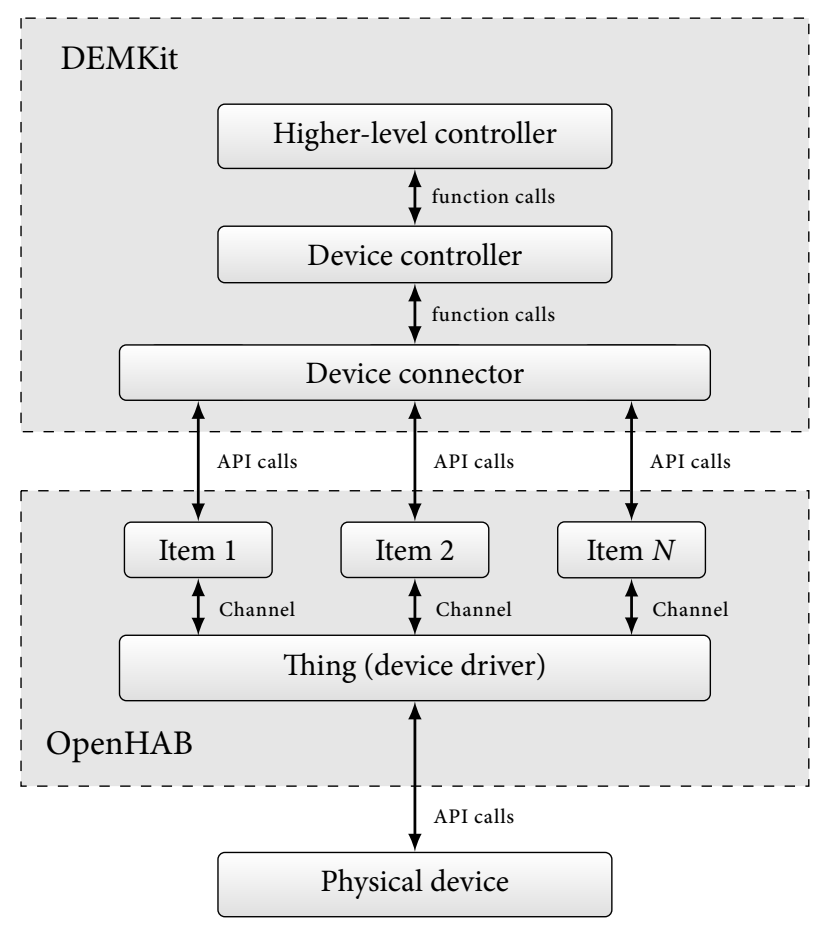

Figure 6.5: Structure of the combination of DEMKit and OpenHAB to control real devices.

The connectors implemented in DEMKit allow for bi-directional communication between the DEMKit platform and OpenHAB items. This stack, consisting of DEMKit, OpenHAB and a physical device is shown in Figure 6.5. The OpenHAB software provides bindings (drivers) for over a hundred technologies and devices, such as Miele smarthome and Tesla cars. Using this home automation platform results in an abstraction layer, such that individual device drivers do not need to be implemented. With the large number of supported devices, this combination is flexible and allows for rapid prototyping.

\subsubsection{VALIDATION}

Correctness of the implemented components and resulting simulation results is critical. Therefore, the correctness of the implementation is verified using three methods: unit tests, assertions and extensive analysis of simulation results. Unit tests are written for the optimization algorithms and helper functions for which the outcomes should not become infeasible or change at all, but for which speed optimizations are likely to be implemented. We chose to create unit tests for the implemented device level algorithms presented in [148] and demand functions for the double-sided auctions. 
Since the behavioural description of physical components may be updated with more realistic components, we have not created unit tests for devices and grid assets. Instead, we inserted assertion statements in the code to ensure that these components do not violate physical properties. The software exits when such an assertion is false. Examples are buffers that have a negative SoC or are filled above their capacity, and devices that consume/produce more power than the maximum rating. The same holds for devices that consume/produce power whilst they are not connected, such as a departed BEV.

Lastly, extensive simulations are being executed. For most components, a small simulation setup is created to validate the model by hand in its isolated form. But also larger scenarios are validated on both the local level, e.g. a single device, and the global level, e.g. total power consumption at the transformer. The extensive set of data allows us to check whether the results of a single component are correct. It also allows us to check the interplay of multiple instantiated components. Thus it can be considered as an integration test as well. Results of simulations with DEMKit are presented in the next chapter.

\subsection{Conclusion}

In this chapter we presented a novel artificial load profile generator to generate power profiles and flexibility information for DEM control strategies and a cyberphysical systems oriented simulation framework to evaluate smart grid control mechanisms. These two tools can work both stand-alone or together, creating flexibility to compare results of different use-cases and control implementations.

The main advantage of the ALPG is that the output explicitly specifies the available flexibility of consumer devices within the smart grid. This flexibility information is provided explicitly and in a generic format, such that other DEM approaches can utilize the tool as well and performance comparison among different tools is possible. As the ALPG simulates the occupancy of individual inhabitants and the flexibility information of devices synchronizes this occupancy profile. To prevent the burden of seemingly endless modelling of a smart grid with all devices, the ALPG uses only a limited number of input parameters. As a result, the tool allows convenient creation of realistic simulation use-cases to evaluate the performance of DEM approaches in residential areas.

The second tool, DEMKit, provides an extensive platform to test DEM approaches in a simulation environment. Herein, a cyber-physical systems approach is taken where control and physical components are modelled separately. This separation gives the platform flexibility to change and add individual components and to evaluate the effect of such a change. On the other hand, all these components are implemented in the framework, allowing for a tight interconnection and interaction between individual components and control mechanisms. Since the structure of interconnected components is not dictated by the platform and information dependency checking has to be resolved on the component level, the framework 
is flexible to support different control structures. Device components can also be replaced by connector interfaces to their physical counterparts, making a seamless transition from a pure simulation setup to a co-simulation or demonstration prototype possible.

This tool chain is used to evaluate the potential of the developed control methodologies and optimization algorithms in future scenarios. Model validation using measurement data and simulation studies are presented in the next chapter. 


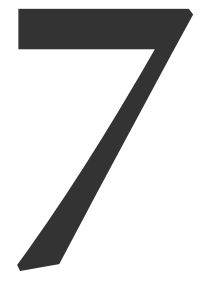

\title{
EXPERIMENTS AND RESULTS
}

\begin{abstract}
In the previous chapter we presented a tool chain to model and evaluate smart grid use cases in a cyber-physical systems context. The versatility and accurateness of the implemented components and control methods are validated in this chapter. Central is the smart grid test site in the Dutch town of Lochem, where measurements and experiments are conducted. One of these experiments was a stress test with 20 battery electric vehicles, which ended with an outage due to long term overloading. The used grid models are found to be accurate when comparing simulation results with the measurement data. Additionally, measurement data from Lochem is used to test the accuracy of the artificial load profile generator output. Several futuristic simulation studies are performed using this tool chain. Firstly, the optimization potential of domestic devices is tested using the control mechanisms presented in Chapters 4 and 5, for which significant power quality and grid stress relief is obtained compared to an uncontrolled case. More realistic scenarios with limited flexibility, based on questionnaires held in Lochem, show that the actual flexibility that users want to provide is significantly less than in the optimistic cases with full flexibility. This results in a significant reduced peak shaving performance. In an islanded use-case, it is shown that the control approach is able to relief a backup system, while incorporating time delays. Finally, the control approach is also able to perform peak shaving when communication networks fail by using the grid voltage or frequency as a communication channel. The performance is reduced when voltage fluctuations of the medium voltage grid are incorporated, but overloading and power quality problems are still avoided.
\end{abstract}

Power quality and capacity issues are expected with further electrification of the energy supply chain. The goal of this chapter is to evaluate the performance of the control methods presented in Chapters 4 and 5 to avoid such problems in futuristic

Parts of this chapter are based on [GH:4], [GH:6], [GH:8] and [GH:11]. 
scenarios. These evaluations are conducted by means of simulation studies. Central to the simulation studies is the smart grid test site in the Dutch town of Lochem. The goal of this test site is to collect know-how on the energy transition and how it impacts both the grid and society. The developed models of the physical grid and the domestic electricity consumption are based on local measurement data and the provided grid topology. This data is fed to the software tools presented in Chapter 6 to study the performance of the presented control mechanisms and to evaluate the flexibility of DEMKit.

The remainder of this chapter is organized as follows: first an introduction to the smart grid in Lochem and its research goals are given in Section 7.1, followed by the results of a 2025 scenario stress test. The obtained measurement data is used to validate the used network models and artificial load profile. Section 7.2 presents four futuristic scenarios in which the presented control strategies are tested. Finally, overall conclusions are drawn from the obtained simulation results in Section 7.3. Additional details are given in Apendix A.

\subsection{SMART GRID LOCHEM}

Central to the simulation results is the smart grid test site in the Dutch town of Lochem. The goal of the test site is to investigate smart grid technologies and the impact of high penetrations of rooftop photovoltaic $(P V)$ and electric mobility usage. Therefore, metering equipment is installed in three substations to collect data on voltage levels, currents and active and reactive power. Measurement equipment is also installed in households of the members of local energy corporation LochemEnergie $^{1}$. These meters collect the power usage and, in case of PV panels, also voltage magnitudes. However, as this concerns privacy sensitive data, the location of each meter is not disclosed. Furthermore, two controllable 3-phase alternating current $(A C)$ charging stations are installed in the grid. One station allows one battery electric vehicle $(B E V)$ to charge at $22 \mathrm{~kW}$, and the second is able to charge $2 \mathrm{BEVs}$ simultaneously at $22 \mathrm{~kW}$ each. In addition to privately owned BEVs and plug-in hybrid electric vehicles (PHEVs), the local energy corporation (LochemEnergie) also rents BEVs to its members.

One feeder within the test site is chosen specifically for the simulation studies. This feeder is situated in a new residential area and is constructed according to new design practices. This feeder services 80 households with a mix of apartments, detached homes and terraced homes. With a maximum distance of $700 \mathrm{~m}$ between the transformer and the end, this feeder is also relatively long. The used cable is an aluminium cable with 4 conductors $\left(150 \mathrm{~mm}^{2}\right.$ cross section per conductor) with an impedance of $Z=0.206+j 0.079 \Omega$ per kilometre cable. The feeder is protected by three $160 \mathrm{~A}$ Weber $500 \mathrm{~V}$ gFF fuses at the transformer to meet safety regulations. A detailed model of this feeder is available for simulation studies.

${ }^{1}$ https://www.lochemenergie.net/ 
A stress test was set up to investigate whether the local grid would withstand a futuristic electrification scenario with increased penetrations of BEVs and electric heating, and if so, how. We aimed to create a year 2025 scenario based on current projections and expectations on electric loads. For this, we used projections from [5] for electric mobility in the Netherlands, which indicates a $12.5 \%$ penetration of electric mobility in 2025 . For the stress test, we had a total of $20 \mathrm{BEV}$ s at our disposal, which results in a penetration of $25 \%$. This is double the Dutch target for 2025 , but considering the local population this is not unrealistic as the city is situated in a rural area and the wealth of inhabitants in the considered grid. Furthermore, an increasing electrification of cooking and heating is expected in the Netherlands. For this, pizzas to be baked in electric ovens and additional loads were available to be added to the grid during the stress test. Finally, power quality measurement equipment was temporary installed at one of the charging stations.

The two controllable charging stations were programmed to perform load shedding to keep the load on each phase below $45 \mathrm{~kW}(\sim 196 \mathrm{~A})$ at the transformer. As the charging station cannot control the three phases independently, data of the highest loaded phase as measured at the transformer is fed into the control system. The Weber $500 \mathrm{~V}$ gFF fuse can sustain a current of $57.5 \mathrm{~kW}(\sim 250 \mathrm{~A})$ for approximately 2 hours. The test was setup in such a way that, starting from an initial situation without BEVs as an additional load, the load was increased in steps with a predefined test plan.

\section{Results}

The test started with the normal evening base load ( $45 \mathrm{~kW}$ in total over the three phases) before 19:00. Then, three BEVs were connected to the two controllable charging stations at 19:00. Each of these cars caused an additional voltage drop of $4.5-5.0 \mathrm{~V}$. Later on, at 19:30, the remaining 17 BEVs were connected using wall sockets and privately owned charging stations, which were all uncontrollable in the test. This resulted in a total load increase of $51 \mathrm{~kW}$. At this point one of the phases already exceeded the predefined threshold of $45 \mathrm{~kW}$ and thus the control system performed load shedding to reduce the load at the charging stations. For this, discrete steps of $1500 \mathrm{~W}$ were used as lab experiments resulted in unstable behaviour with larger steps. At some point the maximum power delivered by the charging station was too low, resulting in BEVs to stop charging completely. In a final step of the stress test pizzas were baked in the electric ovens $(\sim 2 \mathrm{~kW})$ at 19:45 and at the end all households were encouraged to turn on other equipment around 20:00. The observed peak load at 20:05 was $171 \mathrm{~kW}$.

An important observation from the results of the stress test is the risk of an unbalanced load over the three phases. At one point (at 19:52) the load on phase 3 was $25.7 \mathrm{~kW}$ higher than the average load on the other 2 phases (see Figure 7.1). At this point, the load on phase 3 was $69.0 \mathrm{~kW}$ compared to $43.3 \mathrm{~kW}$ and $43.1 \mathrm{~kW}$ for phase 1 and 2 respectively. The maximum neutral point shift measured was 


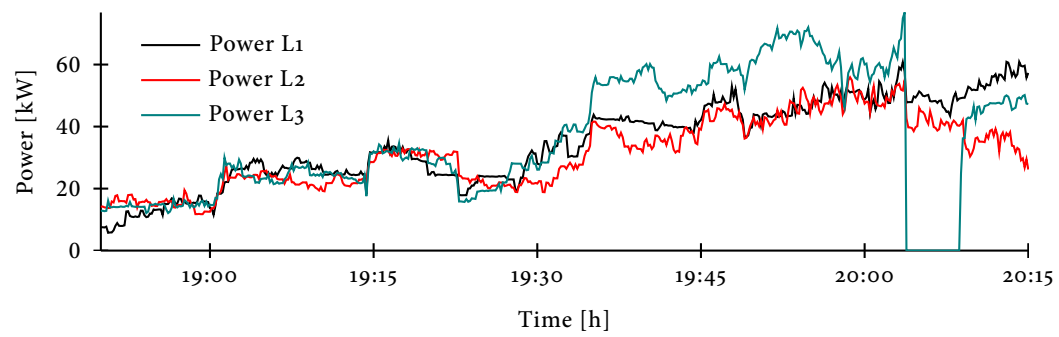

Figure 7.1: Power consumption measured at the transformer for the three phases $\left(\mathrm{L}_{1}, \mathrm{~L}_{2}\right.$ and $\left.\mathrm{L}_{3}\right)$ during the stress test.

7.4 $\mathrm{V}$ and the line-to-neutral voltage for phase 3 was $207.0 \mathrm{~V}$, which is a $31.0 \mathrm{~V}$ drop between the transformer and the charging station. At the very end of the test, when residents switched on other equipment, the power on phase 3 was lost as the fuse melted after sustaining overcurrent for approximately half an hour. As a consequence plastic mounting material in the vicinity of the fuse had also melted due to the heat production. The interruption was resolved within 5 minutes by service engineers who were present at the stress test.

\subsubsection{Network Model Validation}

As it asks quite some effort to carry out field tests, it is important to have simulation tools, which can be used to simulate scenarios without executing them in practice. One crucial issue with such simulations is the validity of the used models. Therefore, we used the measurement data obtained in the stress test, to validate the accuracy of the models presented in Chapter 3. For this, we imported the grid topology and cable parameters of the test site in our simulation framework. The voltage measurement data obtained at the transformer is used to set the reference voltage at the slack bus of the grid model. The power drawn by the controllable charging stations is added to the model at their respective positions in the grid using a constant power model. For the household loads the situations is a bit different as not all households participate in the metering project and available data is anonymous, meaning that the corresponding location is not known to us. This implies that we have to make some assumptions to assign the load to the households.

We first observe that the substantial load from the fast chargers is known. Secondly, we have documented the charging location of each of the 17 BEVs that were connected to domestic wall sockets. Each of these BEVs was charging at a rate of $3 \mathrm{~kW}$ on average, which makes up $51 \mathrm{~kW}$. Furthermore, most of the 20 pizzas were baked in these homes. We add these loads to the model at their respective point using a constant power model. Thirdly, we assume the base load of $45 \mathrm{~kW}$ to remain rather constant and evenly distributed among the households. Finally, for each household we spread the load across the three phases based on the load measured on each phase at the transformer. 
Using this input data, a simulation of the stress test is carried out. The goal is to compare the simulation results with the measurement data obtained during the stress test. We added the aforementioned identified loads to their location in the network model with a relatively high accuracy. A correct placement of the loads is important to ensure that the correct currents run through the cables in the model, which result in the voltage drops as measured during the stress test. The time frame between 19:35 and 19:45 has the highest accuracy as we know where which BEV was connected (making up a total of $91 \mathrm{~kW}$ of load). As mentioned, the remaining $45 \mathrm{~kW}$ measured at the transformer is assumed to be a rather stable base load. This assumption may be quite valid as the majority of the local population gathered around the charging stations to follow the event and thus did not influence their base load consumption a lot.

\section{Results}

Figure 7.2 shows the results of both the measurements and simulation results. It is clear that the simulated voltages match the measurements accurately, especially in the indicated time frame between 7:35 PM and 7:45 PM. For the time frame between 7:35 PM and 7:45 PM we find an average deviation of $0.55 \mathrm{~V}$ with a standard deviation of $0.82 \mathrm{~V}$. The maximum deviation was $+2.46 \mathrm{~V}$ and the minimum $-1.95 \mathrm{~V}$. For the time frame from 7:30 PM to 8:00 PM an average of $1.51 \mathrm{~V}$ and a standard deviation of $1.54 \mathrm{~V}$ is obtained. These simulation results give the confidence that simulations give quite accurate results for this grid, and can be used to get accurate insights in what is to be expected in futuristic scenarios. Furthermore, there are no reasons or indications to believe that for other comparable grids in the Netherlands the results would be less accurate.

\subsubsection{Artificial Load Profiles}

To evaluate the artificial load profile generator presented in Chapter 6, we made a comparison between an artificial load profile and measurement data obtained in Lochem. For this, one year of measurement data from transformers and households in the test site was used. Furthermore, census data [19] was used to create a model of the households in this test side. Additional loads, such as induction cooking, PHEVs and rooftop PV setups were introduced according to survey data [142].

\section{Results}

Figure 7.3 shows the total annual load duration curve for both the generated data and the measurement data in a one minute time granularity. There are some differences observable in the two graphs. Especially the static stand-by power usage from the artificial load profile generator $(A L P G)$ is too flat, which results in the plateau at the end of the load duration curve. The average annual electric energy consumption per household matches quite well, with a measured value of $3144 \mathrm{kWh}$ versus $3250 \mathrm{kWh}$ for the generated model. 


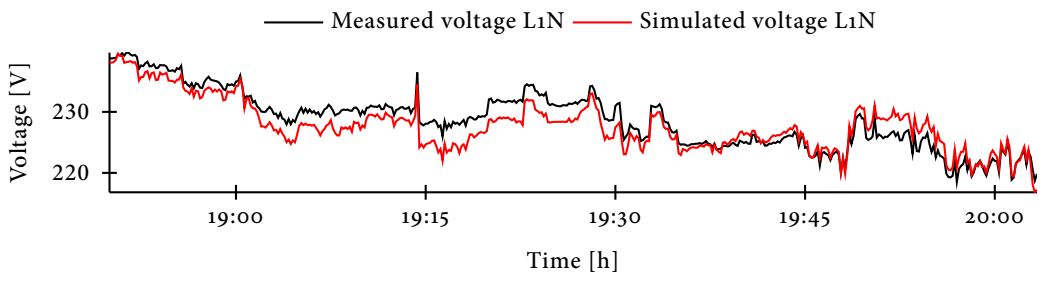

(a) $\mathrm{L}_{1} \mathrm{~N}$

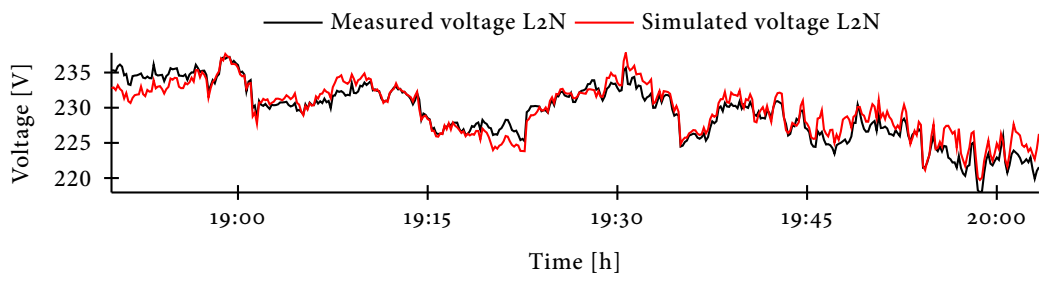

(b) $\mathrm{L}_{2} \mathrm{~N}$

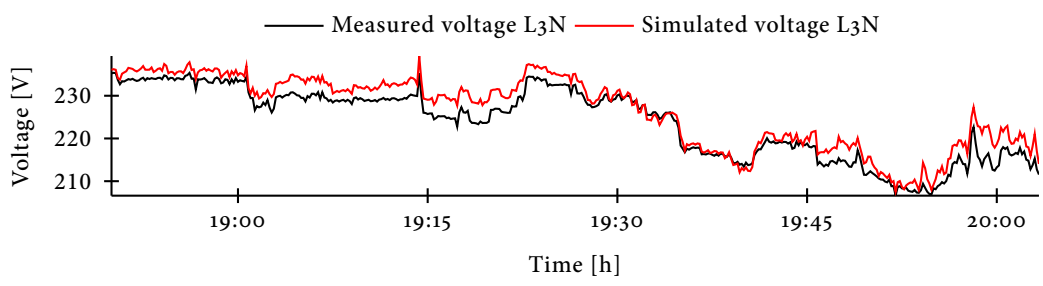

(c) $\mathrm{L}_{3} \mathrm{~N}$

Figure 7.2: Voltage measured at the BEV during the stress test and the simulated voltages between the three phases $\left(\mathrm{L}_{1}, \mathrm{~L}_{2}\right.$ and $\left.\mathrm{L}_{3}\right)$ and the neutral $(\mathrm{N})$.

Figure 7.4 shows a comparison of the data for a single day. The MAE (Mean Absolute Error) for the minute to minute fluctuations is $157 \mathrm{~W}$. The overall reactive power consumption differs from the measurement data, but follows an overall trend, which results in a comparable power factor, of around 0.94 during the night and is close to 1.00 during the morning and evening.

On a single household level, the generated profiles show less fluctuations than the measured data, as is to be expected from the approach taken. However, both show the same peak and stand-by loads. At the neighbourhood level, this ensures that the voltage levels and fluctuations obtained through load-flow calculations match the measured values. The simulated voltage levels for this neighbourhood are generally in the range of $230 \mathrm{~V}$ to $240 \mathrm{~V}$ during the afternoon, with dips down to $225 \mathrm{~V}$ in the evening. These values match the fluctuations observed in the test area. Note that a direct comparison is hard to make since for the given measurements on house level it is not known from what house these measurements are, and thus also not on 


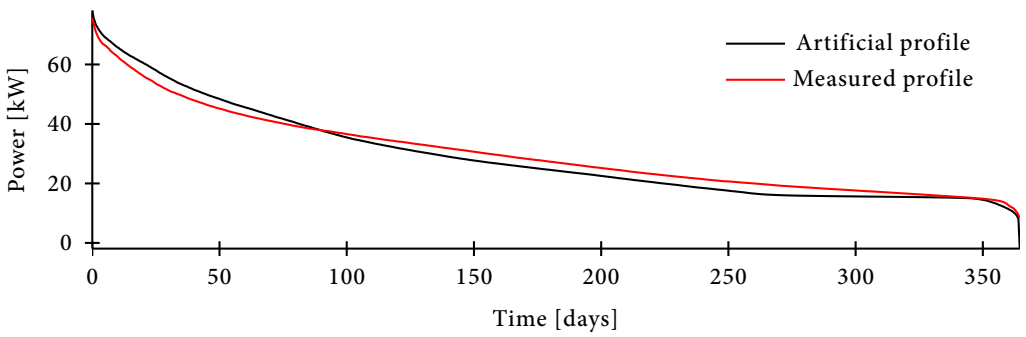

Figure 7.3: Annual electricity duration curve for the considered feeder in Lochem.

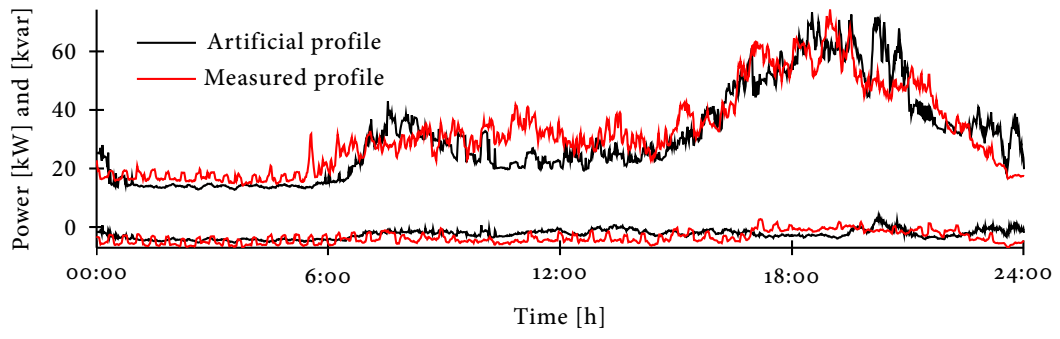

Figure 7.4: Power consumption in Lochem for one day, depicting measurement data and artificial data. The two upper lines depict the active power load in $\mathrm{kW}$, the two lower lines show the reactive power consumption in kvar.

which feeder these measurements were taken. Nor is it known which transformer feeds which house and thus it is unknown what the actual voltage drop is.

The results of the model also show an unbalanced load on the three phases, with the model topping at $15 \mathrm{~kW}$ deviation from the average load and the measurements resulting in a deviation of $16 \mathrm{~kW}$ from the average load.

\subsection{Control System Simulations}

The previous section presented an evaluation of the accuracy of the physical models used within the DEMKit framework presented in Chapter 6. This basis can be used to create futuristic scenarios and evaluate the effects of the energy transition on the physical grid and the delivered power quality. But, more importantly, these scenarios can be used to test what the benefits of the presented control approaches are.

\subsubsection{Control Approaches Evaluation}

A futuristic scenario, based on projections for the year 2025 is created to evaluate the performance of the profile steering heuristic (Chapter 4) and the double-sided auctions (Chapter 5) in normal conditions. For this scenario, we consider the 
network model from Lochem as a connected microgrid. Furthermore, we use the base load profile, as presented in Section 7.1, and we add PV, BEVs, heat pumps and batteries to add more volatility and useful flexibility. Based on this single use-case, the performance of aforementioned control strategies can be evaluated in a direct comparison where only the control algorithms are replaced within the model.

The optimization goal for the considered scenario is to perform peak shaving at the transformer level to reduce or avoid overloading of the local grid. This objective is expressed by a zero-profile as goal profile within the profile steering approach $(\vec{p}=$ $\left.[0,0, \ldots, 0]^{T}\right)$. This objective also results in the desire to perform local demand and supply matching as a perfect match would result in the desired profile. In the following, we describe in detail how the scenario of this smart microgrid is build up.

\section{Scenario}

The load profile is generated by the ALPG, which is configured to reflect the local situation. Additional electrification and local micro generation using PV is added. For example, we consider the same $25 \%$ penetration of BEVs as in the stress test. Furthermore, we envision an accelerated adoption of PV, and we assume that domestic storage solutions become interesting to improve the self consumption of energy due to changing regulations and a decrease of battery costs. Lastly, we expect the adoption of electric space heating with heat pumps and a small vessel. The used parameters and input data for the flexible devices and the PV panels are as follows:

PV panels: We chose to include actual measured and predicted PV production data for the model. Belgium transmission system operator (TSO) Elia provides an extensive dataset of PV data (see [38]), including the real measured production, day-ahead predictions and intraday predictions (see Figure 7.5 for an example). The availability of both day-ahead and intraday predictions is useful for the eventbased profile steering approach, where updated predictions can be incorporated during the realization. More precisely, we used data from Belgium distribution service operator (DSO) Régie de Wavre of 2016. The size of this DSO is limited to a single town and thereby the spread of PV setups is limited in space. The PV data is provided in 15 minute intervals. Within the model we multiply the samples from the dataset by $\frac{1}{12.8 \cdot 10^{3}}$ per square meter of PV panel. With this value, the peak production from the dataset matches the peak production calculated by the ALPG. In our scenario, half of the households is equipped with a set of PV panels, of which the total area depends on the annual energy consumption of the household. No production curtailment is used in this scenario, and predictions are updated every 15 minutes with intraday prediction data up to 6 hours into the future.

Electric vehicles: The same penetration of $25 \% \mathrm{BEVs}$ as used in the stress test is considered in this scenario. We used a total of 12 PHEVs with a battery capacity of $10 \mathrm{kWh}$ and a single phase charger with a maximum power rating of $3.7 \mathrm{~kW}$. Another 8 BEVs are added using a $60 \mathrm{kWh}$ battery capacity with a three phase 


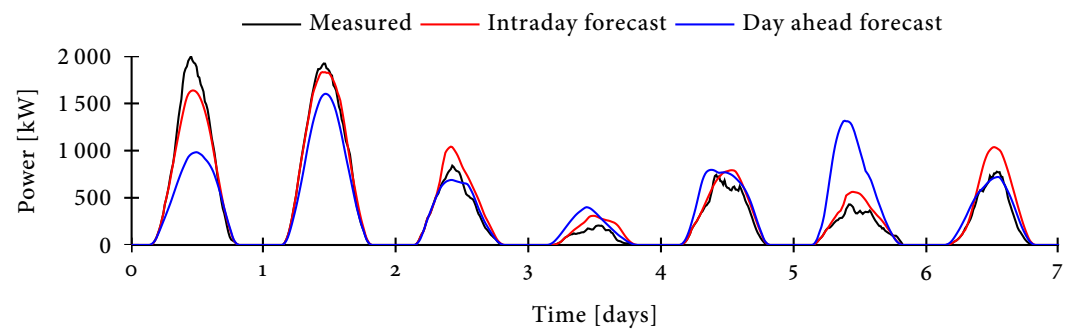

Figure 7.5: Worse mismatches between the PV power production as measured and forecasted during week 22 of 2016. Data taken from [38], DSO Régie de Wavre.

$22 \mathrm{~kW}$ charger. For both types of cars no vehicle to grid option is applied, but reactive power control and phase balancing is possible. Arrival times, departure times and required charge are determined by the ALPG.

Batteries: A total of 16 households, all with PV panels, are equipped with a domestic battery of which the size depends on the annual consumption of the household. Three types are used:

» $3700 \mathrm{~W}$ single phase inverter with a battery capacity of $2 \mathrm{kWh}$,

» $3700 \mathrm{~W}$ single phase inverter with a battery capacity of $7 \mathrm{kWh}$,

» $11 \mathrm{~kW}$ three phase inverter with a battery capacity of $12 \mathrm{kWh}$.

All batteries are ideal and loss free, can provide reactive power and provide phase balancing control options. All batteries are initiated with a 50\% state of charge $(\mathrm{SoC})$. In event-based operation, the batteries perform a replanning every 1 to 2 hours.

Heat pumps with vessel: $25 \%$ of the households is equipped with a heat pump with a buffer. The buffer capacity is $10 \mathrm{kWh}$ and initiated at a $50 \%$ SoC. The heat pump itself has a power rating of $3 \mathrm{~kW}$ with a coefficient of performance (CoP) of 4.5 with modulating capabilities. The heat demand profile is taken from the Flex-street use-case [23] as the ALPG does not generate heat demand profiles. In event-based operation, the heat pumps perform a replanning every 1 to 2 hours.

Timeshiftable devices: All generated washing machines and dishwashers are modelled as smart timeshiftable devices. Real measurement data of a Siemens XL 1462 festival washing machine $\left(30^{\circ} \mathrm{C}\right.$ program) and Bosch Silence dishwasher (normal program) is used. No pre-emption is allowed for these devices.

A model of the aforementioned devices, and the accompanying control structure, is given in Figure 7.6. The details of the scenario, except for the heating demand, can be generated using the ALPG ${ }^{2}$.

\footnotetext{
${ }^{2}$ https://github.com/GENETX/alpg. Use commit egfb945 and the configuration "hoogsteen_PhD_thesis.py" in the examples folder
} 


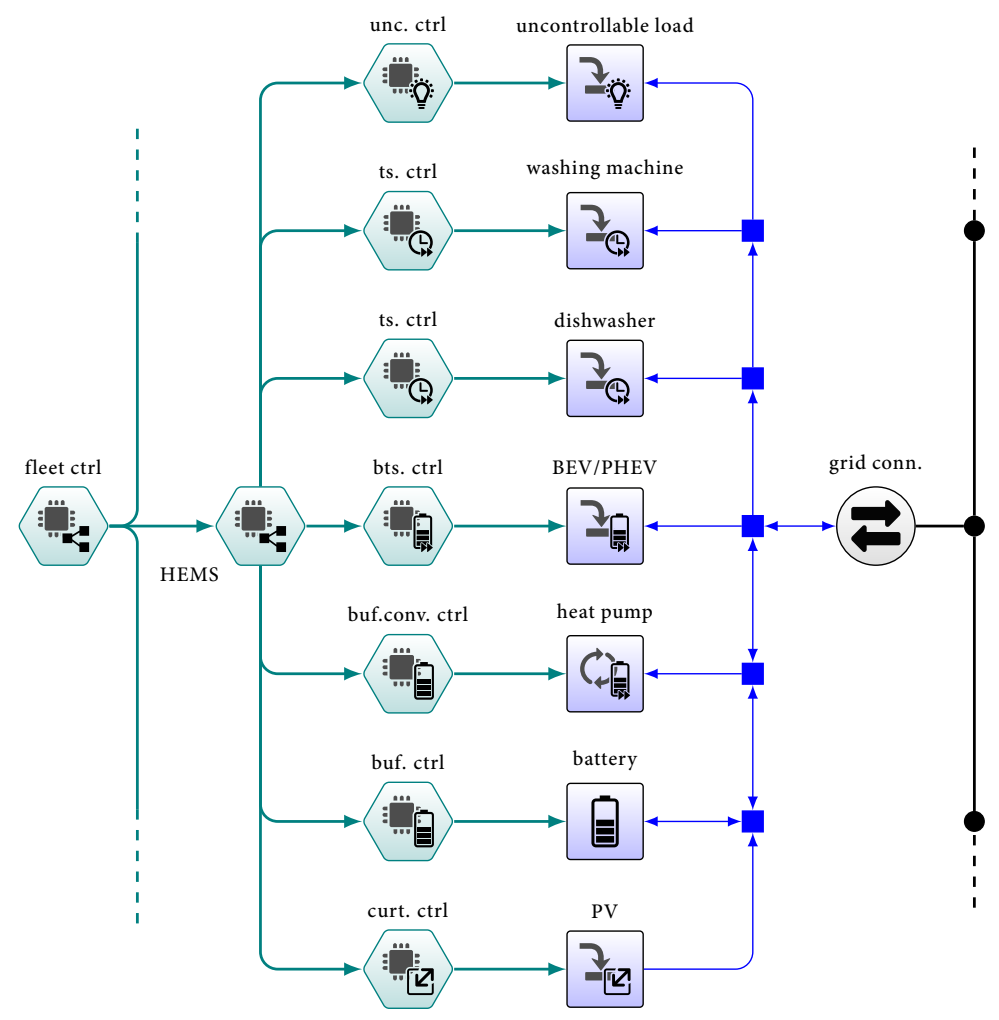

Figure 7.6: A model of a house with all the devices (and streams) as described for the use case, and the accompanying controllers. Each house has a home energy management system (HEMS), which is connected to the fleet controller (on the left side) and a connection to the grid (on the right side).

\section{Control}

A total of five control approaches are simulated and compared with each other, together with a reference case without control. The interval length for simulations is set to 1 minute, while planning and auction control is executed in 15 minute intervals. The optimization horizon for the profile steering heuristic is set to 2 days (192 intervals), for which a new planning is made every day (96 intervals). Furthermore, predictions based on historical data or weather forecasts are used during the optimization. The simulation cases are as follows:

"No control (NC): In this case, no control is applied, indicating that devices use a greedy approach to consume and produce energy. Heat pumps merely supply the heat demand without using the buffer storage. The batteries use a greedy strategy to balance the household consumption. 
"Auction (A): The double-sided auction is used to perform peak shaving, for which the target value $D$ is set to the average energy demand for a given week. The linear clearing demand function is ranging from $1.2 \cdot D$ at $p=-1000$ to $0.8 \cdot D$ at $p=1000$. (Chapter 5)

»Profile Steering with Auction (PSA): The planned power profile from the profile steering heuristic $(\vec{x})$ is used as target value $D$ instead of the constant value as used in case A. A minimum improvement of 100 is used as parameter in the profile steering algorithm. (Chapters 4 and 5)

» Profile Steering with Event-based Control (PSEC): Profile steering with event-based rescheduling is used to control the cluster of devices. A minimum improvement of 100 is used as parameter in the profile steering algorithm. (Chapter 4)

» Profile Steering with Event-based updated Auction (PSEA): Like PSA, but now the realized profile $\vec{r}$ is used as target profile. A minimum improvement of 100 is used as parameter in the profile steering algorithm. (Chapters 4 and 5)

» Multi-Commodity Profile Steering with Event-based Control (MCPSEC): Similar to PSEC, but now with multi-commodity support to perform phase balancing and reactive power control. For the latter the objective is to balance the reactive power to obtain a power factor of 1 (neglecting the effects of the physical grid). Three commodities, representing the three phases are used with a minimum improvement of 20 with weight of 0.333 for each complex (active and reactive power) commodity. (Chapter 4)

" Perfect Profile Steering control (PPS): A reference case with profile steering in which perfect knowledge (predictions) is used to evaluate what would have been possible with the provided flexibility. (Chapter 4 )

To give insight in the performance during different seasons, three weeks are chosen from the simulation scenario to evaluate the performance under different conditions:

»Week 6: A week in the winter with the highest heat demand.

»Week 19: A spring week with the highest energy production from PV panels.

»Week 22: A spring week with average weather conditions, but with large PV prediction errors in both directions.

Results in a specific week for a specific control strategy are indicated by a postfix of the week number, e.g. A-6 for the auction simulation results in week 6 .

\section{Results}

The results of this simulation study are evaluated on three different aspects. Firstly we look at the overall power profile as obtained at the transformer. Secondly, we evaluate the performance of the control systems in the grid with respect to cable 
loads, distribution losses and delivered power quality. Lastly, the performance with respect to the day-ahead planning is evaluated. Additionally, a brief comparison of simulation times is made. An overview of the results is given in Table 7.1.

\section{Power exchanged}

The boxplots in Figure 7.7 show the apparent power at the transformer. They indicate the results between the first $\left(P_{1}\right)$ and 99 -th $\left(P_{99}\right)$ percentile and the disconnected marks at each end indicates the minimum and maximum values. A clear trend can be seen for the power distributed through the transformer. Higher absolute values are observed for both the NC and A cases compared to the cases with profile steering. This is expected for the uncontrolled scenario. However, for the A case even higher maximum powers are obtained than in the NC case. This is the result of postponing $\mathrm{BEV}$ charging and running heat pumps due to market clearing at relative low power values. At some point, these loads cannot postpone their energy consumption any longer to meet comfort constraints, resulting in a synchronized peak power consumption. Similarly, with significant power production from PV, batteries are filled early, resulting in a larger negative power. This problem is significantly less dominant in the PSA case, where the planned power profile from the profile steering heuristic is used to clear the market. However, prediction errors still lead to some load synchronization in this case, resulting in somewhat higher values than observed in PSEA, which uses updated intraday predictions. The eventbased profile steering approaches (PSEC and MCPSEC) use a risk-adverse model predictive control (MPC) strategy which spreads errors, resulting in the smaller peak power values (both negative and positive).

Further observations are that the profile steering-based approaches perform quite similar most of the time. The extremes observed with the pure auction approach are not just a single outlier as shown by the boxplots. When looking at the reactive power we observe that the multi-commodity significantly lowers the amount of reactive power observed at the transformer. The high reactive power in the PSEC case is the result of scheduled operation of timeshifter around the already existing reactive power peak of uncontrollable devices in the evening. The effect of prediction errors is visible when comparing the results with PPS, but in case of the event-based profile steering-approaches (PSEC, PSEA and MCPSEC) these effects are limited. The PV prediction errors of week 22 do result in a significant lower (worse) first percentile in the PSA case compared to the event-based alternatives.

\section{Power Quality}

The supplied voltage should ideally be $230 \mathrm{~V}$ as specified in the EN-50160 norm [113]. Voltages exceeding the permitted upper bound of $253 \mathrm{~V}$ and the general lower bound of $207 \mathrm{~V}$ (we note that $196 \mathrm{~V}$ is permitted for restricted time) by the EN-50160 are breached with the $\mathrm{NC}$ and $\mathrm{A}$ cases due to aforementioned load synchronization (Figure 7.8). The other control strategies supply a significant improved voltage quality within the restrictions. The phase balancing of MCPSEC pays off on the upper side of the supplied voltages, however we note that the effect is not extreme due to the rather balanced scenario. The phase balancing performance of MCPSEC 


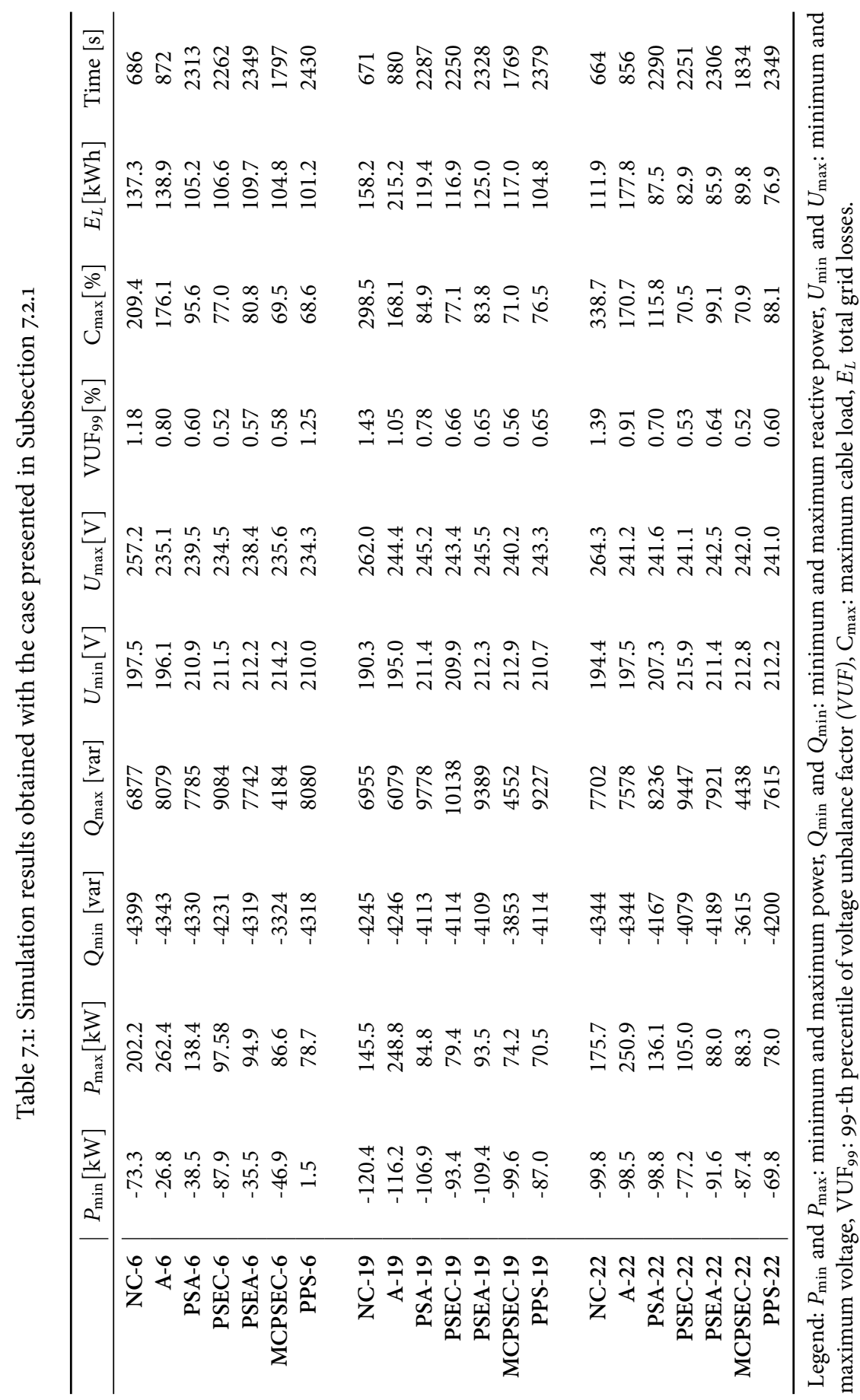




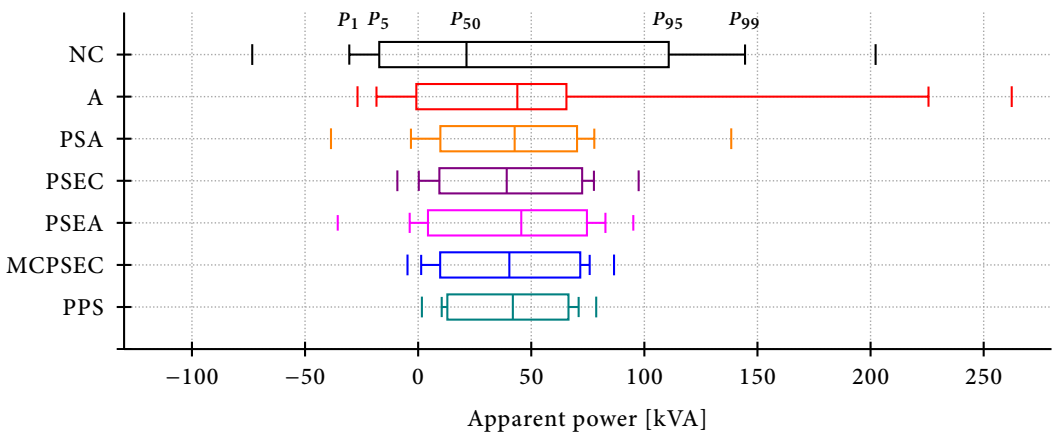

(a) Week 6

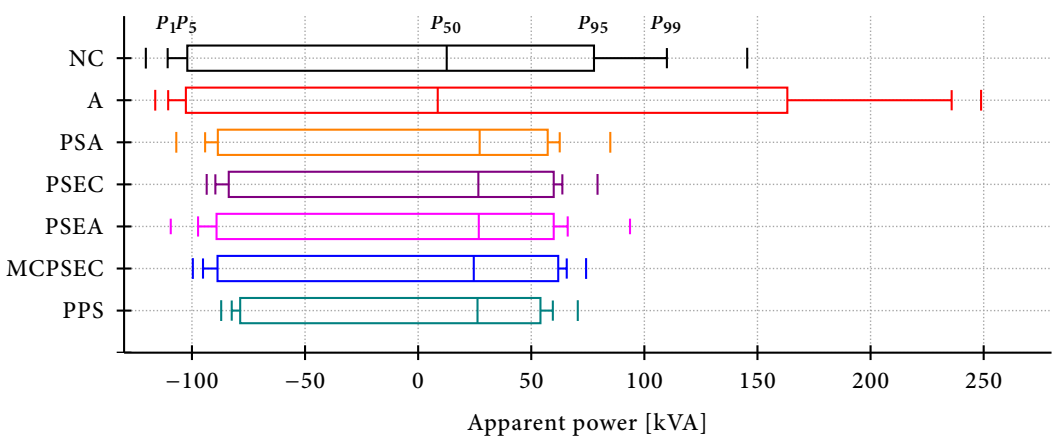

(b) Week 19

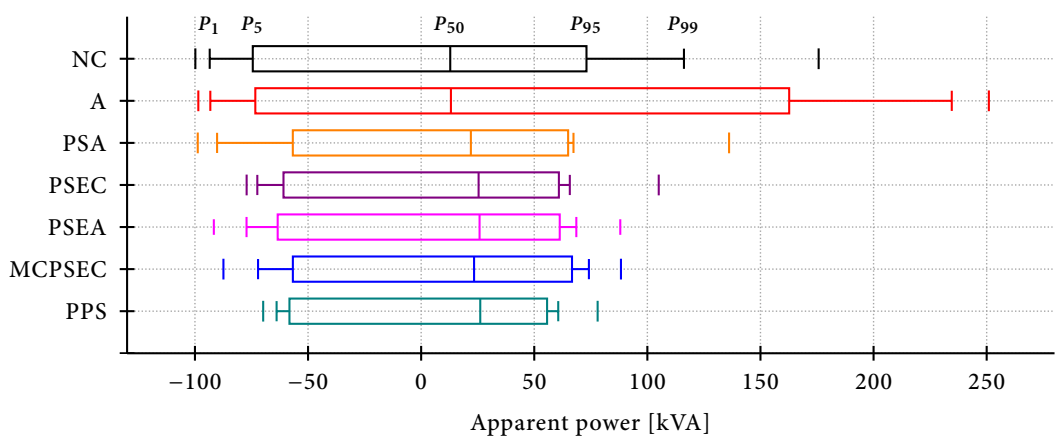

(c) Week 22

Figure 7.7: Load at the transformer for the three simulated weeks.

is visible in the 99-th percentile of the VUF (Table 7.1, $\mathrm{VUF}_{99}$ ). The maximum neutral-to-ground value is $7.5 \mathrm{~V}$ for MCPSEC, compared to $9.3 \mathrm{~V}$ for PSEC.

The load on cables is again very high for the A and NC cases, with severe overloads in the maximum observed cable load with respect to the capacity (see Table 7.1, 


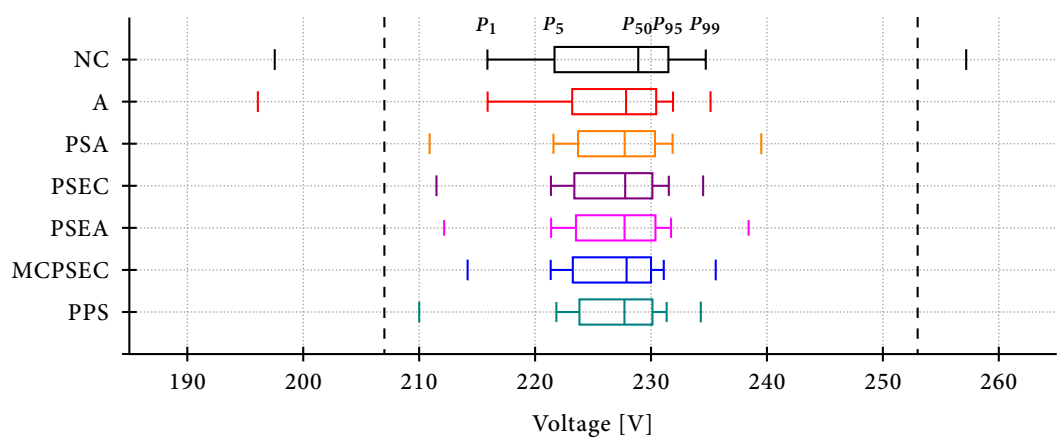

(a) Week 6

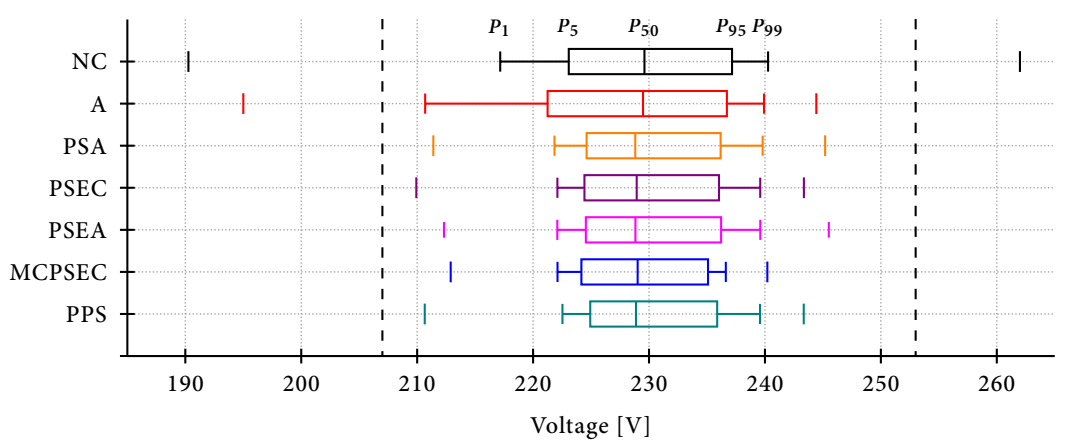

(b) Week 19

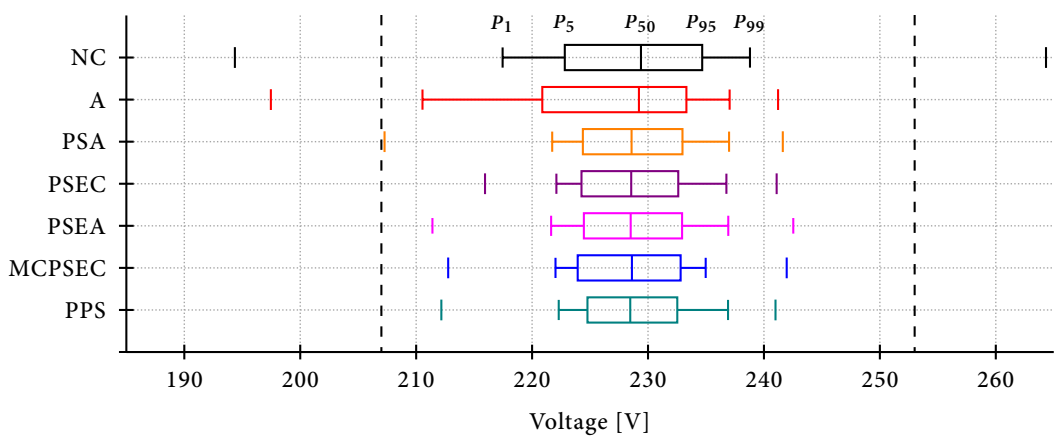

(c) Week 22

Figure 7.8: Phase-to-neutral voltage levels observed in the simulated network. The dashed lines indicate the voltage limitations of the EN-50160.

$\mathrm{C}_{\max }$ and Figure 7.9). Even the PSA reports overloading in week 22, while PSA and PSEA both are close to the limits in the other weeks. In contrast, PSEC (maximum of $77.1 \%$ ) and MCPSEC (maximum of $71.0 \%$ ) perform significantly better. 


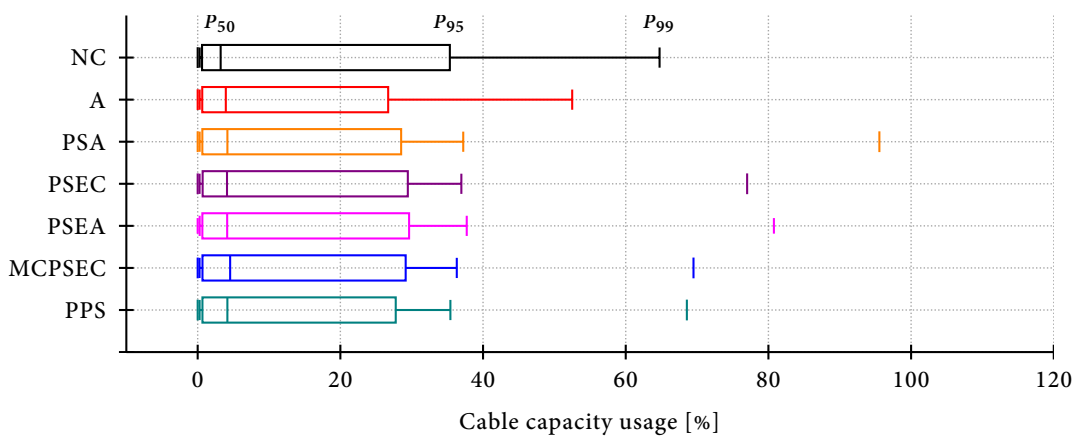

(a) Week 6

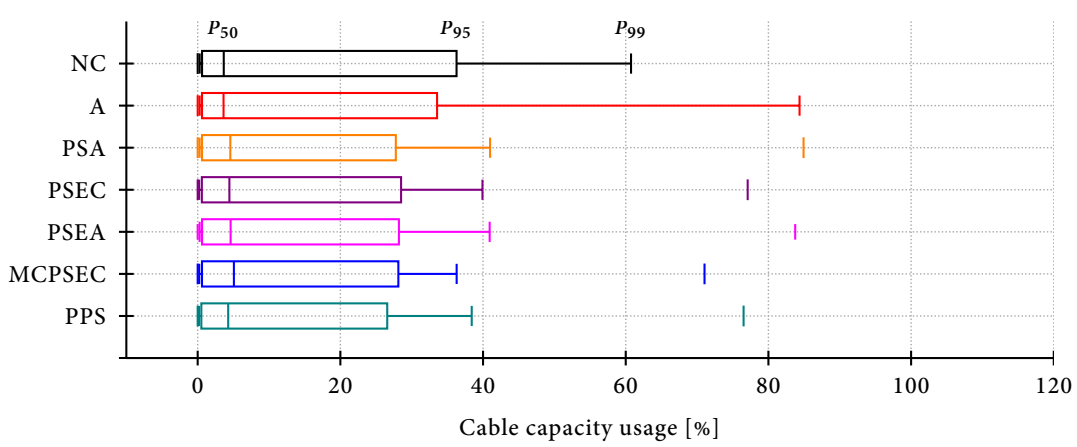

(b) Week 19

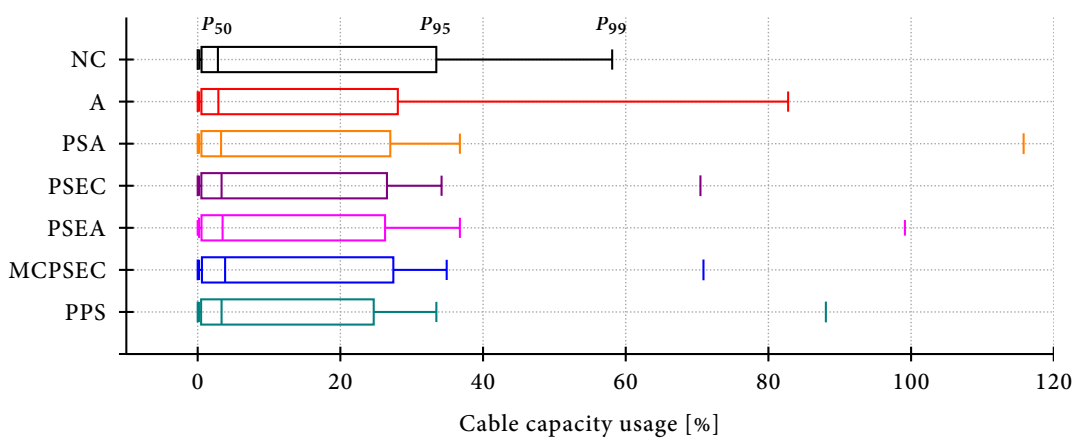

(c) Week 22

Figure 7.9: Load on the cables in the grid. (Note: the maximum value for the NC and A case is left out, please refer to Table 7.1 for these values).

An overall performance indicator for the performance of decentralized energy management (DEM) methodologies is given by the physical grid is the total losses in the distribution grid as it quadratically penalizes high currents in a cable section which lead to larger voltage drops or rises. In Table 7.1 we observe that profile 
steering based approaches perform very similar on the total losses $\left(E_{L}\right)$, whereas the high synchronized peaks observed with A result in the highest total losses. On average, the reduction in losses between NC and PSEC is $222.8 \mathrm{~W}$. No significant improvements are made with the perfect predictions (PSS) when it comes to obtained voltages and cable loads.

\section{Planning}

The last aspect is the accuracy of executing the day-ahead planning. As mentioned in Chapter 2, deviations from a planning are penalized in existing markets. Therefore we compare the 15 minute average power profile obtained at the transformer with the day-ahead planning made in the profile steering control cases. The absolute differences are depicted in Figure 7.10. Overall, PSA performs better at minimizing the error between the planning and realization. However, the risk-adverse behaviour of PSEC, again, results in significant smaller absolute deviations from the planning. Remarkable is that PSEA does not significantly benefit from the added MPC control in the worst-case intervals, while this method also inherits the deteriorated performance in other intervals as observed with PSEC.

\section{Simulation Time}

All simulations are executed on a single core of an Intel Core $17-5820 \mathrm{~K}$ processor clocked at 4.0 GHz. The overhead of device simulations, execution of load-flow simulations and writing of simulation results are captured in the NC simulation. On average, the simulations take $674 \mathrm{~s}$ for a simulation of a week. The auction implementation adds on average $196 \mathrm{~s}$ (total time $870 \mathrm{~s}$ ) per simulated week. Using profile steering significantly increases the computation time as not only the profile steering algorithm is executed, but also predictions are performed. For PSEC we obtain an average of $2255 \mathrm{~s}$ (adding $1581 \mathrm{~s}$ for the profile steering algorithm) per simulated week. Note that this is only marginally faster than the $2267 \mathrm{~s}$ for PSA and $2327 \mathrm{~s}$ for PSEA. Thus, there is no significant difference in required computation power between using an event based approach or an auction for realization of the planning in practice. For MCPSEC a reduction in the number of iterations used for the optimization was observed, resulting in a significant lower average of $1800 \mathrm{~s}$ per week.

We note that no effort was invested to optimize the current profile steering implementation of DEMKit to reduce simulation time. Toersche [143] obtains a total computation time of 14 hours and 50 minutes with the profile steering heuristic for a whole year with 400 households, which is approximately an order of magnitude faster. In Chapter 8 we give recommendations to improve the profile steering heuristic that could help to speed up the algorithm.

\subsubsection{User ACCEPted SCenario}

Flexibility is a key component for the energy transition as discussed in Chapter 2. Domestic smart appliances are expected to play an important role in the future smart grid, possibly at the cost of consumer comfort. In this subsection the relation between the technical potential of devices is linked to the willingness of users to 


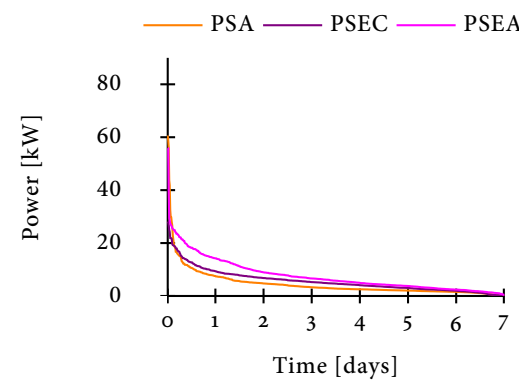

(a) Week 6

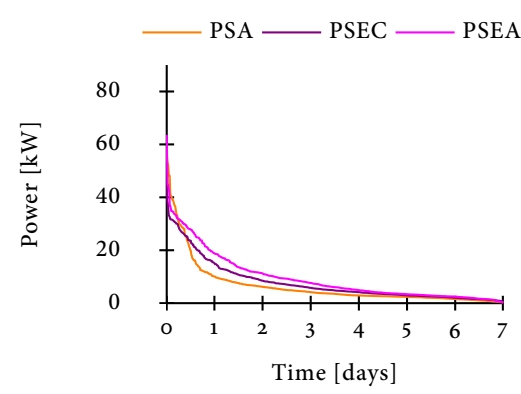

(c) Week 19

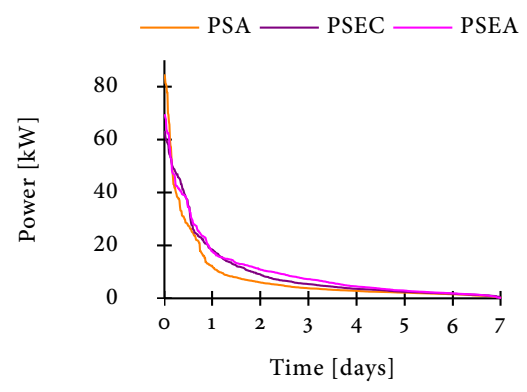

(e) Week 22

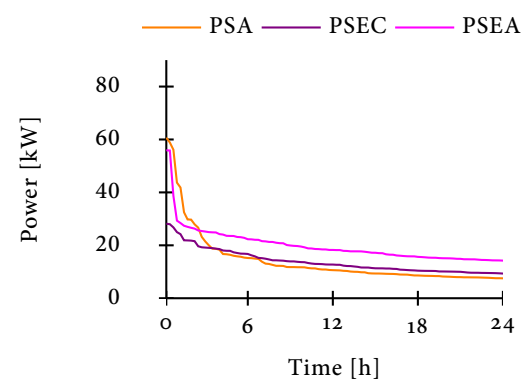

(b) Week 6 - zoomed

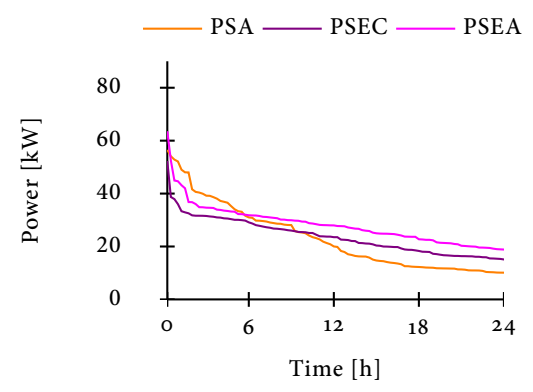

(d) Week 19 - zoomed

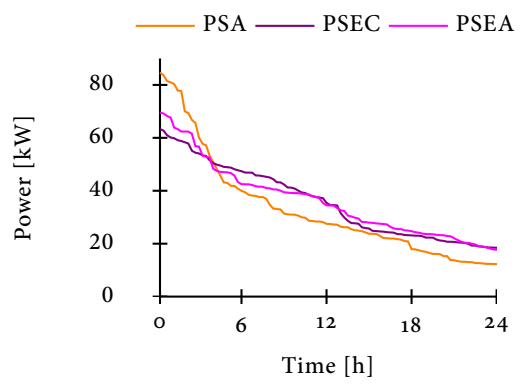

(f) Week 22 - zoomed

Figure 7.10: Load duration curves of the absolute difference between the planned and realized power profile.

give away (part) of the control of these devices. The base of this analyses are questionnaires taken in the Lochem test site by asking users which devices they would be willing to make available for optimizations, why and for which compensation.

Simulations are performed comparing the resulting power profiles with no flexibility, full flexibility and the flexibility resulting from the questionnaire. The objectives 
Table 7.2: Number of devices participants would connect to the HEMS [29]

\begin{tabular}{r|cc}
\hline Device & Yes & No \\
\hline Refrigerator & $26(49.1 \%)$ & $24(45.3 \%)$ \\
Freezer & $23(43.4 \%)$ & $25(27.2 \%)$ \\
Dishwasher & $40(75.5 \%)$ & $5(9.4 \%)$ \\
Washing machine & $44(83.0 \%)$ & $4(7.5 \%)$ \\
Clothes dryer & $31(58.5 \%)$ & $8(15.1 \%)$ \\
Heating & $20(37.7 \%)$ & $24(45.3 \%)$ \\
Heat pump & $6(11.3 \%)$ & $14(26.4 \%)$ \\
Electric vehicle & $15(28.3 \%)$ & $9(17.0 \%)$ \\
\hline
\end{tabular}

Note that the percentages in the table do not add up to $100 \%$ as not every participant was in possession of every device and therefore could not indicate their wish for each device.

within these simulations are balancing production and consumption and satisfying network requirements and capacity constraints. Optimization of the power profiles is performed using the profile steering heuristic as presented in Chapter 4.

\section{Questionnaire}

The results of the questionnaire show that overall participants are interested to some extent in connecting their devices to a HEMS. When people have interest in a HEMS system, this is mostly due to their expectation of saving energy or costs. While for some participants only a financial saving or energy saving was important, other participants also indicated both savings to be important. A summary of which devices the participants would like to connect to a HEMS is given in Table 7.2.

Both the dishwasher and washing machine are devices that most of the participants would like to connect to a HEMS. The questionnaire shows that participants are in general willing to connect devices when the exact moment of operation for these devices is not crucial. Furthermore, as general reasons for connecting devices to the HEMS, energy and/or financial savings and better use of local renewable energy were often mentioned.

One of the reasons for not connecting the device in question was the idea that the device was not suitable for connecting to a HEMS. Another reason is that consumers want to be in control at what time they use a device. Furthermore, some participants expected that connecting a device to the HEMS would be bad for the lifetime of that device, or that the device uses too little energy to make an impact or due to safety issues. 


\section{Scenario}

A simulation scenario is set up to evaluate the potential of the offered flexibility by the users as surveyed and analysed. The goal of these simulations is to see how many users are willing to contribute to peak shaving in different scenarios with different amounts of available flexibility. The base load and flexibility information is generated using the ALPG presented in Chapter 6. The same low voltage grid as before is used and perfect predictions are used to avoid influences of prediction errors on the results. One year is simulated and the simulation interval length is set to 15 minutes.

Two different simulation studies are evaluated:

\section{A. Different flexibility scenarios:}

The first set of scenarios to be simulated concerns the performance of different amounts of offered flexibility. The first scenario BaseCase is a simulation with no control over the domestic appliances. Questionnaire contains the flexibility as specified by users in the questionnaire. Then FullControl simulates a scenario with full control over all appliances which offer flexibility. BufferControl is a variation on FullControl in which all devices except the white goods are controllable. In general, these are devices with a buffer and therefore provide most flexibility to the system. At the same time, these devices have limited impact on the daily life of users as they already operate autonomous, based on a desired setpoint by the end-user. A Reference case is added, which reflects the state of the grid in the year 2015, the year of the measurements. The different amounts of flexibility are given in Table 7.3 .

\section{B. Minimum improvement for flexibility use:}

The focus of the second set of simulations is on the value of the offered flexibility. Within the profile steering algorithm devices contribute to minimize the global objective functions. The time of use and the type of device have a huge impact on the flexibility and therefore the value that a device provides. From this point of view, we may determine what the improvement is of a planned profile of a certain device over a greedy strategy and only control the appliances that offer enough improvement. Within this simulation we use different values for this minimum improvement devices have to offer to find out which devices are worth to control. The total flexibility is the same as in the FullControl case. Note that with this approach we cannot use an initial local flat profile in the initialization phase of the profile steering algorithm as this would influence the improvement that can be achieved. This change affects the performance of the method and therefore the results cannot be compared directly with Case A.

\section{Results}

An overview of the results of case $A$ is given in Table 7.4. A doubling in the peak load for the BaseCase compared to the current situation (Reference) is observed. This peak load of $188 \mathrm{~kW}$ is also significantly more than the peak observed in the 
Table 7.3: Number of devices and controlled devices in Subsection 7.2.2

\begin{tabular}{r|cccc}
\hline & \# of devices & Controlled & Power $[\mathrm{kW}]$ & Capacity $[\mathrm{kWh}]$ \\
\hline Washing m. & 80 & $67^{1}, 80^{2}, 0^{3}$ & $\leq 2$ & N/A \\
Dishwasher & 80 & $72^{1}, 80^{2}, 0^{3}$ & $\leq 2$ & N/A \\
BEV & 11 & $7^{1}, 11^{2}, 11^{3}$ & $\leq 7.4$ & 42 \\
PHEV & 10 & $6^{1}, 10^{2}, 10^{3}$ & $\leq 3.7$ & 12 \\
Battery & 8 & $8^{1}, 8^{2}, 8^{3}$ & $\leq 3.7$ & $2-12$ \\
Heatpump & 20 & $9^{1}, 20^{2}, 20^{3}$ & $\leq 3$ & 10 \\
PV & 40 & $0^{1}, 0^{2}, 0^{3}$ & $\geq-5$ & N/A \\
\hline
\end{tabular}

Legend: ${ }^{1}$ : Questionnaire, ${ }^{2}$ : FullControl, ${ }^{3}$ : BufferControl.

Table 7.4: Simulation results obtained for the cases in Subsection 7.2.2

\begin{tabular}{r|ccccc}
\hline Case A & $P_{\max }[\mathrm{kW}]$ & $U_{\min } / U_{\max }[\mathrm{V}]$ & $\mathrm{VUF}[\%]$ & $\mathrm{C}_{\max }[\%]$ & $E_{L}[\mathrm{MWh}]$ \\
\hline Reference & 87.2 & $216.2 / 243.3$ & 1.13 & 77 & 2.3 \\
BaseCase & 187.5 & $201.9 / 249.0$ & 2.65 & 152 & 5.7 \\
FullControl & 64.2 & $219.6 / 246.5$ & 1.19 & 68 & 3.1 \\
BufferControl & 72.5 & $218.1 / 246.8$ & 1.38 & 71 & 3.2 \\
Questionnaire & 99.1 & $215.1 / 246.9$ & 1.46 & 88 & 3.7 \\
& & & & & \\
Case B & $P_{\max }[\mathrm{kW}]$ & $U_{\min } / U_{\max }[\mathrm{V}]$ & $\mathrm{VUF}[\%]$ & $\mathrm{C}_{\max }[\%]$ & $E_{L}[\mathrm{MWh}]$ \\
\hline Imp. 20 & 76.4 & $216.7 / 246.7$ & 1.44 & 68 & 3.2 \\
Imp. 100 & 76.6 & $217.4 / 247.0$ & 1.38 & 68 & 3.2 \\
Imp. 200 & 80.3 & $219.6 / 246.6$ & 1.18 & 68 & 3.2 \\
Imp. 500 & 79.8 & $218.9 / 246.9$ & 1.24 & 68 & 3.3 \\
Imp. 1000 & 82.0 & $216.5 / 246.7$ & 1.47 & 69 & 3.3 \\
Imp. 2000 & 84.4 & $217.4 / 247.3$ & 1.39 & 71 & 3.3 \\
\hline
\end{tabular}

Legend: $P_{\max }$ : maximum power, $U_{\min }$ and $U_{\max }$ : minimum and maximum voltage, VUF: voltage unbalance factor, $\mathrm{C}_{\max }$ : maximum cable load, $E_{L}$ total grid losses.

stress test. As the fuses of this feeder are rated at $160 \mathrm{~A}$, the resulting power limit is $36.8 \mathrm{~kW}$ per phase at $230 \mathrm{~V}$ (110.4 kW in total for three phases). But it has to be noted that an overload of $25 \%$ can be sustained for approximately 2.5 hours. The load duration curve in Figure 7.11 also shows that this limit is breached for more than 491 hours in total (over 20 days) in the simulated year. The other scenarios with domestic control stay within these power limits. Clever use of domestic batteries and off-peak shifting even results in lower peak loads compared to BaseCase for the FullControl and BufferControl cases. Furthermore, it has to be noted that BufferControl does not sacrifice a lot of performance compared to FullControl and still outperforms the Reference case with respect to the peak load. The flexibility in Questionnaire contains enough potential for significant improvements and results only in a modest increase of the peak load compared to the Reference. 


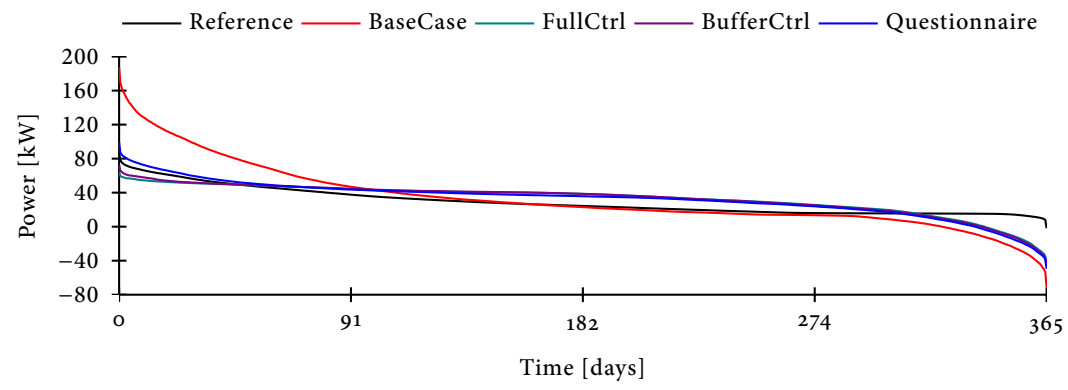

(a) Whole year

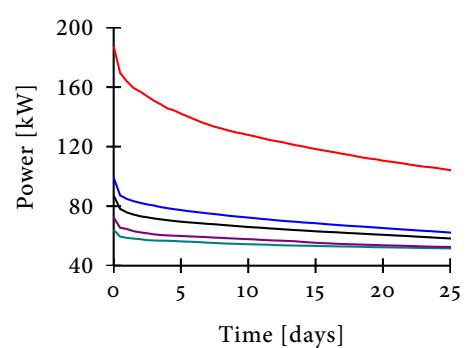

(b) Zoomed - first days

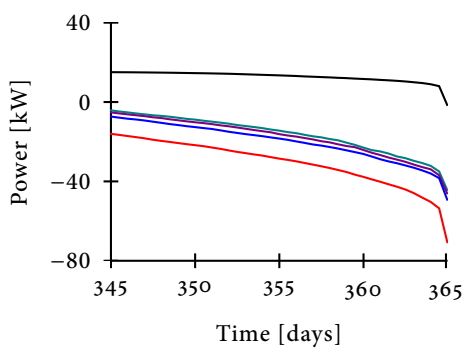

(c) Zoomed - last days

Figure 7.11: Load duration curves for the different scenarios.

The other results, given in Table 7.4, show the same trends, in which BaseCase shows significant power quality reductions compared to Reference together with increases in losses $E_{L}$ and the maximum load on cables $C_{\max }$. The resulting load on cable sections, represented as percentage of the capacity, is depicted in Figure 7.12. Concerning the risks of an unbalanced load over the three phases, Table 7.4 shows that the BaseCase results in a maximum VUF of $2.65 \%$, and thereby exceeds the EN-5016o norm. The other scenarios bring the performance of the distribution grid close to the current situation (Reference) again, resolving overloads and unbalances with a fair margin towards the regulations. Also the outliers in the voltage supply are resolved in the control cases, supplying all customers with a voltage that lies well within the regulatory boundaries. The distribution losses in cables increase slightly compared to Reference because of the slight increase in electricity usage $(+12 \%)$ and mismatch between production and consumption in time (both annually and daily). The annual gain on losses between the BaseCase and FullControl is 2.6 MWh, which is enough to run a small embedded HEMS with a power budget of $3.8 \mathrm{~W}$ per household. Distribution losses in the transformer are not included.

Table 7.5 shows the results of case $B$ for different values of the minimum required improvement by a device. This minimum improvement $\left(e_{m}\right)$ is calculated by replacing the current power profile $\vec{x}_{m}$ by the candidate profile $\overrightarrow{\hat{x}}_{m}$ in the profile steering 


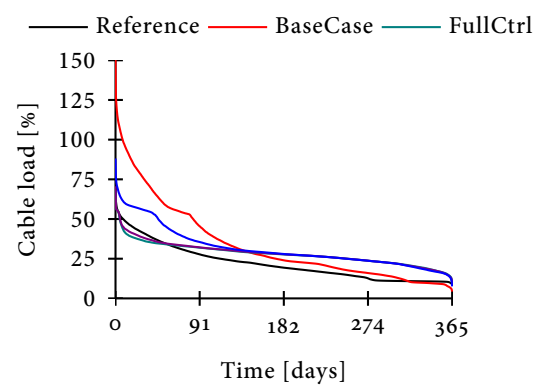

(a) Whole year

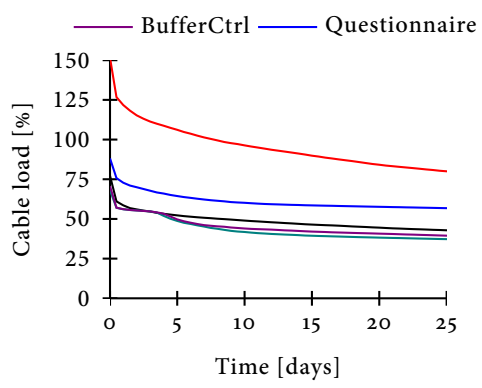

(b) Zoomed - first days

Figure 7.12: Cable load duration curves for the different scenarios.

Table 7.5: Controlled device activations for various minimum improvements

\begin{tabular}{r|cccc}
\hline Case B & BEVs / PHEVs & Heatp. & Washing m. & Dishw. \\
\hline \# of devices & 21 & 20 & 80 & 80 \\
& & & & \\
Imp. 20 & 7645 & 5048 & 10082 & 20802 \\
Imp. 100 & 7645 & 5001 & 8008 & 15626 \\
Imp. 200 & 7645 & 4985 & 6729 & 12139 \\
Imp. 500 & 7645 & 4834 & 4523 & 6346 \\
Imp. 1000 & 7645 & 4631 & 2423 & 1529 \\
Imp. 2000 & 7640 & 4259 & 168 & 7 \\
\hline
\end{tabular}

approach, i.e. $e_{m}=\left\|\vec{x}_{m}-\vec{p}_{m}\right\|_{2}-\left\|\overrightarrow{\hat{x}}_{m}-\vec{p}_{m}\right\|_{2}$ as described in Chapter 4. With a very low minimum improvement of 20 , almost all devices are controlled all the time except for a few washing machine starts. If we gradually increase the minimum improvement, it is clear that the washing machines are controlled less and less often as they provide little flexibility and the amount of energy consumed per activation is limited. The same trend is visible for the dishwashers, which still show a high number of control actions with a lower minimum improvement as it is still beneficial to shift dishwashers off the evening peak. Control of the heat pumps remains largely unaffected until the minimum improvement is 1000 or larger. The energy requirements and the attached buffer make that the heat pump offers a lot of flexibility to the smart grid. The same is true for the BEVs, which also have most energy consumption planned in the late afternoon and evening peak. This results in a large improvement by BEVs, only 5 charging jobs do not result in the required minimum improvement of 2000. Again, the peak shaving performance is largely unaffected when white goods are not controlled as observed in case A. Furthermore, we note that similar results regarding the value of flexibility are obtained by [54]. 


\subsubsection{ISLANDING SimULATIONS}

For evaluating the potential of the islanding control mechanism presented in Subsection 5.3.2, a microgrid consisting of 6 households is used. This microgrid is operated in islanded mode for one day. This time frame may be the result of e.g. severe weather conditions, which make that a part of the distribution or transmission grid may fail or collapse.

A group of 6 Texan houses, connected to one transformer, was considered for this situation instead of the Lochem test site grid. Measurement data of 6 households of June 62015 from the Pecan Street inc. Dataport [123] dataset was used to model the static household load. The samples in the datasets are provided in one minute time intervals. These samples are duplicated 60 times to obtain a sample rate of $1 \mathrm{~Hz}$. Next, the resulting time series are randomly shifted in time (up to 59 seconds) to avoid synchronized load changes by devices that turn on and off. The rest of the model consists of individual measurement data, also from the Pecan Street inc. Dataport [123] dataset, for solar PV setups, heating, ventilation and air conditioning (HVAC) systems, washing machines, dryers and dishwashers.

All 6 households in the considered microgrid have a rooftop PV system and 2 households have a $7 \mathrm{kWh}$ battery system with a power rating of $7 \mathrm{~kW}$. A third house has a BEV with vehicle-to-grid capability with a usable battery capacity of $21 \mathrm{kWh}$ and a power rating of $7.4 \mathrm{~kW}$. All battery systems are assumed to be fully charged prior to the islanding event as a precaution to expected problems, e.g. due to weather forecasts. Within this microgrid, the battery systems can be used to balance the load and generation while the loads can be shed and generation by the PV panels can be curtailed by the system if desired. For each of the controllable loads, a random delay time $T_{d}$ in the range of 1 to 5 seconds is selected and the control action delay $T_{d a}$ is set to 6 seconds. The HVAC models are based on the work presented in [GH:7], with a temperature setpoint of $22.0^{\circ} \mathrm{C}$ and an allowed deviation of $1.0^{\circ} \mathrm{C}$ in islanded mode. Each household has a must-run load of $200 \mathrm{~W}$ to make sure that refrigerators keep running, lighting can be used, the control system is powered and communication devices, such as smartphones, can be charged to access emergency information. A separate battery system with an inverter is used to provide balancing power and grid stabilization.

Three simulations are run. The No Control case shows the business as usual case in which no decentralized control system is in place and no load shedding is performed. In this case, the domestic batteries try to balance the household consumption using a greedy strategy: charge in case of net production, discharge in case of net consumption. The Individual optimization approach has a HEMS in place to optimize the household energy profile. The Cooperative optimization approach combines this HEMS with a global control level in which all households cooperate to achieve energy balance for the microgrid. A flat zero-profile is the objective for the optimization approaches and the proposed real-time control with proportionalintegral-derivative controller (PID) is used as presented in Chapter 5. The demand functions are updated every 5 minutes. 


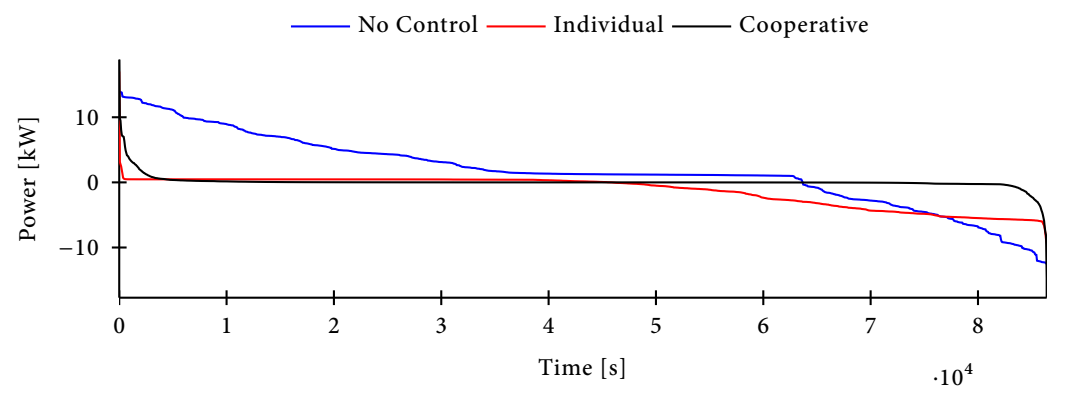

(a) Load duration curve for the microgrid in islanded mode.

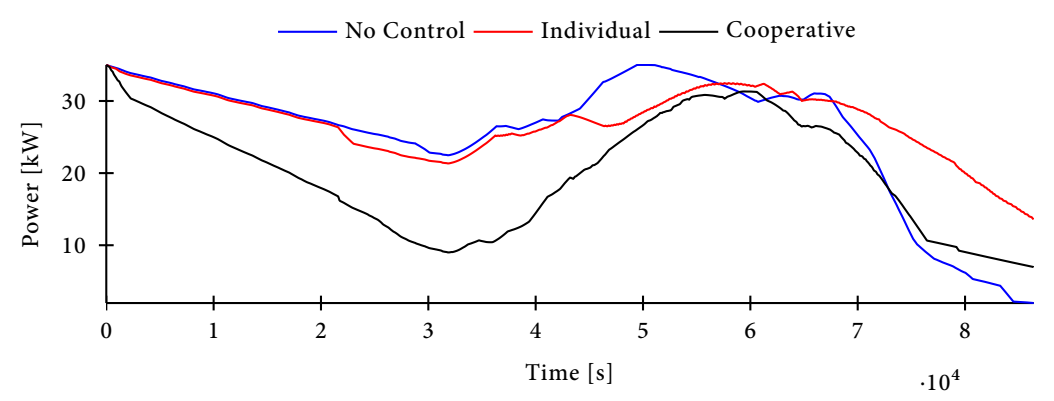

(b) SoC for the microgrid in islanded mode.

Figure 7.13: Islanded operation simulation results.

Table 7.6: Simulation results for the islanded microgrid case in Subsection 7.2.3

\begin{tabular}{r|ccccc}
\hline Approach & $E^{-}[\mathrm{kWh}]$ & $E^{+}[\mathrm{kWh}]$ & $C[\mathrm{kWh}]$ & $E_{\text {shed }}[\mathrm{kWh}]$ & $E_{\text {curt }}[\mathrm{kWh}]$ \\
\hline No Control & 32.9 & 74.2 & 54.3 & 0.0 & 0.0 \\
Individual & 36.6 & 5.4 & 36.2 & 99.3 & 14.8 \\
Cooperative & 3.0 & 3.7 & 0.8 & 46.6 & 0.0 \\
\hline
\end{tabular}

Legend: $E^{-}$and $E^{+}$: energy deficit and surplus in the microgrid, $C$ : Required backup battery capacity, $E_{\text {shed }}$ and $E_{\text {curt }}$ : Energy shed and curtailed.

\section{Results}

The goal here is to offload the load and usage of the potential backup battery system as much as possible. Therefore, it is desired to balance (i.e. a power value of $0 \mathrm{~W}$ ) the microgrid as much as possible with the domestic batteries and BEV as all power deficits and surpluses have to be provided by this backup system. Figure 7.13a shows the aggregated load duration curves for the different control strategies in the islanded microgrid without the balancing battery system included. It is clear from this figure that the control systems are able to deliver a better power balance by optimizing the energy usage and apply load shedding where required. The accu- 
Table 7.7: Supply voltage characteristics for data used in Subsection 7.2.4

\begin{tabular}{r|cc}
\hline & Lochem & Amsterdam \\
\hline Measured Mean & $236.7 \mathrm{~V}$ & $233.0 \mathrm{~V}$ \\
Measured St.dev. & $3.39 \mathrm{~V}$ & $2.16 \mathrm{~V}$ \\
Measured Maximum & $242.3 \mathrm{~V}$ & $237.6 \mathrm{~V}$ \\
Measured Minimum & $230.1 \mathrm{~V}$ & $227.8 \mathrm{~V}$ \\
& & \\
Pred. error St.dev. & $1.66 \mathrm{~V}$ & $1.27 \mathrm{~V}$ \\
Pred. error Maximum & $4.8 \mathrm{~V}$ & $4.9 \mathrm{~V}$ \\
Pred. error Minimum & $-4.8 \mathrm{~V}$ & $-3.8 \mathrm{~V}$ \\
\hline
\end{tabular}

mulated energy deficit $\left(E^{-}\right)$and surplus $\left(E^{+}\right)$given in Table 7.6 must be provided (balanced) by the storage system. The Cooperative approach is able to reduce the required storage capacity $C$ of the backup battery for islanding mode to only 0.8 $\mathrm{kWh}$ as given in Table 7.6. This value is obtained by taking the integral of the power profile and taking the difference between the minimum and maximum.

Figure 7.13b shows that the Cooperative strategy allows to fully use the potential of the domestic storage systems, which avoids curtailment of the PV generation. This in contrast to the Individual case, in which a total of $99.3 \mathrm{kWh}$ of load has to be shed $\left(E_{\text {shed }}\right)$, and a huge amount of PV production gets curtailed $\left(E_{\text {curt }}\right)$.

\subsubsection{Communication-Free Control}

Lastly we evaluate the proposed communication-free control method from Section 5.4 as a backup system in case the communication network fails. In this case, households use local measurements of the voltage or frequency at the point of connection to estimate the state of the distribution grid. This information is used to perform a local clearing to perform peak shaving and avoid grid overloading.

A week of voltage measurement data from a transformer in the Lochem test site is used for the simulations, of which the first and last days are discarded because of initialization and optimization horizon phenomena. The week starts with a Sunday and represents the period June 122016 - June 19 2016. The four weeks prior to this period are used as input data for the prediction algorithm. We use the average voltage of the previous four weeks as prediction. Since voltage fluctuations may differ in areas, we also use a second set of voltage measurements from another area. For this we take measurements from a transformer located at Hogeschool van Amsterdam [126]. These voltage measurements are from March and April 2016. Characteristics of both measured voltages are given in Table 7.7.

The simulation time interval length is set to 6 seconds as a trade-off between accuracy and required computational time. With these settings, we can study how the control system reacts to changes in measurements, which are the result of control 
Table 7.8: Controllable domestic appliances used in Subsection 7.2.4

\begin{tabular}{r|ccc}
\hline & Devices & Power $[\mathrm{kW}]$ & Capacity $[\mathrm{kWh}]$ \\
\hline Washing Machines & 80 & $\leq 2.0$ & N/A \\
Dishwasher & 40 & $\leq 2.0$ & N/A \\
PHEV & 16 & $\leq 3.7$ & 12 \\
BEV & 16 & $\leq 7.4$ & 42 \\
PV & 19 & $\geq-5.0$ & N/A \\
Battery & 8 & $\leq 3.7$ & $2-12$ \\
\hline
\end{tabular}

actions of other households. As measurement data and input models are provided in 60 second intervals we repeat each sample 10 times to preserve the effects of instantaneous load increases due to device activations. Furthermore, these profiles are randomly shifted by o to 9 intervals (of 6 seconds) to avoid power consumption change synchronization of all household profiles.

The objective is to flatten the load by performing peak shaving using control of domestic devices. A futuristic case is considered with a considerable amount of flexibility in the grid which may result in overloads. Different amounts of smart white goods, BEVs, PV panels and batteries are assigned to the household as tabulated in Table 7.8. The relative high amount of flexible appliances and households is required to see if and how the desynchronized control of the cluster is able to maintain a stable power and voltage profile.

Two series of simulations are run. The first carries out a comparison between the following control strategies: 1) NoControl; 2) Auction control through ICT; 3) Voltage based control using the communication-free control method presented in Chapter 5 with voltage measurements and; 4) Frequency based control with frequency measurements. In this series of simulations, the voltage at the transformer is fixed at $230 \mathrm{~V}$ to reduce the evaluation to only the performance on the low voltage $(L V)$ grid.

For the frequency, a generator located at the transformer with nominal frequency $f=50 \mathrm{~Hz}$ is used. A linear droop curve is used to change the frequency based on the power $P$ imported or exported, $f=50-P \cdot 12.5 \cdot 10^{-6} \mathrm{~Hz}$. For Auction control the market will be cleared at the average power consumption over the simulated week, which is $30.7 \mathrm{~kW}$. Fluctuations of the medium voltage $(M V)$ grid are included in a second series of simulation studies where the performance of voltage based control is tested with the voltage measurements from Lochem and Amsterdam.

\section{Results}

An overview of aggregated power values at the transformer and voltage levels in the grid for all simulations are given in Table 7.9. The simulation results with a stabilized voltage supply at the transformer clearly show that the proposed method 
Table 7.9: Results of simulations in the cases of Subsection 7.2.4

\begin{tabular}{r|cccc}
\hline & $P_{\max }[\mathrm{kW}]$ & $P_{\min }[\mathrm{kW}]$ & $U_{\max }[\mathrm{V}]$ & $U_{\min }[\mathrm{V}]$ \\
\hline NoControl & 98.3 & -31.7 & 240.5 & 207.0 \\
Auction & 93.5 & -31.7 & 236.4 & 212.9 \\
Voltage & 77.8 & -31.8 & 236.0 & 211.1 \\
Frequency & 96.8 & -31.8 & 245.1 & 208.6 \\
& & & & \\
Lochem & 83.7 & -28.1 & 243.1 & 219.8 \\
Amsterdam & 81.6 & -30.4 & 239.6 & 216.7 \\
\hline
\end{tabular}

Legend: $P_{\min }$ and $P_{\max }$ : minimum and maximum power, $U_{\min }$ and $U_{\max }:$ minimum and maximum voltage.

results in significant peak reductions at the aggregated level compared to the NoControl. With the Voltage control strategy, the peak load is reduced from $98.3 \mathrm{~kW}$ to $77.8 \mathrm{~kW}$ whereas the Frequency strategy only reduces the peak load slightly to $96.8 \mathrm{~kW}$. However, it has to be noted that the peak load with Frequency control is not sustained for long and is significantly reduced in most high demand intervals compared to the NoControl case as depicted in the load duration curve in Figure 7.14. It is also remarkable that the Frequency control strategy performs close to the Auction control in terms of peak shaving performance as shown in the load duration curve. This is the result of a comparable market clearing price $(M C P)$ and a local clearing price $(L C P)$, which also results in approximately the same usage of available flexibility as shown in the resulting clearing prices depicted in Figure 7.15. Herein the MCP is given for the centralized auctions, and for the other cases the average LCP, together with a heat map showing the spread of the different LCPs. Both the Voltage and Auction control mechanisms perform good in terms of power quality improvement by reducing the voltage band significantly compared to NoControl. This is no surprise as the Voltage control method controls the load based on the feedback loop which is fed by local voltage measurements. It is also clear that the Frequency method lacks this information, leading to worse voltage levels compared to NoControl, despite the fact that the peak load is reduced. Further analysis of the results shows that this is the result of unbalanced load over the three phases, leading to large neutral point shifts.

The fluctuations from the MV grid have a severe impact on the peak shaving performance of the control strategies using local voltage measurements as the measurements are distorted and therefore a large dead band is introduced in the control methodology. Both the dataset used for Lochem and Amsterdam shows significant voltage fluctuations which can be deduced from the standard deviations as shown in Table 7.7. The peak load is still significantly reduced for Lochem $(83.7 \mathrm{~kW})$ and Amsterdam $(81.6 \mathrm{~kW})$ compared to NoControl $(98.3 \mathrm{~kW})$ as tabulated in Table 7.9. However, the load duration curve in Figure 7.14 shows a significant higher load for these cases compared to the Voltage case. The large dead band also has impact on 


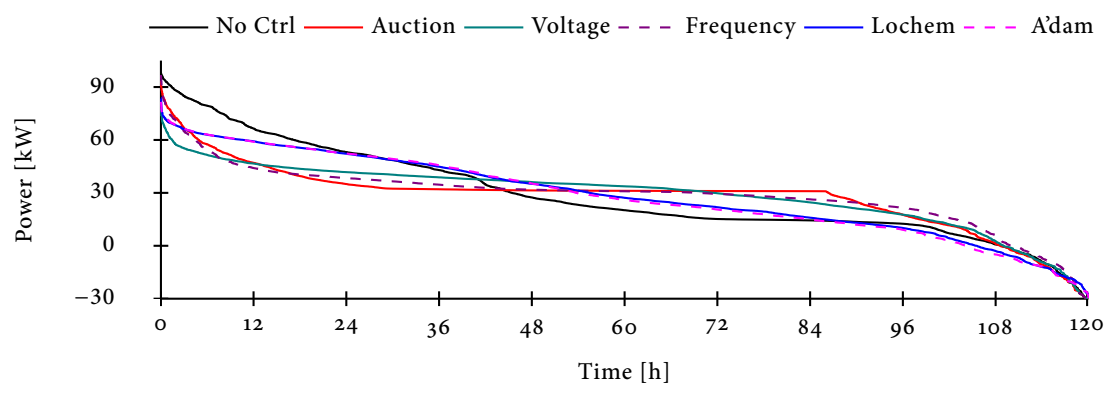

(a) Whole simulation

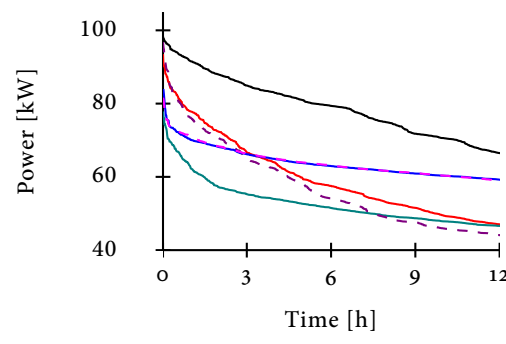

(b) Zoomed - first hours

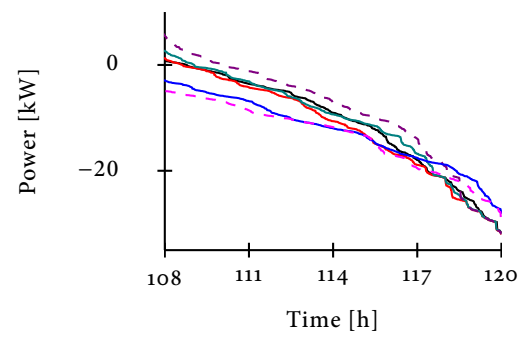

(c) Zoomed - last hours

Figure 7.14: Power load duration curves for the control strategies without communication.

the average LCP for the Lochem and Amsterdam cases (Figure 7.15), which does not touch the high and low prices as much as it did with a stable voltage supply in the Voltage case.

Overall, it can be concluded that the proposed peak shaving method using local data performs well when only one part of the grid is considered. hereby, the Voltage case performing close to the Auction case. However, the performance is significantly reduced when external effects of the power system are introduced, which distort the local measurements. Hence, it can be concluded that voltage based control methods for smart grids need to be evaluated with care. As shown, voltage fluctuations can have a severe impact on the delivered profile. However, in all cases a significant improvement on the profile is obtained when compared to the uncontrolled cases. Therefore, the proposed control mechanism can be used as a fall back system to enhance the reliability of the smart grid for situations when the communication network fails. 


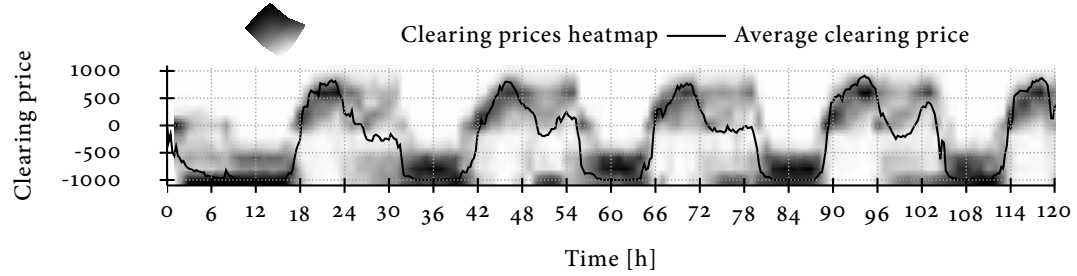

(a) Clearing prices: Voltage

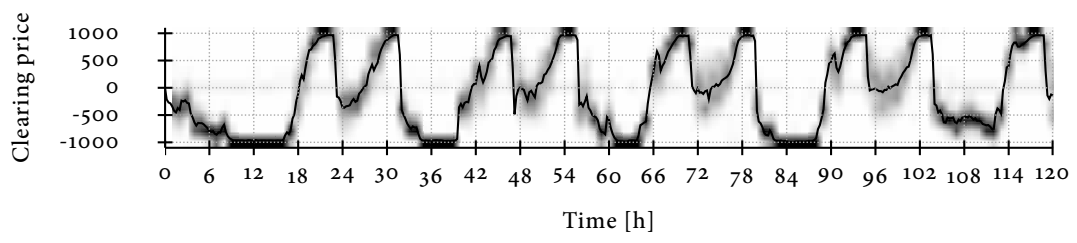

(b) Clearing prices: Frequency

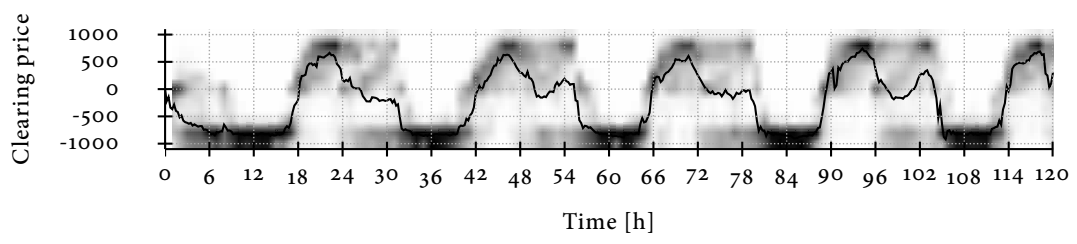

(c) Clearing prices: Lochem

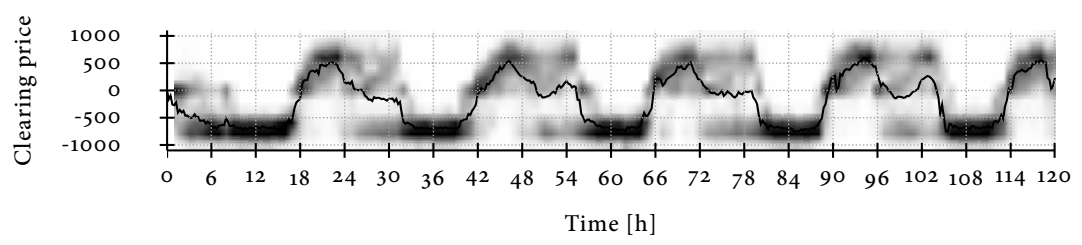

(d) Clearing prices: Amsterdam

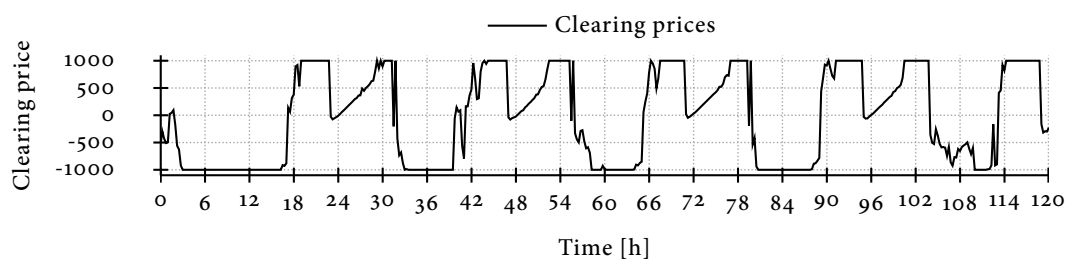

(e) Clearing prices: Auction

Figure 7.15: Clearing prices without the MV profile. 


\subsection{Conclusion}

The stress tests conducted in Lochem show that, largely, uncontrolled charging of electric vehicles, together with electric heating and cooking, may lead to severe power quality issues in low voltage grids. As alternative to grid reinforcements, advanced control systems may prevent such situations to happen. However, it is crucial to have accurate models, scenarios and tools to test the performance of such control strategies for smart grids. In the previous chapters, models and tools to create these scenarios are presented.

These models are verified to be accurate in this chapter. First, a direct comparison between the measurement data and the physical grid model within the Lochem test site is carried out. The resulting simulated voltages showed that the grid model and implemented load-flow solver yield accurate results. Furthermore, a load model for domestic power consumption and flexibility is generated based on the composition of the considered neighbourhood in Lochem. The resulting artificial load profile, for a whole year, is compared with the real measurement data, which is remarkably accurate given the limited input required for the ALPG.

The resulting models are used in various simulation studies to evaluate the impact of electrification on the grid, and how the presented control mechanisms can prevent overloading. In a first case it is shown that control of privately owned domestic assets can be used to avoid grid overloading when applying coordinated control. In all the simulated cases, the usage of the profile steering approach leads to the better results. Depending on the objectives, either an event-based control strategy or an auction for realization of the planning should be used. The former performs better at avoiding extreme corner cases to provide lower stress and a better power quality. However, the auction does a better job at following the original planning, and may therefore give better market performance if the more extreme power peaks fit within the grid constraints.

However, the real-world performance of control system also depends on the flexibility prosumers are willing to provide. Several scenarios with different amounts of offered flexibility, based on questionnaire outcomes, are simulated. The provided flexibility by end-users as indicated by questionnaire results does relief the stress on the grid. Other scenarios with mainly buffer-based devices, which would result in less user discomfort, perform significantly better. These devices also provide more flexibility to perform peak shaving when compared with e.g. white goods.

A promising method to make smart grids robust is the islanded microgrid concept. Control methods to balance such a (Texan) microgrid are tested, in which the control system assists a backup battery pack to balance a microgrid in islanded mode. The control system deals with delays in the communication and execution of commands to balance the microgrid. Only small amounts of energy need to be exchanged with the backup system.

Another risk to the robustness of smart grids is the dependency on communication infrastructure. The performance of the developed control mechanism is therefore 
also studied in a case where the critical communication network fails. In this study, local measurements of the physical grid are fed in the local control system. The grid serves as an alternative communication channel. In all cases, the load is significantly reduced to avoid outages, even when fluctuating voltage profiles at the transformer are incorporated in the model.

The results obtained in this chapter show that the developed tools (the ALPG and DEMKit) provide a flexible environment to test various scenarios and control systems. Therefore, the tools can be used as decision support tools for future smart grids and control systems. Furthermore, the developed control mechanisms do work as expected and can optimize the flexibility potential of devices in a microgrid to avoid overloading and power quality issues. 


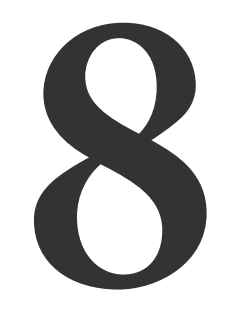

\section{Conclusions}

The energy transition towards a sustainable energy supply chain introduces new challenges to the electricity grid. More fluctuations in production and consumption of electricity are to be expected from the increasing use of decentralized intermittent renewable energy sources (RES) and the electrification taking place. Currently, power plants provide the required flexibility to ensure that the supply follows the demand. However, with the energy transition, increased power peaks are expected on the demand side, while flexibility on the production side is decreasing. Therefore, the traditional approach where production follows demand is not applicable anymore. Flexibility from the demand side is required instead to balance and avoid local overloading in the future decentralized grid.

This paradigm shift requires new control systems and tools to make the energy transition possible. We observed that this new system can be seen as a cyber-physical system (CPS). For this, a set of components of (smart) devices, grid assets and control systems is presented in Chapter 3. These separate components can be used as building blocks to model the technical side of a (future) smart grid. Interaction between the components, and simulation thereof, is required to study how these components influence each other.

In this work, two different control strategies are studied to reach the goals of the smart grid concept. The first presented control methodology is the profile steering approach presented in Chapter 4. Instead of using indirect methods, such as price based incentives, to steer a cluster of devices towards a desired power profile, we use this desired profile directly as a device agnostic steering signal. The used hierarchical tree structure maps nicely to the radial grid structure of the targeted residential microgrids. Peak powers and currents, which result in high losses and asset wearing, are avoided with the use of a localized initial planning. Grid constraints, such as capacity limitations of grid assets, can also be incorporated on each level of the control structure. Realization of the planned power profile is possible with the use of an event-based control methodology, which can be seen as a form of model predictive control (MPC). Finally, profiles for multiple commodities can be communicated together, allowing for multi-commodity control. 
The second control approach, based on double-sided auctions, is presented in Chapter 5. This mechanism is extended to support real-time control based on external measurement data to balance islanded microgrids. Such a solution can be used to reduce the load on a backup storage system or to increase the uptime of an islanded microgrid by utilizing the flexibility of the available devices. The double-sided auction approach can also be used when communication infrastructure fails. Local measurement data can be used as an alternative source of information about the state of the microgrid. This information is then used to increase or decrease a local clearing price, resulting in the cluster of devices to converge to a stable state where peak loads and power quality issues are avoided. Adequate performance is still provided when voltage fluctuations, which is noise to the control system (from the medium voltage ( $M V$ ) grid) is introduced. This methodology can be implemented as a fall back mechanism to enhance the robustness of smart grids.

To study the potential of the aforementioned control systems in the smart grid context, two tools are developed, which together result in a tool-chain. For control systems the information on available flexibility offered by devices is of crucial importance, but this information is not easily obtainable as static load profiles do not provide the necessary information. Therefore, an artificial load profile generator $(A L P G)$ is developed which expresses the available flexibility in a residential neighbourhood. Output from the ALPG can be fed to a second tool: the DEMKit simulation and demonstration framework. DEMKit implements the aforementioned physical components and the two presented control approaches in a modular way. This results in a flexible and extensible framework to perform studies on smart grid technologies. However, it can also be used as decision support tool for future grid investments or in small demonstrators for model verification.

A real-world stress test, where a future electrification scenario was created for one evening, resulted in an actual outage due to sustained overloading. Additionally, severe unbalance and voltage drops were observed in this field test. This indicates the need for advanced control strategies in future grids to continue delivering a stable and reliable supply of electricity.

Next to the real-world field test, also a model of the test site was created based on the obtained measurement data and the provided grid topology. Using this model, the presented control strategies are evaluated with simulations. A first study carries out a direct comparison between the profile steering algorithm, doublesided auction, and a combined control approach. The obtained results point out that using profile steering is beneficial to enhance the operation of the physical grid. The addition of a double-sided auction to the profile steering algorithm results in a better performance in realizing the planned profile, at the cost of increased peak load and reduced power quality. Simulation models with reduced flexibility, based on results of a questionnaire, indicate that also in this case enough flexibility is available to the tested distribution grid to avoid outages in the future. The simulated peak loads are only slightly increased compared to the peak load observed today. Simulations using a Texan microgrid model also indicate benefits of an adapted 
auction mechanism to offload backup storage systems. Lastly, it is shown that local grid measurements can be used as a substitute to communication networks to balance a microgrid. The resulting peak shaving performance indicates that the presented approach can be used as fall back mechanism to improve the robustness of the smart grid.

The remainder of this chapter presents answers to the research questions as introduced in Chapter 1 in Section 8.1. Next, the main contributions of this thesis are listed in Section 8.2. Finally, recommendations and research directions for future work are presented in Section 8.3.

\subsection{Conclusions AND Discussion}

Based on the obtained results presented in this thesis, the main research questions as stated in the introduction can be answered:

How can we effectively exploit the interaction between control systems, devices and physical distribution grids, while respecting physical constraints, in decentralized energy management to reach the objectives of a smart grid?

In order to answer this main question, we consider the three sub-questions:

"How can models of control systems, devices and the physical grid be integrated in one platform?

Essential for a smart grid control methodology is its performance on the physical grid, both in terms of capacity constraints and compliance with power quality norms. Within the scope of a residential microgrid, the optimization potential to meet these requirements comes from domestic devices. In the end, the state of a device results in a certain power consumption/production, which in turn results in a certain load on and delivered power quality from the physical grid. Furthermore, these devices all have their limitations in terms of flexibility and availability, which need to be considered by the control system.

This results in three separate systems to be modelled: devices, grid infrastructure and a control system. Devices and the physical grid belong to the physical domain, whereas the control system is a piece of software and thus belongs to the cyber domain. Therefore, to answer the first sub-question a CPS approach is taken in this work, which allows the interaction between these models. From a model perspective, the used components of either part of the system can be replaced by other components to study the effects of different approaches, or of using more advanced models.

This CPS approach has been used in the presented DEMKit simulation and demonstration platform. The aforementioned separation is used to create a flexible and extensible framework for studies on smart grid systems. These systems can communicate through interfaces and direct function calls. 
" How can properties and constraints of device and grid models be integrated in a decentralized energy management system?

The components and properties of the aforementioned devices and grid infrastructure introduce constraints. These constraints need to be considered by the control mechanism to operate the devices and the grid within their respective boundaries.

Device operation constraints can directly be used within device scheduling algorithms, such as presented in [148], or can be translated into device demand functions as presented in Chapter 5. This results in feasible control decisions and the provided information can be utilized for MPC. With the introduced separation of devices, grid assets and control, it is possible to neglect some high level device characteristics in the optimization process, e.g. to reduce optimization complexity. These characteristics can be included in the device components themselves to evaluate how such a choice affects the performance. Feedback from the actual device state may be used to reschedule devices when the mismatch between the planned and actual power consumption deviates too much.

Capacity constraints from the physical grid can also be incorporated in the discussed control methodologies. In both the profile steering approach and the auction approach, the developed control system consists of a tree structure. Most distribution grids are also operated in a tree structure (radial grids) and thus allow for a natural mapping from physical structure to cyber structure. The layered approach of the control system allows us to introduce the grid capacity constraints on multiple levels of the grid, such that overloading can be avoided.

Additionally, the grid components can also be used to derive optimization heuristics that, next to a primary objective, result in good solutions for secondary objectives. As an example, the overall desired profile is the main objective in the presented profile steering approach. Delivering good power quality and reducing stress on assets are secondary objectives to the approach. From the grid components we know that the peak currents should be avoided, and hence a strategy to flatten the local load curve is integrated as initial step to the profile steering algorithm. The results in Chapter 7 show that this strategy results in a strong performance on all objectives. Other details, such as phase balancing to avoid neutral point shifts, and reactive power control, are also integrated within the presented profile steering approach.

"How can decentralized energy management systems exploit interaction between the physical and cyber parts of smart grids to enhance its robustness?

$\mathrm{Bi}$-directional interaction between the physical and cyber components is possible as indicated in Chapter 3. The developed software tool (DEMKit) implements these components. The different components can communicate with each other through interfaces and direct function calls. Through the simulation tool, the benefits of adding bi-directional communication between components and feedback to the control systems can be evaluated. 
The interaction can be utilized to assess the power quality in a modelled grid given a resulting power consumption from control system decisions. Thus, the results of control actions can be studied and validated on beforehand. If the control actions do not satisfy power quality constraints, a (slightly) different objective function can be used to find a solution that does satisfy power quality constraints. Using the event-based profile steering approach, the interaction between devices and control systems can also be utilized to make the control system robust against prediction errors in the energy domain by integrating new information as soon as it becomes available. This approach avoids extreme power peaks, and thereby avoiding overloading and excessive component wearing, as shown in the results presented in Chapter 7.

Another scenario with fruitful interaction is presented in Chapter 7 , namely the scenario where the communication infrastructure fails. The control system can use locally available measurement information, which reflects the grid state, to change the local power consumption. Simulation results show that a cluster of devices still can converge to stable states with considerable peak shaving performance. Hence, the local grid itself is used as a substitute to the communication infrastructure, making the smart grid robust to the failure of this communication infrastructure.

In conclusion, to answer the main research question, the achieved results have to be compared with the smart grid definition as given in [78]: A smart grid is an electricity network system that uses digital technology to monitor and manage the transport of electricity from all generation sources to meet the varying electricity demands of end users. Such grids are able to coordinate the needs and capabilities of all generators, grid operators, end users and electricity market stakeholders in such a way that they can optimize asset utilization and operation and, in the process, minimize both costs and environmental impacts while maintaining system reliability, resilience and stability.

The proposed control framework optimizes the power profile of a microgrid to a desired profile. The profile steering heuristic thereby takes grid, device and enduser constraints into account. We note that the objectives of some stakeholders may conflict with those of other stakeholders. However, if we look at the physical smart (micro)grid, a flattened power profile to keep energy as local as possible, is desired. With this flat profile as objective in the profile steering algorithm, we find significant reduction in asset stress and losses in the physical grid models, while the delivered power quality is increased. Fall-back solutions, such as islanding and communication-free control algorithms add reliability, resilience and stability to smart microgrids. Therefore, the presented results give a solution to the main research question. 


\subsection{CONTRibutions}

The main contributions of this thesis are:

»Cyber-physical model of smart grids: A CPS oriented description of device components, grid components and control methods is presented. These components can be used as building blocks to model a residential microgrid to study its potential. Components can be exchanged easily due to the modular approach taken. (Chapter 3)

" Profile steering algorithm extensions: In this work, the profile steering approach ([GH:12], [143], [148]) is extended to support multiple commodities, such that it can perform also phase balancing and reactive control. This planning based control approach can be used in the operational phase of a smart grid with the addition of event-based profile steering. This light-weight addition allows the use of already existing optimization algorithms to resolve prediction errors, resulting in a MPC system for smart grids. (Chapter 4)

"Communication-free fall back solution: As the smart grid depends on communication infrastructure to ensure reliable and safe supply of energy, a fall back solution is required for situations where communication systems fail. Therefore, an addition to the auction mechanism is proposed in which local measurement data is used to avoid extreme power peaks that may cause damage to the physical grid. Herein, the grid itself is seen as a communication channel, which can be read out to estimate the current state of the grid. Subsequently, this information is used to avoid extreme power peaks. Simulation results show that this system, under stable conditions, performs close to a system with operational communication infrastructure. (Chapter 5)

"Artificial load profile generator: An ALPG is developed to obtain realistic residential load profiles for use within decentralized energy management (DEM) methodologies. The generator produces explicit flexibility information and user-comfort constraints in a generic format. The results can be used to evaluate the potential of control methodologies in various scenarios or in a direct scenario by using the output as a benchmark set. Additionally, the ALPG requires only high-level information as input, thereby limiting the modelling effort. (Chapter 6)

»DEMKit: a simulation and demonstration platform: A simulation and demonstration framework called DEMKit is developed to study the impact of control mechanisms on the physical grid. The implementation follows the models and CPS approach presented in Chapter 3. This approach resulted in a flexible and extensible framework, with multiple control algorithms, using the same device model. Furthermore, the strict separation allows device components to be replaced with interfaces to real hardware, allowing for co-simulations. (Chapter 6) 


\subsection{Future Work}

The work presented in this thesis forms a solid basis for evaluation of DEM approaches within the smart grid context. The presented results show that, under various conditions, the presented approaches yield good results. Yet, there are several research directions and recommendations for future work to improve the presented work and broaden its applicability.

Concerning the profile steering approach, we already noted that the current implementation is rather slow, especially when compared with the results obtained by [143]. This is in part due to the use of Python instead of a lower level programming language, such as $\mathrm{C}++$, but also partly due to inefficient prototyping code meant to demonstrate the added value. Therefore, it is recommended to improve the implementation of DEMKit and exploit the inherent parallelism. Next to this, also other changes can be thought of to make the solution more effective in larger grids than the considered microgrid setting.

A potential scaling problem is the bottleneck that only one child is selected to commit its profile, which potentially results in numerous iterations for larger clusters and deeper control trees. A possible solution is to accept multiple profiles at once. This may potentially lead to more overshoots, but it is expected that these are quickly resolved in following iterations. Especially if the desired profile is scaled down proportional to the number of candidate profiles that will be accepted in one iteration. Furthermore, the number of accepted candidate profiles could be reduced after each iteration. One other direction, which may be combined, is to gradually reduce the number of involved child controllers based on their last obtained improvement, effectively leaving out children with limited flexibility. In case load-shedding or production curtailment needs to be performed, these options could be enabled when (nearly) all flexibility is exhausted, but grid constraint violations still occur.

A second possible issue with the current implementation of the profile steering algorithm is that mainly the master objective, the one at the fleet controller, is solved. Children with a significant amount of flexibility solve large parts of the problem profile, which potentially results in local peaks. Within the considered microgrid use case, this was not a problem as households initially created a flattened local profile. A possible solution here is to include a local objectives and local costs of the devices. This should result in milder reactions to the steering signals.

With the addition of the event-based profile steering approach, the control and realization of a planning using MPC has become possible at limited computational costs. However, the results presented in Chapter 7 still show room for improvement when it comes to minimizing the deviation from the planned profile. The doublesided auction clearly shows better performance on this performance metric due to the faster control concerning all devices. On the other hand, the auction approach results in larger power peaks when running out of flexibility. Therefore, further improvement of the event-based approach, or a hybrid implementation, may result in the best of both worlds. 
Support for multiple commodities has become possible with the profile steering approach. We tested the approach by considering the three phases, but other commodities, such as heat and natural gas, should be considered. In addition, converting devices as used in [107] should be introduced. This addition does create an interesting challenge to be solved: namely the dependency of a device on other devices. An example is a heat pump with buffer, as this depends on both the heat demand by heating devices and the electricity consumption profile of other devices. On the other hand, there is the balancing question with multiple converters which need to converge to a stable situation.

The addition of event-based profile steering also raises the question whether the approach significantly benefits from the planning made on beforehand. Without the planning phase the approach could possibly be used in a distributed, peerto-peer system where the cluster tries to optimize to a predefined target profile. Herein, unresolved deviations might be passed along the communication grid to neighbouring nodes, which may be able to resolve future peaks using their own flexibility, similar to how waves fade out. With the uprising of local, self organising, energy communities and blockchain technology, it is interesting to see if a variant of profile steering is applicable to these distributed systems.

As the approach relies on forecasts, which arguably will never be accurate, strategies to adequately handle forecast errors are required. However, just as important, one has to know what type of forecast errors are dominant and how they influence the outcomes. Proper solutions to these errors can only be made if the most likely errors are known. A possible solution to this problem is to keep a fraction of the buffer capacity unused in the planning to make up for errors. More effort in forecasts and forecast error statistics should be considered to make a good risk assessment and choose how much capacity should be left unused.

Finally, we are dealing with the energy transition, which results in numerous practical challenges which, in general, cannot be captured in simple models. Therefore, efficient optimization and control algorithms are often non-existent as well. To solve these problems, the research field itself should push for more realistic models to converge to a solution that works in reality, which also implies that multidisciplinary collaboration is required. Ideally, models should reflect reality as accurately as possible, such that simulation results match reality as closely as possible. Similarly, more stakeholders and end-users of a control system should be taken into account. Both the technical and social components should be sound as the energy transition is something we either make or break together. 
200 


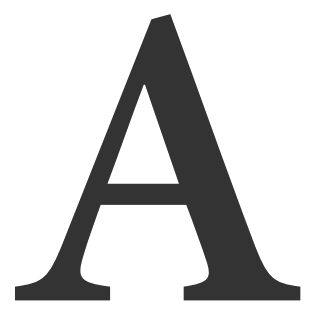

\section{Models AND EQUipMENT}

This appendix provides additional information on device and data models as well as information on the equipment used to obtain data where applicable.

\section{A.1 Device Data And Models}

This section provides additional information on the device data models, presented in Chapter 3, and the data used as input for the evaluation in Chapter 7.

Uncontrollable Devices: Uncontrollable device data models, presented in Subsection 3.1.2, are used for inflexible household loads (aggregated on household level) throughout this thesis. The input is given by a vector which specifies the average complex power consumption (real part in $\mathrm{W}$ and imaginary in var) for a number of discrete time intervals. Real measurement data from the Lochem field test was used in Section 7.1. In other cases this data is generated by the artificial load profile generator $(A L P G)$, presented in Chapter $6^{1}$. The interval length is the same as the simulation timestep setting used for each simulation.

Curtailable Devices: The curtailable device data model (Subsection 3.1.3) is used for photovoltaic $(P V)$ setups in all simulation studies. Furthermore, the curtailable device is also used for the sheddable loads used in Subsection 7.2.3 (measurement data from [123]). The input data is formatted in the same way as used for the uncontrollable device. The input data for PV systems is taken from measurement data from [38] (DSO Régie de Wavre, data from 2016) in Subsection 7.2.1 and from [123] in Subsection 7.2.3. In other cases, the power output of PV setups is calculated using global irradiation data from [89] (2014 measurements of weather station Twenthe). Direct and diffuse irradiation is calculated using [137]. The model presented in [83] is used to calculate the power generation based on the direct and diffuse irradiation, and the efficiency, geographical location, area, and angles of the PV system, assigned by the ALPG.

\footnotetext{
${ }^{1}$ Source code available at https://github.com/GENETX/alpg
} 
Buffer Devices: The buffer device model (Subsection 3.1.4) is used to represent batteries in all cases.

Buffer-Converter Devices: The buffer-converter device model (Subsection 3.1.6) is used to represent heat pumps in Subsection 7.2.1 and 7.2.2. The heat demand, to be supplied by a heat pump, is a vector with the average thermal power per discrete time interval. This vector is created using a given dataset from [23]. The heating, ventilation and air conditioning (HVAC) model presented in [GH:7] is used in Subsection 7.2.3.

Timeshiftable Devices: Timeshiftable devices models (Subsection 3.1.7) are used to model washing machines and dishwashers, except for the results in Subsection 7.2.3 (in which the curtailable device is used). Flexibility information is provided by the ALPG in the form of a vector with times at with the device becomes available and a vector at which the device must be finished (both defined in seconds since the simulation start). The complex power profile (real part in $\mathrm{W}$ and imaginary in var) for a cycle is given by a vector of measurement samples, which is a measured profile. The power consumption of both devices is measured with a Voltcraft Energy Logger 4000 , taking a measurement sample each minute. The washing machine profile is the measured power profile of a Siemens XL 1462 Festival with the $30{ }^{\circ} \mathrm{C}$ program. The dishwasher power profile is obtained by measuring the power consumption of a Bosch Silence on the normal program. The power profiles are included in the ALPG source code, available at https:/github.com/GENETX/alpg/blob/master/devices.py.

Buffer-Timeshiftable Devices: Buffer-timeshiftable devices (Subsection 3.1.8) are used to model battery electric vehicles (BEVs) in all simulation studies. Flexibility information is provided by the ALPG in the form of a vector with times at with the device becomes available and a vector with times at which the device must be finished (both defined in seconds since the simulation start). An additional vector specifies the energy requirement for each charging job (in Wh).

\section{A.2 Measurement Data and Equipment in Lochem}

A total of three transformers were equipped with measurement instruments to collect data on electricity usage within the smart grid Lochem project. The measurement data was collected between February 20, 2014 and October 1, 2015. The used equipment was Powersense DISCOS and a data sample was taken every minute. Multiple feeders on the secondary side of the transformer were measured per phase. Voltages and currents, including phase angles, were measured.

MPare EDB measurement equipment was installed in participating households. People were able to voluntarily sign up to share their measurement information anonymously, starting July 28, 2014. The data collection ended on October 1, 2015. During this period, power data was received from 75 sources of which:

» 18 have only positive (load) data points

» 27 have only negative (generation) data points 
» 30 have both positive (load) and negative (generation) data points.

A total of 36 sources reported a measurement sample each second and provided active power, reactive power and voltage data. The other 39 sources provided only an active power (with a resolution of $10 \mathrm{~W}$ ) measurement sample every 10 seconds.

Additional measurement equipment was temporarily installed during the stress test of April 2, 2015 (Section 7.1) to obtain detailed power quality information. One Fluke 430 II series power quality analyzer was installed at the transformer on the feeder that was tested. A second Fluke 430 II series analyzer was connected to one of the controllable $22 \mathrm{~kW}$ charging stations. 


\section{ACRONYMS}

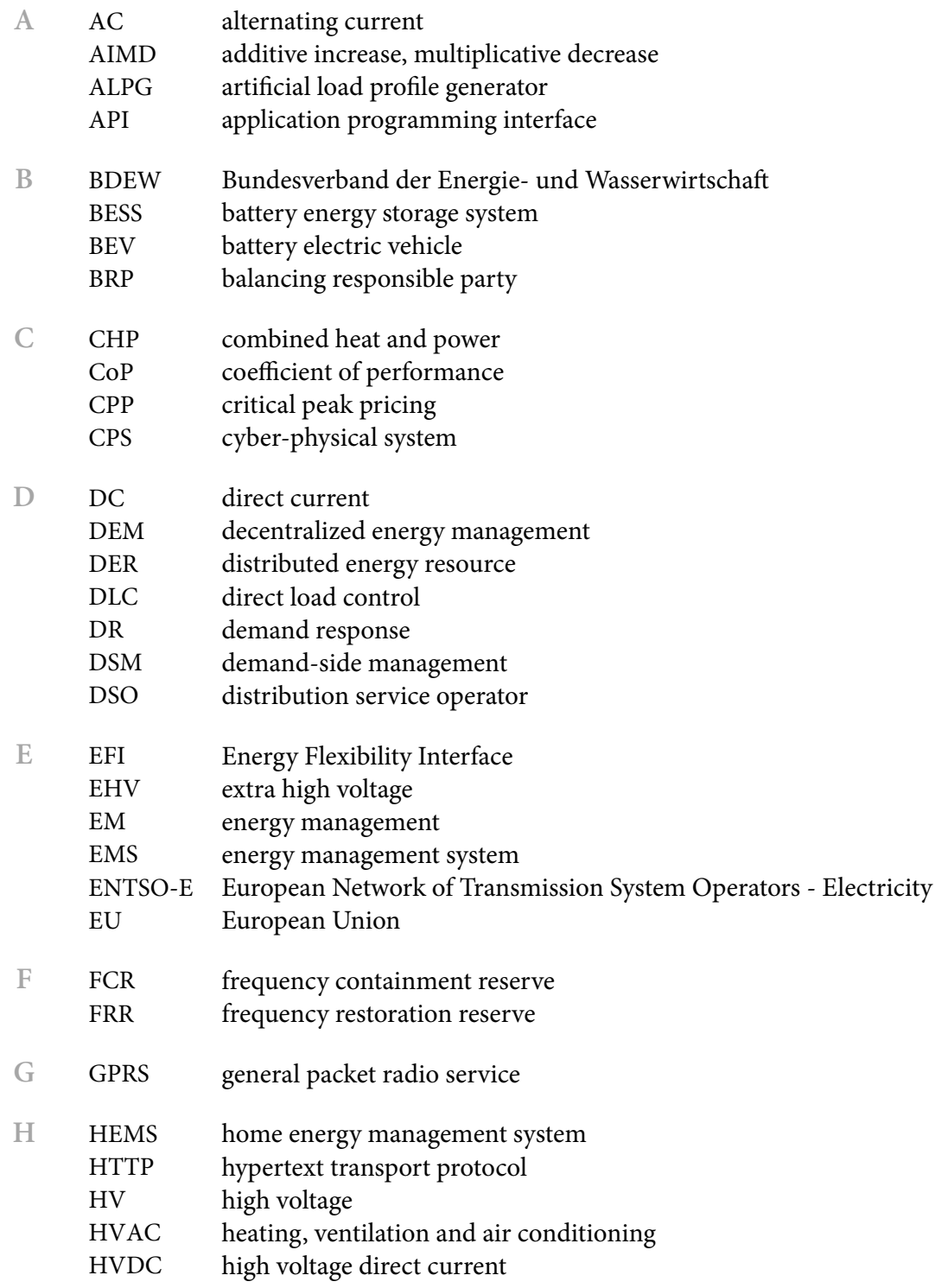




\begin{tabular}{|c|c|c|c|}
\hline \multirow{5}{*}{206} & I & ICT & information communication technology \\
\hline & & IEA & International Energy Agency \\
\hline & & IEC & International Electrotechnical Commission \\
\hline & & ILP & integer linear program \\
\hline & & IoT & internet of things \\
\hline \multirow{27}{*}{ 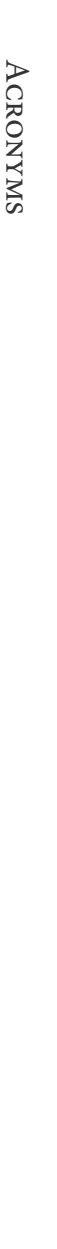 } & $\mathrm{J}$ & JSON & Javascript object notation \\
\hline & K & KCL & Kirchhoff's current law \\
\hline & & KVL & Kirchhoff's voltage law \\
\hline & $\mathrm{L}$ & LCP & local clearing price \\
\hline & & LV & low voltage \\
\hline & M & MCP & market clearing price \\
\hline & & MPC & model predictive control \\
\hline & & MV & medium voltage \\
\hline & $\mathrm{O}$ & OLTC & on-load tap changer \\
\hline & $\mathrm{P}$ & PHEV & plug-in hybrid electric vehicle \\
\hline & & PID & proportional-integral-derivative controller \\
\hline & & PMU & phasor measurement unit \\
\hline & & PQ & power quality \\
\hline & & PTU & program time unit \\
\hline & & PV & photovoltaic \\
\hline & $\mathrm{R}$ & RES & renewable energy sources \\
\hline & & REST & representational state transfer \\
\hline & & RMS & root mean square \\
\hline & & rpm & revolutions per minute \\
\hline & & RR & replacement reserve \\
\hline & & RTP & real time pricing \\
\hline & S & SoC & state of charge \\
\hline & $\mathrm{T}$ & ToU & time of use \\
\hline & & TSO & transmission system operator \\
\hline & $\mathrm{U}$ & US & United States \\
\hline & & USEF & Universal Smart Energy Framework \\
\hline & V & VUF & voltage unbalance factor \\
\hline
\end{tabular}




\section{BibLIOGRAPHY}

[1] C. Abreu, D. Rua, T. Costa, P. Machado, J. A. P. Lopes, and M. Heleno. Anyplace: An energy management system to enhance demand response participation. In 2017 IEEE Manchester PowerTech, pages 1-6, June 2017. doi: 10.1109/PTC.2017.7981062. (Cited on page 28).

[2] A. Al-Fuqaha, M. Guizani, M. Mohammadi, M. Aledhari, and M. Ayyash. Internet of things: A survey on enabling technologies, protocols, and applications. IEEE Communications Surveys Tutorials, 17(4):2347-2376, 2015. ISSN 1553-877X. doi: 10.1109/COMST.2015.2444095. (Cited on page 27).

[3] M. R. Alam, M. St-Hilaire, and T. Kunz. Computational methods for residential energy cost optimization in smart grids: A survey. ACM Comput. Surv., 49(1):2:12:34, April 2016. ISSN 0360-0300. doi: 10.1145/2897165. (Cited on page 28).

[4] P. B. Andersen, J. Hu, and K. Heussen. Coordination strategies for distribution grid congestion management in a multi-actor, multi-objective setting. In 2012 r $r$ IEEE PES Innovative Smart Grid Technologies Europe (ISGT Europe), pages 1-8, October 2012. doi: 10.1109/ISGTEurope.2012.6465853. (Cited on page 31).

[5] A. Andersson and F. Ygge. Managing large scale computational markets. In Proceedings of the Thirty-First Hawaii International Conference on System Sciences, volume 7, pages 4-13 vol.7, January 1998. doi: 10.1109/HICSS.1998.649156. (Cited on page 116).

[6] N. Andreadou, M. Olariaga Guardiola, I. Papaioannou, and G. Prettico. Smart grid laboratories inventory 2016. Technical report, 2016. last accessed on 13-07-2017. (Cited on page 38).

[7] M. Babar, P. H. Nguyen, V. Cuk, and I. G. Kamphuis. The development of demand elasticity model for demand response in the retail market environment. In 2015 IEEE Eindhoven PowerTech, pages 1-6, June 2015. doi: 10.1109/PTC.2015.7232789. (Cited on page 30 ).

[8] V. Bakker. Triana: a control strategy for Smart Grids: Forecasting, planning \& realtime control. PhD thesis, University of Twente, Enschede, January 2012. (Cited on pages 34,78 , and 144 ).

[9] V. Bakker, A. Molderink, J. L. Hurink, G. J. M. Smit, S. Nykamp, and J. Reinelt. Controlling and optimizing of energy streams in local buildings in a field test. In 22nd International Conference and Exhibition on Electricity Distribution (CIRED 2013), pages 1-4, June 2013. doi: 10.1049/cp.2013.0771. (Cited on pages 39 and 144).

[10] A. Barbato and A. Capone. Optimization Models and Methods for Demand-Side Management of Residential Users: A Survey. Energies, 7(9):5787-5824, 2014. ISSN 1996-1073. doi: 10.339o/en7095787. (Cited on pages 28 and 30). 
[11] F. Bliek, A. van den Noort, B. Roossien, I. G. Kamphuis, J. de Wit, J. van der Velde, and M. Eijgelaar. Powermatching city, a living lab smart grid demonstration. In 2010 IEEE PES Innovative Smart Grid Technologies Conference Europe (ISGT Europe), pages 1-8, October 2010. doi: 10.1109/ISGTEUROPE.2010.5638863. (Cited on page 39).

[12] M. Blom, M. Bles, C. Leguijt, F. Rooijers, R. van Gerwen, D. van Hameren, and F. Verheij. Maatschappelijke kosten en baten van intelligente netten. [Online] Available: http://www.ce.nl/publicatie/ maatschappelijke_kosten_en_baten_van_intelligente_netten/1236, 2012. last accessed on 12-07-2017. (Cited on page 24).

[13] Bloomberg Businessweek. The Electric Car Revolution Is Accelerating. [Online] Available: https://www.bloomberg.com/news/articles/2017-07-06/ the-electric-car-revolution-is-accelerating. last accessed on o8-08-2017. (Cited on page 14).

[14] P. Booij, V. Kamphuis, O. van Pruissen, and C. Warmer. Multi-agent control for integrated heat and electricity management in residential districts. In 4 th International Workshop on Agent Technologies for Energy Systems (ATES), a workshop of the 12th International Conference on Autonomous Agents and Multiagent Systems (AAMAS), Minnesota, 2013. (Cited on page 34).

[15] M. Bosman. Planning in Smart Grids. PhD thesis, July 2012. eemcs-eprint-22062; http://eprints.ewi.utwente.nl/22062. (Cited on pages 34 and 78).

[16] S. Boyd, N. Parikh, E. Chu, B. Peleato, and J. Eckstein. Distributed optimization and statistical learning via the alternating direction method of multipliers. Found. Trends Mach. Learn., 3(1):1-122, January 2011. ISSN 1935-8237. doi: 10.1561/2200000016. (Cited on page 36).

[17] Bundesministerium für Wirtschaft und Energie. Broschüre SmartHome2Market - Marktperspektiven für intelligente Heimvernetzung. [Online] Available: http://www.digitale-technologien.de/DT/Redaktion/DE/Downloads/

Publikation/smarthome-broschuere.pdf, 2016. last accessed on 12-07-2017. (Cited on page 27).

[18] Bundesverband der Energie- und Wasserwirtschaft. Smart Grid Traffic Light Concept: Design of the amber phase. Technical report, March 2015. (Cited on page 25).

[19] Centraal Bureau voor de Statistiek. Demografische kerncijfers per gemeente 2014. [Online] Available: https://www.cbs.nl/nl-nl/publicatie/2014/50/ demografische-kerncijfers-per-gemeente-2014, 2014. last accessed on 2507-2017. (Cited on pages 137 and 161).

[20] D. P. Chassin, K. Schneider, and C. Gerkensmeyer. GridLAB-D: An open-source power systems modeling and simulation environment. In 2008 IEEE/PES Transmission and Distribution Conference and Exposition, pages 1-5, April 2008. doi: 10.1109/TDC.2008.4517260. (Cited on page 144).

[21] C. S. Cheng and D. Shirmohammadi. A three-phase power flow method for realtime distribution system analysis. IEEE Transactions on Power Systems, 10(2):671-679, May 1995. ISSN 0885-8950. doi: 10.1109/59.387902. (Cited on page 62). 
[22] J. J. Chromik, A. Remke, and B. R. Haverkort. What's under the hood? improving scada security with process awareness. In 2016 Joint Workshop on Cyber-Physical Security and Resilience in Smart Grids (CPSR-SG), pages 1-6, April 2016. doi: 10.1109/CPSRSG.2016.7684100. (Cited on page 37).

[23] F. Claessen, B. J. Claessens, M. Hommelberg, A. Molderink, V. Bakker, H. Toersche, and M. van den Broek. Comparative analysis of tertiary control systems for smart grids using the Flex Street model. Renewable Energy, 69:260-270, 2014. ISSN 09601481. doi: 10.1016/j.renene.2014.03.037. (Cited on pages 35, 135, 165, and 202).

[24] B. J. Claessens, S. Vandael, F. Ruelens, and M. Hommelberg. Self-learning demand side management for a heterogeneous cluster of devices with binary control actions. In 2012 3rd IEEE PES Innovative Smart Grid Technologies Europe (ISGT Europe), pages 1-8, October 2012. doi: 10.1109/ISGTEurope.2012.6465679. (Cited on page 35).

[25] B. J. Claessens, S. Vandael, F. Ruelens, K. De Craemer, and B. Beusen. Peak shaving of a heterogeneous cluster of residential flexibility carriers using reinforcement learning. In IEEE PES ISGT Europe 2013, pages 1-5, October 2013. doi: 10.1109/ISGTEurope.2013.6695254. (Cited on page 35).

[26] D. Connolly, H. Lund, B. Mathiesen, and M. Leahy. A review of computer tools for analysing the integration of renewable energy into various energy systems. Applied Energy, 87(4):1059-1082, 2010. ISSN 0306-2619. doi: 10.1016/j.apenergy.2009.09.026. (Cited on page 144).

[27] J. Cook, N. Oreskes, P. T. Doran, W. R. L. Anderegg, B. Verheggen, E. W. Maibach, J. S. Carlton, S. Lewandowsky, A. G. Skuce, S. A. Green, D. Nuccitelli, P. Jacobs, M. Richardson, B. Winkler, R. Painting, and K. Rice. Consensus on consensus: a synthesis of consensus estimates on human-caused global warming. Environmental Research Letters, 11(4):048002, 2016. (Cited on page 1).

[28] K. De Craemer, S. Vandael, B. J. Claessens, and G. Deconinck. An event-driven dual coordination mechanism for demand side management of phevs. IEEE Transactions on Smart Grid, 5(2):751-760, March 2014. ISSN 1949-3053. doi: 10.1109/TSG.2013.2272197. (Cited on page 35).

[29] R. de Wolf and S. M. Vosslamber. Studie naar userrequirements en het verschil tussen mannen en vrouwen. Technical report, January 2015. (Cited on page 175).

[30] R. Deng, Z. Yang, M. Y. Chow, and J. Chen. A survey on demand response in smart grids: Mathematical models and approaches. IEEE Transactions on Industrial Informatics, 11(3):570-582, June 2015. ISSN 1551-3203. doi: 10.1109/TII.2015.2414719. (Cited on page 28).

[31] Deutsche Energie-Agentur. Verteilnetzstudie Ausbau- und Innovationsbedarf der Stromverteilnetze in Deutschland bis 2030. [Online] Available: https://shop.dena.de/fileadmin/denashop/media/Downloads_Dateien/ esd/9100_dena-Verteilnetzstudie_Abschlussbericht.pdf, 2012. last accessed on 12-07-2017. (Cited on page 24). 
[32] R. D'hulst, K. Vanthournout, and F. Hoornaert. Lv distribution network voltage control mechanism: Experimental tests and validation. In IECON 2014 - 4oth Annual Conference of the IEEE Industrial Electronics Society, pages 3504-3509, October 2014. doi: 10.1109/IECON.2014.7049019. (Cited on pages 38 and 110).

[33] J. Dickert, M. Domagk, and P. Schegner. Benchmark low voltage distribution networks based on cluster analysis of actual grid properties. In 2013 IEEE Grenoble Conference, pages 1-6, June 2013. doi: 10.1109/PTC.2013.6652250. (Cited on page 58).

[34] B. Dupont, P. Vingerhoets, P. Tant, K. Vanthournout, W. Cardinaels, T. De Rybel, E. Peeters, and R. Belmans. Linear breakthrough project: Large-scale implementation of smart grid technologies in distribution grids. In 2012 3rd IEEE PES Innovative Smart Grid Technologies Europe (ISGT Europe), pages 1-8, October 2012. doi: 10.1109/ISGTEurope.2012.6465708. (Cited on page 39).

[35] Dutch Enterprise Agency. Factsheets ENG 2015. Technical report, 2015. last accessed on 13-07-2017. (Cited on page 39).

[36] Easy Energy. Energie voor de échte inkoopprijs. [Online] Available: https:// www.easyenergy.com. last accessed on 12-07-2017. (Cited on page 24).

[37] Eclipse Smarthome. A flexible framewrok for the smart home. [Online] Available: http://www.eclipse.org/smarthome. last accessed on 12-07-2017. (Cited on page 28).

[38] Elia. Solar-PV power generation data. [Online] Available: http://www.elia.be/en/ grid-data/power-generation/Solar-power-generation-data/Graph. last accessed on 26-07-2017. (Cited on pages 164, 165, and 201).

[39] EMD International. EnergyPRO. [Online] Available: https://www.emd.dk/ energypro. last accessed on 08-08-2017. (Cited on page 144).

[40] Energieonderzoek Centrum Nederland. Energietrends 2014. [Online] Available: http://energietrends.info/wp-content/uploads/2014/09/ EnergieTrends2014.pdf. last accessed on 08-08-2017. (Cited on page 135).

[41] EnergyPLAN. EnergyPlan - Advanced energy system analysis computer model. [Online] Available: http://www.energyplan.eu. last accessed on o8-o8-2017. (Cited on page 144).

[42] EPEX Spot. Continuous Markets: Intraday \& Strips. [Online] Available: https:// www.apxgroup.com/trading-clearing/continuous-markets-intraday. last accessed on 12-07-2017. (Cited on page 19).

[43] Eurelectric. Power Distribution in Europe Facts \& Figures. [Online] Available: http://www.eurelectric.org/media/113155/dso_report-web_final2013-030-0764-01-e.pdf, 2013. last accessed on 12-07-2017. (Cited on page 24).

[44] European Commission. 2020 climate \& energy package. [Online] Available: https: //ec.europa.eu/clima/policies/strategies/2020_en. last accessed on 28-072017. (Cited on page 2). 
[45] European Commission. Energy Roadmap 2050. [Online] Available: https://ec.europa.eu/energy/en/topics/energy-strategy-and-energyunion/2050-energy-strategy, 2012. last accessed on 12-07-2017. (Cited on page 24).

[46] European Commission. 2030 Energy Strategy. [Online] Available: https://ec.europa.eu/energy/en/topics/energy-strategy-and-energyunion/2030-energy-strategy, 2016. last accessed on 28-07-2017. (Cited on page 2).

[47] European Commission Joint Research Centre. Smart Metering deployment in the European Union. [Online] Available: http://ses.jrc.ec.europa.eu/smartmetering-deployment-european-union. last accessed on 12-07-2017. (Cited on page 24).

[48] European Parliament. Directive 96/92/ec of the european parliament and of the council of 19 december 1996 concerning common rules for the internal market in electricity. [Online] Available: http://eur-lex.europa.eu/LexUriServ/ LexUriServ.do?uri=CELEX: 31996L0092: EN: HTML. last accessed on 11-07-2017. (Cited on page 16).

[49] European Regulators Group for Electricity and Gas . Revised ERGEG Guidelines of Good Practice for Electricity Balancing Markets Integration (GGP-EBMI). Technical report, September 2009. (Cited on page 20).

[50] Eurostat. Your key to European statistics. [Online] Available: http:// ec.europa.eu/eurostat/data/database. last accessed on 28-07-2017. (Cited on pages 1,2 , and 5 ).

[51] Flexiblepower Alliance Network. The energy flexibility platform \& interface. [Online] Available: http://flexiblepower.github.io/technology/efpi. last accessed on 11-07-2017. (Cited on pages 28, 29, 46, and 141).

[52] F. Gangale, J. Vasiljevska, C. Felix, A. Mengolini, and G. Fulli. Smart Grid Projects Outlook 2017. Technical report, 2017. last accessed on 13-07-2017. (Cited on page 39).

[53] D. Geelen, A. H. M. E. Reinders, and D. Keyson. Empowering the end-user in smart grids: Recommendations for the design of products and services. Energy Policy, 61: 151-161, 2013. ISSN 0301-4215. doi: 10.1016/j.enpol.2013.05.107. (Cited on page 39).

[54] M. E. T. Gerards and J. L. Hurink. On the value of device flexibility in smart grid applications. In 2017 IEEE Manchester PowerTech, pages 1-6, June 2017. doi: 10.1109/PTC.2017.7981170. (Cited on page 179).

[55] D. Geysen, P. Booij, and C. Warmer. A framework for simulation and control of hybrid energy networks. In 2014 IEEE International Energy Conference (ENERGYCON), pages 989-995, May 2014. doi: 10.1109/ENERGYCON.2014.6850546. (Cited on page 34 ).

[56] P. Goergens, F. Potratz, M. Cramer, A. Schnettler, and S. Willing. Review of the smart operator in the field. In CIRED Workshop 2016, pages 1-4, June 2016. doi: 10.1049/cp.2016.0739. (Cited on page 39). 
[57] M. Goulden, B. Bedwell, S. Rennick-Egglestone, T. Rodden, and A. Spence. Smart grids, smart users? The role of the user in demand side management. Energy Research \& Social Science, 2:21-29, 2014. ISSN 2214-6296. doi: 10.1016/j.erss.2014.04.008. (Cited on page 39).

[58] Grafana Labs. Grafana - the open platform for analytics and monitoring. [Online] Available: https://grafana.com. last accessed on 25-07-2017. (Cited on page 148).

[59] GridWise. Transactive Energy Framework Version 1.o. [Online] Available: http: //www.gridwiseac.org/pdfs/te_framework_report_pnnl-22946.pdf. last accessed on 13-07-2017. (Cited on page 32).

[6o] J. M. Guerrero, M. Chandorkar, T. L. Lee, and P. C. Loh. Advanced control architectures for intelligent microgrids: Part i: Decentralized and hierarchical control. IEEE Transactions on Industrial Electronics, 6o(4):1254-1262, April 2013. ISSN 0278-0046. doi: 10.1109/TIE.2012.2194969. (Cited on pages 27, 37, and 110).

[61] J. M. Guerrero, P. C. Loh, T. L. Lee, and M. Chandorkar. Advanced control architectures for intelligent microgrids: Part ii: Power quality, energy storage, and ac/dc microgrids. IEEE Transactions on Industrial Electronics, 6o(4):1263-1270, April 2013. ISSN 0278-0046. doi: 10.1109/TIE.2012.2196889. (Cited on page 18).

[62] V. C. Gungor, D. Sahin, T. Kocak, S. Ergut, C. Buccella, C. Cecati, and G. P. Hancke. A survey on smart grid potential applications and communication requirements. IEEE Transactions on Industrial Informatics, 9(1):28-42, February 2013. ISSN 1551-3203. doi: 10.1109/TII.2012.2218253. (Cited on page 32).

[63] C. A. Hall, J. G. Lambert, and S. B. Balogh. EROI of different fuels and the implications for society. Energy Policy, 64:141-152, 2014. ISSN 0301-4215. doi: 10.1016/j.enpol.2013.05.049. (Cited on page 1).

[64] R. Halvgaard, L. Vandenberghe, N. K. Poulsen, H. Madsen, and J. B. Jørgensen. Distributed model predictive control for smart energy systems. IEEE Transactions on Smart Grid, 7(3):1675-1682, May 2016. ISSN 1949-3053. doi: 10.1109/TSG.2016.2526077. (Cited on pages 36 and 79).

[65] A. Hartmanns and H. Hermanns. Modelling and Decentralised Runtime Control of Self-stabilising Power Micro Grids, pages 420-439. Springer Berlin Heidelberg, Berlin, Heidelberg, 2012. ISBN 978-3-642-34026-o. doi: 10.1007/978-3-642-34026o_31. (Cited on pages 38 and 110).

[66] A. Hartmanns, H. Hermanns, and P. Berrang. A comparative analysis of decentralized power grid stabilization strategies. In Proceedings of the 2012 Winter Simulation Conference (WSC), pages 1-13, December 2012. doi: 10.1109/WSC.2012.6465083. (Cited on pages 38 and 110).

[67] N. Hatziargyriou, H. Asano, R. Iravani, and C. Marnay. Microgrids. IEEE Power and Energy Magazine, 5(4):78-94, July 2007. ISSN 1540-7977. doi: 10.1109/MPAE.2007.376583. (Cited on page 18).

[68] J. Heres, W. van Westering, G. van der Lubbe, and D. Janssen. Stochastic Effects of Customer Behaviour on Bottom Up LoadEstimations. In CIRED 2017, Glasgow, pages 1-5, June 2017. (Cited on page 21). 
[69] B. Homan, R. P. van Leeuwen, G. J. M. Smit, L. Zhu, and J. B. de Wit. Validation of a predictive model for smart control of electrical energy storage. In 2016 IEEE International Energy Conference (ENERGYCON), Leuven, Belgium, USA, July 2016. IEEE Power Electronics Society. (Cited on page 52).

[7o] Home Assistant. Awaken your home. [Online] Available: https://homeassistant.io. last accessed on 12-07-2017. (Cited on page 27).

[71] HOMER. Hybrid Renewable and Distributed Generation System Design Software. [Online] Available: http://www.homerenergy.com. last accessed on o8-08-2017. (Cited on page 144).

[72] S. Iacovella, K. Lemkens, F. Geth, P. Vingerhoets, G. Deconinck, R. D’hulst, and K. Vanthournout. Distributed voltage control mechanism in low-voltage distribution grid field test. In IEEE PES ISGT Europe 2013, pages 1-5, October 2013. doi: 10.1109/ISGTEurope.2013.6695393. (Cited on pages 37 and 110).

[73] S. Iacovella, K. Lemkens, P. Vingerhoets, F. Geth, G. Deconinck, R. D’hulst, and K. Vanthournout. Standalone lv distribution network voltage control mechanism. In IECON 2013 - 39th Annual Conference of the IEEE Industrial Electronics Society, pages 7493-7498, November 2013. doi: 10.1109/IECON.2013.670038o. (Cited on pages 37 and 110).

[74] S. Iacovella, F. Ruelens, P. Vingerhoets, B. J. Claessens, and G. Deconinck. Cluster control of heterogeneous thermostatically controlled loads using tracer devices. IEEE Transactions on Smart Grid, 8(2):528-536, March 2017. ISSN 1949-3053. doi: 10.1109/TSG.2015.2483506. (Cited on page 36).

[75] In4Energy. Proeftuin Slim Net in Duurzaam Lochem. Technical report. last accessed on 13-07-2017. (Cited on page 39).

[76] InfluxData. Influxdb - time series database monitoring and analytics. [Online] Available: https://www.influxdata.com. last accessed on 25-07-2017. (Cited on page 148).

[77] International Energy Agency (IEA). Key electricity trends 2016, excerpt from: Electricity information. Technical report. last accessed on 28-07-2017. (Cited on pages 1 and 5).

[78] International Energy Agency (IEA). Technology roadmap - smart grids. Technical report, 2011. last accessed on 11-07-2017. (Cited on pages 4 and 195).

[79] International Energy Agency (IEA). World Energy Outlook, Executive Summary. Technical report, 2016. last accessed on 28-07-2017. (Cited on pages 2 and 23).

[8o] J. A. Jardini, C. M. V. Tahan, M. R. Gouvea, S. U. Ahn, and F. M. Figueiredo. Daily load profiles for residential, commercial and industrial low voltage consumers. IEEE Transactions on Power Delivery, 15(1):375-380, January 200o. ISSN 0885-8977. doi: 10.1109/61.847276. (Cited on pages 3 and 134).

[81] M. R. Jongerden and B. R. Haverkort. Which battery model to use? IET Software, 3 (6):445-457, December 2009. ISSN 1751-8806. doi: 10.1049/iet-sen.2009.0001. (Cited on page 52). 
[82] P. Kadurek, J. Blom, J. F. G. Cobben, and W. L. Kling. Theft detection and smart metering practices and expectations in the netherlands. In 2010 IEEE PES Innovative Smart Grid Technologies Conference Europe (ISGT Europe), pages 1-6, October 2010. doi: 10.1109/ISGTEUROPE.2010.5638852. (Cited on page 25).

[83] M. Kaltschmitt, W. Streicher, and A. Wiese. Renewable Energy: Technology, Economics and Environment. Springer Verlag, 2007. ISBN 978-3-540-70947-3. (Cited on page 201).

[84] H. G. J. Kamp. Tijdpad uitrol slimme meter en dynamische leveringstarieven. [Online] Available: https://www.rijksoverheid.nl/documenten/kamerstukken/ 2016/03/04/kamerbrief-over-tijdpad-uitrol-slimme-meter-endynamische-leveringstarieven, 2016. last accessed on 12-07-2017. (Cited on page 30).

[85] S. Keshav and C. Rosenberg. How internet concepts and technologies can help green and smarten the electrical grid. In Proceedings of the First ACM SIGCOMM Workshop on Green Networking, Green Networking '10, pages 35-40, New York, NY, USA, 2010. ACM. ISBN 978-1-4503-0196-1. doi: 10.1145/1851290.1851298. (Cited on pages 38 and 110).

[86] D. K. Khatod, V. Pant, and J. Sharma. A novel approach for sensitivity calculations in the radial distribution system. IEEE Transactions on Power Delivery, 21(4):20482057, October 2006. ISSN 0885-8977. doi: 10.1109/TPWRD.2006.874651. (Cited on page 62).

[87] S. Killinger, N. Kreifels, B. Burger, B. Müller, G. Stiff, and C. Wittwer. Impact of the solar eclipse from 2oth march 2015 on the german electrical supply-simulation and analysis. Energy Technology, 4(2):288-297, 2016. ISSN 2194-4296. doi: 10.1002/ente.201500228. (Cited on page 3).

[88] E. Klaassen, C. Kobus, J. Frunt, and H. Slootweg. Load shifting potential of the washing machine and tumble dryer. In 2016 IEEE International Energy Conference (ENERGYCON), pages 1-6, April 2016. doi: 10.1109/ENERGYCON.2016.7513895. (Cited on page 30).

[89] KNMI. Uurgegevens van het weer in Nederland. [Online] Available: http:// www.knmi.nl/nederland-nu/klimatologie/uurgegevens. last accessed on 2710-2017. (Cited on page 201).

[90] C. B. Kobus, R. Mugge, and J. P. Schoormans. Washing when the sun is shining! How users interact with a household energy management system. Ergonomics, 56 (3):451-462, 2013. doi: 10.1080/00140139.2012.721522. PMID: 23009607. (Cited on page 39$)$.

[91] K. Kok. The PowerMatcher: smart coordination for the smart electricity grid. $\mathrm{PhD}$ thesis, Vrije Universiteit Amsterdam, July 2013. (Cited on pages 34, 36, 46, 79, 110, 111, 115, and 116).

[92] K. Kok, B. Roossien, P. MacDougall, O. van Pruissen, G. Venekamp, I. G. Kamphuis, J. Laarakkers, and C. Warmer. Dynamic pricing by scalable energy management systems: Field experiences and simulation results using powermatcher. In 
2012 IEEE Power and Energy Society General Meeting, pages 1-8, July 2012. doi: 10.1109/PESGM.2012.6345058. (Cited on page 34).

[93] E. Koliou, C. Eid, J. P. Chaves-Ávila, and R. A. Hakvoort. Demand response in liberalized electricity markets: Analysis of aggregated load participation in the German balancing mechanism. Energy, 71:245-254, 2014. ISSN 0360-5442. doi: 10.1016/j.energy.2014.04.067. (Cited on page 19).

[94] W. Kong, Z. Y. Dong, G. Chen, and Y. Jia. A rule based domestic load profile generator for future smart grid. In 2014 Australasian Universities Power Engineering Conference (AUPEC), pages 1-5, September 2014. doi: 10.1109/AUPEC.2014.6966579. (Cited on page 134).

[95] K. Kreuzer. openHAB 2.0 and Eclipse SmartHome. [Online] Available: http://kaikreuzer.blogspot.nl/2014/06/openhab-20-and-eclipsesmarthome.html, June 2014. last accessed on 12-07-2017. (Cited on page 27).

[96] J. O. Krist. The effect of residential storage and control on the distribution net compared to central storage and control. [Online] Available: http:// essay.utwente.nl/65437, June 2014. last accessed on 12-07-2017. (Cited on page 26).

[97] L'Abbate, A. and Fulli, G and Starr, F and Peteves, S. D. Distributed Power Generation in Europe: technical issues for further integration. [Online] Available: http://publications.jrc.ec.europa.eu/repository/bitstream/ JRC43063/dg_jrc_report.pdf. last accessed on 08-08-2017. (Cited on page 18).

[98] B. Lasseter. Microgrids [distributed power generation]. In 2001 IEEE Power Engineering Society Winter Meeting. Conference Proceedings (Cat. No.o1CH37194), volume 1, pages 146-149 vol.1, January 2001. doi: 10.1109/PESW.2001.917020. (Cited on page 26).

[99] J. Laurikko, R. Granström, and A. Haakana. Realistic estimates of EV range based on extensive laboratory and field tests in nordic climate conditions. In 2013 World Electric Vehicle Symposium and Exhibition (EVS27), pages 1-12, November 2013. doi: 10.1109/EVS.2013.6914919. (Cited on page 140).

[100] E. A. Lee and S. Seshia. Introduction to Embedded Systems - A Cyber-Physical Systems Approach. Lee and Seshia, 2 edition, 2015. ISBN 978-1-312-42740-2. (Cited on pages 7 and 9).

[101] E. K. Lee, R. Gadh, and M. Gerla. Energy service interface: Accessing to customer energy resources for smart grid interoperation. IEEE Journal on Selected Areas in Communications, 31(7):1195-1204, July 2013. ISSN 0733-8716. doi: 10.1109/JSAC.2013.130704. (Cited on page 28).

[102] S. Lehnhoff, O. Nannen, S. Rohjans, F. Schlogl, S. Dalhues, L. Robitzky, U. Hager, and C. Rehtanz. Exchangeability of power flow simulators in smart grid co-simulations with mosaik. In 2015 Workshop on Modeling and Simulation of Cyber-Physical Energy Systems (MSCPES), pages 1-6, April 2015. doi: 10.1109/MSCPES.2015.7115410. (Cited on page 144). 
[103] Liander. Kwaliteits- en capaciteitsdocument elektriciteit 2015. [Online] Available: https://www.liander.nl/sites/default/files/Kwaliteits_en_capaciteitsdocument_2015_Elektriciteit.pdf, 2015. last accessed on 11-07-2017. (Cited on page 58).

[104] K. McKenna and A. Keane. Discrete elastic residential load response under variable pricing schemes. In IEEE PES Innovative Smart Grid Technologies, Europe, pages 1-6, October 2014. doi: 10.1109/ISGTEurope.2014.7028769. (Cited on pages 30 and 31).

[105] McKinsey and Company. Battery storage: The next disruptive technology in the power sector. [Online] Available: http://www.mckinsey.com/businessfunctions/sustainability-and-resource-productivity/our-insights/ battery-storage-the-next-disruptive-technology-in-the-powersector. last accessed on 08-08-2017. (Cited on page 14).

[106] W. Mert. Consumer acceptance of smart appliances. Technical report, December 2008. last accessed on 13-07-2017. (Cited on pages 39 and 77).

[107] A. Molderink. On the three-step control methodology for Smart Grids. PhD thesis, University of Twente, May 2011. (Cited on pages 34, 46, 56, 78, 144, and 198).

[108] A. Molderink, V. Bakker, M. G. C. Bosman, J. L. Hurink, and G. J. M. Smit. Management and control of domestic smart grid technology. IEEE Transactions on Smart Grid, 1(2):109-119, September 2010. ISSN 1949-3053. doi: 10.1109/TSG.2010.2055904. (Cited on pages 34 and 135).

[109] A. Molderink, V. Bakker, J. L. Hurink, and G. J. M. Smit. Comparing demand side management approaches. In 2012 3rd IEEE PES Innovative Smart Grid Technologies Europe (ISGT Europe), pages 1-8, October 2012. doi: 10.1109/ISGTEurope.2012.6465699. (Cited on pages 33, 35, and 120).

[110] A. Molderink, V. Bakker, J. L. Hurink, and G. J. M. Smit. On indirect controlled cost function based dsm strategies. In 2013 IEEE Grenoble Conference, pages 1-6, June 2013. doi: 10.1109/PTC.2013.6652464. (Cited on pages 33, 35, and 120).

[111] P. Monshizadeh, C. de Persis, N. Monshizadeh, and A. van der Schaft. A communication-free master-slave microgrid with power sharing. In 2016 American Control Conference (ACC), pages 3564-3569, July 2016. doi: 10.1109/ACC.2016.7525466. (Cited on pages 110 and 128).

[112] NEDU. Verbruiksprofielen. [Online] Available: http://www.nedu.nl/portfolio/ verbruiksprofielen. last accessed on 11-07-2017. (Cited on page 21).

[113] NEN-EN 50160:2010. Voltage characteristics of electricity supplied by public distribution networks, 2010. (Cited on pages 18, 36, 57, 78, 133, and 168).

[114] Netbeheer Nederland. Kerngegevens energienetten . [Online] Available: https: //energiecijfers.info/hoofdstuk-1. last accessed on 11-07-2017. (Cited on pages 16 and 58 ).

[115] New York Independent System Operator. Blackout august 14, 2003 final report. Technical report, February 2005. last accessed on 12-07-2017. (Cited on page 25). 
[116] S. Nykamp. Integrating renewables in distribution grids: Storage, regulation and the interaction of different stakeholders in future grids. PhD thesis, October 2013. (Cited on pages 21 and 26).

[117] S. Nykamp, M. G. C. Bosman, A. Molderink, J. L. Hurink, and G. J. M. Smit. Value of storage in distribution grids: Competition or cooperation of stakeholders? IEEE Transactions on Smart Grid, 4(3):1361-1370, September 2013. ISSN 1949-3053. doi: 10.1109/TSG.2013.2254730. (Cited on pages 26 and 31).

[118] S. Nykamp, T. Rott, N. Dettke, and S. Kueppers. The project elche wettringen: storage as an alternative to grid reinforcements - experiences, benefits and challenges from a dso point of. In International ETG Congress 2015; Die Energiewende - Blueprints for the new energy age, pages 1-6, November 2015. (Cited on pages 23 and 26).

[119] F. Ocker, S. Braun, and C. Will. Design of european balancing power markets. In 201613 th International Conference on the European Energy Market (EEM), pages 1-6, June 2016. doi: 10.1109/EEM.2016.7521193. (Cited on pages 20 and 24).

[120] OpenADR Alliance. OpenADR 2.o Specifications. [Online] Available: http:// www.openadr.org/specification. last accessed on 12-07-2017. (Cited on page 28).

[121] OpenHAB. Empowering the smart home. [Online] Available: http: //openhab.org. last accessed on 12-07-2017. (Cited on pages 27, 29, 132, and 152).

[122] A.-G. Paetz, E. Dütschke, and W. Fichtner. Smart Homes as a Means to Sustainable Energy Consumption: A Study of Consumer Perceptions. Journal of Consumer Policy, 35(1):23-41, March 2012. ISSN 1573-0700. doi: 10.1007/s10603-011-9177-2. (Cited on page 39$)$.

[123] Pecan Street inc. Pecan Street Dataport. [Online] Available: https:// dataport.cloud, 2017. last accessed on 25-07-2017. (Cited on pages 134, 180, and 201).

[124] N. Pflugradt, J. Teuscher, B. Platzer, and W. Schufft. Analysing low-voltage grids using a behaviour based load profile generator. In International Conference on Renewable Energies and Power Quality, volume 11, page 5, 2013. (Cited on page 134).

[125] M. Pipattanasomporn, M. Kuzlu, S. Rahman, and Y. Teklu. Load profiles of selected major household appliances and their demand response opportunities. IEEE Transactions on Smart Grid, 5(2):742-750, March 2014. ISSN 1949-3053. doi: 10.1109/TSG.2013.2268664. (Cited on page 134).

[126] PQube. PQube Hogeschool van Amsterdam. [Online] Available: http:// maps.pqube.com/HVA_NL, 2017. last accessed on 26-07-2017. (Cited on page 182).

[127] Quintel. Energy Transition Model. [Online] Available: http://www.energyplan.eu. last accessed on 08-08-2017. (Cited on page 144).

[128] I. Richardson, M. Thomson, and D. Infield. A high-resolution domestic building occupancy model for energy demand simulations. Energy and Buildings, 40(8):15601566, 2008. ISSN 0378-7788. doi: 10.1016/j.enbuild.2008.02.006. (Cited on page 134). 
[129] Rijksdienst voor Ondernemend Nederland. Cijfers elektrisch vervoer. [Online] Available: http://www.rvo.nl/onderwerpen/duurzaam-ondernemen/energie-enmilieu-innovaties/elektrisch-rijden/stand-van-zaken/cijfers. last accessed on 11-08-2017. (Cited on page 23).

[130] E. Rivero, J. Barquín, and L. Rouco. European balancing markets. In 2011 8th International Conference on the European Energy Market (EEM), pages 333-338, May 2011. doi: 10.1109/EEM.2011.5953033. (Cited on page 19).

[131] S. Rohjans, S. Lehnhoff, S. Schütte, S. Scherfke, and S. Hussain. Mosaik - a modular platform for the evaluation of agent-based smart grid control. In IEEE PES ISGT Europe 2013, pages 1-5, October 2013. doi: 10.1109/ISGTEurope.2013.6695486. (Cited on page 144).

[132] F. Ruelens, S. Vandael, W. Leterme, B. J. Claessens, M. Hommelberg, T. Holvoet, and R. Belmans. Demand side management of electric vehicles with uncertainty on arrival and departure times. In 2012 3rd IEEE PES Innovative Smart Grid Technologies Europe (ISGT Europe), pages 1-8, October 2012. doi: 10.1109/ISGTEurope.2012.6465695. (Cited on page 35).

[133] K. P. Schneider, J. C. Fuller, and D. Chassin. Analysis of distribution level residential demand response. In 2011 IEEE/PES Power Systems Conference and Exposition, pages 1-6, March 2011. doi: 10.1109/PSCE.2011.5772572. (Cited on pages 30 and 31).

[134] S. Schütte, S. Scherfke, and M. Tröschel. Mosaik: A framework for modular simulation of active components in smart grids. In 2011 IEEE First International Workshop on Smart Grid Modeling and Simulation (SGMS), pages 55-6o, October 2011. doi: 10.1109/SGMS.2011.6089027. (Cited on page 144).

[135] C. Schwaegerl and L. Tao. The Microgrids Concept, pages 1-24. John Wiley and Sons Ltd, 2013. ISBN 9781118720677. doi: 10.1002/9781118720677.cho1. (Cited on page 5).

[136] P. Siano. Demand response and smart grids-A survey. Renewable and Sustainable Energy Reviews, 30:461-478, 2014. ISSN 1364-0321. doi: 10.1016/j.rser.2013.10.022. (Cited on page 28).

[137] W. H. Slob and W. A. A. Monna. Bepaling van directe en diffuse straling en van zonneschijnduur uit 10-minutenwaarden van de globale straling. [Online] Available: http: //bibliotheek.knmi.nl/knmipubTR/TR136.pdf, 1991. last accessed on 2710-2017. (Cited on page 201).

[138] S. Sridhar, A. Hahn, and M. Govindarasu. Cyber-physical system security for the electric power grid. Proceedings of the IEEE, 100(1):210-224, January 2012. ISSN 0018-9219. doi: 10.1109/JPROC.2011.2165269. (Cited on pages 37 and 124).

[139] R. Stamminger. Synergy potential of smart appliances. [Online] Available: http://www.come-on-labels.eu/download-library/synergy-potentialof-smart-appliances, 2008. last accessed on 13-07-2017. (Cited on page 135).

[140] S. Stüdli, E. Crisostomi, R. Middleton, and R. Shorten. A flexible distributed framework for realising electric and plug-in hybrid vehicle charging policies. International Journal of Control, 85(8):1130-1145, 2012. doi: 10.1080/00207179.2012.679970. (Cited on pages 38 and 110). 
[141] S. M. Tabatabaei, S. Dick, and W. Xu. Toward non-intrusive load monitoring via multi-label classification. IEEE Transactions on Smart Grid, 8(1):26-40, January 2017. ISSN 1949-3053. doi: 10.1109/TSG.2016.2584581. (Cited on page 134).

[142] T. Tekelenburg, N. Verkade, H. Hof, and H. Stemerdink. Knelpunten en effecten van een optimale mix van lokale duurzame energiebronnen voor een stabiel elektriciteitsnetwerk in de proeftuin slim net lochem. Technical report, 2015. (Cited on pages 135, 137, and 161).

[143] H. A. Toersche. Effective and efficient coordination of flexibility in smart grids. $\mathrm{PhD}$ thesis, University of Twente, October 2016. (Cited on pages 14, 28, 33, 35, 46, 79, 116, $117,173,196$, and 197).

[144] D. P. Tuttle and R. Baldick. The evolution of plug-in electric vehicle-grid interactions. IEEE Transactions on Smart Grid, 3(1):500-505, March 2012. ISSN 1949-3053. doi: 10.1109/TSG.2011.2168430. (Cited on page 27).

[145] United Nations Convention on Climate Change. Kyoto protocol to the United Nations framework convention on climate change. [Online] Available: http: //unfccc.int/resource/docs/convkp/kpeng.pdf, 1998. last accessed on 28-072017. (Cited on page 2).

[146] United Nations Convention on Climate Change. Adoption of the Paris agreement. [Online] Available: https://unfccc.int/resource/docs/2015/cop21/ eng/109r01.pdf, 2015. last accessed on 28-07-2017. (Cited on page 2).

[147] Universal Smart Energy Framework. Usef: The framework explained. [Online] Available: https://www.usef.energy. last accessed on 11-07-2017. (Cited on pages 25 and 28).

[148] T. van der Klauw. Decentralized Energy Management with Profile Steering - Resource Allocation Problems in Energy Management. PhD thesis, University of Twente, PO Box 217, 7500 AE Enschede, The Netherlands, May 2017. (Cited on pages 33, 46, 94, 153, 194, and 196).

[149] T. van der Klauw, M. E. T. Gerards, G. J. M. Smit, and J. L. Hurink. Optimal scheduling of electrical vehicle charging under two types of steering signals. In IEEE PES Innovative Smart Grid Technologies Conference Europe (ISGT-Europe), Istanbul, Turkey, page 0122, USA, October 2014. IEEE Power \& Energy Society. (Cited on page 70).

[150] T. van der Klauw, M. E. T. Gerards, and J. L. Hurink. Resource allocation problems in decentralized energy management. OR Spectrum = OR Spektrum, online prepublication, January 2017. ISSN 0171-6468. (Cited on page 95).

[151] R. van Leeuwen. Towards 100\% renewable energy supply for urban areas and the role of smart control. PhD thesis, May 2017. CTIT Ph.D. thesis series no. 17-433. (Cited on page 29).

[152] C. van Limpt. In de praktijk vreet populaire warmtepomp juist energie. [Online] Available: https://www.trouw.nl/groen/in-de-praktijk-vreet-populairewarmtepomp-juist-energie aa0993ee, June 2011. last accessed on 11-07-2017. (Cited on page 23). 
[153] T. van Melle, L. Ramaekers, and W. Terlouw. Waarde van Congestiemanagement. [Online] Available: http://www.ecofys.com/files/files/ecofys-2016waarde-van-congestiemanagement.pdf, 2016. last accessed on 12-07-2017. (Cited on page 24 ).

[154] P. van Oirsouw. Netten voor distributie van elektriciteit. Phase to Phase, 2 edition, 2012. ISBN 978-90-817983-1-0. last accessed on 19-08-2017. (Cited on pages 15, 17, 21, 58 , and 62).

[155] S. Vandael, B. J. Claessens, M. Hommelberg, T. Holvoet, and G. Deconinck. A scalable three-step approach for demand side management of plug-in hybrid vehicles. IEEE Transactions on Smart Grid, 4(2):720-728, June 2013. ISSN 1949-3053. doi: 10.1109/TSG.2012.2213847. (Cited on pages 35 and 135).

[156] J. S. Vardakas, N. Zorba, and C. V. Verikoukis. A survey on demand response programs in smart grids: Pricing methods and optimization algorithms. IEEE Communications Surveys Tutorials, 17(1):152-178, 2015. ISSN 1553-877X. doi: 10.1109/COMST.2014.2341586. (Cited on pages 28, 29, 30, and 31).

[157] M. G. Vayá, G. Andersson, and S. Boyd. Decentralized control of plug-in electric vehicles under driving uncertainty. In IEEE PES Innovative Smart Grid Technologies, Europe, pages 1-6, October 2014. doi: 10.1109/ISGTEurope.2014.7028989. (Cited on pages 36 and 79 ).

[158] G. P. Verbong, S. Beemsterboer, and F. Sengers. Smart grids or smart users? Involving users in developing a low carbon electricity economy. Energy Policy, 52:117-125, 2013. ISSN 0301-4215. doi: 10.1016/j.enpol.2012.05.003. Special Section: Transition Pathways to a Low Carbon Economy. (Cited on page 39).

[159] R. A. Verzijlbergh, L. J. de Vries, and Z. Lukszo. Renewable energy sources and responsive demand. do we need congestion management in the distribution grid? IEEE Transactions on Power Systems, 29(5):2119-2128, September 2014. ISSN 08858950. doi: 10.1109/TPWRS.2014.2300941. (Cited on page 31).

[160] J. Wang, M. Biviji, and W. M. Wang. Case studies of smart grid demand response programs in north america. In ISGT 2011, pages 1-5, January 2011. doi: 10.1109/ISGT.2011.5759162. (Cited on page 31).

[161] S. Weckx and J. Driesen. Load balancing with EV chargers and PV inverters in unbalanced distribution grids. IEEE Transactions on Sustainable Energy, 6(2):635643, April 2015. ISSN 1949-3029. doi: 10.1109/TSTE.2015.2402834. (Cited on page 36).

[162] S. Weckx and J. Driesen. Optimal local reactive power control by PV inverters. IEEE Transactions on Sustainable Energy, 7(4):1624-1633, October 2016. ISSN 1949-3029. doi: 10.1109/TSTE.2016.2572162. (Cited on page 38).

[163] S. Weckx, R. D’hulst, B. J. Claessens, and J. Driesensam. Multiagent charging of electric vehicles respecting distribution transformer loading and voltage limits. IEEE Transactions on Smart Grid, 5(6):2857-2867, November 2014. ISSN 1949-3053. doi: 10.1109/TSG.2014.2345886. (Cited on page 36). 
[164] S. Weckx, R. D’hulst, and J. Driesen. Voltage sensitivity analysis of a laboratory distribution grid with incomplete data. IEEE Transactions on Smart Grid, 6(3):12711280, May 2015. ISSN 1949-3053. doi: 10.1109/TSG.2014.2380642. (Cited on pages 25 and 126).

[165] Wikipedia. War of Currents. [Online] Available: https://en.wikipedia.org/ wiki/War_of_Currents. last accessed on 11-07-2017. (Cited on page 15).

[166] Y. R. Yang and S. S. Lam. General aimd congestion control. In Proceedings 2000 International Conference on Network Protocols, pages 187-198, 200o. doi: 10.1109/ICNP.2000.896303. (Cited on page 38).

[167] H. Zhong, L. Xie, and Q. Xia. Coupon incentive-based demand response: Theory and case study. IEEE Transactions on Power Systems, 28(2):1266-1276, May 2013. ISSN 0885-8950. doi: 10.1109/TPWRS.2012.2218665. (Cited on page 31).

[168] ZigBee Alliance. Zigbee Smart Energy 2.0 Standard and Specification. [Online] Available: http://www.zigbee.org/zigbee-for-developers/ applicationstandards/zigbee-2030-5. last accessed on 12-07-2017. (Cited on page 28).

[169] R. D. Zimmerman. Comprehensive distribution power flow: modeling, formulation, solution algorithms and analysis. $\mathrm{PhD}$ thesis, Cornell University, January 1995. (Cited on page 62). 
222 


\section{List of Publications}

[GH:1] M. H. H. Schoot Uiterkamp, G. Hoogsteen, M. E. T. Gerards, J. L. Hurink, and G. J. M. Smit. Multi-commodity support in profile steering. In Accepted for presentation at 2017 IEEE PES Innovative Smart Grid Technologies Europe, Turin, page 1-6, September 2017.

[GH:2] G. Hoogsteen, A. Molderink, J. L. Hurink, and G. J. M. Smit. Asynchronous event driven distributed energy management using profile steering. In 2017 IEEE Manchester PowerTech, page 1-6, June 2017. doi: 10.1109/PTC.2017.7980986.

[GH:3] J. S. Nutma, G. Hoogsteen, A. Molderink, W. E. Wijbrandi, J. L. Hurink, and G. J. M. Smit. On integrating device level schedules into market based control. In 2017 IEEE Manchester PowerTech, page 1-6, June 2017. doi: 10.1109/PTC.2017.7980984.

[GH:4] G. Hoogsteen, A. Molderink, J. L. Hurink, G. J. M. Smit, F. Schuring, and B. Kootstra. Charging electric vehicles, baking pizzas and melting a fuse in Lochem. CIRED Open Access Journal, page 1-5, 2017. ISSN 2515-0855. doi: 10.1049/oapcired.2017.0340.

[GH:5] G. Hoogsteen. DEMKit: a flexible smart grid simulation and demonstration platform written in python. In International workshop Energy-Open, Enschede, page 1-2, May 2017.

[GH:6] G. Hoogsteen, T. van der Klauw, A. Molderink, J. L. Hurink, G. J. M. Smit, X. Feng, and R. E. Hebner. Balancing islanded residential microgrids using demand side management. In 2016 IEEE Power \& Energy Society Innovative Smart Grid Technologies Conference, Minneapolis, MN, USA, page 1-5, USA, September 2016. IEEE Power \& Energy Society. doi: 10.1109/ISGT.2016.7781167.

[GH:7] T. van der Klauw, G. Hoogsteen, M. E. T. Gerards, J. L. Hurink, X. Feng, and R. E. Hebner. Assessing the potential of residential hvac systems for demandside management. In 2016 IEEE Power \& Energy Society Innovative Smart Grid Technologies Conference, Minneapolis, MN, USA, page 1-6, USA, September 2016. IEEE Power \& Energy Society. doi: 10.1109/ISGT.2016.7781193.

[GH:8] G. Hoogsteen, A. Molderink, J. L. Hurink, and G. J. M. Smit. Generation of flexible domestic load profiles to evaluate demand side management approaches. In 2016 IEEE International Energy Conference (ENERGYCON), Leuven, page 1-6, April 2016. doi: 10.1109/ENERGYCON.2016.7513873.

[GH:9] T. van der Klauw, M. E. T. Gerards, G. Hoogsteen, G. J. M. Smit, and J. L. Hurink. Considering grid limitations in profile steering. In 2016 IEEE International Energy Conference (ENERGYCON), Leuven, page 1-6, April 2016. doi: 10.1109/ENERGYCON.2016.7514033. 
[GH:1o] K. X. Perez, M. Baldea, T. F. Edgar, G. Hoogsteen, R. P. van Leeuwen, T. van der Klauw, B. Homan, J. Fink, and G. J. M. Smit. Soft-islanding a group of houses through scheduling of chp, pv and storage. In 2016 IEEE International Energy Conference (ENERGYCON), Leuven, page 1-6, April 2016. doi: 10.1109/ENERGYCON.2016.7513972.

[GH:11] G. Hoogsteen, A. Molderink, J. L. Hurink, G. J. M. Smit, F. Schuring, and B. Kootstra. Impact of peak electricity demand in distribution grids: A stress test. In PowerTech, 2015 IEEE Eindhoven, page 1-6, June 2015. doi: 10.1109/PTC.2015.7232412.

[GH:12] M. E. T. Gerards, H. A. Toersche, G. Hoogsteen, T. van der Klauw, J. L. Hurink, and G. J. M. Smit. Demand side management using profile steering. In PowerTech, 2015 IEEE Eindhoven, page 1-6, June 2015. doi: 10.1109/PTC.2015.7232328.

[GH:13] G. Hoogsteen, A. Molderink, J. L. Hurink, and G. J. M. Smit. Managing energy in time and space in smart grids using triana. In 2014 IEEE PES Innovative Smart Grid Technologies Europe, Istanbul, page 1-6, October 2014. doi: 10.1109/ISGTEurope.2014.7028973.

[GH:14] G. Hoogsteen, A. Molderink, V. Bakker, and G. J. M. Smit. Integrating lv network models and load-flow calculations into smart grid planning. In 2013 IEEE PES Innovative Smart Grid Technologies Europe, Copenhagen, page 1-5, October 2013. doi: 10.1109/ISGTEurope.2013.6695427.

[GH:15] G. Hoogsteen, J. O. Krist, V. Bakker, and G. J. M. Smit. Non-intrusive appliance recognition. In 2012 IEEE PES Innovative Smart Grid Technologies Europe, Berlin, page 1-7, October 2012. doi: 10.1109/ISGTEurope.2012.6465688.

\section{THIS THESIS}

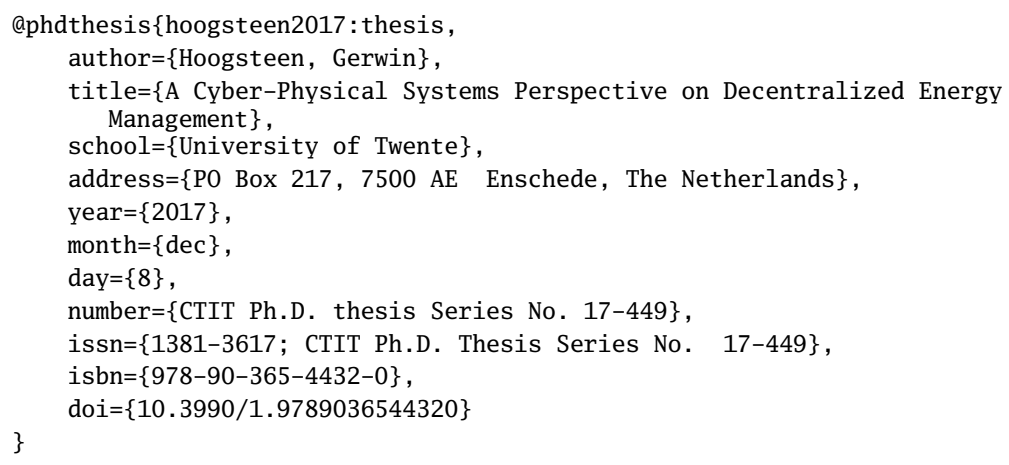

Bı̈TEX of this thesis 

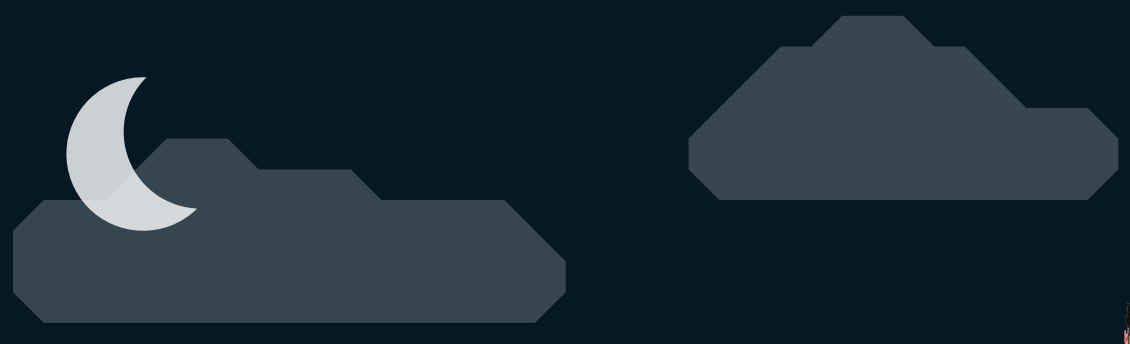

\section{Pbout the authar}

Gerwin Hoogsteen received his B.Eng. degree in Electrical Engineering from the Hanze University of Applied Sciences, Groningen, The Netherlands, in 2010 and received the M.Sc. degree in Embedded Systems from the University of Twente, Enschede, The Netherlands, in 2013. After obtaining the M.Sc. degree he continued conducting research in the field of smart grids towards a Ph.D. degree in the Computer Architecture for Embedded Systems (CAES) group at the University of Twente.

His research focuses on the interaction between control systems and the physical infrastructure of the smart grid. The CAES group, together with the Discrete Mathematics and Mathematical Programming (DMMP) group, have a multidisciplinary team with broad experience in optimization and control systems for energy management. 